\title{
Biological-Physical Interactions on Georges Bank: Plankton Transport and Population Dynamics of the Ocean Quahog, Arctica islandica.
}

\author{
by
Craig Van de Water Lewis
B.S., Mechanical Engineering and Biology, Stanford University (1990)
Submitted in partial fulfillment of the requirements for the degree of

\section{Doctor of Philosophy}

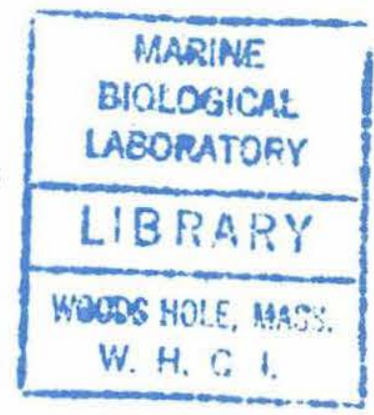

at the

\section{Woods Hole Oceanographic Institution}

and the

\section{Massachusetts Institute of Technology}

June 1997

(c) Craig Van de Water Lewis 1997. All rights reserved.

\section{The author hereby grants to MIT and to WHOI permission to reproduce and to distribute copies of this thesis document in whole or in part.}

Signature of Author:

Joint Program in Biological Oceanography

Woods Hole Oceanographic Institution

Massachusetts Institute of Technology March 17, 1997

Certified by:

Cabell S. Davis

Associate Scientist with Tenure Thesis Advisor

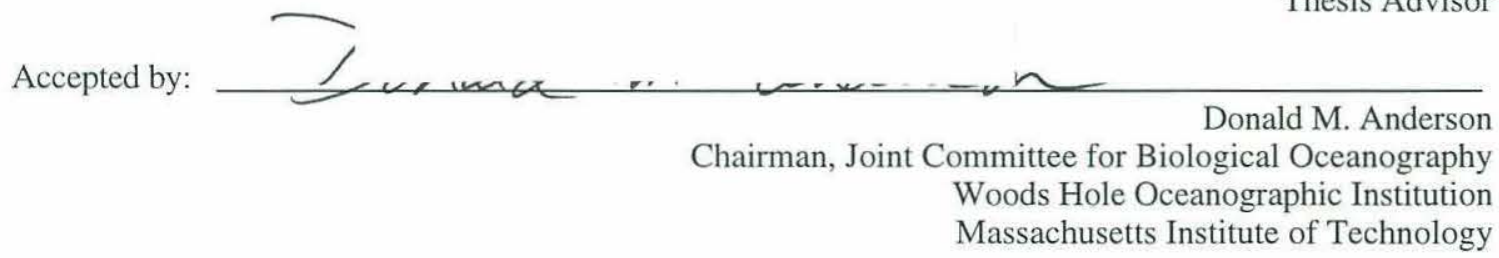




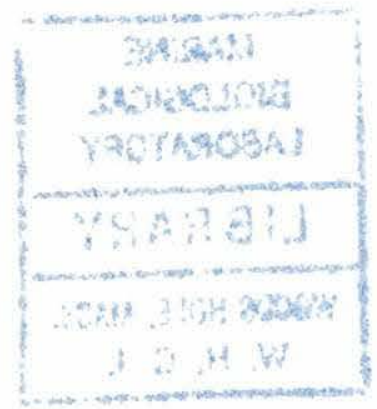




\section{TABLe OF Contents}

Table of Contents................................................ 3

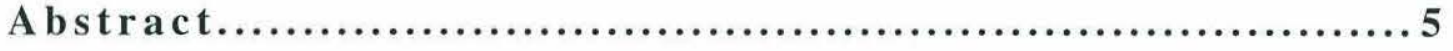

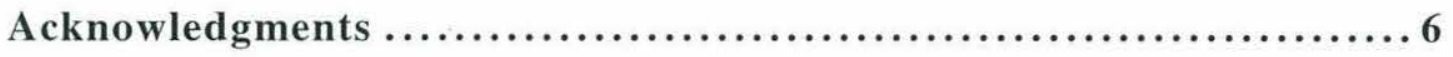

Chapter 1: Introduction.........................................

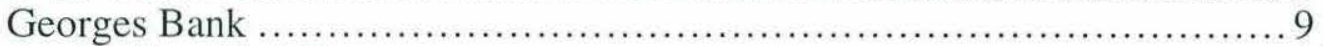

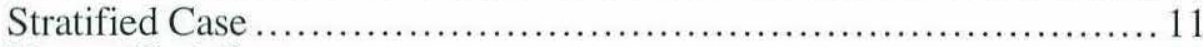

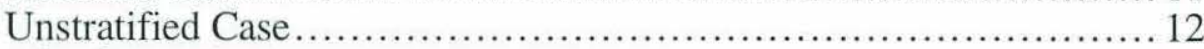

Arctica islandica review ............................................... 13



Larval Biology ................................................... 18

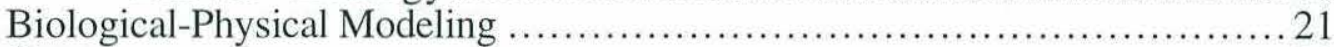

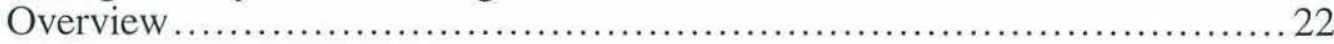

Chapter 2: Wind Forced Biological-Physical Interactions on an

Isolated Offshore Bank ....................................... 25

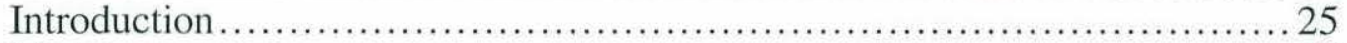

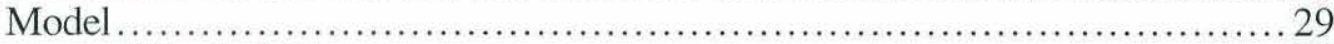

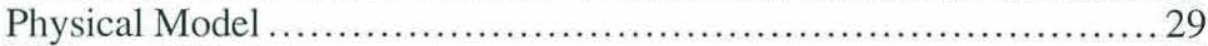

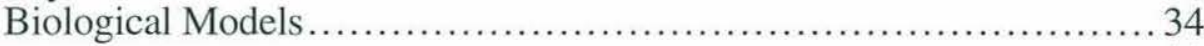

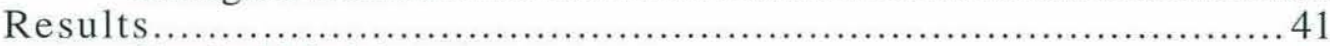

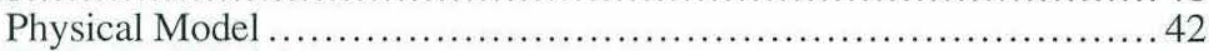

Biological Models .......................................... 45

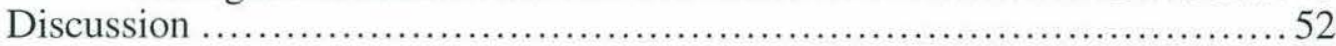

Chapter 3: Population structure of Arctica islandica.................61

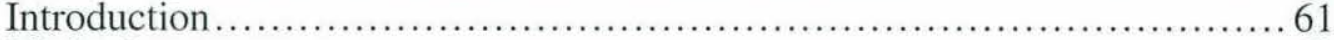

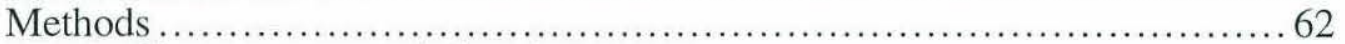

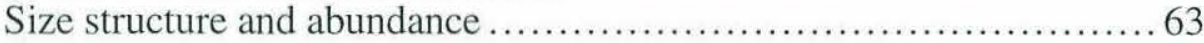



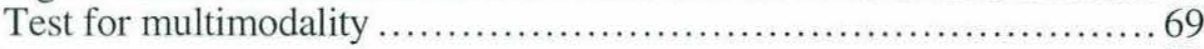

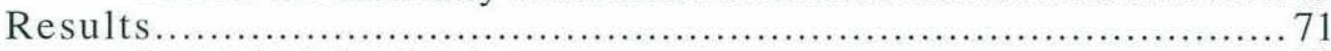

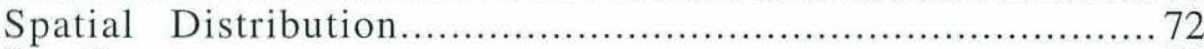

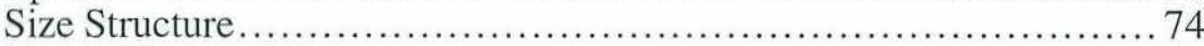

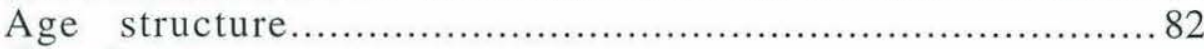

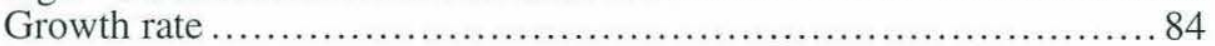

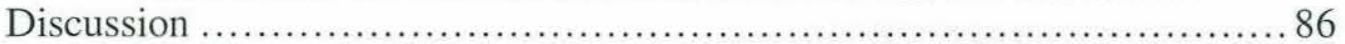

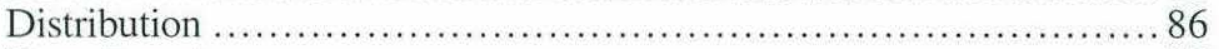

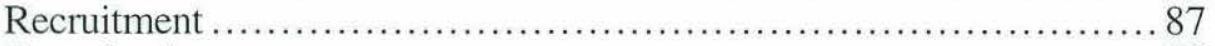

Conclusions.................................................... 89

Chapter 4: Modeling plankton transport in wind and tidally driven

circulation over Georges Bank..............................93

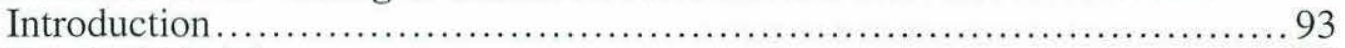

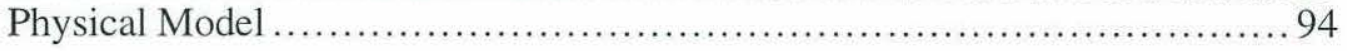


Model Physics.................................................... 95

Numerical Methods …......................................... 99

Initial Conditions and Forcing .................................. 102

Results and Discussion.................................................. 107

Circulation ....................................................... 109

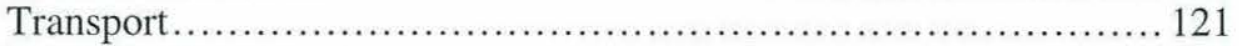

Tracer Transport.................................................... 124

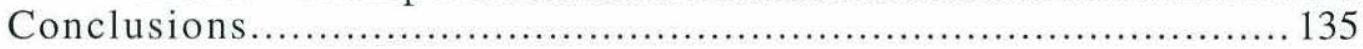

Chapter 5: Modeling Population Dynamics of Arctica islandica.........139

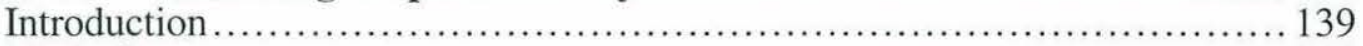

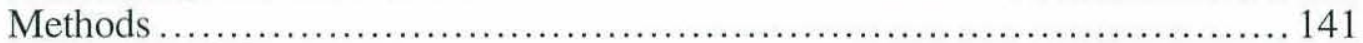

Model Formulation................................................... 141

Projection matrix analysis..................................... 145

Multiregional model.................................................... 146

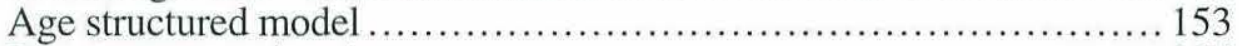

Parameter selection...................................................... 154

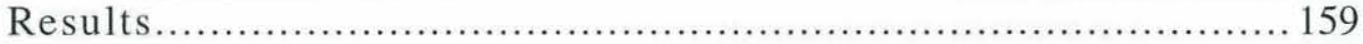

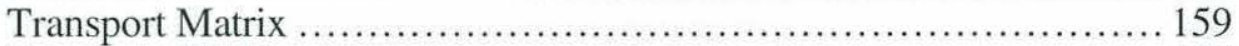

Demographic Structure ….................................... 170

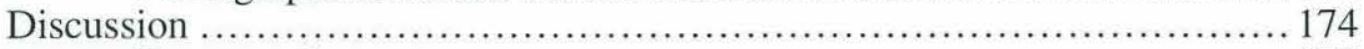

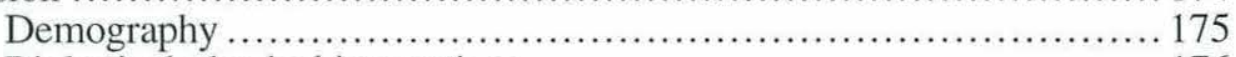

Biological-physical interactions ................................ 176

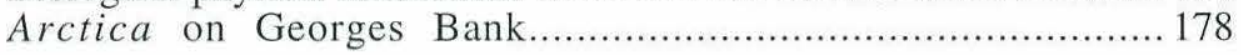

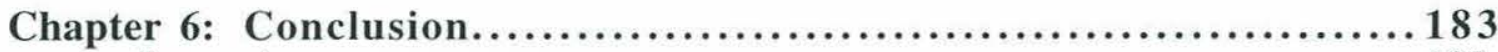

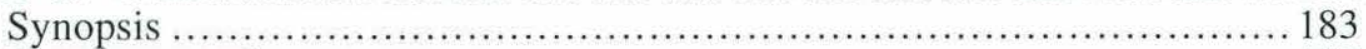

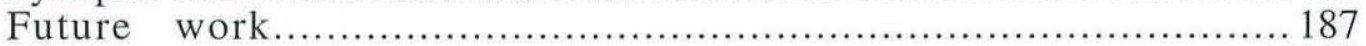

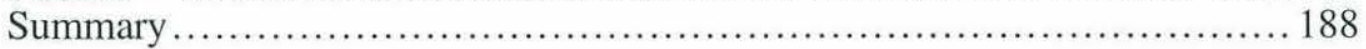

Appendix A: Transport matrices................................. 191

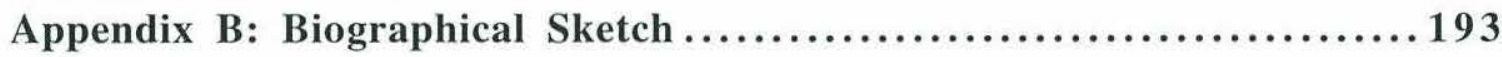

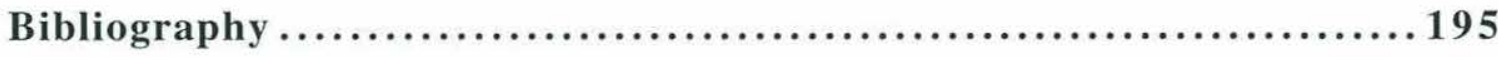




\title{
Biological-Physical Modeling on Georges Bank: Plankton Transport and Population Dynamics of the Ocean Quahog, Arctica islandica.
}

by

\author{
Craig Van de Water Lewis
}

Submitted in Partial Fulfillment of the Requirements for the Degree of Doctor of Philosophy at the Massachusetts Institute of Technology and the Woods Hole Oceanographic Institution March 17, 1997

\section{Abstract}

Advective losses of bank water during winter because of strong wind forcing were hypothesized to be a significant factor limiting recruitment of Georges Bank communities. This hypothesis was examined using biological-physical models of bank circulation with wind, tidal, and density driven circulation resembling winter conditions.

Models of stratification-driven flow over an idealized bank addressed effects of storms on the spring plankton bloom. An NPZ model and a copepod stage structure model were modeled as passive tracers. Results indicate that strong storms $(13 \mathrm{~m} / \mathrm{s}$ wind for 20 days) can cause marked replacement of bank water and loss of zooplankton and phytoplankton. These alterations in bank trophic structure may impair energy transfer from primary to secondary production and reduce recruitment of higher trophic levels.

Georges Bank Arctica islandica abundance data indicates that adults appear primarily below 50 meters, with highest abundances on the South Flank. Age and size structures suggest that a large cohort, detected on the southeast flank in 1992 and 94 surveys, was spawned in 1986; no other comparable recruitment was seen.

Larval transport was modeled using tidal forcing and winter wind data from 1974, 1978, and 1991. This work revealed that modeled transport driven by vector-averaged and realistic winds from the same periods differed. Circulation using realistic winds was highly variable; Ekman transport frequently overwhelmed tidal rectification and reversed the residual flow for several days.

Transport and matrix models of Arctica populations were compared with field data; correlation of models with NMFS Survey data was best for realistic wind simulations from 1974 and 1991. Projection matrix eigenvalues were most sensitive to changes in adult and larval survival and planktonic duration. Lower wind models identified the NE Peak region as having the highest reproductive value and sensitivity.

This work indicates that winter wind forcing is a factor determining transport of plankton. Models suggest that interannual differences in Georges Bank transport depend partially on temporal wind variability. They indicate that the Northeast Peak may be a source region for larvae and that Arctica research should focus on adult survival and planktonic mortality and duration.

Thesis Supervisor:

Dr. Cabell S. Davis III, Associate Scientist

Woods Hole Oceanographic Institution 


\section{ACKNOWLEDGMENTS}

I owe my grandparents for setting standards of excellence, in areas both human and scientific, that I someday hope to approach. This thesis is dedicated to their memory.

This work would not have been possible, and I would not have survived my graduate career without the support and friendship of a large number of people. First and foremost I must thank my family for their high expectations, love, humor, and advice, as well as their confidence in my ability to survive MIT and WHOI. Without the support of Verna, George, Nancy, Peter, Susan and John, I would have long since given up this whole project.

My deepest gratitude to Cabell Davis for endless enthusiasm, patience, support, advice, friendship, and even the occasional "kick in the pants". I could not have found a better person to tolerate six and a half years of graduate high-jinks, and I am proud to have been his student. I will miss his lab and its camaraderie, friendship, and humor.

My heartfelt thanks to Stacy Kim for her kindness, support, friendship, love, and enthusiasm. I look forward to many more years of the same. We can now officially play doctor in every ocean in the world.

My love to Rebecca Thomas, may her path through graduate school be an easier one than mine, but with at least as much fun and excitement. If I have the opportunity to facilitate any of the above, I most assuredly will.

A big hug to the Ewannigator and the Delicate Flower of Science. I will happily carry the memory of their friendship, love, hugs, and food (and the weight of the last) as long as I live.

My thanks to the membership of Dubious Outdoor Activities (DOA) for a number of great trips into the White Small Hills of New Hampshire. Especially Bill Williams and Sarah Zimmerman, the leaders of a variety of highly dubious and very enjoyable outdoor activities. I look forward to more dubious activities with Bill, Sarah, Gwyneth, Alice, Kelsey, Jamie, Dave, Prad, Steve, Miles, Stephan, Kirsten and all uninitiated members!

In the line of dubious activity, thanks to the fine folks of Cape Cod Underwater Hockey for gallons of beer, mudslides, and pool water. I will never find quite another group as diverse and enjoyable with which to spend hours at the bottom of the pool and ocean, chasing small lead pucks and large lobsters.

I'd like to thank numerous other WHOI friends, most notably "those Alvin Guys", and the past and present denizens of Redfield 222: Phil, Carin and Steve. Also, thanks to the many staff and fellow students from whose friendship, support and advice I have benefited over the years. I look forward to working with and seeing all of you in the future.

Acknowledgment must also go to Apple, Silicon Graphics, SUN, Starbucks, Red Hook and Samuel Adams for their fine products and workmanship. 
My thanks to my diverse committee for their advice and assistance in completing this work. To Hal Caswell for his dedication to the accuracy and scientific relevance of this work and his advice and support. To Glenn Flierl for his patience in solving the hardest problems and making the answers look easy. To Jim Weinberg for providing me access to the resources and data of the National Marine Fisheries Service and his assistance in analyzing that data.

A special thanks goes to Glen Gawarkiewicz for considerable effort in developing the model in Chapter 3, as well as his contributions to the modeling shown in Chapter 4 and 5. He put many long hours and late nights into this work, and deserves a significant portion of the credit for the results.

I am also very grateful to Changsheng Chen for providing the physical modeling foundation without which Chapters 4 and 5 would not have been possible. $\mathrm{He}$ parameterized the physical model discussed in Chapter 4. Thanks also to Alan Blumberg of Hydroqual, Inc. for allowing me to use his code.

Thanks to Andy Solow for his advice and intellectual support; his suggestions repeatedly cut right to the heart of a statistical morass, and his perspective, humor, and advice on Science, WHOI, and Graduate School were invaluable.

Scientific support also came from a wide variety of sources. Chris Weidman originally suggested Arctica as a model species, which I thank him for now that the project is finished. Chris also provided extensive further support for the shell sectioning work, and I have greatly enjoyed my interactions with him. Jim Manning provided much of the FNOC and Georges Bank wind data used to force the models. Many of my fellow students provided valuable assistance in this work. The crew and volunteers of the 1994 NMFS Shellfish Assessment Survey also deserve credit and thanks for the samples collected on that cruise.

The physical models for this work were run on computers at the National Center for Atmospheric Research in Boulder through a cooperative agreement with NSF. I am indebted to NCAR for the high quality of their staff, systems and support.

Last, but definitely not least, I am grateful to the WHOI Education office for funding a variety of meetings, courses, and my final protracted period at WHOI. They have made possible some of the best experiences and opportunities of my graduate career. I am especially grateful to Abbie, Julia, and Gary for always having the answer and Jake, Judy and John for their support in some of the best and worst times of my graduate career.

I have received funding for this work from a variety of sources. Tuition and stipend support came from an Office of Naval Research Graduate Fellowship. National Science Foundation funding to Cabell Davis and Glen Gawarkiewicz (NA36GP0289, OCE-90-16893, OCE-95-29402) and Office of Naval Research University Research Initiative funding to Hal Caswell and C. Davis (\#N00014-92-J-1527), provided stipend support and computer facilities. National Center for Atmospheric Research grants (\#35781038 and \#35781046) provided computer time and a grant from the WHOI Coastal Research Center provided critical support for research and thesis preparation. 


\section{ChAPTER 1: INTRODUCTION}

Population dynamics of marine organisms have long been hypothesized to be highly dependent on settlement of larvae and recruitment of the settled juveniles into the reproducing stages of the population (Thorson, 1950; Mileikovsky, 1971; Scheltema, 1974; Scheltema and Williams, 1983; Gaines, et al., 1985; Gaines and Roughgarden, 1985; Scheltema, 1985; Roughgarden, et al., 1988). Unfortunately, the processes controlling settlement and recruitment are often difficult to quantify; larvae of many species spend weeks or months in the plankton and their small size and low densities often make vital rates difficult to measure (Rumrill, 1990). Multiple interacting ecological and physical processes determine the fate of the larvae, and experimentally distinguishing between the effects of various processes is often nearly impossible.

This work focuses on the interaction of biological and physical processes and their effects on the population growth and distribution of holoplankton and meroplankton on Georges Bank, with particular emphasis on the Ocean Quahog, Arctica islandica. Several approaches, relying on models of biological-physical interactions and data concerning population structure, are used to better quantify the effects of physical and biological processes on these populations.

\section{GEORGES BANK}

The oceanography, geology and ecology of Georges Bank has been extensively summarized previously (Backus and Bourne, 1987). The bank is a shallow, roughly elliptical submarine plateau lying east of Cape Cod, Massachusetts (Figure 1.1). As 
defined by the 100 meter isobath, Georges Bank is approximately $150 \mathrm{~km}$ wide by 280 $\mathrm{km}$ long with an area of about $33,700 \mathrm{~km}^{2}$ (Uchupi and Austin, 1987).

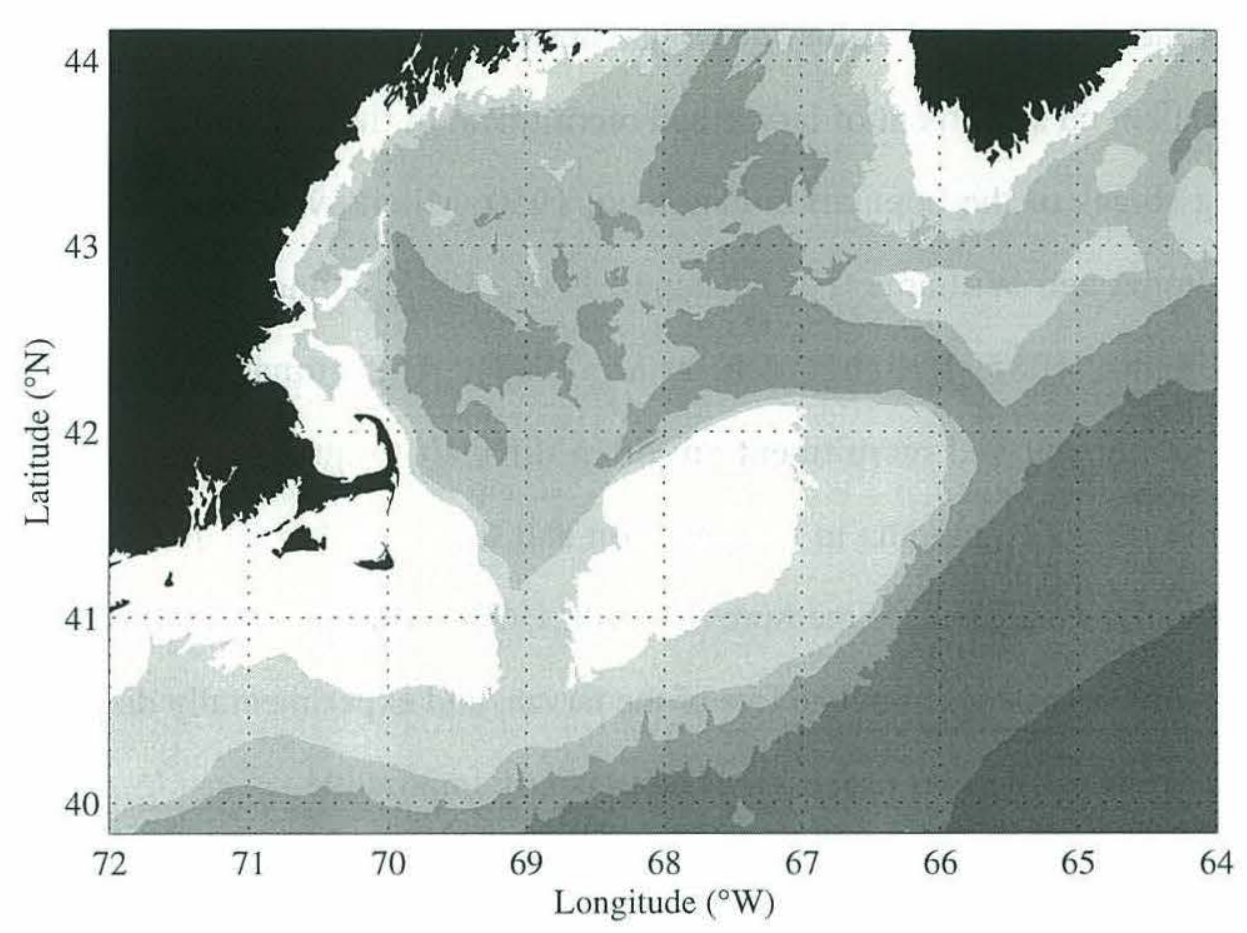

Figure 1.1: Map of Georges Bank and the surrounding region. Shown are the New England coast and the $60,100,200,2000$ and 4000 meter isobaths.

The southern half of the bank is dominated by a gradual sloping plain, extending from the 60 meter isobath out to a continental slope at about 120 meters. On the northern half, within the 60 meter isobath, are a complex series of shoals and overlying sand waves that rise, in some places, to within a few meters of the surface (Uchupi and Austin, 1987). This terrain is constantly shifting, driven by storms and strong tidal currents that resuspend and deposit the sediment in submarine sand dunes (Twichell, et al., 1987; Uchupi and Austin, 1987).

The dominant processes driving bank circulation in all seasons are density 
stratification, tidal rectification and wind stress, with the overall circulation and strength of the contributing processes varying seasonally (Butman and Beardsley, 1987). Only a broad overview of the essential differences between stratified (summer) and unstratified (winter) circulation and a brief discussion of the processes involved is presented here. A detailed discussion of this region can be found in Georges Bank (Backus and Bourne, 1987); this summary draws heavily from that volume.

\section{Stratified Case}

Although the exact timing and magnitude of the development of stratification over the bank seems to be strongly dependent on the weather conditions, the overall pattern between years is fairly similar. Starting in spring and stretching into late summer, the net heat flux into bank waters is positive and the surface waters heat up as the days lengthen and the air warms. Over the crest of the bank, semidiurnal tidal currents cause the area within the 60 meter isobath to remain well mixed throughout the summer. Little stratification occurs over the crest of the bank, and a sharp front (the tidal mixing front), typically near the 60 meter isobath, delineates this region of low stratification and high mixing (Butman and Beardsley, 1987; Flagg, 1987).

On the Northeast Peak and along the South Flank a seasonal thermocline builds during the spring and early summer months, extending from the tidal mixing front to the edge of the bank. This stratification caps a deeper band of cold water that extends out to the shelf break front, near the 100 meter isobath. Then shelf break front is delineated by the transition from lower salinity $(\sim 33 \mathrm{ppt})$ shelf water to higher salinity ( $35 \mathrm{ppt})$ Slope Water (Flagg, 1987).

On the North Flank, a narrow jet follows the topography between the tidal mixing 
front and the 100 meter isobath. Outside the 100 meter isobath are the stratified waters of the Gulf of Maine; inside the tidal mixing front are the tidally mixed waters over the crest of the bank (Flagg, 1987). The stratified period is characterized by intense around-bank recirculation in the stratified region (Butman and Beardsley, 1987).

Water temperatures over the crest of the bank have a seasonal mean temperature of $14.6^{\circ} \mathrm{C}$, but may reach $\sim 17^{\circ} \mathrm{C}$ in early September; in the stratified region, temperatures range from a high of $\sim 19^{\circ} \mathrm{C}$ in the surface water to lows below $10^{\circ} \mathrm{C}$ in the cold band. Occasional injections of Slope Water onto the shelf can cause surface temperatures in this region to rise as high as $25^{\circ} \mathrm{C}$ (Flagg, 1987).

By early fall, the stratification begins to weaken, reducing the strength of the recirculation. Shorter days and cooler air begin to cool the water, causing convective overturn to break down the seasonal thermocline, and fall and winter storms cause further mixing. The final transition from stratified to unstratified conditions is believed to be fairly abrupt, induced by a single mixing event (Flagg, 1987).

\section{Unstratified Case}

With onset of winter and breakdown of stratification, the intense recirculation and frontal structures also weaken and may be lost entirely in the face of intense winter storms. The spatial transition from thermally stratified to well-mixed water that characterizes the tidal mixing front on the South Flank disappears, although a weakened version of the tidal mixing front persists on the North Flank (Flagg, 1987).

Frequent mixing by winter storms keeps stratification very low over the entire bank during winter, and the isopleths are nearly vertical in all regions. The shelf break 
front remains, although somewhat weakened. Density effects due to salinity gradients (highest in the Slope Water) are largely compensated for by gradients in temperature (colder over the bank). Temperatures on the bank in winter are uniformly low, typically averaging approximately $4^{\circ} \mathrm{C}$ over much of the bank and $10^{\circ} \mathrm{C}$ in the shelf slope front (Flagg, 1987).

Flagg (1987) states, "Relative to that of other continental shelves, the hydrography of Georges Bank and the adjacent Gulf of Maine is very complex." This summary has addressed only a small portion of that complexity and is intended as a frame of reference for the models presented in Chapters 2 and 4 . Neglected in this consideration are the effects of a number of processes, either because they will be discussed later (winds, tidal rectification), or because they are not directly relevant to the scope of this work (e.g. Gulf Stream rings and meanders, riverine fluxes, Gulf of Maine hydrography, and Scotian Shelf inflow).

\section{ARCTICA ISLANDICA REVIEW}

The selection of Arctica islandica as a model species is motivated by a number of factors: small individuals are rarely found (implying minimal recruitment), individuals live for over 100 years, and extensive data on the population size structure are available.

While the species has been recognized for centuries and is distributed across the boreal North Atlantic (Nicol, 1951), there has been little study of recruitment variability or population structure. The data that do exist indicate that populations of this clam in southern New England and Georges Bank have had undetectable levels of recruitment in

recent years. Research by the National Marine Fisheries Service (NMFS) indicates that the populations south of the Maine Coast may be dominated by individuals of 30 to 100 
years in age (NEFSC, 1990, 1995a,b, 1996; Weinberg, 1993) and few small ( 10-30 yrs. of age) clams have been detected in the population (although fisheries dredges rarely sample juveniles less than $50 \mathrm{~mm}$ in shell length).

Arctica islandica, with its long life span and low recruitment, may be in danger of overfishing and stock depletion as a rapidly expanding fishery "mines" the accumulated mature adults. If recruitment is indeed limited as present data suggest, it is possible for fishing pressure to eliminate the brood stock without sufficient young returning to maintain population levels. There are already signs of this trend in the Middle Atlantic Bight, where the catch per unit effort (CPUE) has been dropping steadily. Stock estimates from research vessel surveys indicate a $42.9 \%$ reduction of the Delmarva (Delaware, Maryland and Virginia) population density since the inception of the fishery. This evidence for a population decline is corroborated by Leslie stock estimates indicating that $45 \%$ of the harvestable biomass had been taken by April 1993 (Weinberg, 1993).

The key problem at present is the lack of knowledge about the recruitment dynamics and population biology of Arctica. Little is known about the relative rates of recruitment and mortality that govern the population or about Arctica stock structure and biogeography. Accurate management of the fishery is rendered nearly impossible without knowledge of the rate at which larval recruitment replenishes the population. A summary of the present understanding of Arctica biology is included for reference.

Arctica islandica is a boreal species common throughout the temperate, coastal waters of the North Atlantic. It is found along the United States Coast as far south as Cape Hatteras and to the north along the Maine Coast, extending to the coast of Newfoundland (Merrill and Ropes, 1969). Along the coast of Europe it is found from 
the White Sea to the Bay of Cadiz, while the Arkona Sea is the eastern limit in the Baltic (Nicol, 1951; Merrill and Ropes, 1969; Brey, et al., 1990). The genus has been reported as abundant on the coasts of Iceland, the Faroes, and the Shetlands, as well as throughout the British Isles and the coast of Norway (Nicol, 1951). Shells have been found off the coast of Labrador and Greenland, but these are believed to be of fossil origin (Nicol, 1951; Funder and Weidick, 1991). From these and other references, it appears that the species may be ubiquitous along all temperate and subarctic coasts of the North Atlantic (Winter, 1969; von Oertzen, 1972; De Wilde, et al., 1984; De Wilde, et al., 1986; Brey et al., 1990).

Along the United States coast, the depth range of this species varies slightly, with average depths increasing from 39 meters down to 52 meters off the North Carolina coast (Merrill and Ropes, 1969). A depth range of 24.5-61 meters included 97\% of Ocean Quahogs taken during a survey of the Middle Atlantic Bight by the R/V Undaunted (Merrill and Ropes, 1969). The species was found in 35\% of all tows taken during that survey, which covered a large region of the Middle Atlantic Bight and the Gulf of Maine.

Arctica can dominate both biomass and abundance in its preferred depth range. The species makes up $15.83 \%$ of biomass and $10.35 \%$ of numerical density of stations sampled by Thouzeau on the Canadian section (Northeast Peak) of Georges Bank (Thouzeau, et al., 1991b). In Kiel Bay (Western Baltic) it dominates the biomass below the halocline, with a median abundance between 1968 and 1985 of 53 individuals $\mathrm{m}^{-2}$ (Brey et al., 1990).

Evidence indicates that Arctica prefers coarse sand and sand-shell substrate. On the Northeast Peak of Georges Bank, highest abundances were recorded in coarse sand 
and sand-shell regions (Thouzeau et al., 1991b), while observations off Rhode Island demonstrated highest densities in substrate consisting predominately of medium $(0.25$ $0.49 \mathrm{~mm}$ ) sand and shell fragments (Fogarty, 1981).

Arctica adults are most abundant in temperate and boreal waters. This probably reflects temperature limits, as adults soon die if kept in $70^{\circ} \mathrm{F}\left(21.1^{\circ} \mathrm{C}\right)$ water $($ Landers, 1976, referencing Turner, 1949). Nicol (1951) indicated a possible range from $0.7^{\circ}$ to $19^{\circ} \mathrm{C}$, and also noted that Arctica was more abundant in shallow waters in colder climes (Nichols and Thompson, 1982), suggesting an aversion to the warm summer surface waters common in temperate climes. Mann (1989) noted that adults appeared to be limited by the position of the $16^{\circ} \mathrm{C}$ bottom isotherm during summer (Mann, 1982, 1989). However, very low temperatures also seem to reduce growth rates, if not survival. Murawski, et al. (1982) noted that small quahogs may grow faster in Long Island Sound than in the colder waters of Northumberland Straight and Passamaquoddy Bay.

Literature summarizing the depth range and distribution of Arctica on Georges Bank is sparse. The National Marine Fisheries Service "Fishermen's Report" for the Surf Clam and Ocean Quahog indicate that the depth range of the species on Georges Bank may be deeper than that seen along much of the Middle Atlantic Bight (NEFSC, 1986, 1989, 1992, 1994). Merrill and Ropes (1969) state "Ocean quahogs are found on southern Georges Bank and nearly to its eastern tip", but it appears from the NMFS reports that a population exists along the Northern Flank and in the Great South Channel as well. Observations on the Northeast Peak indicate high abundances in the deeper waters on the south side of the Northeast Peak, with a decline in abundance at 105 meters (Thouzeau et al., 1991b). Empty shells have been observed down to 140 meters on the south flank (Maciolek and Grassle, 1987). Merrill and Ropes (1969) reported a live 
individual was taken at 256 meters. The viable depth range of this species is known to extend from the intertidal to 482 meters (Nicol, 1951). Hence, while Arctica population distributions are often clearly delimited by depth, it is more likely that some other ecological or physical process, or combination thereof, structures the population.

\section{Growth Banding}

Extensive research has addressed the determination of age for oceanic bivalves in general and Arctica islandica in particular. This work indicates that microscopic growth lines within the shell are deposited annually and yield a reliable estimate of individual age (Ropes, et al., 1983; Ropes, 1984b, 1987). These methods have been used to generate growth curves for Arctica in a number of areas (Forster, 1981; Murawski, et al., 1982; Ropes and Pyoas, 1982; Sager and Sammler, 1983; Kraus, et al., 1989; Brey et al., 1990), but there has been little interest in using this information to study population demographics.

Measurement of ${ }^{228} \mathrm{Ra} / 228 \mathrm{Th}$ ratios and anthropogenic ${ }^{14} \mathrm{C}$ levels in bands suggest band formation is annual in deeper dwelling clams from the New York Bight, but indicate that clams in shallow water, high disturbance (sludge dumping) areas may have too many bands (Turekian, et al., 1982). Work on ${ }^{210} \mathrm{~Pb} / 226 \mathrm{Ra}$ ratios also indicates that bands are laid down annually (Bennett, et al., 1982). Recent work by Chris Weidman has found ${ }^{18} \mathrm{O}$ ratios in Arctica shells provide a useful indicator of annual temperature variation (Weidman and Jones, 1993a,b).

A series of studies on annual banding in Arctica islandica, conducted primarily by researchers at the National Marine Fisheries Service, addressed the causes of band formation, optimal methods for band counting, and the accuracy of banding in 
determining age (Jones, 1980; Thompson, et al., 1980a; Ropes et al., 1983; Ropes, 1984a,b, 1985, 1987; Ropes, et al., 1984; Ropes and Jearld, 1987). In one study, about 42,000 quahogs were marked and released at a site in 53 meters of water off Long Island, New York in 1978. Clams from this release were recaptured at a number of later dates, including the most recent (as of this work) cruise in 1994. Clams recaptured 1 and 2 years later were sectioned, and clearly showed annual periodicity in shell microstructure, resulting in distinct annual bands (Ropes et al., 1984).

The process of marking the shells caused a visible break in the shell growth that was visible in the internal band structure as well (Ropes et al., 1984). This observation of band formation following disturbance is consistent with observations of Turekian (1982) and Ropes (1984). In summary, the cited literature strongly supports the assumption that growth banding is annual, although spurious bands deposited after disturbance events (Turekian et al., 1982; Ropes et al., 1983; Ropes, 1984b) and loss of bands due to shell wear (Ropes, 1984b) may prevent an exact determination of age.

\section{Larval Biology}

A number of factors are likely to limit Arctica distributions. Survival and reproduction of the benthic individuals are two of the keys to maintenance of a population. However, in a population with meroplanktonic larvae, recruitment may be decoupled from local reproduction and larval supply from distant populations may also control population dynamics (Thorson, 1950; Gaines et al., 1985; Gaines and Roughgarden, 1985; Roughgarden et al., 1988). If all larvae spawned locally are swept away by currents, and none are carried in from other populations, the population will soon die off even when local conditions are optimal for survival of the benthic phase. 
Temperature tolerance of larvae has been assessed by Landers (1976); percent development to veliger stage averaged $18 \%$ at $10^{\circ} \mathrm{C}, 24 \%$ at $15^{\circ} \mathrm{C}, 2 \%$ at $20^{\circ} \mathrm{C}$ and $0 \%$ at $23^{\circ} \mathrm{C}$. At $15^{\circ} \mathrm{C}$ larvae took about 48 hours to reach veliger stage, whereas they took 72 hours at $10^{\circ} \mathrm{C}$. Larval duration is about 60 days at $10-12^{\circ} \mathrm{C}$, causing Landers (1976) to remark,
"This would force the larvae to remain in the plankton for weeks, possibly subjecting them to prolonged predation and widespread dispersal, a consideration in the proper management of the resource if it is ever used to its fullest extent."

Mann and Wolfe (1983) studied the swimming behavior of Arctica larvae in response to temperature and pressure. In their work, swimming activity of different larval stages was correlated with temperature. Trochophore larvae swam upward continuously and actively within a thermal gradient from $9-25^{\circ} \mathrm{C}$, showing no temperature preference. In contrast, $110 \mu \mathrm{m}$ veligers swam actively only between $10-17^{\circ} \mathrm{C}$, preferring $12-15^{\circ} \mathrm{C}$, while veligers of $120 \mu \mathrm{m}$ length swim between 9 and $23^{\circ} \mathrm{C}$, preferring $14-17^{\circ} \mathrm{C}$ (Mann and Wolf, 1983). Veligers of 145-204 $\mu \mathrm{m}$ length are limited to a temperature range of 6 to $20^{\circ} \mathrm{C}$, becoming dormant at low temperatures (Mann and Wolf, 1983). Finally, they found that the threshold pressure change for a change in swimming pattern appears to be less than 0.5 bar (Mann and Wolf, 1983). These behaviors dictate the depth range of larval distribution and favor aggregation below the thermocline during the summer months on the Middle Atlantic Bight, but would result in surface aggregations after the Fall breakdown of the seasonal thermocline (Mann and Wolf, 1983).

Arctica islandica has been found to have a similar spawning season throughout the North Atlantic, with spawning typically initiated in late Spring, peaking between August and October, and concluding by late Fall (Loosanoff, 1953; von Oertzen, 1972; Muus, 
1973; Thompson, et al., 1980b; Jones, 1981a,b; Mann, 1981; Mann, et al., 1981; Rowell, et al., 1990). Off Rhode Island, spawning begins in late June or early July (at a water temperature of $\sim 13.5^{\circ} \mathrm{C}$ ), then peaks in August and September and ends by mid to late October (Loosanoff, 1953).

Mann (1985) also conducted a field survey of bivalve larval depth distributions at a single station on the southern New England shelf from April to October of 1981. He found Arctica larvae at two times of the year. In September and October of 1981, high

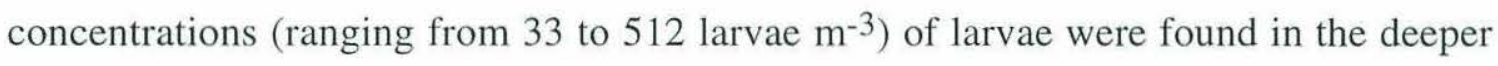
waters, at 20, 30 and 40 meters. In May of 1981 he found 70 larvae $\mathrm{m}^{-3}$ at 10 meters depth, and 16 larvae $\mathrm{m}^{-3}$ at 1 meter. Larvae found in May were all relatively large (length $>200 \mu \mathrm{m}$ ), implying that they had been in the water column for 6 weeks or longer (Lutz, et al., 1982; Mann, 1985). The presence of two groups of larvae probably resulted from very different developmental processes and timing: the larvae found in May indicate either an overwintering cohort or a midwinter spawning event, whereas the late summer and fall measurements are much more consistent with the known spawning season of Arctica.

Based on the hydrographic conditions, Mann (1985) hypothesized that larval survival on the southern New England Shelf is greatest during the months of October and November. The breakdown of stratification by fall storms would allow the larvae to range throughout the water column, whereas summer surface temperatures are known to exceed the $20^{\circ} \mathrm{C}$ temperature limit for larvae (Landers, 1976; Mann, 1982).

In summary, Arctica larvae spend a relatively long period of time in the plankton, during which time they are subject to extensive transport and dispersal. The observed scarcity of young clams on Georges Bank suggests that larval dispersal and settlement 
patterns may be a key factor in determining recruitment and population dynamics in this species. Coupled biological-physical models are a relatively simple and inexpensive method (in comparison to intensive multi-annual plankton and sediment sampling cruises) to estimate the effects of temporal and spatial variability of larval transport on population dynamics.

\section{BIOLOGICAL-PHYSICAL MODELING}

Use of three-dimensional numerical models in physical oceanography is relatively advanced. While computational limits prevent full representation of processes at all relevant scales, recent work has expanded to include the three-dimensional structure of biological communities within the modeled systems. These models reduce the complexity of multiple scales by neglecting one or more spatial dimensions or using highly simplified topography and physical forcing.

Several biological and physical models have been developed specifically to describe plankton distributions on Georges Bank. Gawarkiewicz (1993) used a physical model (Semi-spectral Primitive Equation Model or SPEM, Haidvogel, et al., 1991) of Georges Bank with simple topography (a circular bank with a conical top) to represent the short term process of wind forced advection over Georges Bank in early spring. This

model was then coupled to two different biological models in order to test the effects of wind forcing on resident plankton populations (Chapter 2, Lewis et al., 1994) A physical model of Georges Bank circulation developed at Dartmouth College by Dan Lynch, Chris Naimie and others has been used to study cod, haddock and sea scallop larvae, typically by tracking a large number of discrete particles as they are carried around the simulation domain (Lynch and Naimie, 1993; Werner, et al., 1993; Naimie, et al., 1994; Tremblay, 
et al., 1994; Lynch, et al., 1995, 1996; Naimie, 1996; Werner, et al., 1996).

Several recent papers have addressed the effect of physical variability in a generalized abstract model of a population distributed along a coastline (Hastings and Higgins, 1994) and in more specific models looking at single species in specific locales (Roughgarden et al., 1988; Botsford, et al., 1994; Alexander and Roughgarden, 1996). Hastings and Higgins (1994) used a simple model of a linearly distributed population with density dependent production of diffusive larvae to show that transients in such a model can persist for many centuries, indicating that the transient response of such models may be more relevant than the final equilibrium in predicting interannual variation in population size.

Using a variant of SPEM, Botsford, et al. (1994) studied the dispersion of dungeness crab and red sea urchin larvae along the coast of California in a variety of oceanographic conditions. Their models addressed effects of temperature dependent growth, diel vertical migration, and some wind forcing regimes on the growth and transport of the larvae.

\section{OVERVIEW}

The work presented here attempts to characterize the magnitude of physical processes and their effects on biological populations on Georges Bank. Two different animal models are used, one holoplanktonic copepod (Pseudocalanus sp.) and one benthic clam (Arctica islandica) with meroplanktonic larvae. The physical models used, while solving similar equations, incorporate the effects of distinctly different processes.

The results of a model of copepod (Pseudocalanus sp.) populations living on a 
shallow, isolated bank are presented in Chapter 2. Stratification and wind were the active physical processes in the model. A geostrophically adjusted gyre, driven by low density water overlying the bank's peak, is subjected to the effects of a constant 1 or 3 dyne $\mathrm{cm}^{-2}$ wind stress for 20 days. Two biological models are coupled into the physical model. The first biological model addresses the effect of trophic interactions by modeling nitrogen transfers between nutrient pools, a phytoplankton species, and a one component model of Pseudocalanus. The second biological model incorporates the effects of population dynamics within the copepod population, but neglects trophic interactions. The effects of the weak and strong wind stresses on these systems over the isolated bank are compared. A slightly modified version of this work has been published previously in Deep Sea Research II: Topical Studies in Oceanography (Lewis, et al., 1994).

Chapter 3 presents the results of an analysis using annual banding of Arctica islandica shells and the extensive National Marine Fisheries Survey size structure data to identify regions of Georges Bank and time periods in which detectable recruitment has occurred. A single recruitment event on the South Flank in 1986 and 1987 was suggested by the data, although limitations in the sampling scheme prevented a definitive identification of the true nature and extent of that event.

Chapter 4 describes a more detailed physical model of Georges Bank which was used to model transport of passive tracers. This physical model included effects of tidal rectification, realistic topography, realistic mixed layer dynamics, and time varying wind forcing. Five different scenarios were considered for this work. Wind records for three years $(1974,1978$, and 1991) during the period from December 12th to February 10th of the following year, were used to force the model in each of three cases. Two additional cases considered the effect of a vector average of the 1974 and 1978 wind velocities over 
the same length of time. The passive tracer transport predictions resulting from these model runs were used in modeling Arctica populations discussed in Chapter 5.

Chapter 5 presents the results of a multiregional matrix population model. This model incorporates both biological and transport processes into a single linear model, allowing comparison of the importance of various processes in determining Arctica population growth on Georges Bank.

The work concludes (Chapter 6) with a synopsis of the results and recommendations for further work in this field. 


\section{Chapter 2: Wind ForCed Biological-PhysicAl INTERACTIONS ON AN ISOLATED OFFSHORE BANK ${ }^{1}$}

\section{INTRODUCTION}

Recruitment of larvae into an adult population is the most important natural process controlling population size in many species of marine and freshwater fish and invertebrates (Davis, et al., 1985; Houde, 1987; Roughgarden et al., 1988). Recruitment dynamics in marine systems remain poorly understood despite much study (GLOBEC, 1989). Recruitment variability has been hypothesized to result from variable survival during larval planktonic stages induced by variations in water column stability (the stable ocean hypothesis; Lasker, 1975), timing of spawning with plankton production cycles (the match-mismatch hypothesis; Cushing, 1975), predation pressure (Bailey and Houde, 1989), and advective losses of larvae (Hjort, 1914; Sinclair, 1988). While the first two hypotheses relate to interactions between larvae and their zooplankton prey, studies of advective transport have focused on fish larvae (Chase, 1955; Nelson, et al., 1977; Bailey, 1981; Iles and Sinclair, 1982; Myers and Drinkwater, 1988) without considering the potential importance of advective losses of prey populations.

We hypothesize that, in isolated high productivity areas such as Georges Bank, high turnover rates of water masses occur during winter due to characteristically strong wind forcing, and that such advective losses reduce the efficiency of transfer of energy

1 This work has previously been published in a similar form and should be referenced as: Lewis, C. V. W., C. S. Davis and G. Gawarkiewicz (1994). "Wind forced biological-physical interactions on an isolated offshore bank." Deep Sea Research II 41(1): 51-73. It is reprinted here with permission of Prof. John Milliman. 
from phytoplankton production into higher levels of the food chain. We suggest that only in rare years are winter winds on Georges Bank low enough to permit efficient energy transfer through the food web, allowing unusually high survival of larval fish. At cold winter temperatures $\left(\sim 5^{\circ} \mathrm{C}\right)$, the slow growth rates of zooplankton ( $\sim 50$ day generation time) relative to phytoplankton ( $\sim 1$ doubling per day) makes them much more sensitive to advective loss. This "washout" hypothesis views bank areas as flow-through systems with particularly high turnover rates during most winters. In occasional low-wind winters, the advective losses are low and the system may enter a "batch culture" mode where the efficiency of trophic energy transfer is high. We suggest that the advective transport of planktonic prey populations in temperate shelf areas prior to the spring spawning period is a dominant factor controlling prey availability and, consequently, recruitment success in fish populations.

Evidence for this hypothesis is seen in data for Georges Bank haddock and their major zooplanktonic prey, the copepods Pseudocalanus moultoni and P. newmani (Frost, 1989). Analysis of the interaction between Pseudocalanus moultoni and the mean circulation on Georges Bank, during the winter of 1974-75, suggested that population growth commenced in December, 1974, and, over a two month period, the first generation developed while circulating in a clockwise pattern around the bank (Davis, 1984b). In this way, a large first cohort of newly molted adults was produced (and retained on the bank by recirculation) in late winter and early spring coincident with the spring diatom bloom (Davis, 1987; O'Reilly, et al., 1987). Peak concentration of Pseudocalanus was reached in June (after two recirculation periods of the bank gyre) and two more generations had been produced (Davis, 1984b) (Pseudocalanus newmani may also have contributed to the spring population; Frost, 1989). 
By contrast, in February 1979 concentrations of Pseudocalanus (and all other zooplankton) on Georges Bank were extremely low, resembling those typical of Gulf of Maine waters to the north (Figure 2.1). These low abundances coincided with a series of strong wind events in January and February, 1979, whereas the winter of 1974-5 had unusually weak winds and Ekman transport (Figure 2.1, inserts). Weekly averaged winter wind stress data from 1973-9 show that the wind stress in the winter of 1974-5 was anomalously low $\left(<1\right.$ dyne $\mathrm{cm}^{-2}$ ) whereas storms (wind stress of 2-3 dyne $\mathrm{cm}^{-2}$ ) were quite common in most other years (unpublished data provided by the Atlantic Environmental Group, NMFS, Narragansett, RI). This unusually calm winter also produced a bonanza year class of haddock. The ratio of recruits to eggs produced was 25 times higher than average (1963-1983; Davis, et al., 1991) and this cohort dominated the fishery for several years (Brown, 1987). Many other spring spawning fish species also had outstanding recruitment in 1975 (Brown, 1987), implying a system level effect.

Series of winter storms potentially can replace large volumes of Georges Bank water with Gulf of Maine or Slope Water, but the mechanisms and magnitude of these fluxes are poorly understood (Butman, et al., 1982). Since the Pseudocalanus population on Georges Bank increases from rudimentary levels in December to peak concentrations in June, elimination of the initial cohort (produced during December-February) by major advective events could cause a large reduction in June abundances. Since haddock spawn in February and March, a wash-out of plankton prior to spawning may affect subsequent food availability to the larvae. 


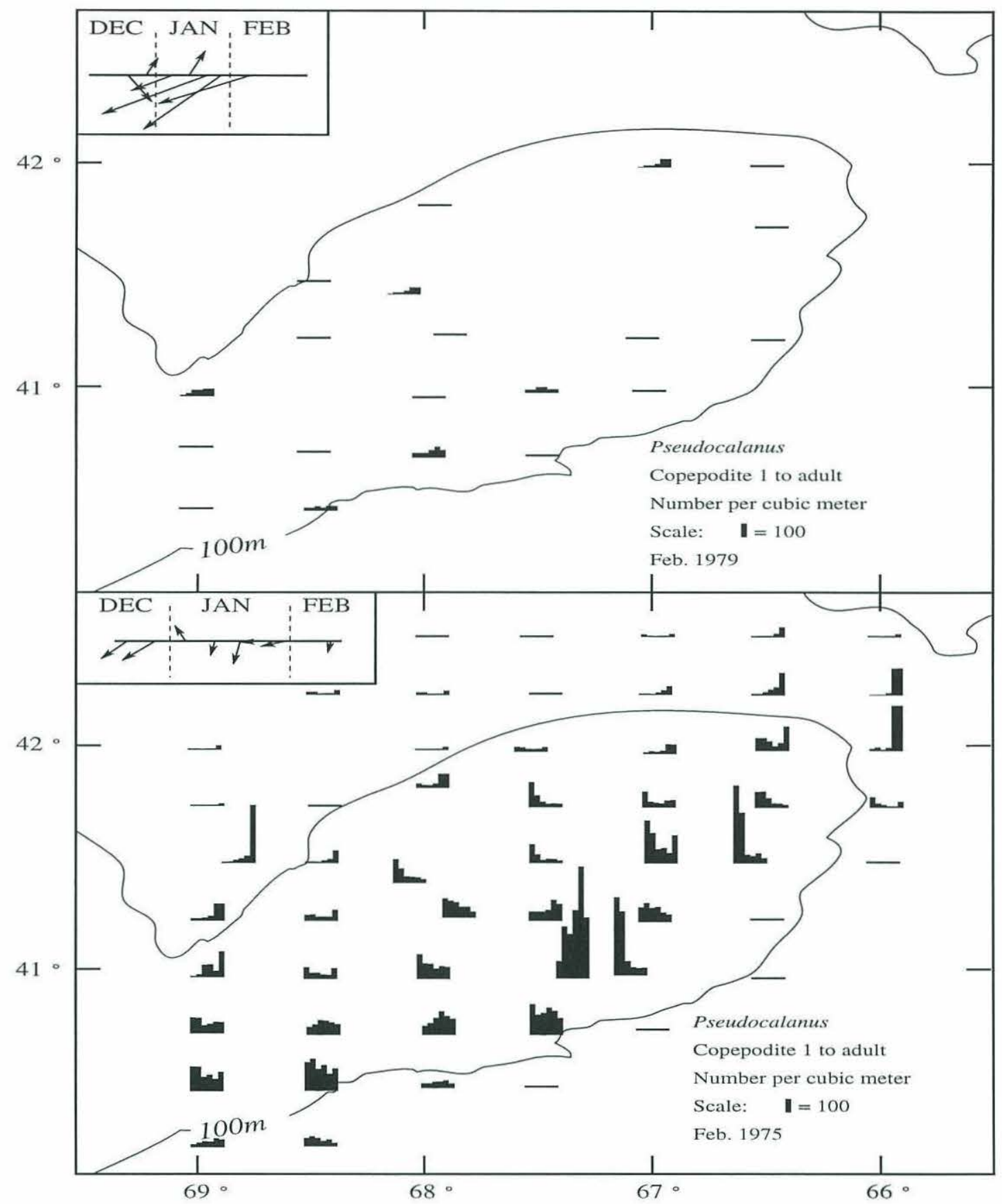

Figure 2.1: Spatial distribution of Pseudocalanus population stage structure on Georges Bank in: February 1979 (top) and February 1975 (bottom). Histograms at each station show absolute abundance (number $\mathrm{m}^{-3}$ ) of copepodite stages $\mathrm{CI}$ to adult from left to right. The vectors plotted in the insets represent the weekly averaged wind induced Ekman transport during the corresponding December-February period. No stations were sampled off bank in 1979 (figure from Davis, 1984b). 
Despite the potential importance of strong wind forcing on bank plankton dynamics, there have been no studies to date that address this issue. This is in part due to difficulties in sampling during these periods and to the large computational demands of time-dependent, three-dimensional numerical modeling on the small scales $(\sim 5 \mathrm{~km})$ necessary to resolve the flow. It has only recently become possible to model the advective transport of plankton during periods of high winds. We present the results of a numerical modeling study of the effects of strong wind forcing on bank plankton dynamics. The essential features of the wind effects on the ecosystem are considered by approximating the bank system as an isolated offshore bank surrounded by a density front, analogous to the south flank of Georges Bank.

\section{MODEL}

Simple biological models of a copepod population and a planktonic food chain were combined with a three-dimensional primitive equation model to explore the effects of strong versus weak wind forcing on advective losses of plankton from an isolated bank. Each biological model was tested with two levels of wind forcing; strong forcing at 3 dyne $\mathrm{cm}^{-2}$ and weak forcing of 1 dyne $\mathrm{cm}^{-2}$. These values represent the conditions during a normal winter and a winter such as the one of 1974-5.

\section{Physical Model}

We use the semi-spectral primitive equation model (SPEM) of Haidvogel et al. (1991). Description of the model is provided by Hedstrom (1990). A study of the initial dynamics of the flow field has been published by Gawarkiewicz (1993); here we will address only the aspects most relevant to this study. 
The momentum equations are, with subscripts, $x, y, z$, and $t$ denoting partial differentiation,

$$
\begin{aligned}
& u_{t}+\mathbf{u} \bullet \nabla u-f v=-\frac{1}{\rho_{0}} p_{x}+\left(A_{v} u_{z}\right)_{z}+F_{u} \\
& v_{t}+\mathbf{u} \bullet \nabla v+f u=-\frac{1}{\rho_{0}} p_{y}+\left(A_{v} v_{z}\right)_{z}+F_{v}
\end{aligned}
$$

$A_{v}$ is the vertical eddy viscosity and $F_{u}$ and $F_{v}$ are lateral mixing terms applied along sigma-coordinate surfaces (used for numerical stability). A biharmonic operator is used for $F_{u}, F_{v}$, with a mixing coefficient of $5 \times 10^{9} \mathrm{~m}^{4} \mathrm{~s}^{-1}$. The continuity equation is,

$$
\nabla \cdot \mathbf{u}=0
$$

The model assumes a rigid surface. The hydrostatic approximation is made, so that,

$$
p_{z}=-\rho g
$$

The $x$ and $y$ directions are defined in Figure 2.2; the wind stress was applied in the $-y$ direction. The vertical coordinate is $z$, and is defined positive upward with the origin located at the (rigid) surface. Variables $u, v$, and $w$ are the velocities in the $x, y$, and $z$ directions. Time is denoted by $t$, and the pressure by $p$. The reference density is $\rho_{0}=1000 \mathrm{~kg} \mathrm{~m}^{-3}$. The equation for the density field is,

$$
\rho_{t}+u \rho_{x}+v \rho_{y}+w \rho_{z}=\left(K_{v} \rho_{z}\right)_{z}
$$

where $\rho$ is the deviation from the reference density $\rho_{0} ; K_{v}$ is the vertical eddy diffusivity. A scheme to insure that static stability is maintained throughout the water column is also 
used in the model.

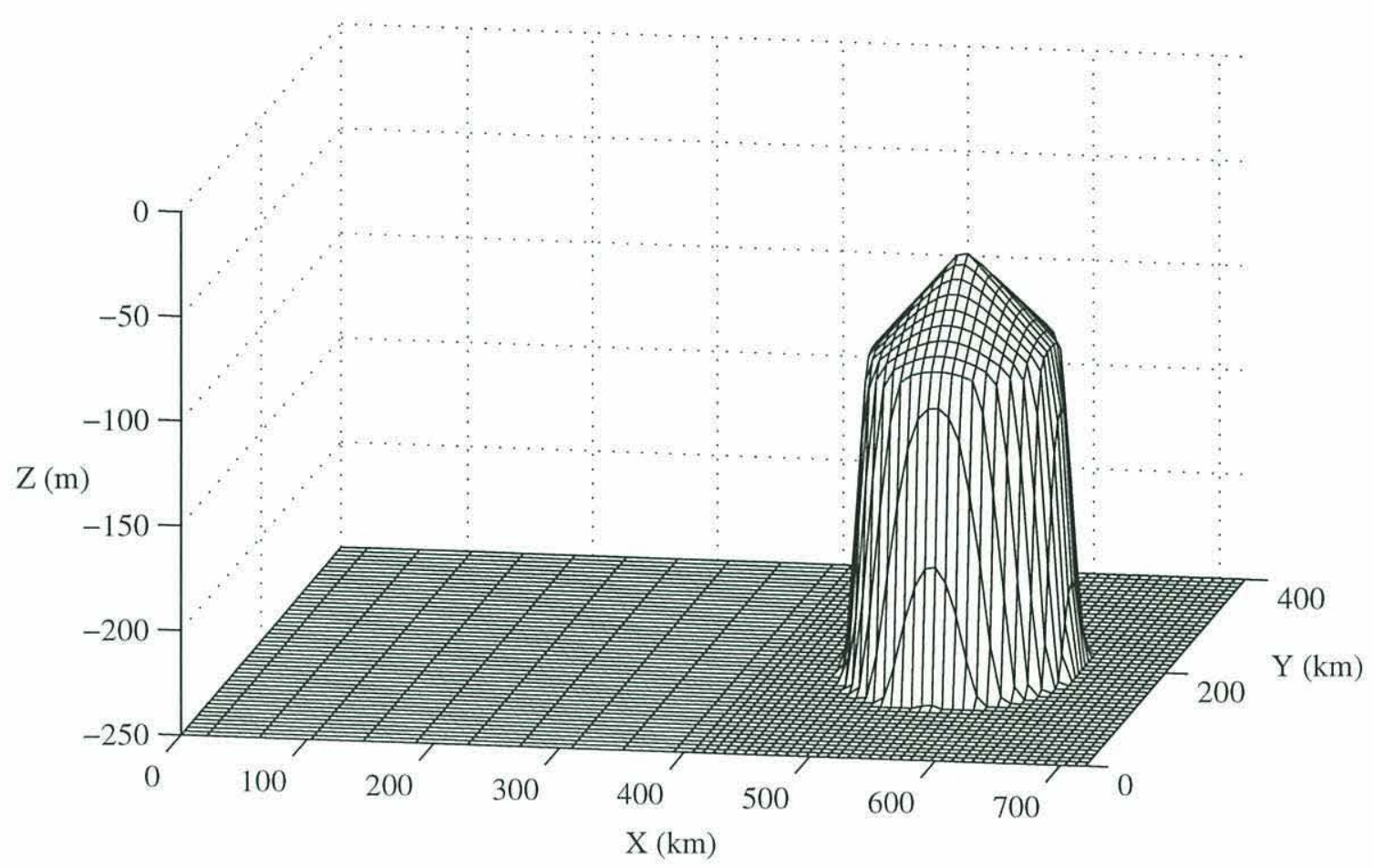

Figure 2.2: The model domain is rectangular and extends $700 \mathrm{~km}$ in the $x$ direction and $400 \mathrm{~km}$ in the $y$ direction. The grid is stretched by a factor of 5 for the first $400 \mathrm{~km}$ in the $x$ direction. A circular bank is present in the center of the fine grid area, with the peak being at $560 \mathrm{~km}$.

The model employs an Arakawa C grid with finite differences in the horizontal and a spectral expansion in modified Chebyshev polynomials in the vertical. The vertical grid points are concentrated near the surface and bottom boundaries with a minimum spacing of 3.35 meters at the center of the bank adjacent to the surface and bottom boundaries ( $h=50$ meters) and 16.7 meters in the deepest portion of the model domain ( $h$ $=250$ meters). Vertical mixing coefficients were set at $A_{v}=K_{v}=0.018 \mathrm{~m}^{2} \mathrm{~s}^{-1}$. It was necessary to fix the mixing coefficient in order to eliminate the effects of variable mixing on phytoplankton growth (low mixing rates resulted in higher growth rates of phytoplankton off the bank, while not greatly affecting on-bank primary production). This assumption is not unreasonable given the relatively high level of tidally induced 
mixing around the bank. We also tested models where the vertical mixing coefficient was dependent upon wind stress (Halpern, 1974; Santiago-Mandujano and Firing, 1990) but saw little difference in the observed distribution of the density field after twenty days. The mixing rates in either case were high enough to generate nearly homogeneous vertical distributions of all fields over the bank. Additionally, variation in the biological fields resolved by the highest vertical spectral modes was removed separately in order to correct for errors in the spectral treatment of vertical diffusion. This correction was tested by comparison with one-dimensional finite difference models before implementation. It was necessitated by extremely sharp boundary gradients in phytoplankton that were not being diffused with the original scheme.

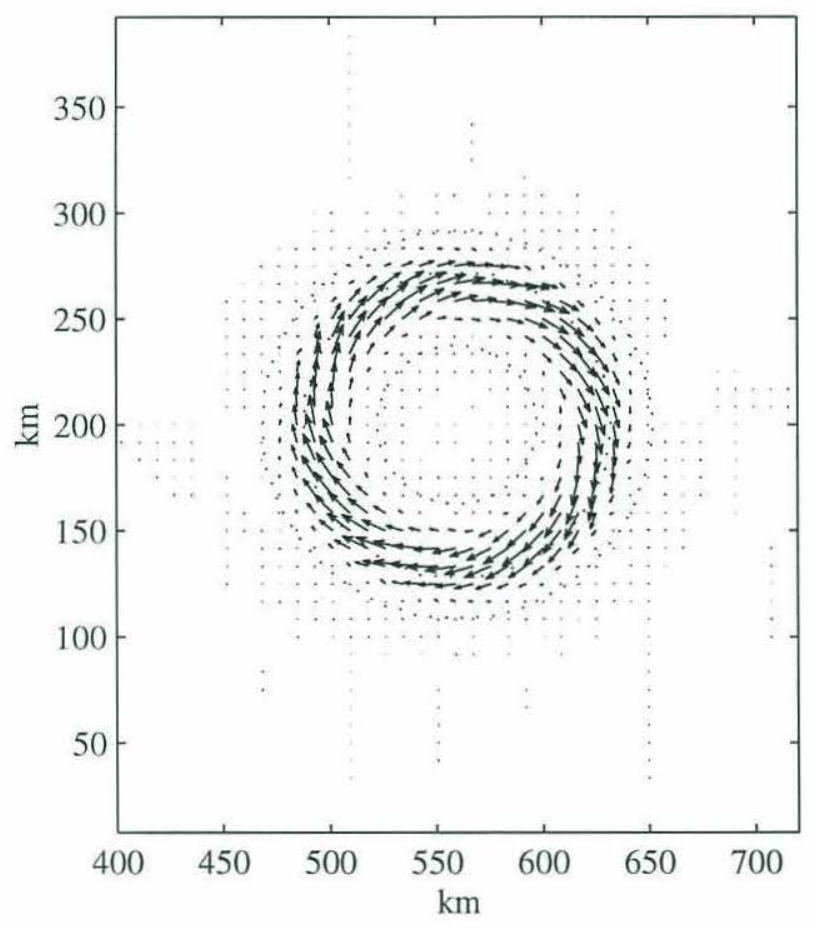

Figure 2.3: A plan view of the surface velocity field after 10 days of geostrophic adjustment of the light fluid centered over the bank. This flow is surface trapped with a typical maximum value of $0.15 \mathrm{~m}$ $\mathrm{s}^{-1}$. This was the initial flow field for all simulations described here.

The surface boundary conditions are: 


$$
A_{v} u_{z}=\tau_{x} / \rho_{0}, A_{v} v_{z}=\tau_{y} / \rho_{0} \text { at } z=0 \text {, }
$$

where $\tau_{x}$ and $\tau_{y}$ are the $x$ and $y$ components of the wind stress.

Model runs consisted of wind forcing of a light fluid with a density-driven flow encircling the edge of the bank. For the initial conditions, both $\tau_{x}$ and $\tau_{y}$ are set to zero and the initially quiescent, light fluid over the bank is allowed to adjust to a geostrophic and frictionally balanced flow for a period of ten days (Figure 2.3). During the wind forcing, $\tau_{y}$ is set to a constant value and $\tau_{x}$ remains zero.

Linear bottom friction is used:

$$
A_{v} u_{z}=-\gamma u, A_{v} v_{z}=-\gamma v \text { at } z=-h,
$$

with $\gamma=5 \times 10^{-4} \mathrm{~m} \mathrm{~s}^{-1}$ for all of the runs. No flux was allowed through the surface or bottom for density and all biological fields.

The model domain consists of a circular bank with a $75 \mathrm{~km}$ radius placed in a rectangular $720 \mathrm{~km}$ by $400 \mathrm{~km}$ computational domain (Figure 2.2). The fluid depth is described by:

$$
\begin{aligned}
& h(r)=\left\{\begin{array}{cc}
50+0.00067 r & r<75 \mathrm{~km} \\
100+0.03(r-75 \mathrm{~km}) & 75 \mathrm{~km}<r<80 \mathrm{~km} \\
250 & r>80 \mathrm{~km}
\end{array}\right\}, \\
& r=\sqrt{(x-560 \mathrm{~km})^{2}+(y-200 \mathrm{~km})^{2}}
\end{aligned}
$$

where $h$ and $r$ are in units of meters; $r$ is the radial distance from the center of the bank. At the lateral boundaries, a channel configuration is used with periodic boundary 
conditions in the direction of the Ekman transport. Solid walls with free-slip conditions line the channel parallel to the direction of the Ekman transport.

A 98 by 97 stretched horizontal grid ( $4.2 \mathrm{~km}$ resolution in the bank region) was used. Seven Chebyshev polynomials were used in the vertical. The use of higher horizontal and vertical resolution did not affect the results. The time step for all runs was $270 \mathrm{~s}$ (this was the longest time step for which the model was computationally stable in the shallow water). In all cases, the rotation rate is uniform with $f=10^{-4} \mathrm{~s}^{-1}$.

The initial flow field in the absence of wind consists of a surface-trapped front which encircles the bank edge (Figure 2.3) with a maximum around-bank velocity of $0.15 \mathrm{~m} \mathrm{~s}^{-1}$. A density difference of $0.5 \mathrm{~kg} \mathrm{~m}^{-3}$ is imposed between the light fluid over the center of the bank and the ambient fluid surrounding the bank. The physical circulation resulting from the wind forcing is discussed below.

\section{Biological Models}

The two cases considered for the biology were: a life stage model representing four approximately equal length periods of a copepod life cycle and a 3 element food web model representing a limiting nutrient, phototrophic phytoplankton, and herbivorous zooplankton all expressed as concentration of nitrogen per cubic meter tied up in each pool. The biological equations were solved simultaneously with the physical equations at every point in the model, using the same numerical scheme.

The biological quantities were incorporated into the physical model as a set of Eulerian fields. Physical transport of the various elements was performed using routines that mirrored the existing SPEM routines for the transport of salinity and temperature; 
namely:

$$
B_{t}+u B_{x}+v B_{y}+w B_{z}=\left(K_{v} B_{z}\right)_{z}+\text { biological interactions, }
$$

where $B$ is the abundance or concentration of the biological quantity in question, and the biological interaction equations are described in the section below. The biological fields were treated as purely passive tracers having no effect on the physical dynamics. No migration or swimming behavior was included in any of the models, as such behavior is still a subject of great uncertainty.

\section{Life Stage Model}

The copepod life stage model addresses the effects of advection on copepod abundance over the bank. The life history was divided into four segments representing early and late naupliar and copepodite stages: $\mathrm{N}_{1}$ (NI-NIII), $\mathrm{N}_{2}$ (NIV-NVI), $\mathrm{C}_{1}$ (CICIII), and $\mathrm{C}_{2}$ (CIV-CVI). This choice was made to reduce, as much as possible, the numerical diffusion inherent in low dimension life stage models such as these. This model allowed us to track the maturing populations, yielding a distribution of age classes rather than biomass. Early stage nauplii were assumed to hatch out uniformly within the 100 meter isobath during the entire simulation. Concentration of prey was assumed, for this model, to be sufficient for maximal growth throughout the model domain (Davis, 1984a,b).

The population model was defined by the following equations: 


$$
\begin{aligned}
& \frac{\partial N_{1}}{\partial t}=s-\left(d_{1}+m_{1}\right) N_{1} \\
& \frac{\partial N_{2}}{\partial t}=m_{1} N_{1}-\left(d_{2}+m_{2}\right) N_{2} \\
& \frac{\partial C_{1}}{\partial t}=m_{2} N_{2}-\left(d_{3}+m_{3}\right) C_{1} \\
& \frac{\partial C_{2}}{\partial t}=m_{3} C_{1}-d_{4} C_{2}
\end{aligned}
$$

parameters are defined in Table 2.1.

Each biological field was subjected to the effects of the advective fields from the physical model above and vertical diffusion, being treated as a passive tracer within the model domain. The value of each quantity represents the abundance of that life stage in number per cubic meter.

Table 2.1: Parameter values for copepod life stage model.

\begin{tabular}{ccl}
\hline Parameter & Definition & Value \\
\hline$s$ & spawning & 28 ind. $^{-3} \mathrm{~d}^{-1}$ \\
$m_{1}$ & $\mathrm{~N}_{1}$ molting rate & $0.108 \mathrm{~d}^{-1}$ \\
$d_{1}$ & $\mathrm{~N}_{1}$ death rate & $0.100 \mathrm{~d}^{-1}$ \\
$m_{2}$ & $\mathrm{~N}_{2}$ molting rate & $0.072 \mathrm{~d}^{-1}$ \\
$d_{2}$ & $\mathrm{~N}_{2}$ death rate & $0.100 \mathrm{~d}^{-1}$ \\
$m_{3}$ & $\mathrm{C}_{1}$ molting rate & $0.058 \mathrm{~d}^{-1}$ \\
$d_{3}$ & $\mathrm{C}_{1}$ death rate & $0.040 \mathrm{~d}^{-1}$ \\
$d_{4}$ & $\mathrm{C}_{2}$ death rate & $0.020 \mathrm{~d}^{-1}$ \\
\hline
\end{tabular}

Parameter values for this model were chosen to reflect those observed for Pseudocalanus on and around Georges Bank during late winter (Davis, 1984b,c) and from related work in temperate waters (Ohman, 1986). Spawning was assumed to take place only within the 100 meter isobath, consistent with field data (Davis, 1984b, 1987), and all spawning is assumed to come from a preexisting, overwintering population, rather than from adults that mature during the 20 day simulation period. The naupliar production rate assumes a constant low background population of 25 female adults per 
cubic meter over the entire domain with spawning occurring only in the food-rich water over the bank. Fertility rate was 1.3 eggs female $^{-1}$ day $^{-1}$ (Davis, 1984b), and egg loss was approximately $15 \%$ over the period between spawning and hatching (Ohman, 1986) yielding the listed $\mathrm{N}_{1}$ hatching rate. This formulation assumes that the late stage copepodites (theoretically including mature adults) produced over the course of the model run do not contribute to spawning. This is reasonable considering the period of model run (20 days) was shorter than the generation time at typical winter water temperatures $\left(\sim 50\right.$ days at $\left.5^{\circ} \mathrm{C}\right)$. The use of a constant population of spawning adults is a conservative assumption; it implies that advective events have little impact on adults (e.g. adult populations on and off bank are identical).

Mortality rates were derived from Ohman (1986), assuming a uniform $5^{\circ} \mathrm{C}$ water temperature; molting rates were based on Davis (1984c). Molting rates for our stage classes were determined from the sum of the mean stage durations in each of the four groups (naupliar stages 1-3 and 4-6 and copepodite stages 1-3 and 4-6). Varying these parameters within the ranges specified in the literature (Corkett and McLaren, 1978; Davis, 1984c; Ohman, 1986), had little qualitative effect on the final results.

Two cases using these biological parameters are considered: high and low wind. The physical model was initialized as described above, with light water on the bank allowed to geostrophically adjust to a clockwise gyre for ten days. After the adjustment had completed, the copepod abundances were initialized to uniform zero fields throughout the model domain. The wind stress was set to 1 or 3 dyne $\mathrm{cm}^{-2}$ (wind speeds of roughly 7.5 or $13 \mathrm{~m} \mathrm{~s}^{-1}$ ) across the channel, and the model fields were allowed to evolve for 20 days. As detailed above, these wind conditions were chosen to approximate those on Georges Bank during the winters of 1975 and 1979 respectively. 


\section{Trophic Model}

The second model considered two trophic levels and a dissolved nutrient pool in terms of millimoles nitrogen per cubic meter. Phytoplankton grew in the presence of light and nitrogen, respired a small portion of their biomass each day, and were grazed upon by zooplankton. The zooplankton grazing included a term for excretion and inefficient feeding with saturation of feeding rate at high phytoplankton concentrations. The model conserved total nitrogen. Phytoplankton respiration, zooplankton excretion, and zooplankton death all fed nitrogen back into the dissolved nitrogen pool.

The model was based on work by Franks, et al. (1986) and Marra and Ho (1993), with modifications in the phytoplankton response to light saturation based on parameters measured on the Scotian Shelf in late winter or early spring (Harrison and Platt, 1986). Photosynthetic uptake involved a Michaelis-Menten nutrient uptake curve, modified for saturating (but not photoinhibiting) light levels in the surface waters. Phytoplankton respiration and death returned a constant proportion of phototroph biomass to the dissolved nitrogen pool. Zooplankton grazing on phytoplankton was formulated with an Ivlev grazing term. Excretion and feeding inefficiency were represented as a constant proportion of the grazing. All biological fields were subjected to the full three-dimensional circulation, as well as vertical diffusion. Zooplankton swimming behavior and detrital nitrogen were not included in this formulation. The equations describing the biological interactions were: 


\begin{tabular}{ll} 
Trophic Level & Equations \\
\hline $\mathrm{N}$, Nitrogen & $\frac{\partial N}{\partial t}=d \mathrm{Z}+m P+\gamma \mathrm{G}(P) Z-\mathrm{U}(\mathrm{I}, N) P$ \\
P, Phytoplankton & $\frac{\partial P}{\partial t}=\mathrm{U}(\mathrm{I}, N) P-m P-\mathrm{G}(P) Z$ \\
Z, Zooplankton & $\frac{\partial Z}{\partial t}=(1-\gamma) \mathrm{G}(P) Z-d Z$
\end{tabular},

where:

$$
\begin{array}{ll}
\text { 2.11) } & \text { Uight: } \quad \mathrm{I}=I_{0} \mathrm{e}^{-k z} \\
\text { Uptake: } & \mathrm{U}=V_{m}\left(\frac{N}{K_{m}+N}\right)\left(1-\mathrm{e}^{-\left(\alpha I / V_{m}\right)}\right) .
\end{array}
$$

$I_{0}$ was the surface intensity of photosynthetic active radiation, $k$ was the light extinction coefficient, $z$ was the depth, taken with the origin at the water's surface, and positive upwards. $V_{m}$ was the maximum phytoplankton growth rate, $\alpha$ was the initial slope of the photosynthesis versus irradiance curve, and $K_{\mathrm{m}}$ was the half saturation constant for nutrient uptake by phytoplankton. The equation governing zooplankton grazing, $\mathrm{G}(P)$, was the standard Ivlev grazing curve:

$$
\text { 2.12) } \mathrm{G}(P)=R_{m}\left(1-\mathrm{e}^{-\Lambda P}\right) \text {. }
$$

$R_{m}$ was the maximum weight specific consumption rate of phytoplankton $\left((1-\gamma) R_{m}\right.$ was the maximum zooplankton growth rate) and $\Lambda$ was the Ivlev constant (Ivlev, 1955).

Values for all biological parameters listed below were taken from a variety of literature sources. The values chosen represent an approximation to conditions in late winter on Georges Bank. The model was run with non-equilibrium starting conditions, representing a period of time when the bank ecosystem begins to respond to the lengthening days and better conditions as winter ends. For a sensitivity analysis of the 
basic biological model (without depth structure) see Franks, et al. (1986). Corroborative sources exist for many of these parameter choices, but disagreement in the literature over exact values is common. Within the measured ranges we chose values that, in the absence of wind forcing, allowed phytoplankton to grow in the shallow water over the bank but not in the deeper, off-bank areas. This is consistent with our desire to represent the plankton dynamics in late winter.

Table 2.2: Parameters values and references for trophic model.

\begin{tabular}{cccc}
\hline & Definition & Value & Source \\
\hline$d$ & Zooplankton mortality & $0.1 \mathrm{~d}^{-1}$ & Ohman, 1986 \\
$m$ & Phytoplankton death & $0.1 \mathrm{~d}^{-1}$ & Franks et al., 1986 \\
$\gamma$ & Unassimilated grazing fraction & 0.3 & Corkett and McLaren, 1978 \\
$I_{0}$ & Surface light intensity & $150 \mathrm{~W} \mathrm{~m}^{-2}$ & Sverdrup et al., 1942 \\
$k$ & Light extinction coefficient & $0.2 \mathrm{~m}^{-1}$ & Parsons et al., 1984 \\
$V_{m}$ & Maximum phytoplankton growth & $1.1 \mathrm{~d}^{-1}$ & Eppley, 1972 \\
$K_{m}$ & Michaelis constant & $1.0 \mathrm{mmol}^{-\mathrm{N} \mathrm{m}}-3$ & Eppley et al., 1969 \\
$\alpha$ & Initial slope, P-I curve. & $0.08 \mathrm{~m}^{2} \mathrm{~W}^{-1} \mathrm{~d}^{-1}$ & Harrison and Platt, 1986 \\
$R_{m}$ & Maximum zooplankton feeding & $0.2 \mathrm{~d}^{-1}$ & Corkett and McLaren, 1978 \\
$\Lambda$ & Ivlev constant & $0.9 \mathrm{~m}^{3} \mathrm{mmol}^{-1}$ & Frost, 1972 \\
\hline
\end{tabular}

Zooplankton mortality, $d$, was taken from a survivorship curve in Ohman (1986), assuming a water temperature of about $5^{\circ} \mathrm{C}$. The value is reasonably accurate for the early life stages that dominate the population during this period of intensive spawning. The phytoplankton mortality, $m$, was taken from Franks et al. (Harris and Piccinin, 1977; Franks, et al., 1986). The zooplankton grazing efficiency $(1-\gamma)$ was based on the review of Pseudocalanus biology by Corkett and McLaren (1978). Surface light intensity in this area was from Sverdrup et al. (1942), and the light extinction coefficient was based on Parsons et al. (1984), assuming fairly clear coastal water. Maximum phytoplankton growth, $V_{m}$, was tuned to generate phytoplankton growth over the bank, but not in the deeper off-bank waters; it is consistent with work by Eppley (1972) for water temperatures of $5^{\circ} \mathrm{C}$. The half saturation constant for nutrient limitation of 
phytoplankton growth, $K_{m}$, was based on work by Eppley, et al. (1969). The initial slope for the photosynthesis-irradiance curve, $\alpha$, was determined by Harrison and Platt (1986) over the Scotian Shelf in April. The zooplankton feeding rate was chosen such that $(1-\gamma) R_{m}$, the maximum weight specific growth rate of the zooplankton, was consistent with growth rates for food-unlimited Pseudocalanus (Davis, 1984a,c; Ohman, $1986)$ at $5^{\circ} \mathrm{C}$. The value for the Ivlev constant was determined by Frost (1972) for Calanus pacificus. There is great uncertainty about the values of many of these parameters, but we feel that the above choices represent a close approximation to the processes on Georges Bank in late winter. They give behavior in one-dimensional, vertical models consistent with the observed plankton dynamics on Georges Bank in late winter. In essence, our choices were made within the limits of measured values and drive model behavior that we feel is consistent with observations over the bank at that time of year; namely, the initiation of a bloom in phytoplankton combined with a slower response in zooplankton concentrations (Cura, 1987; Davis, 1987).

The model was initialized with uniform values throughout the domain; 0.2 mmol$\mathrm{N} \mathrm{m}^{-3}$ in zooplankton, $1.0 \mathrm{mmol}-\mathrm{N} \mathrm{m}^{-3}$ in phytoplankton, and $4.8 \mathrm{mmol}-\mathrm{N} \mathrm{m}^{-3}$ in the dissolved nitrogen pool. We allowed the biological quantities to react towards equilibrium, using the interactions to represent a short term phytoplankton bloom and a lagging bloom in zooplankton. Physical forcing was treated as described above; a geostrophically balanced flow was forced with high or low wind for 20 days.

\section{RESULTS}

Both models supported the hypothesis that wind forced advection over an isolated bank causes reduction in abundance of zooplankton. Reduction was greatest on the 
Ekman gain side of the bank. The results of the physical model extend previous work (Gawarkiewicz, 1993) over a longer period of time. For brevity, we will consider mainly the fields after the full twenty days of simulation. Figure 2.4 depicts the major physical processes operating in the model and indicates the regions (Ekman gain and Ekman loss) where we observed the most significant effects.

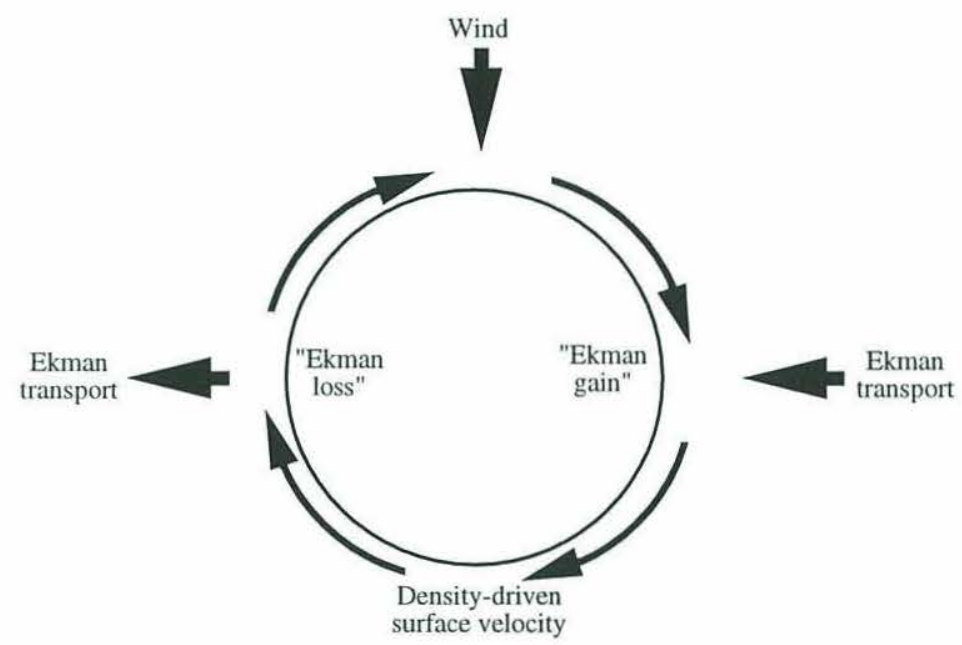

Figure 2.4: A schematic of the flow field under the joint influence of wind and density driven flow. The Ekman transport is off the bank to the right of the wind, and the near-surface flow field is dominated by this wind driven transport. Note that the Ekman transport is onto the bank on the side to the left of the wind, the "Ekman gain" region, and is off the bank on the side to the right of the wind, the "Ekman loss" region.

\section{Physical Model}

The primary effect of the wind forcing is to advect light fluid off the bank. Over short time scales, the response of the velocity field is primarily a linear superposition of the wind-driven and buoyancy-driven fields near the surface, except in a localized region where the around-bank density gradients are weakened by advection (Gawarkiewicz, 1993). On short time scales, the flow beneath the surface Ekman layer is not affected by 
the wind-driven flow and reflects only the initial density distribution.
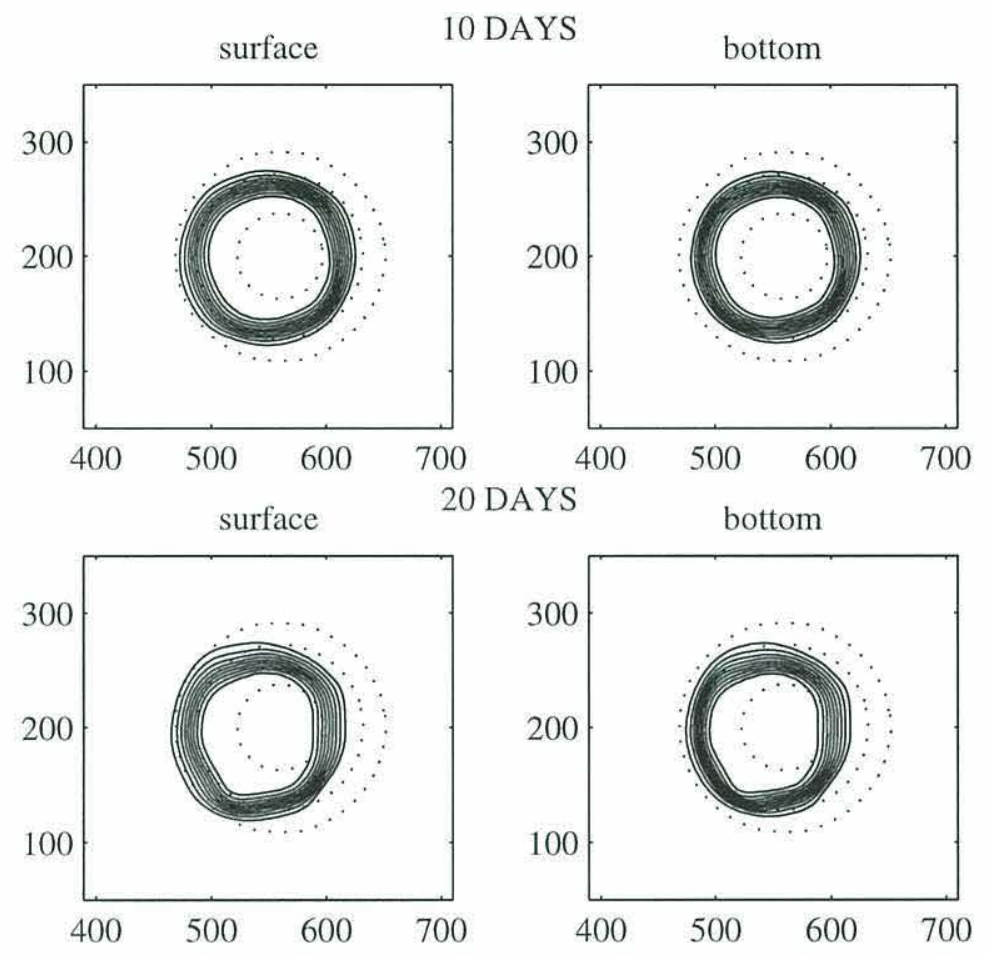

Figure 2.5: Contours of density at the surface and bottom after ten and twenty days of low wind forcing from the north. Contour interval was $0.05 \mathrm{~kg} \mathrm{~m}^{-3}$, from 1000.05 to $1000.45 \mathrm{~kg} \mathrm{~m}^{-3}$. Axis units are kilometers.

For longer time scales the wind-driven advection removes more buoyant fluid from the bank surface water and the sub-surface structure of the density field is strongly affected. Figure 2.5 shows the surface and bottom density (relative to reference density,

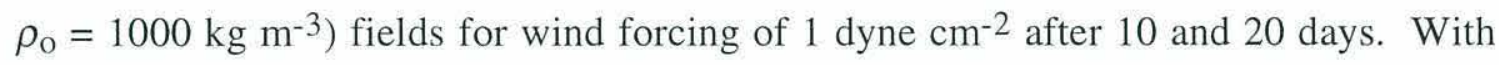
weak wind forcing, the light fluid is not advected off the bank to any significant degree although the density front region is shifted in the direction of the Ekman transport on both sides of the bank.

For strong wind forcing ( 3 dynes $\mathrm{cm}^{-2}$ ) over extended time scales, the density structure over the bank (and thus the subsurface circulation) is profoundly affected by the 
large loss of buoyant fluid in the surface layer. After 10 days (Figure 2.6), the inner edge of the density front along the bottom has already intersected the center of the bank. By day 20 , the outer edge of the density front is carried over the center of the bank. At this point, the flow tries to continue along constant depth contours and rapidly deforms away from the center of the bank in the direction of Ekman transport.
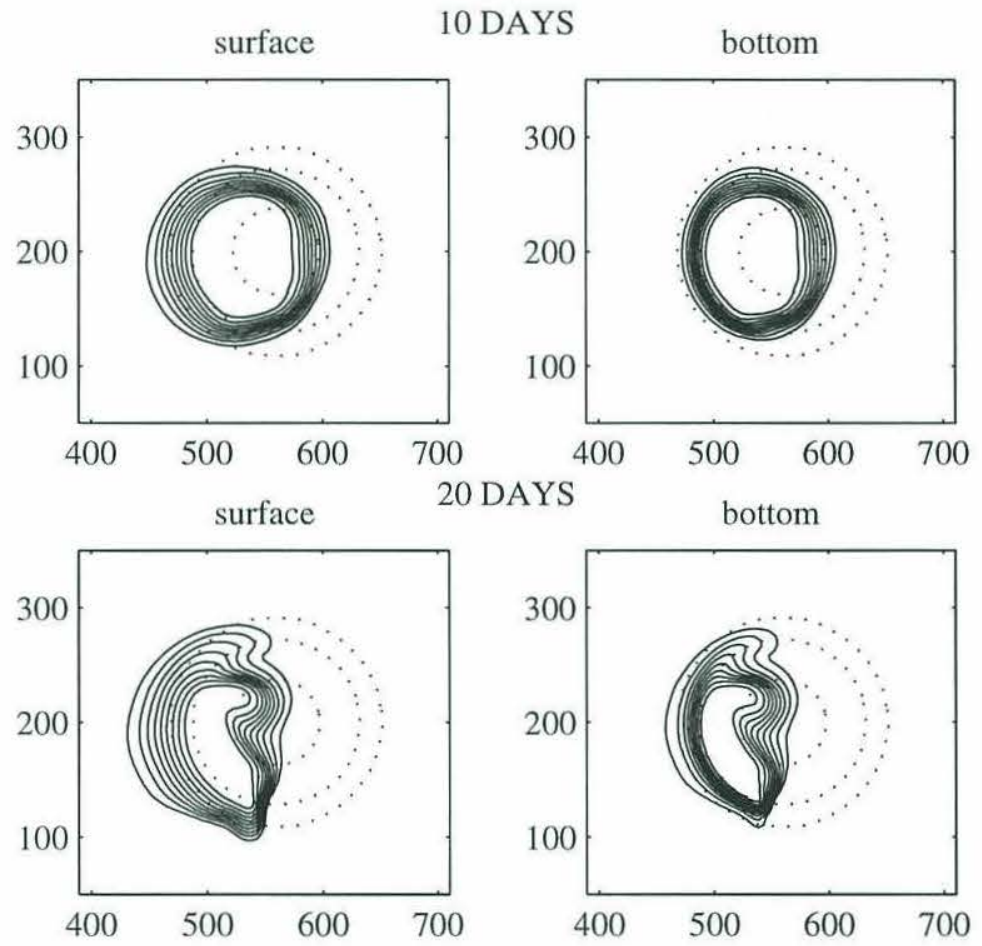

Figure 2.6: Contours of density at the surface and bottom after ten and twenty days of high wind forcing from the north. Contour interval was $0.05 \mathrm{~kg} \mathrm{~m}^{-3}$, from 1000.05 to $1000.45 \mathrm{~kg} \mathrm{~m}^{-3}$. Axis units are kilometers.

By thirty days (not shown) the flow breaks into two large eddies and the entire buoyancy-driven flow around the bank is disrupted. This behavior is inherently nonlinear as the advection of the density field redistributes the geostrophic flow beneath the Ekman layer, and differs drastically from the case of synoptic (3 day) scale wind forcing described before (Gawarkiewicz, 1993). We emphasize that for sufficiently long time 
scales of wind forcing, the wind-driven flow is capable of entirely disrupting the densitydriven circulation.

\section{Biological Models}

\section{Life Stage Model}

The results of the copepod model show significant displacement of the zooplankton and reduction of abundance over the Ekman gain region (Figures 2.7 and 2.8) when the low wind and high wind results are compared. After twenty days of wind forcing, the mean abundance of the late stage copepodites over the Ekman gain half of the bank was 3.2 times higher in the low wind case than in the high wind case. Smaller disparities were seen in the younger stage classes as the late stage copepodite distributions reflected the organisms that had been exposed to wind forced advection the longest. Organisms transported off the bank were mixed throughout the 250 meter water column, sharply reducing their abundances as they crossed over the 100 meter isobath.

Table 2.3: Total water column abundance of copepod stages in selected regions of the bank, in numbers per square meter.

\begin{tabular}{cccc}
\hline Area & Stage & Low Wind & High Wind \\
\hline Total bank & Early naupliar & 109.5 & 99.5 \\
& Late naupliar & 59.5 & 48.2 \\
& Early copepodite & 26.6 & 19.3 \\
& Late copepodite & 10.6 & 7.1 \\
\hline \multirow{2}{*}{ Ekman Gain } & Early naupliar & 104.8 & 84.7 \\
& Late naupliar & 53.8 & 33.1 \\
& Early copepodite & 22.7 & 9.9 \\
& Late copepodite & 8.6 & 2.6 \\
\hline
\end{tabular}

Table 2.3 summarizes the effects of the varying wind forcing on all copepod abundances over the whole bank and the Ekman gain flank after twenty days. The values calculated represent the mean abundance throughout the water column over the areas specified. The total bank was defined as the area inside the $100 \mathrm{~m}$ isobath and the Ekman 
gain flank as that region within the 100 meter isobath where $x>560 \mathrm{~km}$ (Figure 2.4).
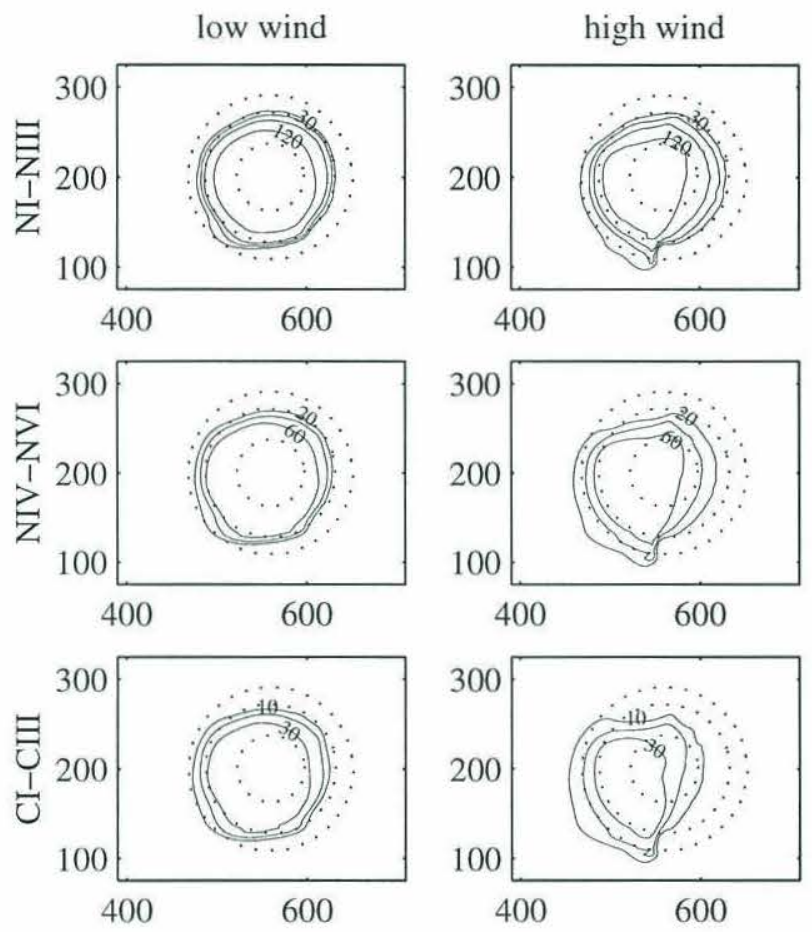

Figure 2.7: Contour plots of surface abundance of naupliar and early copepodite stages of Pseudocalanus after 20 days of wind forcing. Values off bank fell to zero, and the contour interval and maximum contour are indicated in each panel. Low and high wind results are presented for comparison. Axis units are kilometers.

The copepod population was sharply impacted by advective transport as the newly spawned individuals matured. These differences can be best seen in a comparison of the results of the low wind model to those of the high wind model. The low-wind forcing gave only a $10 \%$ greater mean abundance of the early naupliar stage over the whole bank and a $24 \%$ increase over the Ekman gain flank, while the late copepodite stage saw $49 \%$ and $227 \%$ increases in the same areas. The modeled process of wind-driven advective transport caused a significant reduction of copepod abundance on the Ekman gain side of the bank and smaller reductions over the entire bank. 

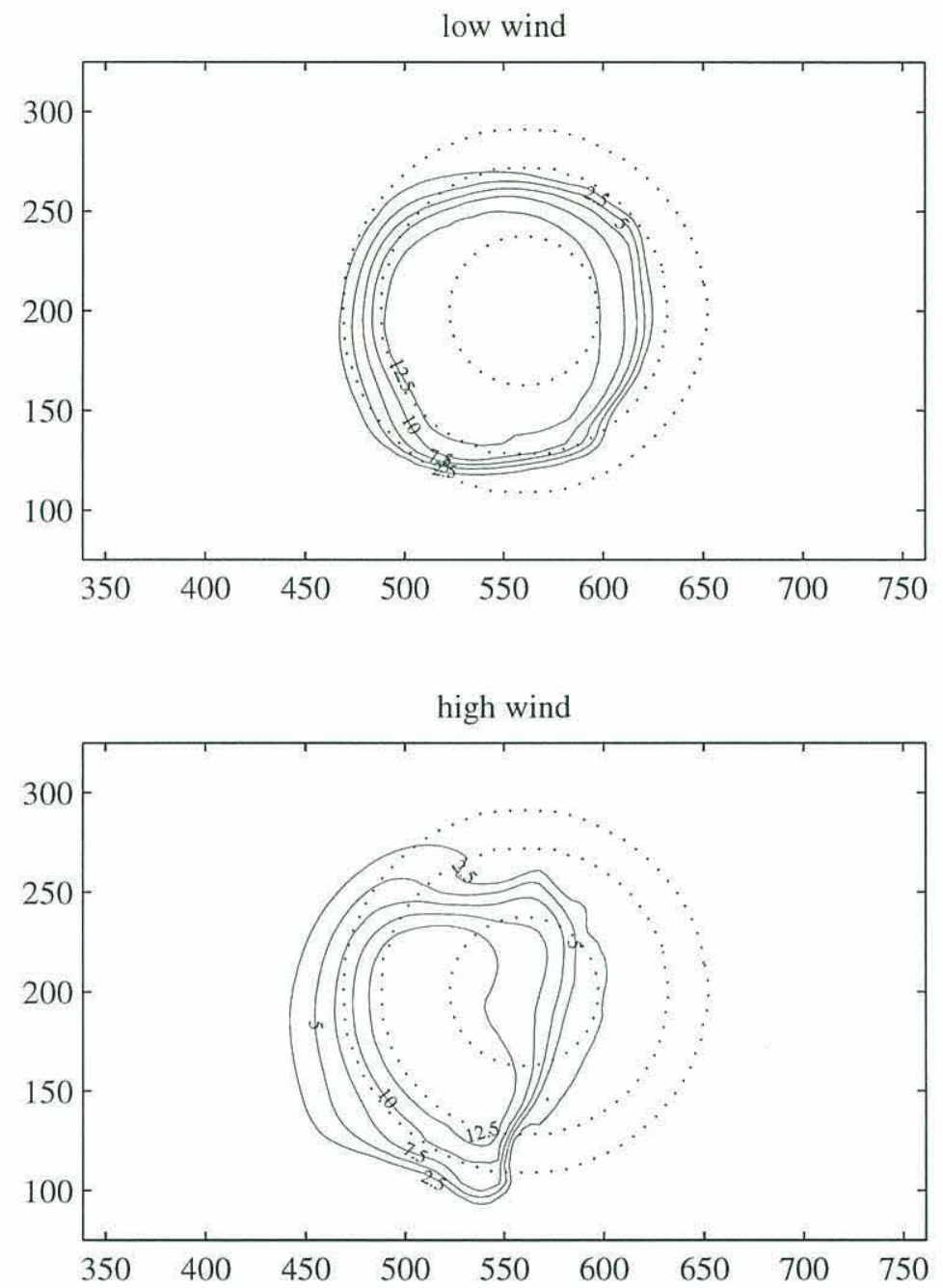

Figure 2.8: Distributions of surface abundance of late copepodite stages of Pseudocalanus after 20 days of wind forcing. Values outside the lowest contour fell linearly to zero. The contour interval was 2.5 individuals $\mathrm{m}^{-3}$; contours range from 2.5 to 12.5 individuals $\mathrm{m}^{-3}$. Low and high wind results are presented for comparison. Axis units are kilometers.

\section{Trophic Model}

Also tested was a model simulating the effect of the low and high wind stress on physically coupled food chain dynamics. This model included the effects of wind forced advective transport on phytoplankton productivity over a shallow bank with higher depth averaged growth rates (shallower bank depths resulted in higher growth rates in the 
vertically mixed phytoplankton). The transient response of the model showed significantly enhanced phytoplankton growth over the bank in both cases (Figure 2.9), but the advective transport inhibited the primary production with higher wind forcing. Zooplankton in many areas of the bank and off-bank experienced a net decrease in concentration as their death rate due to predation and incidental mortality exceeded their rate of growth in areas with low phytoplankton biomass.

The highest zooplankton concentrations in the simulation with 3 dyne $\mathrm{cm}^{-2}$ wind stress were well over the Ekman loss flank, within ten kilometers of the 100 meter isobath that marked the downstream edge of the bank (Figure 2.10). Over the whole bank, the mean zooplankton biomass declined $8.5 \%$ after twenty days high wind. In the low wind simulation mean zooplankton biomass experienced a net $7 \%$ increase in the same area. In a smaller area closer to the bank crest the difference is more striking. Within the 75 meter isobath (defined as the bank crest) the zooplankton biomass decreased by $2 \%$ after 20 days of high wind forcing; under low wind conditions mean zooplankton biomass in the same area grew $31.5 \%$. These changes in mean biomass are summarized in Table 2.4; the initial condition for all cases was $Z=0.20 \mathrm{mmol}^{-\mathrm{N} \mathrm{m}^{-3}}$.

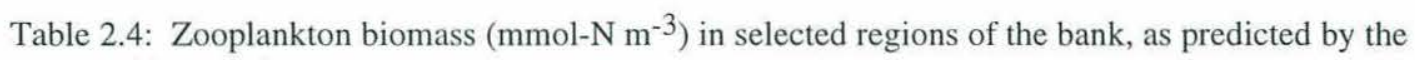
trophic model.

\begin{tabular}{lcc} 
Area & Low Wind & High Wind \\
\hline Total bank & 0.214 & 0.183 \\
bank crest & 0.263 & 0.196 \\
Ekman gain & 0.187 & 0.146 \\
\hline
\end{tabular}

After twenty days, zooplankton biomass was $17 \%$ higher in the low wind case. Phytoplankton bloomed much more rapidly in the calmer weather as well. Figures 2.9 and 2.10 show the downstream displacement of the zooplankton biomass and the effect on phytoplankton over the Ekman gain half of the bank as a result of the increased 
advection through the region of highest growth.
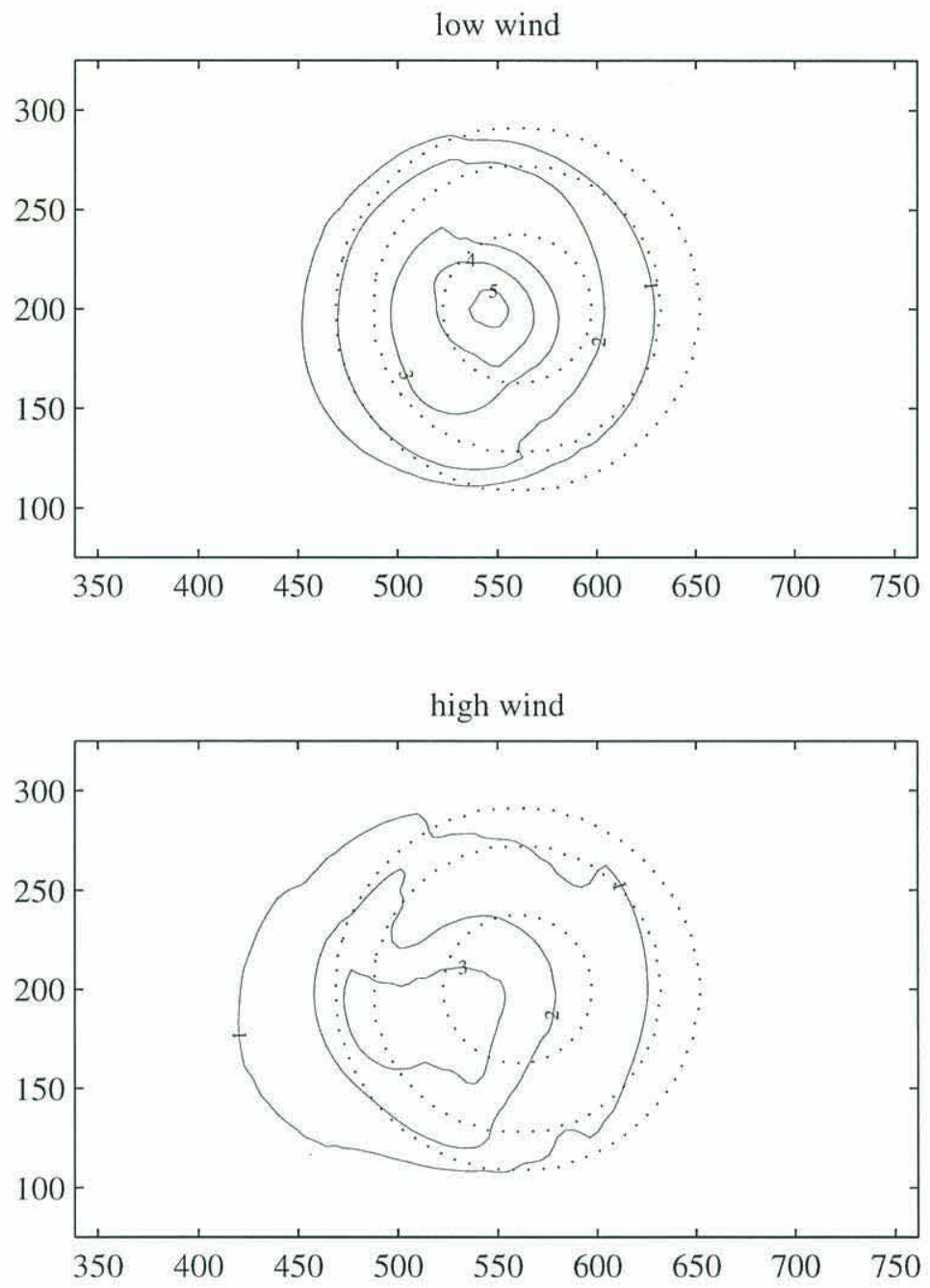

Figure 2.9: Surface phytoplankton concentration after 20 days of wind, in model units of mmol- $\mathrm{N} \mathrm{m}^{-3}$. The model was initialized with uniform values over the entire domain of $1.0 \mathrm{mmol}-\mathrm{N} \mathrm{m}^{-3}$ in phytoplankton. Low and high wind results are shown for comparison.

Figure 2.11 shows mean zooplankton production over the entire water column, compared between the two cases. Based on the equations of this model presented above, this value is calculated by, 


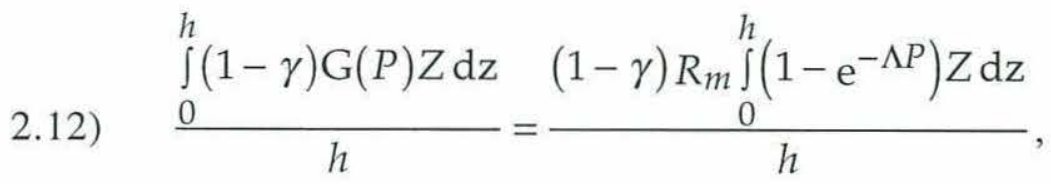

where $h$ is the total water depth at a given point.
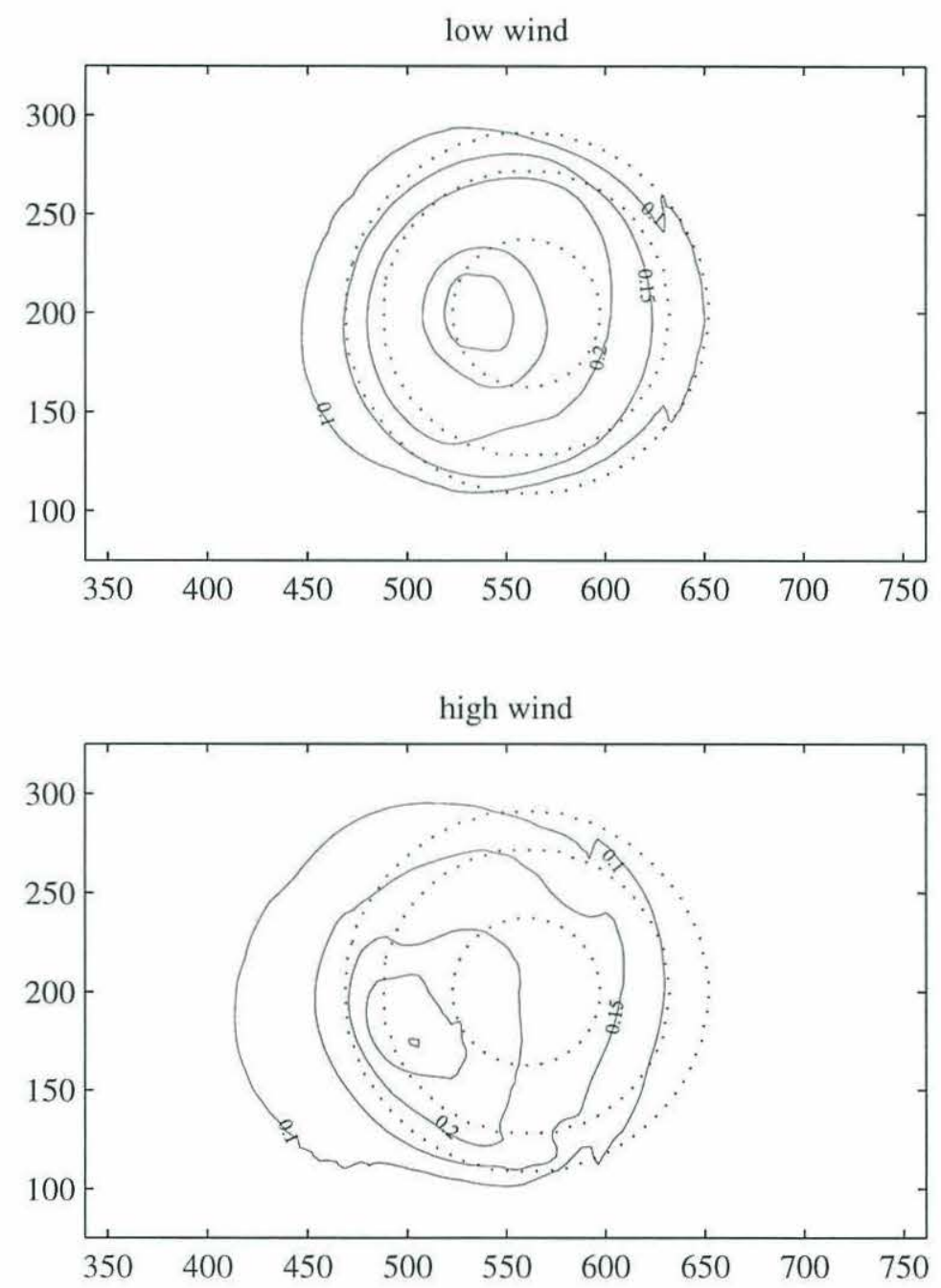

Figure 2.10: Surface zooplankton concentration, in model units of mmol- $\mathrm{N} \mathrm{m}^{-3}$. The model was initialized with uniform values over the entire domain of 0.2 mmol- $\mathrm{N} \mathrm{m}^{-3}$ in zooplankton. Results are after 20 days of low and high wind forcing.

The zooplankton production peak was much closer to the center of the bank in the low wind case, indicating that much of the production in the occasional calm periods is 
retained in the center of the bank. In contrast, the higher winds caused the peak production to be located about 60 kilometers from the bank crest (about 50 degrees to the right of the wind). Secondary production also was reduced by the higher winds. In the high wind case, a smaller area over the bank actually had production greater than 0.04 mmol- $\mathrm{N} \mathrm{m}^{-2} \mathrm{~d}^{-1}$. The typical high winter winds push the area of peak zooplankton productivity well away from the crest of the bank.
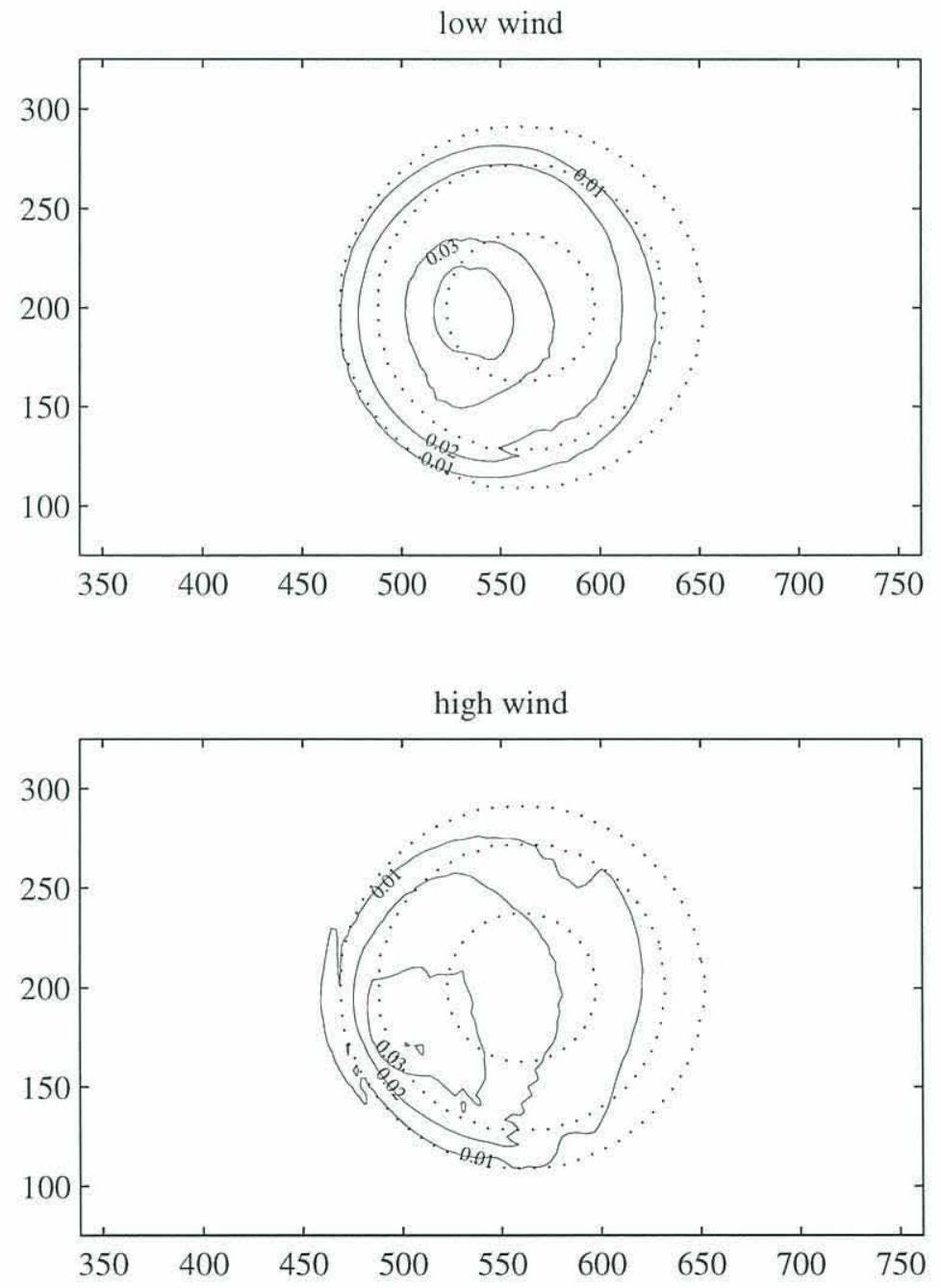

Figure 2.11: Depth averaged zooplankton production at day 20. Contours are labeled in units of mmol-N $\mathrm{m}^{-3} \mathrm{~d}^{-1}$. Values were calculated from the model equations as described in the text, and reflect instantaneous gross production at the end of our simulation. Axis units are kilometers. 


\section{DISCUSSION}

Due to cold temperatures $\left(3-8^{\circ} \mathrm{C}\right)$ the copepod population on Georges Bank develops very slowly from minimal levels in December to peak values in June. During this period, the system is vulnerable to major advective events since the recovery time for the zooplankton is so long. The average generation time for copepods at $5^{\circ} \mathrm{C}$ is about 2 months (Davis, 1983; McLaren, et al., 1989). Phytoplankton growth rate, on the other hand, can be quite high $\left(\sim 1.0 \mathrm{~d}^{-1}\right)$ at low temperatures (Goldman, 1977) with optimal conditions. Thus phytoplankton would recover quickly from a wash-out event, but the zooplanktonic link to higher trophic levels would be severely damaged. Wash-out would not only affect food available to larval, but also to post-planktonic juvenile fish, and more generally would affect transfer to other higher level components of the system such as the benthos. Juvenile haddock eat large zooplankton as well as small benthos (Lough, et al., 1989) and overall food demand is highest in this stage (Davis et al., 1985). Since the juvenile stage is also important in determining recruitment, wash-out events which reduce food availability through the juvenile stage would influence recruitment.

The wash-out hypothesis contains aspects of both Lasker's wind-mixing and Cushing's match-mismatch hypotheses (Cushing, 1975; Lasker, 1975). Like Lasker's hypothesis, physical forcing, such as wind events, reduces food availability to higher trophic levels, although in this case through advective transport rather than dispersion. As in Cushing's theory, physical variability affects transfer of primary production to

higher levels. In the wash-out hypothesis, the main effect of physical forcing, instead of affecting prey micro-patches or timing of the spring bloom, is advective loss of plankton from the spawning region prior to spawning. This forcing, combined with the differential growth rates for phytoplankton and zooplankton, prevents fish larvae in the 
areas of high productivity over the bank from benefiting from that productivity through efficient transfer up the food chain.

The results from both models indicate that wind driven advective transport can significantly reduce zooplankton populations, even in the presence of density driven frontal structures that might be expected to reduce advective transport off the bank. The models also highlighted some important biological-physical interactions, indicating areas where the impact is the strongest (such as the Ekman gain flank). It should be emphasized that strong wind forcing for periods longer than twenty days is capable of complete washout of the modeled zooplankton population. Our models predict that zooplankton growth rates are too slow to maintain a high bank population in the face of such large scale transport, and that forcing is likely to cause greatly reduced abundances such as those observed in 1979 (Figure 2.1).

In comparison to earlier work addressing the advection and loss rates of Lagrangian particles (Gawarkiewicz, 1993), the depth dependent behavior of the transport losses shows very different trends between the Eulerian and Lagrangian studies. The drifters were lost primarily from the surface waters, but the biological fields in the model were transported much more uniformly over the entire depth. The surface layer was swept clear and replaced by waters of different concentration, but the high vertical mixing homogenized the concentrations over the entire water column. This mixing caused the biological fields over the bank to appear to move as a vertically homogeneous mass even though transport was limited primarily to the Ekman layer. This caused the effects of the transport to be felt uniformly over the entire water column, rather than merely in the surface layer as the Lagrangian studies and observation of the flow field might have predicted. 
The copepod life stage model strongly supports the "wash-out" hypothesis. In comparison of the results of the low-wind and high-wind model results, the abundance of late stage copepodites in the low-wind run was $227 \%$ higher over the Ekman gain flank of the bank after twenty days. The higher quantities present over the Ekman loss flank reflected the transport of copepods towards the deep water as passive tracers (Figure 2.8). This four element life stage model only roughly approximates the actual dynamics of a stage structured population of this sort. The growth between stages is artificially enhanced by the fact that, while the mean times in the successive juvenile stages were set at $9.3,13.9$ and 17.4 days respectively, the probability of molting to the next stage is the same for any member of a given stage, whether it has just molted from the preceding stage or has been present in the stage for a long period. This effect can be seen in both simulations; new late stage copepodites were present after only 20 days. This is long before they should appear in a population taking about 40 days to reach copepodite stage IV, the threshold for entering our late copepodite stage class. However, the model incorporates the basic life history structure of the copepod population. The stage structure incorporates a crucial lag before recruitment of a new generation of zooplankton into a given water mass, as it focuses on the transport of a single generation and its distribution at the end of a storm event.

The results of this model have significant implications for some of the higher trophic levels as well. The Ekman gain region of the bank had much greater recruitment in the low wind case than was seen in the high wind case. Large portions of the bank saw almost no late stage copepodite recruitment in the high wind case. Cod and haddock spawning at the end of such a high-wind period would face a comparatively depauperate planktonic ecosystem; in comparison, those spawning when the winds had been 
comparatively low, such as the winter of 1974-5, would be rewarded with significantly higher densities of prey. If one assumes food limitation is a significant cause of larval mortality, either through prolonging exposure to predation, starvation, or lengthened growth period, then the two to fourfold increase in prey abundance over much of the bank after even a short period of calm weather could significantly increase larval fish survival.

The food chain model also demonstrated variations in bank zooplankton production as a result of changes in wind stress. This model didn't include the life history structure of the zooplankton community, but it did demonstrate that wind forcing could uncouple phytoplankton growth from zooplankton growth. The phytoplankton growth on the bank was also reduced in the high wind case due to the fact that the area of maximum growth was limited to areas near the peak of the bank. Phytoplankton responded quickly to the increased depth-averaged light levels in the shallow water as they were advected onto the Ekman gain side of the bank, but the high winds pushed the blooming population out of this optimum area, reducing the net production over the bank. Zooplankton experienced this effect much more strongly; there was a slight decline in total bank zooplankton biomass and a significant loss of zooplankton over the Ekman gain flank after twenty days of high wind. The phytoplankton levels over much of the bank were high enough, even in the high wind case, to generate near maximal zooplankton growth. For phytoplankton concentrations of $1 \mathrm{mmol}-\mathrm{N} \mathrm{m}^{-3}$, which included nearly all of the area within the 100 meter isobath, the zooplankton growth was $59 \%$ of the maximum. In the area around the bank crest, where phytoplankton concentrations were about $2 \mathrm{mmol}-\mathrm{N} \mathrm{m}^{-3}$, zooplankton growth rates were $84 \%$ of the maximum possible. The effects of food limitation probably only account for a small part 
of the $34 \%$ increase in zooplankton production over the bank crest with low wind forcing. Zooplankton production is taking place, but it is being swept off the bank (Figure 2.10). The peak herbivore biomass has been pushed to the Ekman loss flank, well away from the bank crest. In periods of low wind, the zooplankton are allowed to remain on the bank and develop a significant population earlier in the spring.

The two models combined strongly support the washout hypothesis. The trophic model shows that the phytoplankton respond quickly to the increase in mean light levels as they move onto the bank, but that zooplankton responding to increases in phytoplankton biomass are being swept off the bank before they can establish a high resident stock. The stage structured model demonstrates that the rate of advective loss under high wind forcing is large enough to push developing copepods off the bank before they reach maturity. In the life stage model, recruitment of late stage copepodites on the Ekman gain half of the bank was near zero after twenty days of high wind. The continuous displacement of the water mass prevents a zooplankton population from developing in the Ekman gain and bank crest regions.

The food chain and life stage model differed in their overall patterns of zooplankton abundance and areal mean measurements for several reasons. First, the trophic model included a significant population of zooplankton as its initial condition; the life stage model represents only the development of 20 days of continuous egg production by a fixed number of a single species of copepod. Second, the trophic model was initialized with concentrations of phytoplankton that were too low to sustain growth of the zooplankton in the model, and the zooplankton over the bank in the food chain model were food limited for much of the early time course. In short, these two models represent different approaches to a single problem. The life stage model addresses the effects of 
time delays inherent in the stage structure of the copepod species; the food web model incorporates the relative growth rates of zooplankton and their phytoplankton food source. We are developing models that couple trophic structure to a stage structured herbivore population, but coupling dynamic physical and complex biological models is computationally intensive. Model simplification techniques or improved computational capabilities are required to solve this problem (Flierl and Davis, 1995).

The impact of the wash-out process is likely to vary seasonally. The greatest effect is expected to occur during winter when winds are highest, temperature is coldest, and zooplankton recovery times are longest. During the warmer months, late summer and fall, zooplankton growth rates are much faster, (generation times are 10-14 days at 15$20^{\circ} \mathrm{C}$ versus two months at $5^{\circ} \mathrm{C}$ ), so that recovery from washout would be quicker. In addition, storms are typically less frequent during summer and fall than during winter and spring, and the water column is strongly stratified. Nutrients become limiting in the surface layer and the system enters a recycling mode (O'Reilly et al., 1987). Thus, wash-out events are likely to be less frequent and have a smaller impact during fall.

Effects of wash-out on zooplankton recovery rate may also vary among different species of zooplankton, depending on particular characteristics of their life cycles. Rate of loss will depend on the concentration of a given species in the spawning area relative to that in surrounding waters. If the gradient is zero, wash-out obviously will not affect concentration; if the gradient is large, then the starting level for recovery after wash-out will be relatively small. Loss rate will also depend on vertical distribution and migration behavior. For example, depending on the flow field, species inhabiting the surface layer may suffer greater losses than those which reside at or near the bottom. Species which lay bottom resting eggs may recover more quickly due to offspring hatching from the 
sediments; this may be a mechanism by which these species can maintain their populations in favorable locations (Davis, 1987). Finally, since life history parameters (fecundity, development rate, and mortality), as affected by temperature, food, and predation, determine rate of population growth, these individual species characteristics must be examined in relation to turnover time of the water mass.

While this highly idealized study supports the ideas of the wash-out hypothesis, numerous features of the physics and biology have been neglected and require future attention. On Georges Bank, the tidal residual flows are very important in both the mean flow field and the mixing, particularly on the northern flank, and future work needs to address this contribution. The use of a mixed layer model, such as Price et al. (1986) or Mellor and Yamada (1982), will be an important feature to add to understand the details of the biological physical interactions near the surface. More realistic wind-forcing that includes periodic storm passages must be included. Finally, the linkage of the bank flows to the larger scale flows in the Gulf of Maine needs to be addressed. The biological models will also profit from the inclusion of the physical processes mentioned above. In addition, increased resolution of stage structure and trophic structure should make the results clearer, as the numerical diffusion problems can be further reduced. With modifications in the scheme for resolving vertical profiles, we expect to be able to include vertical and horizontal behavior and particle sinking, better resolving fluxes into and out of the photic zone.

The wash-out hypothesis can be applied not only to isolated banks such as Georges but to straight shelf and oceanic regions as well. Regions of exposed sea, neritic or oceanic, which have relatively low physical turnover rates, and are otherwise favorable for survival, can serve as point sources of abundance within a species geographical range 
(Davis, 1984b). Our models demonstrate that physical forces which cause large scale advection of plankton out of these favorable regions (whether straight shelf, bank, or oceanic areas) can reduce zooplankton recruitment and decrease trophic efficiency. 


\section{Chapter 3: Population structure of Arctica ISLANDICA}

\section{INTRODUCTION}

Data on the size structure of a population is often a useful indicator of cohort strength. Such structure is often determined by larval settlement and subsequent growth and mortality. In some cases, variability in larval supply overshadows growth and mortality and may be a dominant factor determining the size structure of adults (Garlo, 1982; Bachelet, 1986; Thouzeau, et al., 1991a). In these cases, cohorts may appear as distinct peaks in the size frequency curves. Arctica islandica, however, possesses a slow growth rate, and length is a poor indicator of age in all but the youngest individuals (Murawski et al., 1982; Kraus, et al., 1992); an individual of $90 \mathrm{~mm}$ length may be anywhere between 20 and 100 years of age. Nonetheless, pulses of juvenile Arctica at a site in 53 meters of water off the coast of Long Island, N.Y., have been distinguished using size structured data (Murawski et al., 1982; Brey et al., 1990). Additionally, the age of individuals in those pulses can be estimated from growth bands internal to the shell (Ropes and Pyoas, 1982; Ropes et al., 1983).

This work has two goals: to identify the spatial and temporal variation in size structure and abundance on Georges Bank (as revealed by data from NMFS survey tows), and to determine if annual banding in individuals can be used to infer historical trends in recruitment and population dynamics. Two sets of data are used: size structure and abundance derived from National Marine Fisheries Service (NMFS) survey work on Georges Bank from 1982 to 1994, and age structure from a tow taken on the southern 
flank during the 1994 shellfish assessment survey. The survey work has been presented previously in Fishermen's Reports (NEFSC, 1986, 1989, 1992, 1994) and in analyses of interannual trends in catch data and abundance over regions of the Middle Atlantic Bight (NEFSC, 1990, 1995a,b, 1996; Weinberg, 1993).

Previous work on Georges Bank Arctica has not fully utilized the size frequency data to identify interannual variation in population structure. The previously cited work by scientists at the Northeast Fisheries Science Center (NEFSC) has focused on interannual trends in abundance, both from these tows and from commercial landing data.

The current perception of Arctica population dynamics in the Middle Atlantic Bight and Georges Bank region is that the population is dominated by older ( $>40$ years) clams with low recruitment (Murawski and Serchuk, 1989; Weinberg, 1993; NEFSC, 1995a,b). Only along the Maine coast is there significant evidence of younger clams and recent recruitment (Weinberg, 1993; NEFSC, 1995a,b). Data from Georges Bank has not been fully analyzed for variation in size structure and abundance, and the nature of recruitment in this region remains uncertain.

\section{METHODS}

The National Marine Fisheries Service has been conducting surveys of Arctica islandica stocks on an approximately biannual basis since the mid-1960's. Length frequency and abundance data for this work were collected on cruises conducted in 19821984, 1986, 1989, 1992 and 1994; data from earlier years was omitted because changes in gear type and sampling protocol made comparison difficult. Subsamples for aging were retained from some tows during the 1994 cruises. 


\section{Size structure and abundance}

The sampling method used for the size structured data varied slightly by year. Occasional slight improvements and changes have been made in the protocol and equipment but the process has remained essentially the same over the 7 survey years considered here. A hydraulic dredge with a 1.5 meter wide blade and a $51 \mathrm{~mm}$ mesh was used in all areas of Georges Bank. The dredge uses an attached pump and a line of jets at the leading edge to break up the sediment in front of the blade; its theory, operation and design have been extensively described elsewhere (Smolowitz and Nulk, 1982).

The dredge was lowered from the stern of RV Delaware II and towed at a speed of 1.5 knots for 5 minutes. At the end of the tow, the dredge was raised, emptied onto a sorting table, and sorted by hand. Typically, up to 600 Arctica from the tow were measured. Lengths were recorded to the nearest millimeter, and total abundance in each tow was counted by NMFS staff and volunteers. In the 7 survey years considered here, 265 tows made in all Georges Bank strata (strata 53-74, Figure 3.1) were considered by the National Marine Fisheries service to be "representative hauls"; in such tows, all gear was felt to have functioned effectively enough to yield a useful sample for comparison to other tows and years.

A number of factors complicate a rigorous statistical analysis of the Georges Bank Arctica data. Early cruises in the Georges Bank area did not use randomly spaced tows and conducted few tows over the bank. The Northeast Peak region (region 4 in Chapters 4 and 5) was sampled only once, during the 1982 survey, so that data concerning population dynamics in this area is unavailable. Tows in 1994 consistently collected more clams in almost every area along the Middle Atlantic Bight and Georges Bank, 
suggesting a change in gear efficiency for that year (NEFSC, 1995a). In addition, the hydraulic pump and lines on the dredge were not designed for water pressures at depths below 80 meters, so deeper water populations were rarely sampled.

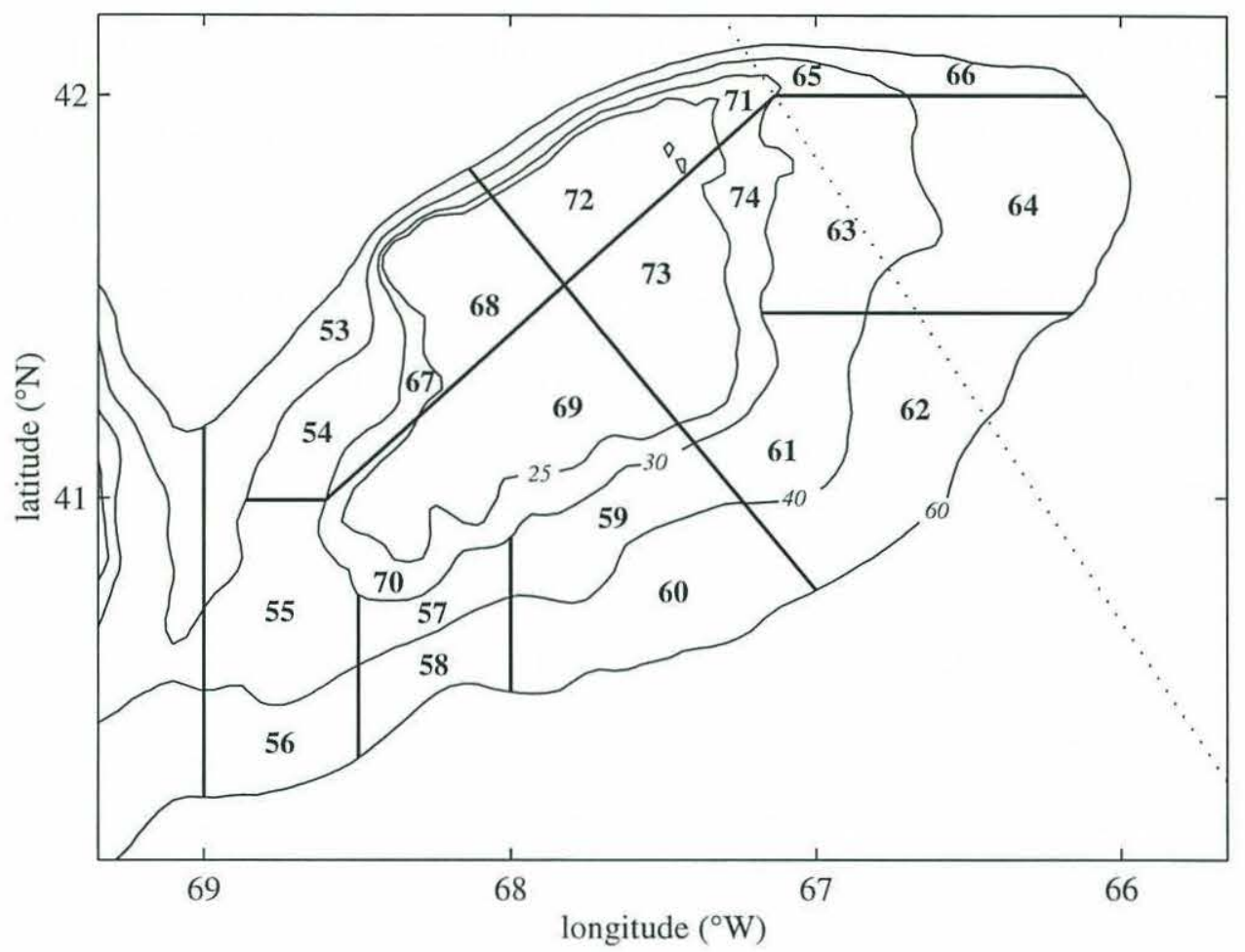

Figure 3.1: Approximate location of National Marine Fisheries Service survey strata on Georges Bank. Isobaths are marked in fathoms. dotted line indicates approximate location of the boundary between U.S. and Canadian waters.

In order to compensate for variation in tow length, the density of individuals was calculated; the Doppler distance reading (distance over ground, taken by the ship during each tow) and the known width (1.52 meters) of the dredge were used to estimate the area sampled by the tow and to calculate the density of individuals (in numbers per square meter). This estimate of true density is a conservative one, as the dredge is likely to pass over and destroy some clams (Smolowitz and Nulk, 1982). Again, these errors are believed to be similar for all tows and between all years, excluding 1994, and probably 
do not affect the comparison of size structures. The 1994 survey data yielded unusually high abundance estimates consistently throughout the Middle Atlantic Bight so both the abundance and size structure estimates from that survey are treated with some caution. In addition, length measurements were biased, apparently by observer error, against numbers ending in 4 and 9 . The effects of this bias were reduced by grouping the data into size classes of $5 \mathrm{~mm}$.

A critical problem lies in the inability of the dredge to reliably sample small clams; detection of recruitment events is made more difficult by the fact that an unknown portion of small clams are lost through the dredge mesh. Although small clams $(<50 \mathrm{~mm})$ were caught in some tows, the $50 \mathrm{~mm}$ mesh on the dredge allowed an unknown portion of clams of this size to slip through, resulting in undersampling of this portion of the population. Based on this and previous analyses of Arctica growth on the South Flank of Georges Bank, 50 mm clams may be as much as 7 years old (Ropes and Pyoas, 1982) and this study). This bias complicates any analysis of the age or length structure of young clams since a distinct group of 50-60 mm individuals might be the largest and oldest of a multi-year recruitment event or might indicate a single year of high recruitment.

These limitations on the sampling resolution make it difficult to use time variation in size structure alone as a correlate to recruitment and environmental variability. There exists only a narrow "window" between $\sim 50 \mathrm{~mm}$ (the dredge size) and $\sim 70 \mathrm{~mm}$ (the lower limit of the size range for mature adults) in which a recruitment event can reliably be seen as a distinct peak in the size structure. In addition, the detection of a large group of $50 \mathrm{~mm}$ clams does not indicate whether variation in larval transport or juvenile mortality is responsible for a recruitment event. 
Despite these limitations, the data present a wealth of basic information about Arctica demographics. Specifically, the data provide information on broad scale interannual changes in size structure and overall abundance. The measured sizefrequency distributions possess obvious biases in undersampling of the smallest size classes; however, these biases are expected to be the same in all years as there is no evidence that the size selectivity of the dredge changed markedly between years (NEFSC, 1995a).

\section{Age structure}

During the course of the 1994 Shellfish Assessment survey cruise on Georges Bank, the existence of a marked bimodal size structure was noted in several tows (most notably 446 and 448) on the South Flank. One of these stations was chosen as the focus for the age structure determination work, as the existence of a large group of small (length less than $65 \mathrm{~mm}$ ) clams provided an indication that recent recruitment had occurred at that site.

A random subsample of 144 clams was taken from tow number 448 in stratum 61 $\left(41^{\circ} 9^{\prime} \mathrm{N}\right.$ and $67^{\circ} 1^{\prime} \mathrm{W}$ ) on the South Flank of Georges Bank during the 1994 cruise. This sample was placed immediately in a $-20^{\circ} \mathrm{C}$ freezer aboard RV Delaware II and transferred to a $-20^{\circ} \mathrm{C}$ freezer upon arrival in Woods Hole. Processing of the clams shells for age structure analysis was done in several batches of 30 to 50. Refinements to the process were incorporated during the work. The following procedure represents the processing technique that best minimized processing time while also yielding readable slides.

Individuals used for age structure analysis were thawed and shucked about a year after collection. The meats were discarded and the shell length, defined as the maximum 
dimension of the clam (approximately parallel to the hinge line) was measured and recorded. Each clam was labeled individually and a valve was selected for sectioning and band counting. No preference was given to right or left valves. The sectioned valve needed to have a complete band of material in a line ranging from umbo to the shell margin, but it was not necessary for it to be intact.

Shells were sectioned from the umbo to the most distant portion of the shell edge on a glass cutting saw. The kerf width was taken into account so that one of the resulting pieces contained the entire tip of the umbo. That piece was selected for future work while the extra half was set aside. The retained half valve was polished on Buehler Polimet Polisher with a wet $12 "$ sanding wheel at approximately $200-300 \mathrm{rpm}$. A first pass with 220 grade paper removed cutting marks then 400 grade removed the sanding marks left by the coarser paper.

The half shells were glued to 3 " by 2 " microscope slides with slow setting epoxy. Both West Marine West System 105 Resin and 206 Hardener and Epoxy Technology Inc. Epo-tek 301 epoxies were used, yielding little difference in final sample quality. The polished face of each shell was laid on the dry slide, then the wet epoxy was placed at the joint between shell and slide and drawn under the shell by capillary action. Enough epoxy was laid on the slide to surround the shell by 1-3 mm. The shells were allowed to dry for at least 24 hours or until the epoxy was no longer sticky to the touch. In some cases, a $50^{\circ} \mathrm{C}$ oven was used to induce final curing. Shells that were too big to fit on a slide intact were broken into two pieces; both pieces were glued to the same slide.

In order to leave a section on the slide, a Buehler Isomet 11-1180 Low Speed Saw was used to cut all but a thin piece of the shell away from the slide. This left a 600- 
$800 \mu \mathrm{m}$ thin section of shell, embedded in epoxy, attached to the slide. These sections were ground to 250-300 $\mu \mathrm{m}$ on a Ingram Laboratories Model 305 Thin Section grinder, using multiple passes to remove $75 \mu \mathrm{m}$ per pass. Small cuts were needed to prevent the shell from cracking due to the grinder vibration.

The slide was then polished at $\sim 200 \mathrm{rpm}$, using 200 grade sandpaper to reduce the thickness of the section to $150 \mu \mathrm{m}$ then finished with 400 grade paper to remove the sanding marks and smooth the surface. This process required continuous monitoring with a digital micrometer and a microscope to insure that none of the sample was lost and that the final product was readable across the entire length of the shell. Samples were counted at $25 \mathrm{x}$ magnification on a Zeiss binocular microscope.

As a result of several factors, the likelihood of missing a band or counting an extra band increases with the number of bands. Traumatic events often cause the clam to lay down a shell band very similar to an annual band (Kraus et al., 1992); the longer a clam lives, the more likely it is that it will have experienced such a traumatic injury. In addition, a counter has a higher chance to miss or miscount a band when there are more bands to count. Older clams tend to be heavily abraded around the umbo where the first few bands are laid down in fairly fine lines; frequently these bands are lost entirely or appear only in a small region away from the umbo. In order to estimate error caused by counting mistakes, a portion of the sample was counted twice. No efficient and reliable method for estimating error caused by extra or missing bands was available.

The variability in shell banding and difficulty in counting made determination of exact age (to within one year) impossible. Bands were much easier to resolve in some individuals than in others and, in many cases, the strength of the banding varied along the 
length of the shell. For the aforementioned reasons, the number of bands in a given shell could not be assumed to be the exact age of an individual clam. Differences between the two replicate counts showed that the precision of this method is not sufficient to unambiguously resolve the age of an individual. As the sampling could not precisely determine the true number of annual bands in a shell, the term band structure will be used here to mean the histogram of the number of individuals by band number; band structure is assumed here to approximate of age structure.

The method for approximating the age of a clam from the number of bands can be seen in the following example. If we assume that band formation takes place during winter (Weidman and Jones, 1993a), then a clam spawned in 1986 would lay down detectable bands in every winter from 1987 to 1993 before being sampled in the summer of 1994. A band laid down in the first winter would be only a few millimeters in length, and would be unlikely to be detected by sectioning. Thus, clams spawned in 1986 would be most likely to have 7 bands, and, given the measurement error, 6-8 bands would be counted.

\section{Test for multimodality}

Both age and size structures generated by the surveys above were subjected to a randomization test designed to identify the present of multiple modes or local maxima in a sampled population (Silverman, 1981; Silverman, 1983; Efron and Tibshirani, 1993). The test determines the minimum value of a smoothing kernel width, $h_{1}$ (referred to as "window size"), that will smooth the sampled frequency distribution until there is only one global maximum. This smoothing can be thought of as a sum of $n$ Gaussian distributions, each of which is centered around one of the $n$ measurements in the sample. 
The value of $h_{1}$ for the data is compared to a probability density function generated by calculating $h_{1}$ ' for each of a large number of bootstrap samples. The null hypothesis:

3.1) $H_{0}$ : number of modes $=1$,

is rejected if the probability of finding $h_{1}^{\prime}$ greater than $h_{1}$ exceeds 0.05 .

The exact procedure for this bootstrap involves a number of numerical steps. The minimum value of $h$ such that the function,

3.2) $f(t ; h)=\frac{1}{n h} \sum_{1}^{n} \phi\left(\frac{t-x_{i}}{h}\right)$

has only one mode, is determined by successive approximation. This minimum value is the test statistic, $h_{1}$.

Each bootstrap sample contains $n$ individuals drawn at random from the smoothed distribution of the original data. The generation of each bootstrap sample was conducted as described by Efron and Tibshirani (1993). In all tests conducted here, the distribution of $h_{1}$ ' was based upon 200 bootstrap samples. First, $n$ individuals values, $y_{1}^{\prime} \ldots y_{\mathrm{n}}$ ', were sampled, with replacement, from the original data set, $x_{1} \ldots x_{\mathrm{n}}$. The values of the $n$ members of the bootstrap sample were calculated from the $y^{\prime}$ values using the following formula:

$$
x_{i}{ }^{\prime}=\bar{y}^{\prime}+\sqrt{1+\frac{h_{1}^{2}}{\sigma^{2}}}\left(y_{i}{ }^{\prime}-\bar{y}^{\prime}+h_{1} \varepsilon_{i}\right) ; i=1,2, \ldots n .
$$

Where $\bar{y}^{\prime}$ is the mean of the $y^{\prime}$ values, $\sigma^{2}$ is the variance of the original sample, $x$, and 
the $\varepsilon_{\mathrm{i}}$ are standard normal random variables. Rather than determine the exact value of $h_{1}$ needed to generate a smoothed bootstrap sample with one mode, it was only necessary to know whether $h_{1}{ }^{\prime}$ was greater than or less than $h_{1}$ for each bootstrap sample. If $h_{1}{ }^{\prime}$ was greater than $h_{1}$ more than $5 \%$ of the time (10 out of 200 bootstrap samples), then the null hypothesis was accepted; if $h_{1}^{\prime}$ was greater than $h_{1} 5 \%$ of the time or less, then the alternative hypothesis, that there was more than one mode, was accepted.

If the null hypothesis was rejected, this procedure was repeated, calculating $h_{k}$, a window size that generated $k$ modes, and generating a new set of bootstrap samples based on that window size. In the case where the null hypothesis, $\mathrm{H}_{0}$ : number of modes $=k$, was rejected, then the hypothesis, $\mathrm{H}_{0}$ : number of modes $=k+1$, was tested. This procedure was repeated, starting at $k=1$, until the null hypothesis was not rejected.

Two types of data were analyzed using this method. First, all available size structures for Georges Bank were individually tested for multimodality. The test was applied only to the counted sample by using scaling factors in the NMFS survey data to determine the proportion of the total abundance that was actually counted and applying that scaling factor to the length frequency data. The second type of data considered was the band structure data; for this data the $x$ values were based on band number for individual clams.

\section{RESULTS}

In overview, this analysis shows that Arctica on Georges Bank are concentrated around the periphery of the bank, with greatest concentrations between the 60 and 75 meter isobaths. A cohort on the southeast flank of the bank, settling in 1986 or 1987, is indicated by the band structure data, and the size structure of clams from that region 
supports this observation. The band structure also provides an indication of other likely recruitment events and allows estimation of a growth curve for clams in one region of the South Flank.

\section{Spatial Distribution}

The geographic distribution of Arctica in the sampled regions is consistent with a pattern of depth limitation (Figure 3.2 and 3.3). Almost all stations deeper than 50 meters yielded Arctica in every tow, whereas stations shallower than 50 meters yielded very few clams (Figure 3.2).

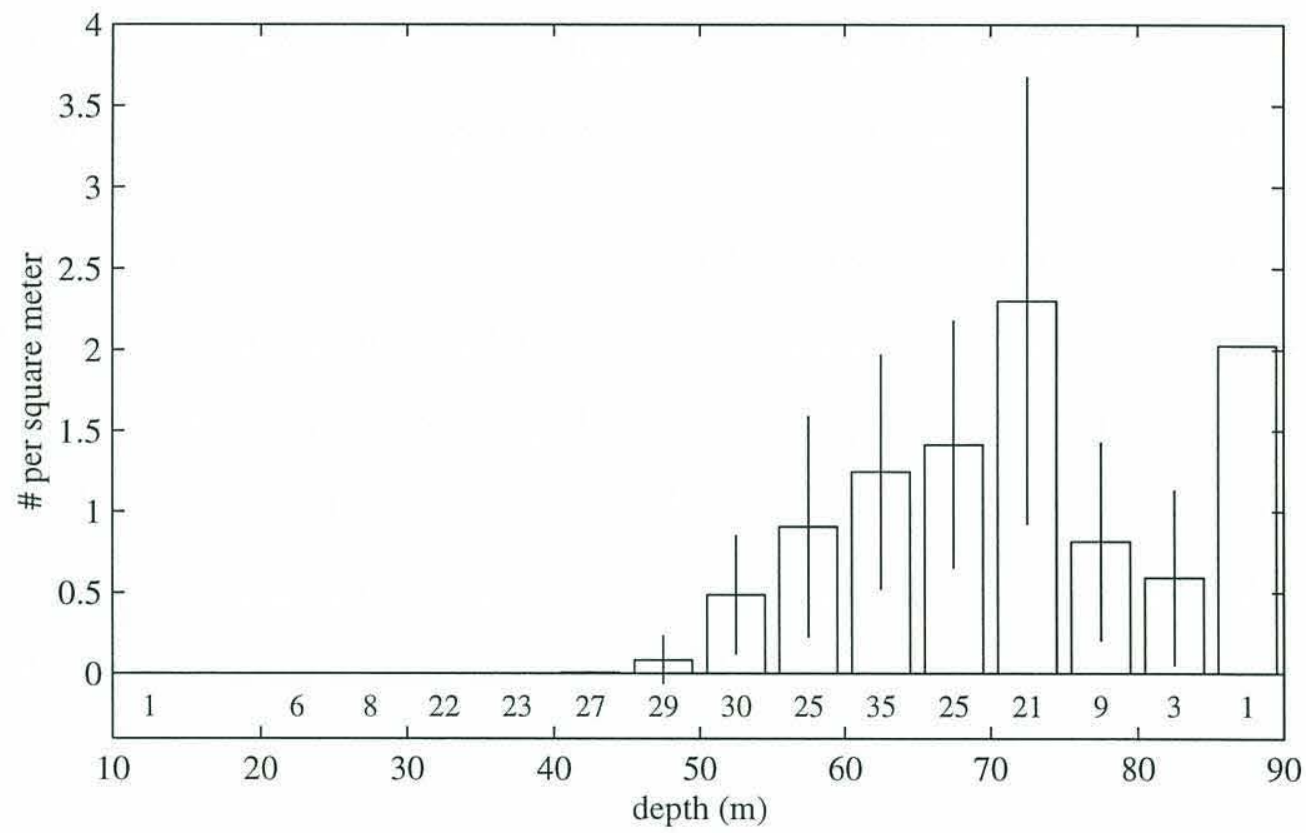

Figure 3.2: Mean (bar) and 95\% confidence interval (line) of Arctica islandica density (\# individuals per square meter) in each five meter depth interval (for all representative tows on Georges Bank taken from 1982 to 1994). The number of tows taken within each depth interval during all years is shown at bottom of the bar.

The deep water limit for the species is not adequately resolved by this sampling; the lines and hydraulic pump on the dredge were not designed for pressures below 80- 
100 meters and few tows were made below 80 meters. The few samples taken in deeper waters suggest that density may decrease slightly in waters deeper than 75 meters (Figure $3.3)$,

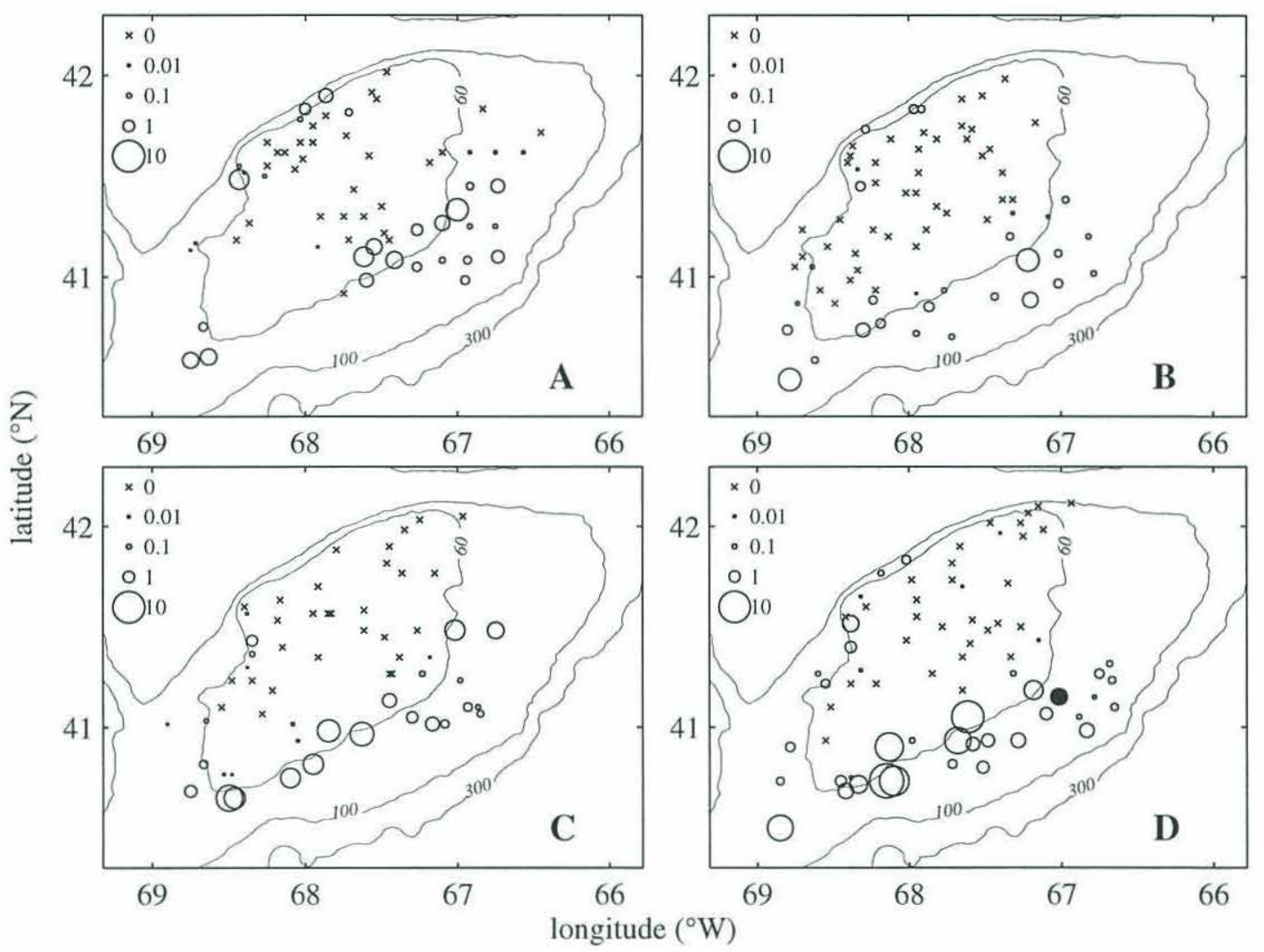

Figure 3.3: Arctica islandica density ( $\#^{-2}$ ) from the A) 1982, 83 and 84, B) 1986 and 89, C) 1992, and D) 1994 survey cruises. Area of circle is proportional to density. The station at which age frequency sampling was performed is designated by a filled circle. Isobaths are in meters.

The region of the South Flank between the 60 and 75 meter isobaths yielded the highest number of clams per tow. Sampling in the narrow area between the 50 and 100 meter isobaths on the Northern Flank was sparse, but the few tows conducted in this area indicate high densities of clams in this region (Figure 3.3).

Overall, the abundance and distribution of Arctica on Georges Bank appears to be sharply defined by depth, with very low densities in areas shallower than 45 meters 
(Figure 3.2). This distribution shows that a large area of the center of the bank contains very few Arctica (Figure 3.3); highest abundances were measured between the 60 and 75 meter isobaths on the South Flank. The sampling also indicates that the deeper water limits of this species have not been revealed and that the true extent of Arctica distributions on Georges Bank is not fully resolved with the present equipment.

\section{Size Structure}

The size structures recorded during the survey cruises are similar in their overall pattern. The mean size structure ${ }^{2}$ in the various NMFS survey strata (Figure 3.1) all typically show a peak between 70 and $90 \mathrm{~mm}$, with few clams under $65 \mathrm{~mm}$ (Figures 3.4A-D). While the sampling gear is known to undersample individuals less than $50 \mathrm{~mm}$ in length, few individuals of less than $65 \mathrm{~mm}$ length were observed in any stratum, and the majority of clams were between 75 and $90 \mathrm{~mm}$ in length.

However, several strata stand out as having a large cohort of small clams (gray bars). Most notable are stratum 60 in 1986, strata 59 and 61 in 1992, and strata 59, 60 and 61 in 1994. In each of these strata, there are noticeable numbers of smaller clams (shaded bars, Figure 3.5).

In 1986 the smaller clams in stratum 60 appear as the lower tail of the dominant group in the population, whereas the 1992 results for stratum 59 and 61 and the 1994 results for 59, 60 and 61 all show a distinct local maxima in the size structure below 65 $\mathrm{mm}$.

2 Mean abundance within each $5 \mathrm{~mm}$ size class, for all tows in which any clams were found. 

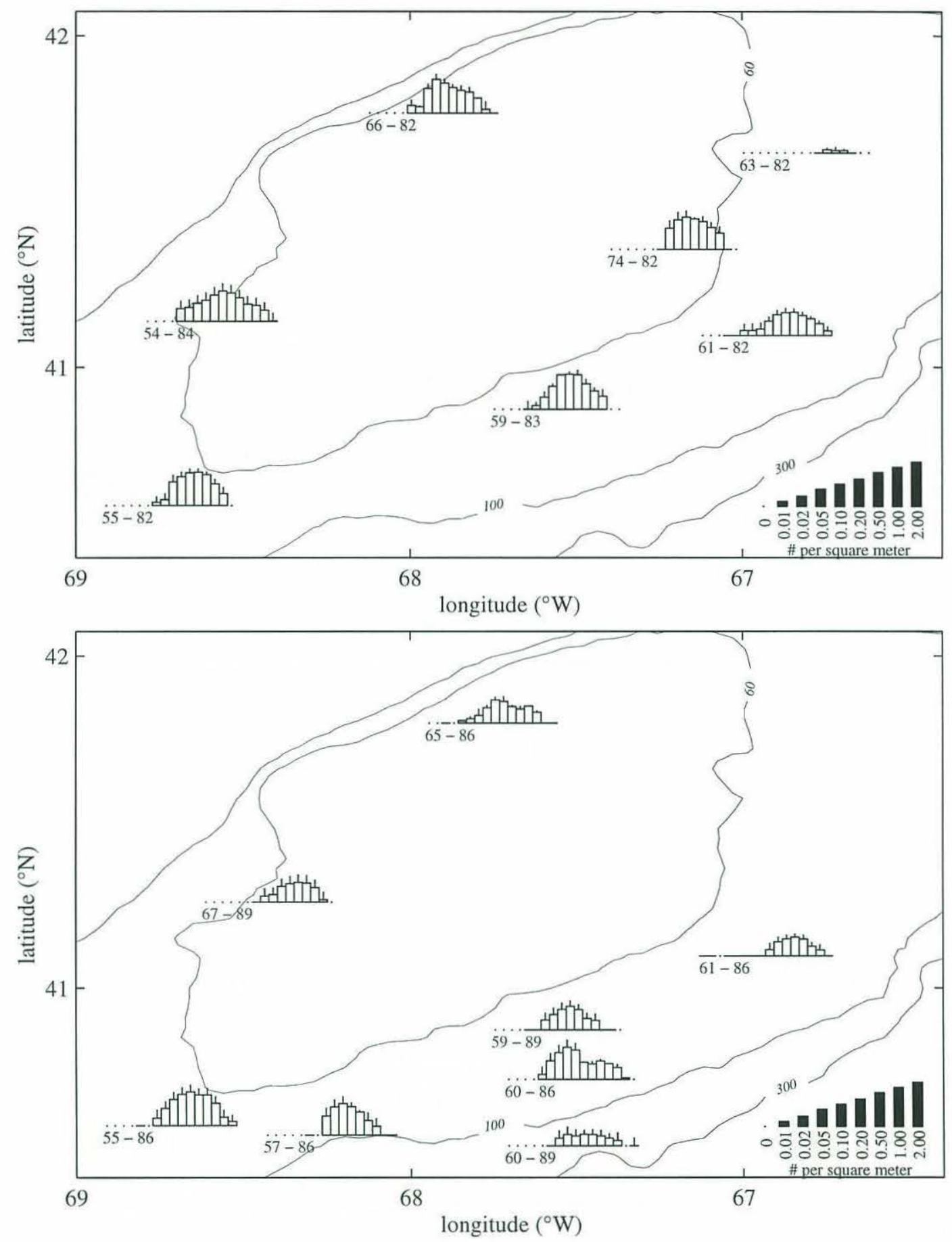

Figure 3.4A-B: Size structure by stratum (for strata in which more than one tow was made) in (A, top) 1982, 83 and 84 and (B, bottom) 1986 and 89. Numbers below each histogram denote the stratum number and year of sampling. Individual graphs show the log of the mean (bars) and upper $95 \%$ confidence interval (line) for abundance in each size class from 40 to $110 \mathrm{~mm}$. Size classes under the $50 \mathrm{~mm}$ are shown in black, those under $65 \mathrm{~mm}$ are shown in gray. 

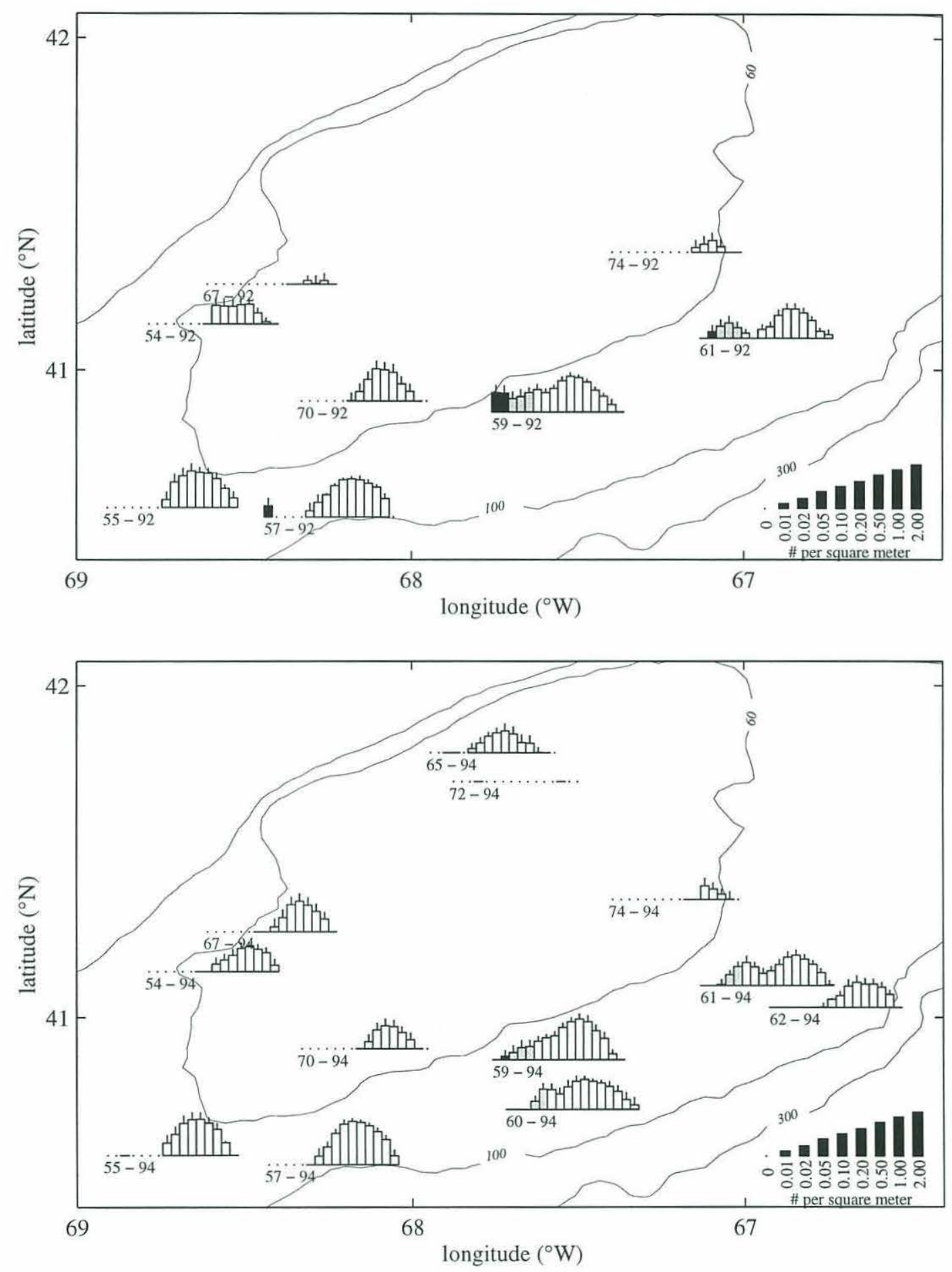

Figure 3.4C,D: Size structure by stratum (for strata in which more than one tow was made) in (C, top) 1992 and (D, bottom) 1994. Labeling conventions as Figure 3.4A. Clams used for age structure estimation were taken from stratum 61 . 

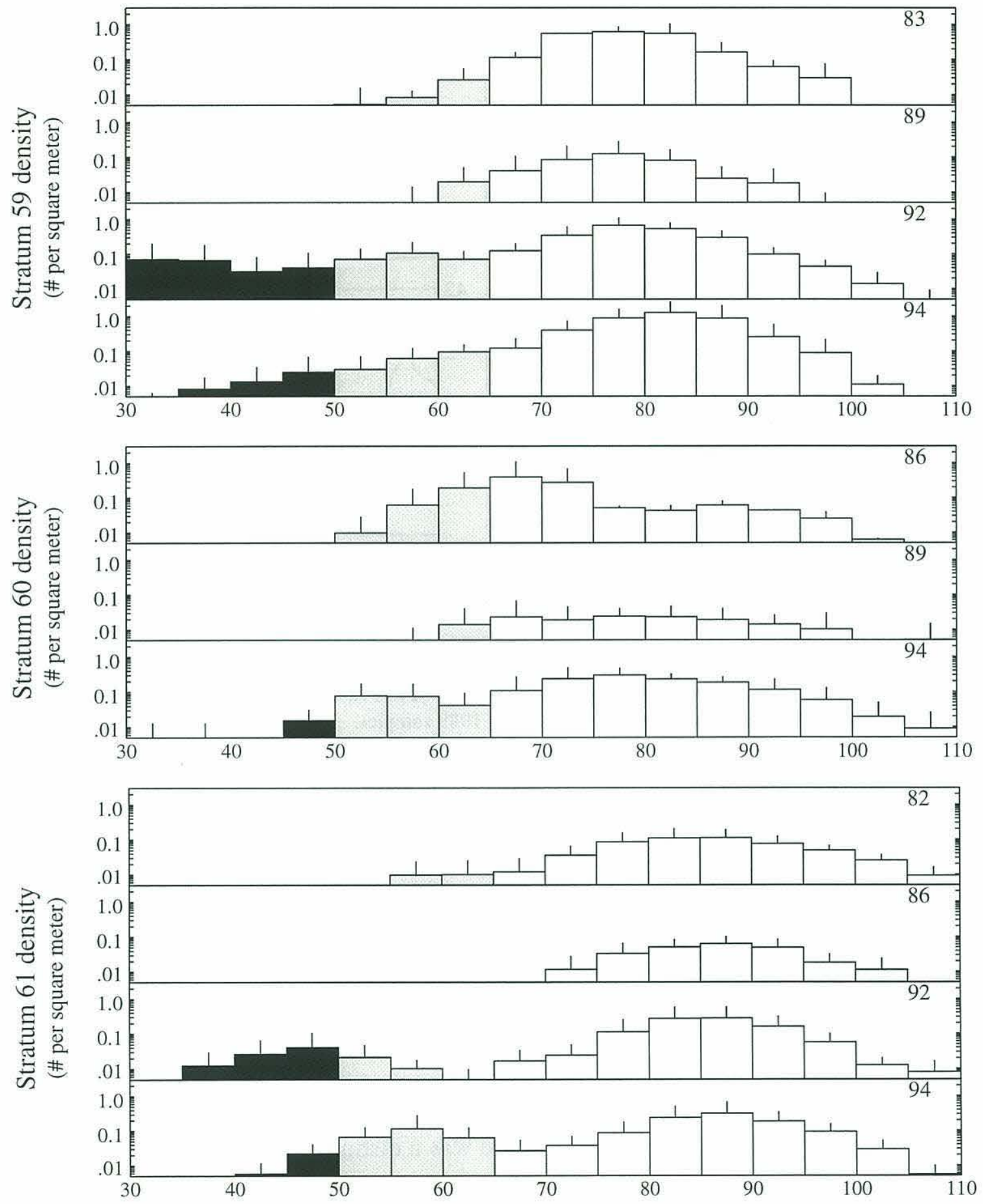

Figure 3.5: Size structure for stratum 59 in 1983, 1989, 1992 and 1994 (top), stratum 60 in 1986, 1989 and 1994 (middle) and stratum 61 in 1982, 1986, 1992 and 1994 (bottom). Graphs show mean (bars) and upper $95 \%$ confidence interval (line) for years indicated by the number in the upper right hand corner. Size classes under $50 \mathrm{~mm}$ are shown in black, those under $65 \mathrm{~mm}$ are shown in dark gray. 


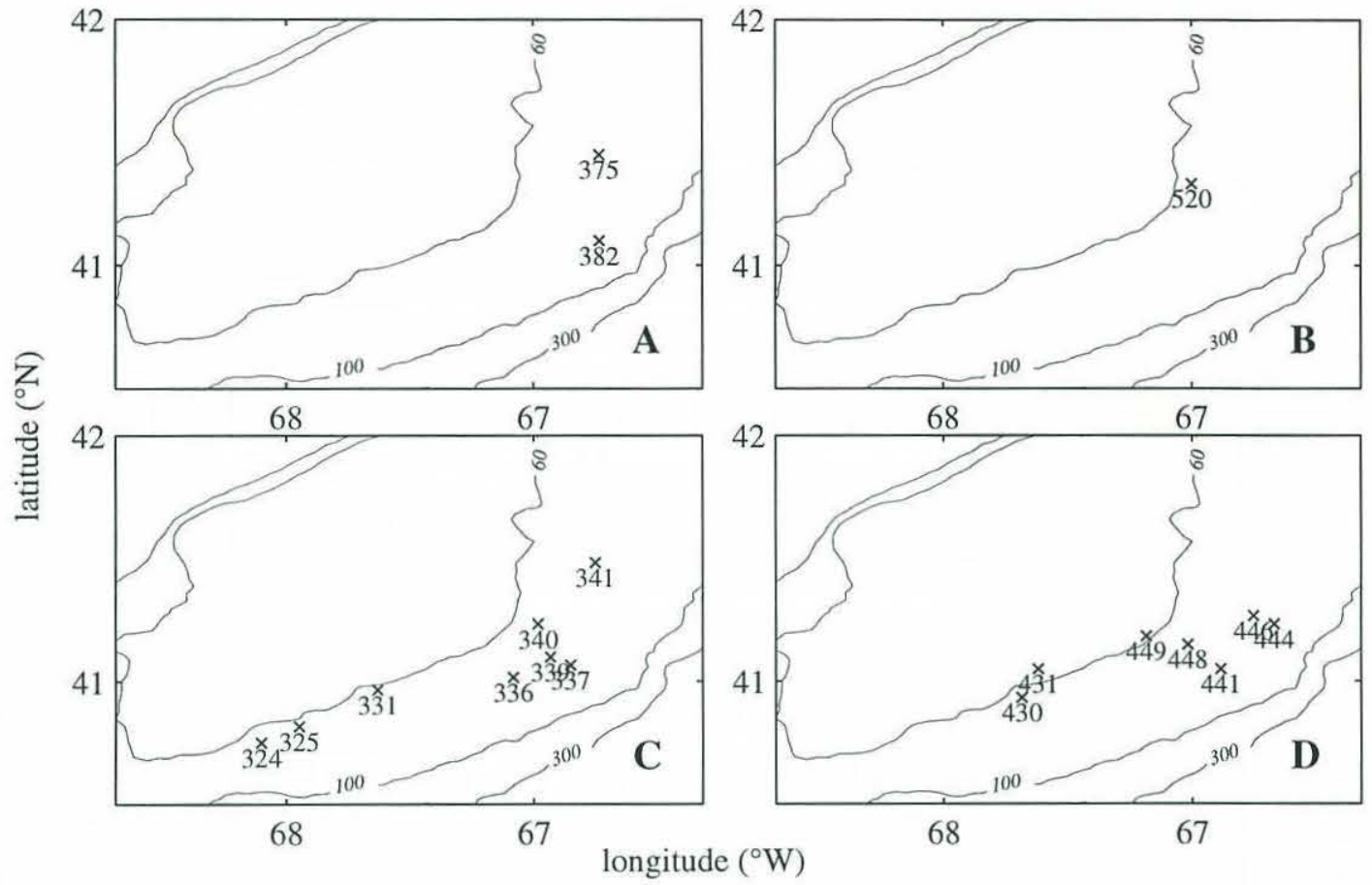

Figure 3.6: Location of all tows in which two or more modes were detected in the size structure, the lowest mode was centered below $65 \mathrm{~mm}$, and density of all individuals less than $65 \mathrm{~mm}$ was greater than $0.02 \mathrm{~m}^{-2}$. (A) all tows for 1982 (B) tows in 1983 (C) 1992 and (D) 1994. No tows satisfying the three criteria were found in the 1984,1986 or 1989 samples.

Based on this observation, a test for multimodality was used to determine exactly which tows and years showed such a strong bimodal structure. This procedure was applied in hopes of identifying the region and time in which a recruitment event may have occurred. The previously described bootstrap procedure (Silverman, 1981; Silverman, 1983; Efron and Tibshirani, 1993) was used to identify all tows in which there were two or more modes ${ }^{3}$.

In order to identify cases where there was a distinct, large, mode in the smaller (younger) portion of the population, tows were further selected based upon the location of the smallest modes and the density of small clams (Figure 3.6 and 3.7). The three

3 The method is designed to be applied to actual samples, rather than mean distributions, so mean size structure by strata or year were not analyzed using this method. 
criteria used to identify small cohorts were: 1) presence of two cohorts, 2) presence of a local maxima below $65 \mathrm{~mm}$, and 3) abundance of small (length $<65 \mathrm{~mm}$ ) clams of greater than 0.02 clams m-2. Of the 265 tows (from all 7 years) used for this analysis, 34 had two modes; 27 of those had a lower mode centered below $65 \mathrm{~mm}$ and 18 of those had a sample density of at least 1 small clam for every 50 square meters (the location and size structure of all tows satisfying the indicated criteria are shown Figure 3.6 and 3.7). Among these 18 tows, 15 are from the South Flank in 1992 or 1994.

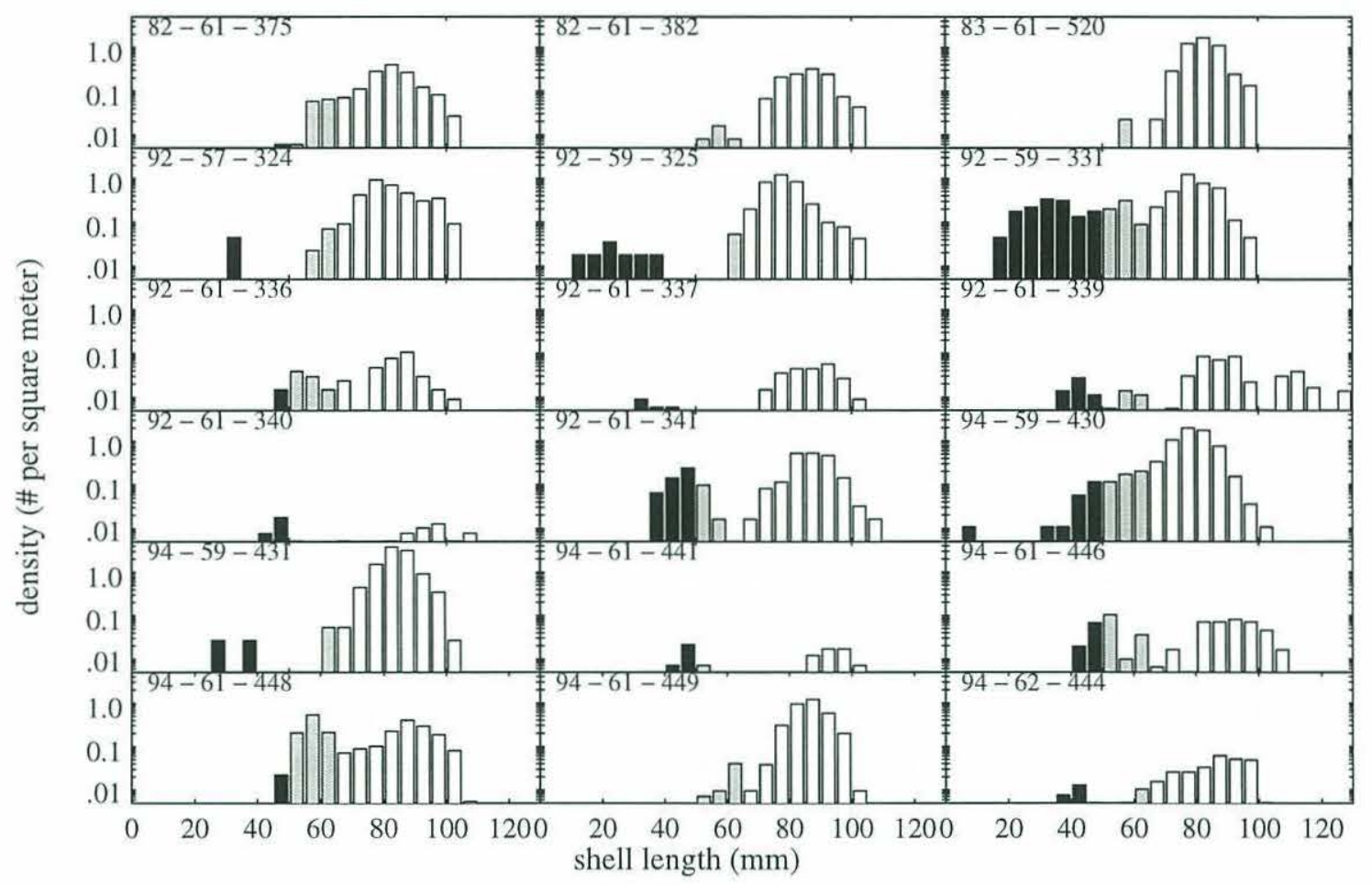

Figure 3.7: Size structure for all tows identified by the criteria described in Figure 3.6. Year and tow number are indicated by the number in the upper right hand corner. Size classes under the $50 \mathrm{~mm}$ dredge mesh are shown in black, those under $65 \mathrm{~mm}$ are shown in dark gray. The upper limit of each axis is shown in the upper left corner of each graph. Y axis scaling is logarithmic, as in Figure 3.4A-D.

In the 1992 and 1994 tows, a group of small (length < $65 \mathrm{~mm}$ ) clams is seen in strata 59, 60 and 61 on the eastern South Flank in the region south of $41^{\circ} 30^{\prime} \mathrm{N}$ and east 
of $68^{\circ} \mathrm{W}$. The absolute abundance (Figure 3.8) and percentage (Figure 3.9) of clams under $65 \mathrm{~mm}$ in each tow also showed much higher densities of small quahogs in this region during 1992 and 1994.4

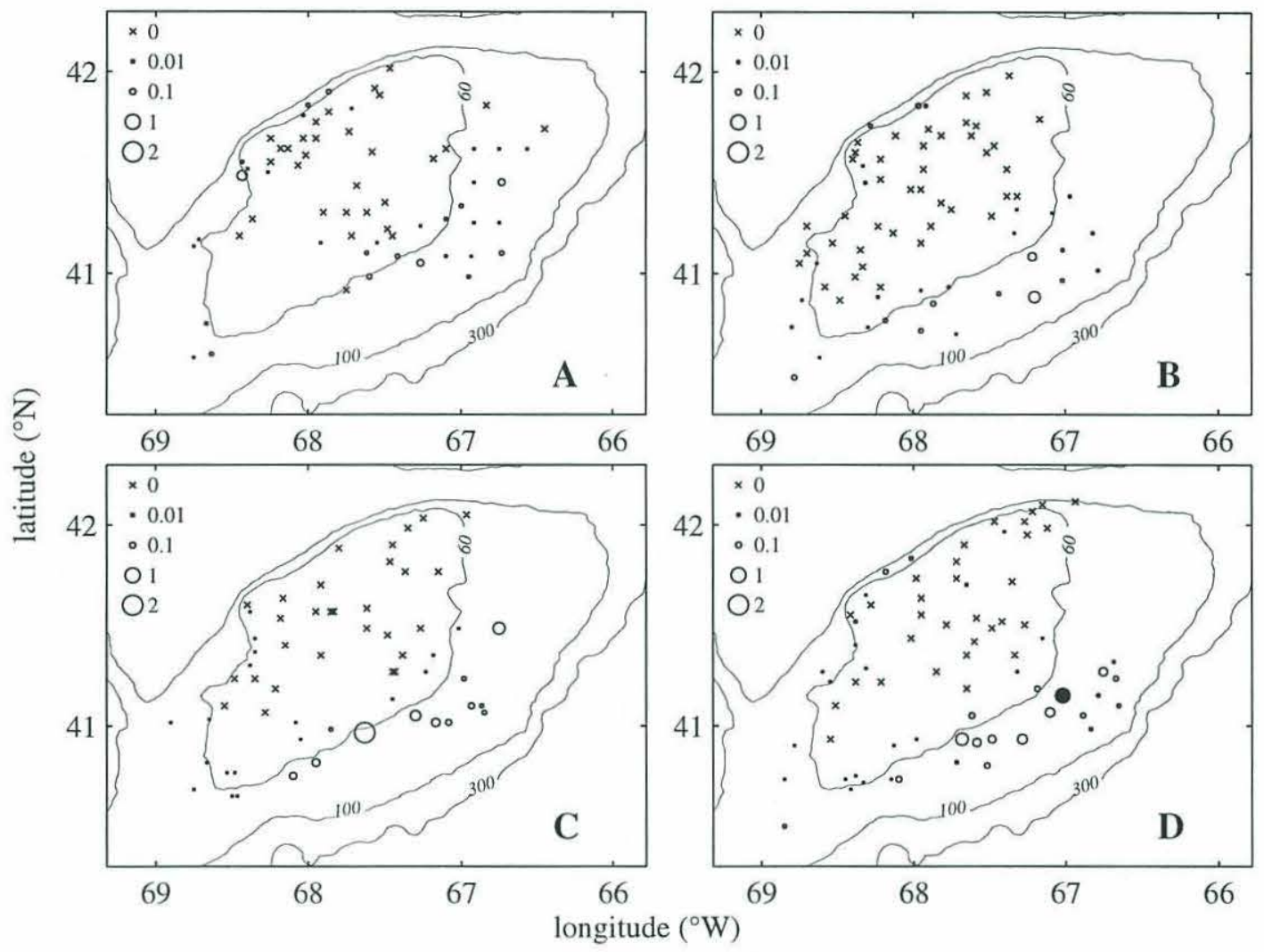

Figure 3.8: Density (\# $\mathrm{m}^{-2}$ ) of individuals smaller than $65 \mathrm{~mm}$ in each tow from the A) 1982,83 and 84, B) 1986 and 89, C) 1992, and D) 1994 cruises. Circle area proportional to \# of individuals.

4 A single factor ANOVA on the square-root transformed abundance of individuals under $65 \mathrm{~mm}$ for all samples in stratum 61 taken during the years 1982, 1984, 1992, and 1994. Only years in which more than 2 samples were taken were considered, and the analysis focused on stratum 61 as 12 of the 18 samples identified in Figure 3.6 and the sample used for age structure analysis were from this stratum. The statistical analysis was performed using Statview II ${ }^{\mathrm{TM}}$ on an Apple Quadra 610.

\begin{tabular}{|l|c|c|c|}
\hline Source & D F & S SE & MSE \\
\hline Between Groups & 3 & .536 & .179 \\
\hline Within Groups & 22 & .993 & .045 \\
\hline Total & 25 & 1.53 & \\
\hline
\end{tabular}

The $\mathrm{F}$ value was 3.96 , yielding $\mathrm{p}=0.0213$. 

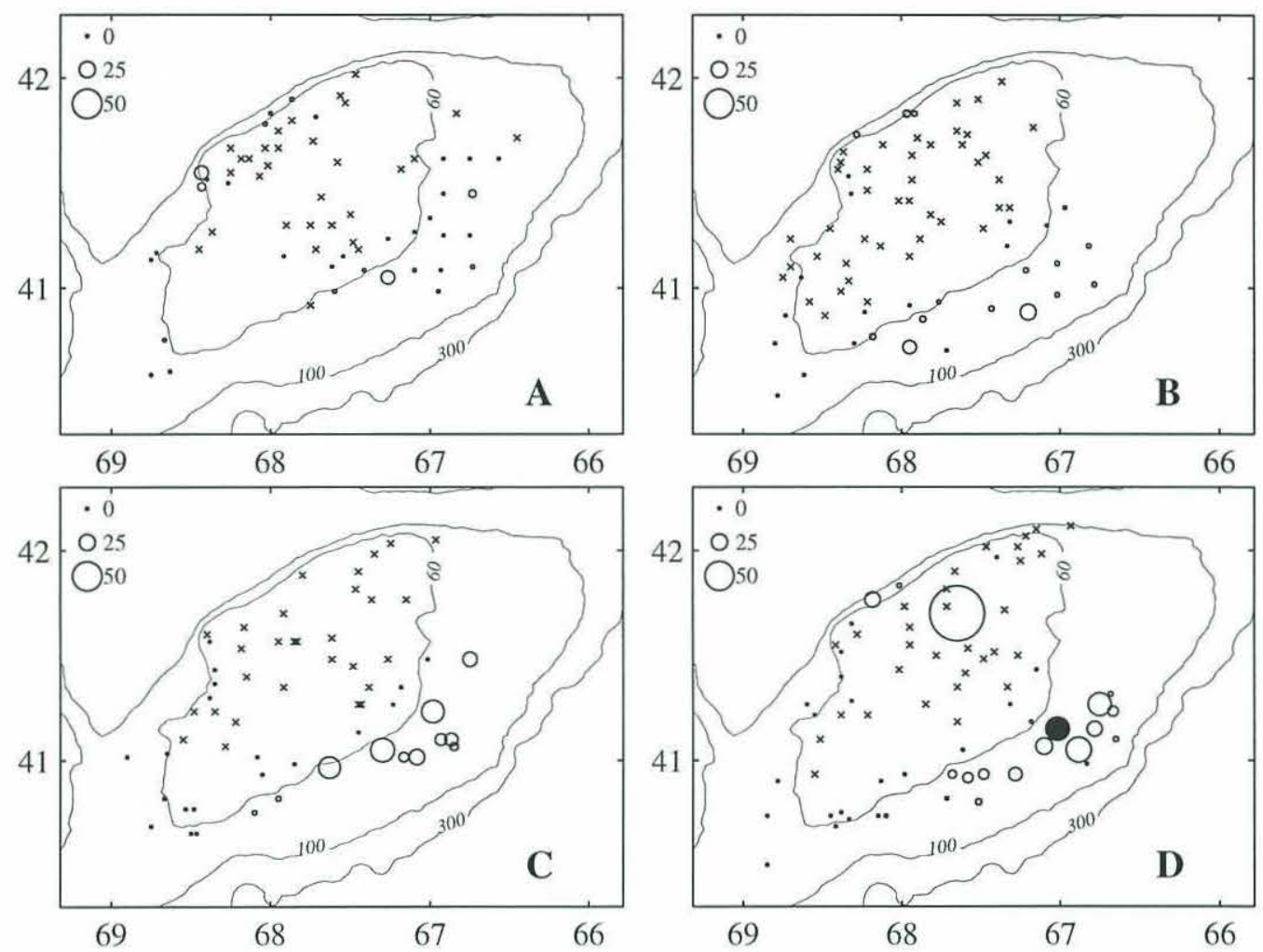

Figure 3.9: Percent of catch that was smaller than $65 \mathrm{~mm}$ in each tow from the A) 1982, 83 and 84, B) 1986 and 89, C) 1992, and D) 1994 survey cruises. Radius of circle is proportional to percentage (the single large circle in 1994 reflects the presence of a single small clam at that station).

The sampling design and the biases in the sampling equipment make it difficult to determine precisely the extent or true nature of the cohort observed here. The noted inconsistency between the results of the 1994 survey and previous surveys make comparison of these results difficult. Sampling was sparse in some regions and years, admitting the possibility that a recruitment event may have been missed.

In summary, the preceding analysis shows that mainly in 1992 and 1994, and only on the South Flank were there large numbers of small clams found in a distinct mode centered below $65 \mathrm{~mm}$; in no other period or area is such a consistent, distinct group of small clams evident. This evidence indicates that a group of young clams has recently 
appeared on the South Flank of Georges Bank. The results motivated further study of age structure of the clams in this region, specifically to identify the age of individuals within this youngest cohort, but also as a general assessment of the age structure of the population in this region.

\section{Age structure}

Age structure data from the station at $41^{\circ} 9^{\prime} \mathrm{N}$ and $67^{\circ} 1^{\prime} \mathrm{W}$ (tow number 448 from leg 3 of the 1994 shellfish assessment cruise) were examined to determine whether individuals in the cohort observed in the size structure data were in fact of the same age.

The band structure revealed the existence of a number of groups with similar band number (Figure 3.10). Replicate counts of the band structure of the entire sample yielded similar results, identifying a group of clams with fewer than 20 bands and another group with 27 or more bands. There were only 7 clams with over 40 bands found in this sample, one each with 48, 52, 53, 54 and 101 bands and 2 with 78 bands.

This analysis indicated that most of the small $(<65 \mathrm{~mm})$ clams in this sample had 6-9 bands (Figure 3.11). In order to determine if the smaller mode identified in size structure sampling resulted from a single event or a pair of events, a test for multimodality (Silverman, 1981; Silverman, 1983; Efron and Tibshirani, 1993) was applied to the band structure of all individuals with less than 14 bands. The hypothesis that this group had only one mode was rejected $(\mathrm{p}<0.005)$, but the hypothesis that the group had more than two modes was not rejected ( $\mathrm{p}>0.05)$. The two modes identified with this method were centered around 7 and 12 bands. The group centered around 12 bands may correspond to a smaller recruitment event, although no sign of its appearance is evident in the size structure data. 


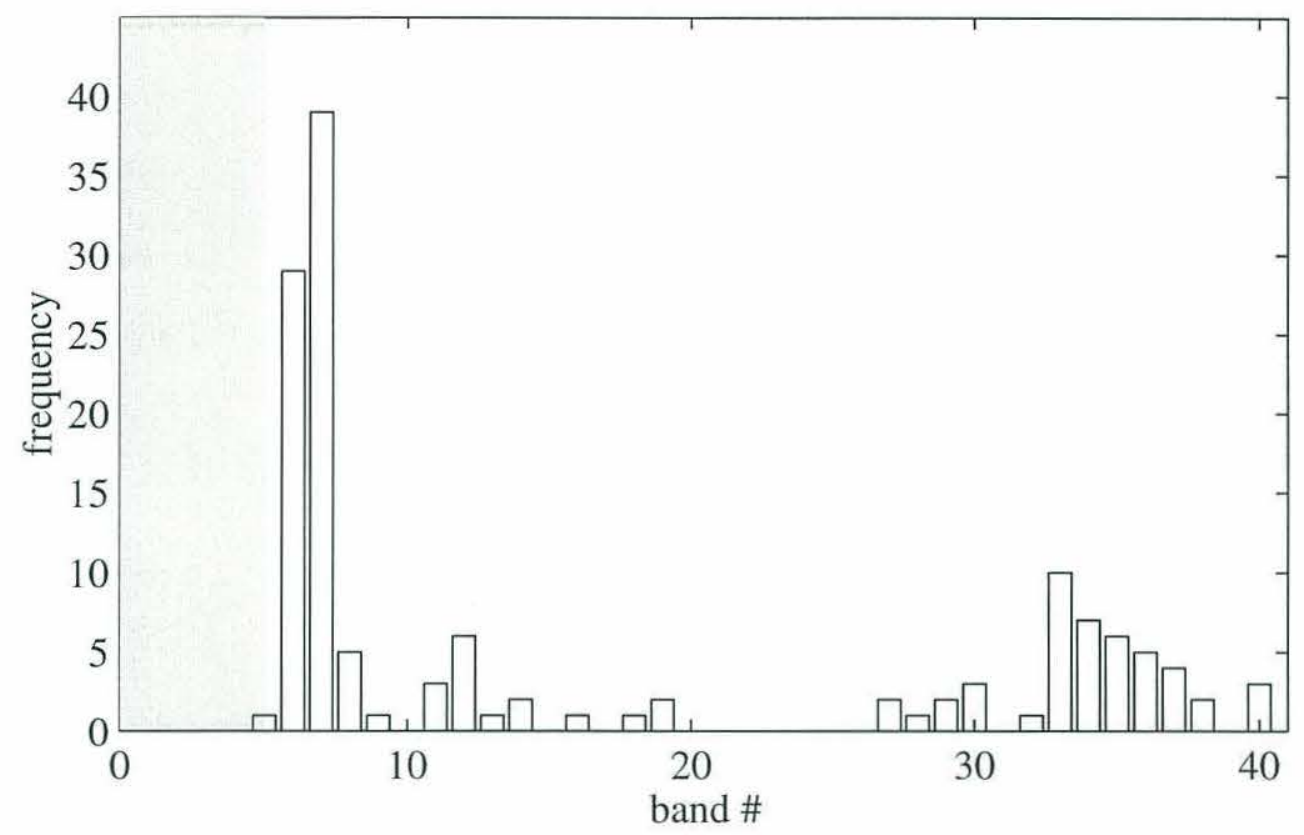

Figure 3.10: Band structure of clams with up to 40 bands. Gray shading shows ages that are expected to be undersampled by the dredge, due to their small size.

The band structure showed 137 out of 144 clams with fewer than 40 bands and 69 with 6-9 bands. The length frequency of the group with more than 10 bands is very similar to that observed in many regions of the bank (Figure 3.11), indicating that Georges Bank clams as a group may range from 30-60 years in age.

The band structure and size structure combine to strongly support the hypotheses that the small clams (under $65 \mathrm{~mm}$ ) appearing in the 1992 and 1994 survey are from the same cohort, and that cohort, in 1994, consisted primarily of clams with 6 to 8 bands (Figure 3.10). Comparison of size structure and band structure, combined with the uncertainty in estimation of true band number, indicates that the single cohort event described above may have resulted from a single year's recruitment; in the case of 6-9 year old group, the number of bands is most consistent with a 1986 spawning event. 


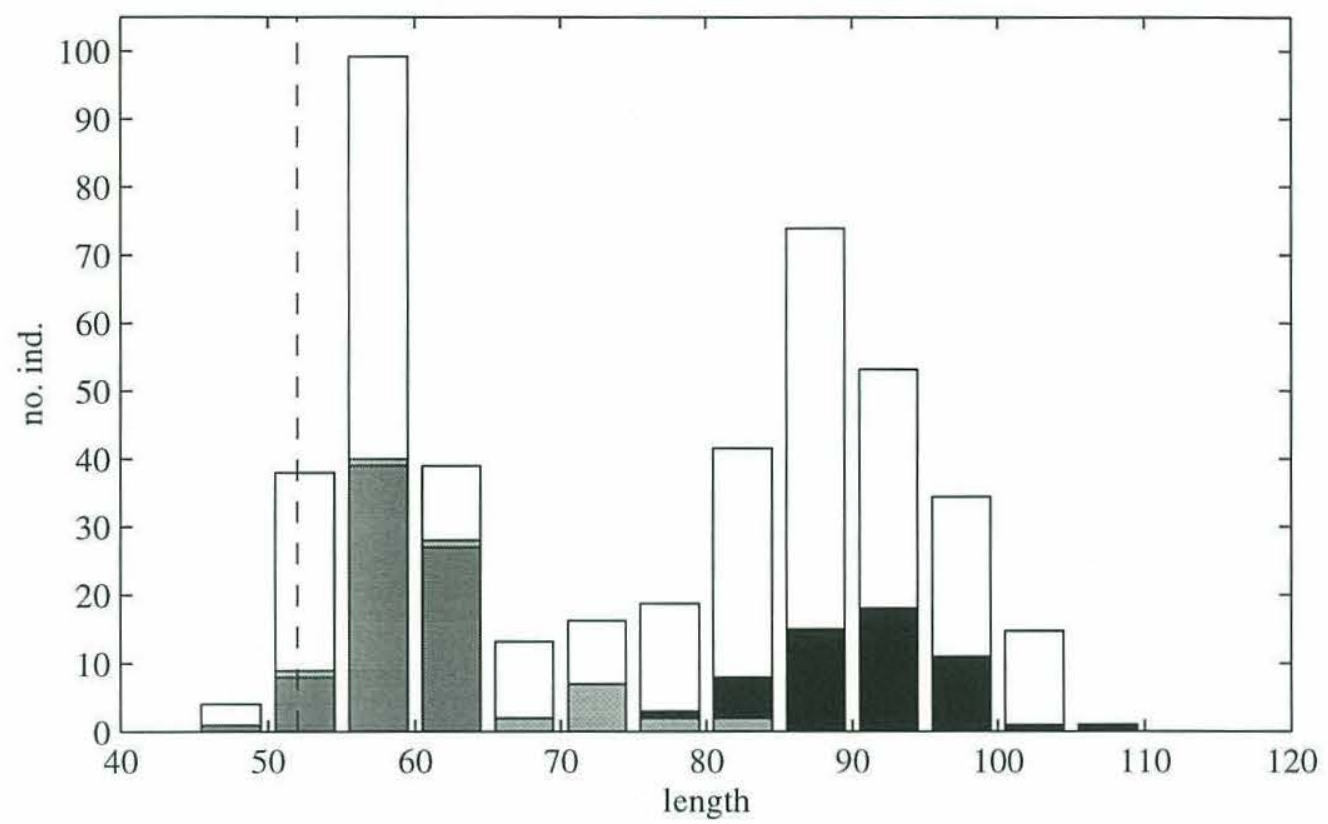

Figure 3.11: Size structure (for tow \#448, 1994 shellfish assessment cruise) for all individuals with 5-9 bands (dark gray), between 11-14 bands (light gray) and over 15 bands (black). The size structure of the shaded bars indicates the size structure of the subsample analyzed for age structure; the highest (unshaded) bar shows the distribution of the subsample measured by the NMFS volunteers at the time the tow was made. Dashed line indicates dredge mesh size. (No individuals of 105-110 mm length were recorded in the NMFS sample, but 1 was found in the subsample used for this work.)

\section{Growth rate}

Although band counting did not provide exact age estimates, it did provide useful data on the growth rate of Arctica on the South Flank and aided in the interpretation of the size structure data and estimation of recruitment frequency (Figure 3.12). For comparison to growth rates from other work on Arctica in this region (Ropes and Pyoas, 1982; NEFSC, 1996), a von Bertalanffy growth curve was fitted to the age-length data generated by the band structure analysis. Based on the assumption that the first year's banding is not detectable by this work, the age of each clam was assumed to equal the band number plus 1 year. 


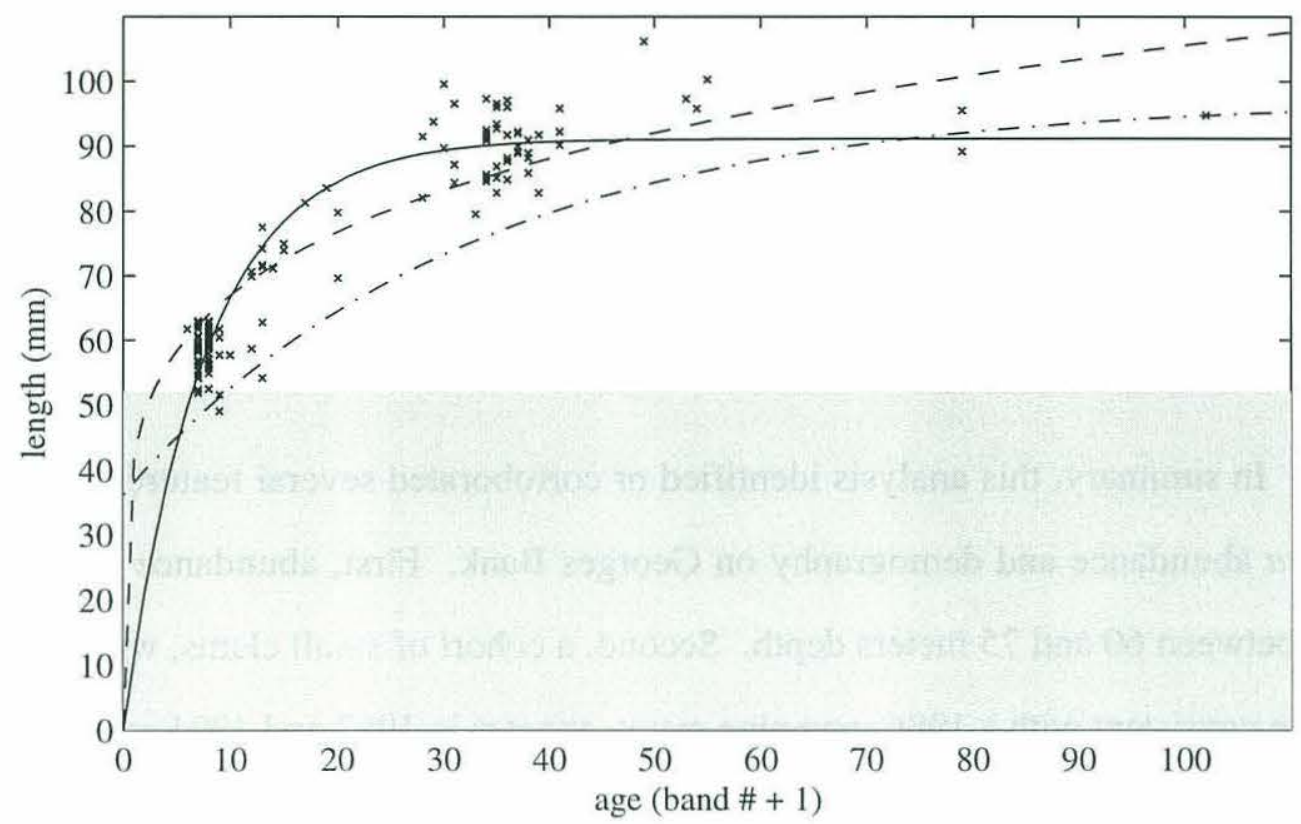

Figure 3.12: Age versus length for all clams for which band number was assayed. Solid line designates a least squares fit of von Bertalanffy equation to data (length $=\mathrm{L}_{\infty}\left(1-\mathrm{e}^{-\mathrm{k}} \times\right.$ age $) ; \mathrm{k}=0.131, \mathrm{~L}_{\infty}=91.13$ $\mathrm{mm} ; \mathrm{R}^{2}=0.879$ ). Dashed line is a power exponential curve (length $=42.4(\text { age })^{0.198}$ ) from Ropes and Pyoas, 1982. Dash-dot line is a von Bertalanffy curve fit (length $=\mathrm{L}_{\infty}\left(1-\mathrm{e}^{-\mathrm{k}} \times\left(\right.\right.$ age- $\left.\left.\mathrm{t}_{0}\right)\right) ; \mathrm{k}=$ 0.031, $\mathrm{L}_{\infty}=97.28 \mathrm{~mm}, \mathrm{t}_{0}=-14.967$ ) for Arctica off the coast of Long Island, New York (NEFSC, 1996). Gray region indicates sizes that are less efficiently captured by the dredge, due to the mesh size.

The clams possessing 11-14 bands had an average length of $69.2 \mathrm{~mm}$, which is just under the $70 \mathrm{~mm}$ definition for marketable size (Weinberg, 1993). This growth rate of young clams is higher than that reported for the Middle Atlantic Bight (Murawski et al., 1982) or Gulf of Maine (Kraus et al., 1992), but is consistent with, and slightly lower than, Ropes' (1982) estimate for Georges Bank. It is exceeded only by rates for clams experimentally placed in optimal feeding conditions (Brey et al., 1990; Kraus et al., 1992) and by the results of the Ropes (1982) study.

In this sample, full adult size is reached fairly early in the life span (Figure 3.12). The three clams with over 70 bands were smaller than some with as few as 29 bands, implying either highly variable growth rate and size at maturity or a change in growth rate 
with time. An abrupt transition in band structure, from broad $(5-10 \mathrm{~mm})$ to narrow $(\sim 1$ $\mathrm{mm}$ ) spacing between successive bands, occurred between 7 and 10 bands, implying a shift from rapid juvenile growth to relatively slow adult growth.

\section{DISCUSSION}

In summary, this analysis identified or corroborated several features concerning Arctica abundance and demography on Georges Bank. First, abundance is highest in areas between 60 and 75 meters depth. Second, a cohort of small clams, whose age and size are consistent with a 1986 spawning event, appears in 1992 and 1994 samples on the South Flank of the bank. Third, this group is younger and faster growing than the Middle Atlantic Bight population. In addition, this work suggests some further studies that may be helpful in quantifying Arctica demography.

\section{Distribution}

From the abundance data, it appears likely that the region between the 50 and 100 meter isobaths is well populated by Arctica in all sampled areas of Georges Bank, with highest concentrations between 60 and 75 meters. Based upon this and other work (Thouzeau et al., 1991b), Arctica is likely to be found down to at least 100 meters around the entire periphery of the bank, including the unsampled areas on the Northeast Peak (although the abundance of Arctica below 80 meters is more difficult to predict). Inferences from this work concerning distribution of deep water populations or populations on the Northeast Peak should be treated with caution, as very few samples have been taken below 80 meters or in Canadian waters. Additionally, tows taken during 1994 yielded more adult clams in almost every region than were taken in previous years, despite the fact that the sampling protocol was not changed during that year (NEFSC, 
1994, 1995a,b).

The peak abundance of Arctica islandica between 60 and 75 meters corresponds with a region of the bank in which stratification is not broken down by tidal mixing. This region typically maintains a cooler temperature and lower seasonal variation than the shallow tidally mixed region within the 60 meter isobath (Flagg, 1987). The greatest densities on the Southern Flank were recorded along the 60 meter isobath in all years (Figure 3.3), corresponding to the convergent front that defines the boundaries of the stratified shelf water and the tidally mixed Georges Bank Water.

Several possible mechanisms can be postulated to explain this distribution. Arctica adults do not survive long in water temperatures greater than $20^{\circ} \mathrm{C}$, and, although their tolerance of temperatures below this is not known, occasional high temperatures observed in the well-mixed central bank water may be sufficient to prevent successful maintenance of a population in this region. Tidal currents over the central bank consistently resuspend sediments there, which may overwhelm the feeding capability of these filter-feeding bivalves. Competition between Arctica and Spisula solidissima may favor the latter in the shallow waters (J. Weinberg, personal communication). The distributions of these two species typically are complimentary throughout the Middle Atlantic Bight, with Arctica found in deeper waters. The long life span and relatively slow development of Arctica (in comparison to other bivalves in the region) implies that its best chance of survival is in areas where the probability of a mass mortality event is very low.

\section{Recruitment}

The numbers of small clams on the Southeast Flank is a strong indication of a 
single recent recruitment event which, based on band number and typical spawning patterns, probably occurred during the period between Spring, 1986, and Spring, 1987. Only two surveys, 1992 and 1994, showed evidence of such a consistent and widespread cohort of small individuals (Figures 3.6 to 3.9). The bulk of this cohort possessed 6 to 8 bands (Figure 3.11), most consistent with a 1986 year class. This younger cohort was observed only in a region of the bank ranging from $66.5^{\circ} \mathrm{W}$ to $68^{\circ} \mathrm{W}$, between the 60 and 100 meter isobaths, although no data is available from the Northeast Peak.

The size structure for stratum 61 in the 1994 Shellfish Assessment Survey shows a peak in abundance in the 55-60 mm size class (Figure 3.5), whereas in 1992 this peak was in the $45-50 \mathrm{~mm}$ class. The von Bertalanffy curve fit based on the band structure data (Figure 3.12) predicts a size of $49.6 \mathrm{~mm}$ in 1992 and $59.2 \mathrm{~mm}$ in 1994 for a cohort spawned in 1986. The location of the maxima in the 1992 size structure and the $10 \mathrm{~mm}$ shift in that maxima between 1992 and 1994 are consistent with the von Bertalanffy growth curve generated from the band structured data.

No other recruitment is evident in the length frequency survey data between 1982 and 1994, implying that only one major recruitment event occurred during that 12 year period. However, some other recruitment did occur during the 12 sampled years since 12 clams with between 11 and 15 bands were observed.

In comparison, research on the distribution of larval Sea Scallop, Placopecten magellanicus, was conducted over the Northeast Peak of Georges Bank in late summer and early autumn of 1985, 1986 and 1987 (Tremblay and Sinclair, 1990, 1992), providing an interesting contrast to these observations. Placopecten larvae were most abundant in samples taken between the 60 and 100 meter isobaths at the end of 
September, and, while Tremblay and Sinclair did not comment on the interannual variation in abundance, their data show no noticeable differences between years (Tremblay and Sinclair, 1992). Work by Thouzeau et al, did show distinct peaks in the size structures of Placopecten surveyed over the Northeast Peak of Georges Bank which were identified as corresponding to a specific age class (Thouzeau et al., 1991a). The size structure observed for that species and region differs markedly with the results for Arctica presented here.

\section{Conclusions}

The population of Arctica islandica on Georges Bank is found to be somewhat younger and faster growing than Middle Atlantic Bight populations, consistent with some previous observations by Ropes and Pyoas (1982). The 1995 stock assessment workshop described a $50 \mathrm{~mm}$ clam off Long Island as being "about 12 years old", whereas a $50 \mathrm{~mm}$ clam in this study might be as young as 5 years old (NEFSC, 1995b). Clams of $60.6 \mathrm{~mm}$ were assumed to be 17 years of age (NEFSC, 1995a), whereas this work shows 17 year old clams in this region were more likely to be 80 to $85 \mathrm{~mm}$ in length, and $60 \mathrm{~mm}$ clams might be as young as 6 years old. The 1995 stock assessment workshop also stated that "Growth studies conducted off New Jersey, Long Island, and on Georges Bank indicate that ages in excess of 100 are common." In this work, only one clam with over 100 bands and 7 with over 50 bands were found, out of 144 sampled. The sample was admittedly biased, due to the fact that it was selected for the presence of a large number of smaller clams. However, no attempt was made to discriminate based on the size structure of the group of larger clams, and this group consisted primarily of clams between 30 and 55 years of age. 
Large recruitment events into the Georges Bank population appear to be rare, as only one such event is evident from the size structured data shown here. However, the existence of multiple smaller modes in the band structure implies that other recruitment, undetected in the size structure, has taken place. Although small clams were collected in many tows, no other cases were found where their abundance was consistently high in the same strata between years. At a station in the region where recruitment was indicated by size structure data, 87 out of 144 randomly selected clams were less than 15 years old, of which 12 were not part of the large class of 6-9 year old clams that motivated the consideration of this sample. Excluding the 1986 event, some recruitment occurred at this site between 1982 and 1994; 18\% of the older, larger cohort recruited during this period.

Several possible methods of resolving some of the extant questions concerning Arctica demographics on Georges Bank are suggested. Foremost in the list is increased spatial sampling of Georges Bank. Recent cruises have begun to provide replicate samples within all NMFS survey strata (Figure 3.1) in United States waters, and it is only in those surveys that meaningful comparisons of size structure are easily made. Greater sampling of the Canadian portions of the bank and samples from deeper water populations would help resolve the full extent of the population. The species is very common on the Northeast Peak and is found there in great abundance at depths up to 100 meters (Thouzeau et al., 1991b). The species is known to exist in much deeper waters in this region and others (Nicol, 1951; Maciolek and Grassle, 1987). Definitive conclusions concerning stock structure and stability are difficult when the full range of the species is not sampled.

Additional sampling of two features would greatly increase the understanding of 
Arctica population dynamics; first, the age structure of numerous locations on the bank should be sampled if resources can be found to support such work. This would determine if the population is indeed as young and fast growing in other regions of the bank as it was in the tow described here. The second change recommended by this work is for increased sampling of smaller size classes. The present mesh size of the dredge allows recruits to slip through, while retaining the older portion of the population. This imposes a bias in the size structure that makes detection of episodic recruitment events (such as the one noted here) more difficult. Unfortunately, any changes in the dredge design would prevent easy comparison of future survey tows with past data (this problem has, however, already arisen due to the anomalous results of the 1994 cruise).

Based on the limitations of the dredge, it is not possible to determine with certainty whether the recruitment shown here occurred in a single year, two or three years, or is an ongoing process. However, the change in size structure for stratum 61 between 1992 and 1994 (Figure 3.5) implies that the small clams seen in the 1992 survey are not being replaced and indicates that recruitment probably occurred in a single season. Assuming that the cohort seen here is indeed a single cohort, spawned in 1986 and detected in 1992 and 1994, then a rough estimate of the time period covered by this survey can be made. If recruitment pulses are only detectable between 6 and 8 years of age (as seen here), then the survey data from 1982 to 1994 would actually have a chance of detecting recruitment between 1974 and 1988. However, many of these surveys missed large regions of the bank, so the resolution may be less than 14 years for many regions.

Finally, the nature of the processes causing this recruitment event are not determined by this work. Recent study has focused on larval transport and settlement as 
one of the key factors controlling interannual variation in recruitment (Roughgarden, et al., 1985; Roughgarden et al., 1988), but mortality in the larval and juvenile stages could equally be responsible for the pattern seen here. While this work helps identify the spatial and temporal scales associated with a single recruitment event, it does not conclusively determine that the recruitment is caused by variation in larval supply. An alternative hypothesis, based upon a brief reduction in mortality of the smallest juveniles, could also account for the patterns observed here.

However, the existing information regarding Arctica demographics can support the use of existing oceanographic and ecological models to determine to which processes the population is most sensitive. A combination of information concerning mortality, growth, and fecundity can be used to identify the parameters that are most important in controlling population growth and abundance, and thereby can serve to focus limited research resources on the critical factors driving population structure and growth. 


\section{Chapter 4: Modeling PlankTON TRANSPORT IN WIND AND TIDALLY DRIVEN CIRCULATION OVER GEORGES BANK}

\section{INTRODUCTION}

Physical transport of plankton populations by strong wind forcing can affect survival and production (Chapter 2; Lewis, et al, 1994). Larval transport can determine settlement and recruitment patterns in adult populations of benthos (Gaines et al., 1985; Roughgarden et al., 1988, 1991). This chapter and subsequent work (Chapter 5) address the possibility that recruitment variation and abundance patterns in Arctica islandica on Georges Bank (Chapter 3) may be due to wind-induced transport variation. Specifically, this chapter examines the effects of time-varying versus constant wind forcing, also incorporating the effects of tidal forcing that were not considered in previous work (Chapter 2; Lewis, et al, 1994).

Previous modeling of plankton circulation and transport over Georges Bank has either ignored wind forcing or used time-invariant winds, typically drawn from climatological or annual means (Greenberg, 1983; Chen, 1992; Lynch and Naimie, 1993; Werner et al., 1993; Lewis et al., 1994; Lough, et al., 1994; Naimie et al., 1994; Chen and Beardsley, 1995; Chen, et al., 1995). The use of long term average winds provides an estimate of seasonal circulation, but the question remains; does time-averaged forcing generate accurate estimates of plankton transport? Are physical models that assume timeinvariant forcing accurately predicting the effects of that forcing on planktonic ecosystems? 
The objective of this work is to identify the effects of wind and tidally driven circulation on plankton distributions. A series of numerical experiments were conducted to isolate effects of wind forcing on the transport of a generic meroplanktonic larval population on Georges Bank. Transport within the boundaries of the bank between subpopulations was examined, as well as loss off the bank. The selection of forcing conditions was designed to identify the range of variation in wind-forced processes driving larval settlement patterns, rather than to simulate specific conditions and settlement distributions within a given year.

Plankton transport was modeled for three periods: December 10 to February 13 of 1974-5, 1978-9 and 1991-2. The first two years were simulated using both time-variant synoptic wind forcing (hereinafter referred to as synoptic forcing) and vector-averaged wind forcing. These simulations concentrated on two questions. First, does synoptic forcing of coupled biological physical models affect the results of those models relative to the steady case? Second, can interannual variation in wind forcing cause variation in long-term transport and retention of plankton over Georges Bank? The transport results presented here were incorporated into a simple linear matrix model to examine effect of wind-forced larval transport on recruitment to a benthic population (Chapter 5).

\section{PHYSICAL MODEL}

This work is based on a computer model written by Alan Blumberg and George Mellor (1983) with parameterization for Georges Bank developed by Changsheng Chen. The equations and solution scheme used incorporate assumptions about the time and spatial scale and are not expected to perfectly mirror the circulation on Georges Bank. This work specifically relies on the model to predict the mesoscale response of an 
unstratified water column to tidal and synoptic wind forcing.

The code used to model transport over Georges Bank is a version of ECOM-si (Estuarine, Coastal and Ocean Model - semi-implicit; Blumberg and Mellor, 1983, 1987; Blumberg, 1993) developed for Georges Bank and the Gulf of Maine region by Dr. Changsheng Chen (University of Georgia). The model has been used extensively for two-dimensional modeling of this region (Chen, 1992; Chen and Beardsley, 1995; Chen et al., 1995), and the present study represents the first three-dimensional use of this code for Georges Bank. Detailed description of the model code and limitations has been published before (Blumberg and Mellor, 1983, 1987; Blumberg, 1993; Chen and Beardsley, 1995; Chen et al., 1995), and only a summary of the salient features used in this work will be presented here.

\section{Model Physics}

ECOM-si is designed to solve the primitive equations of fluid motion over scales

of 1-100 km. The equations for momentum advection include the Boussinesq, incompressibility and $f$-plane approximations:

$$
\begin{aligned}
& u_{t}+\mathbf{u} \bullet \nabla u-f v=-\frac{1}{\rho_{0}} p_{x}+\left(K_{m} u_{z}\right)_{z}+\mathrm{F}_{u} \\
& v_{t}+\mathbf{u} \bullet \nabla v+f u=-\frac{1}{\rho_{0}} p_{y}+\left(K_{m} v_{z}\right)_{z}+\mathrm{F}_{v},
\end{aligned}
$$

4.2) $\nabla \cdot \mathbf{u}=0$,

where $u, v$ and $w$ are the $x, y$, and $z$ components of the velocity vector, $\mathbf{u}$ (subscripts $x$, $y, z$, and $t$ denote the three spatial and one temporal derivative), $p$ represents pressure, $\rho$ is density, $K_{m}$ is the turbulent eddy viscosity, and $\mathrm{F}_{u}$ and $\mathrm{F}_{v}$ represent the sub-grid scale 
horizontal momentum diffusion terms. The exact form of these terms is available in Blumberg and Mellor (1987). This work assumed constant horizontal mixing for all properties; the Smagorinsky scheme has been incorporated into the code but was not used (Smagorinsky, 1963; Blumberg and Mellor, 1987). The Coriolis parameter is calculated for latitude $41^{\circ} \mathrm{N}\left(f=9.57 \times 10^{-5} \mathrm{~s}^{-1}\right)$.

The model uses the hydrostatic approximation for pressure,

4.3) $\quad p_{z}=-\rho_{0} g$.

The cases addressed here all assume an unstratified water column.

The mixing coefficients, $K_{m}$ and $K_{H}$, are derived from the Mellor and Yamada second order turbulence closure model; they are calculated from a model of the turbulent kinetic energy $\left(q^{2}\right)$ and turbulent macroscale $(l)$ as follows (Mellor and Yamada, 1982; Blumberg and Mellor, 1987; Chen et al., 1995):

$$
\begin{aligned}
& q_{t}^{2}+\mathbf{u} \cdot \nabla q^{2}=2\left(\mathrm{P}_{\mathrm{s}}-\frac{q^{3}}{B_{1} l}\right)+\left(K_{q} q_{z}^{2}\right)_{z}+\mathrm{F}_{q}, \\
& \left(q^{2} l\right)_{t}+\mathbf{u} \bullet \nabla\left(q^{2} l\right)=l E_{1} \mathrm{P}_{\mathrm{s}}-\frac{q^{3} W}{B_{1}}+\left(K_{q}\left(q^{2} l\right)_{z}\right)_{z}+\mathrm{F}_{l} .
\end{aligned}
$$

$\mathrm{P}_{\mathrm{S}}$ represents the production of turbulent kinetic energy from shear,

$$
\text { 4.6) } \quad \mathrm{P}_{\mathrm{S}}=K_{m}\left(u_{z}^{2}+v_{z}^{2}\right) \text {, }
$$

$W$ represents a wall proximity function that limits the turbulence scale in proximity to the surface and bottom boundaries. The mixing coefficients for momentum $\left(K_{m}\right)$, tracer 
quantities $\left(K_{H}\right)$, and the two turbulence quantities $\left(K_{q}\right)$, then can be calculated from the following equations:

4.7) $\quad K_{m}=\operatorname{lq} S_{m}$,

4.8) $K_{H}=l q S_{H}$,

4.9) $K_{q}=l q S_{q}$.

$\mathrm{S}_{m}, \mathrm{~S}_{H}$ and $\mathrm{S}_{q}$ are analytically derived stability functions, and $E_{1}$ and $B_{1}$ are empirically derived constants (Mellor and Yamada, 1982; Blumberg and Mellor, 1987; Chen et al., 1995).

The surface $(z=\eta)$ boundary conditions for the above equations included only the effects of wind stress $\left(\tau_{\mathrm{w}}\right)$ :

$$
\left.\begin{array}{l}
\rho_{0} K_{m}\langle u, v\rangle_{z}=\tau_{w} \\
\mathrm{~W}=u \eta_{x}+v \eta_{y}+\eta_{t} \\
q^{2}=B_{1}^{2 / 3}\left|\tau_{w}\right| \\
q^{2} l=0
\end{array}\right\} \text { at } z=\eta,
$$

The wind stress, $\tau_{w}$, is calculated from the wind vector, $\mathbf{u}_{w}$, as follows:

4.12) $\quad C_{d}= \begin{cases}1.2 \times 10^{-3} & \left|\mathbf{u}_{w}\right|<11 \mathrm{~m} / \mathrm{s} \\ \left(0.49+0.065 \mid \mathbf{u}_{w}\right) \times 10^{-3} & 11 \mathrm{~m} / \mathrm{s}<\left|\mathbf{u}_{w}\right|<25 \mathrm{~m} / \mathrm{s} . \\ (0.49+0.065 \times 25) \times 10^{-3} & \left|\mathbf{u}_{w}\right|>25 \mathrm{~m} / \mathrm{s}\end{cases}$ 
where $\left|\mathbf{u}_{w}\right|$ denotes the magnitude of the wind vector $\left(u_{w}^{2}+v_{w}^{2}\right)^{1 / 2}$ (Large and Pond, 1981).

The bottom boundary condition $(z=-H)$ is governed only by bottom friction:

$$
\left.\begin{array}{l}
\rho_{0} K_{m}\langle u, v\rangle_{z}=\tau_{f} \\
\mathrm{~W}=-u H_{x}-v H_{y} \\
q^{2}=B_{1}^{2 / 3}\left|\tau_{f}\right| \\
q^{2} l=0
\end{array}\right\} \text { at } z=-H .
$$

The bottom stress $\left(\tau_{\mathrm{f}}\right)$ is determined from the bottom velocity, $\mathbf{u}_{b}$ :

$$
\tau_{f}=C_{d} \mathbf{u}_{b}\left|\mathbf{u}_{b}\right|
$$

$$
C_{d}=\max \left(\frac{\kappa^{2}}{\ln \left(z_{b} / z_{0}\right)^{2}}, 0.0025\right)
$$

where $\kappa(0.4)$ is the von Kármán constant, $z_{b}$ is the thickness of the bottom layer $(1.39 \mathrm{~m}$ in the shallowest region of the bank), and $z_{0}(0.001)$ is the roughness parameter (Mellor and Yamada, 1982; Blumberg and Mellor, 1987).

The above equations provide three dimensional prognostic prediction of three velocity components, surface elevation, turbulent kinetic energy and turbulent macroscale. They also allow the prediction of transport of passive and actively swimming tracer quantities $(B)$ :

$$
B_{t}+\left(\mathbf{u} \bullet \nabla B+w_{b} B_{z}\right)=\left(K_{H} B_{z}\right)_{z}+\mathrm{F}_{B} .
$$

This set of equations incorporates an active vertical swimming term, $w_{b}$, representing the swimming behavior of larvae. Sub-grid scale diffusion is included using 
the term $\mathrm{F}_{B}$. Reaction terms to reflect the effects of biological interactions can be included on the right hand side of equation 4.16, but this work discusses only the effects of physical transport. The effects of demographic processes will be addressed in Chapter 5 .

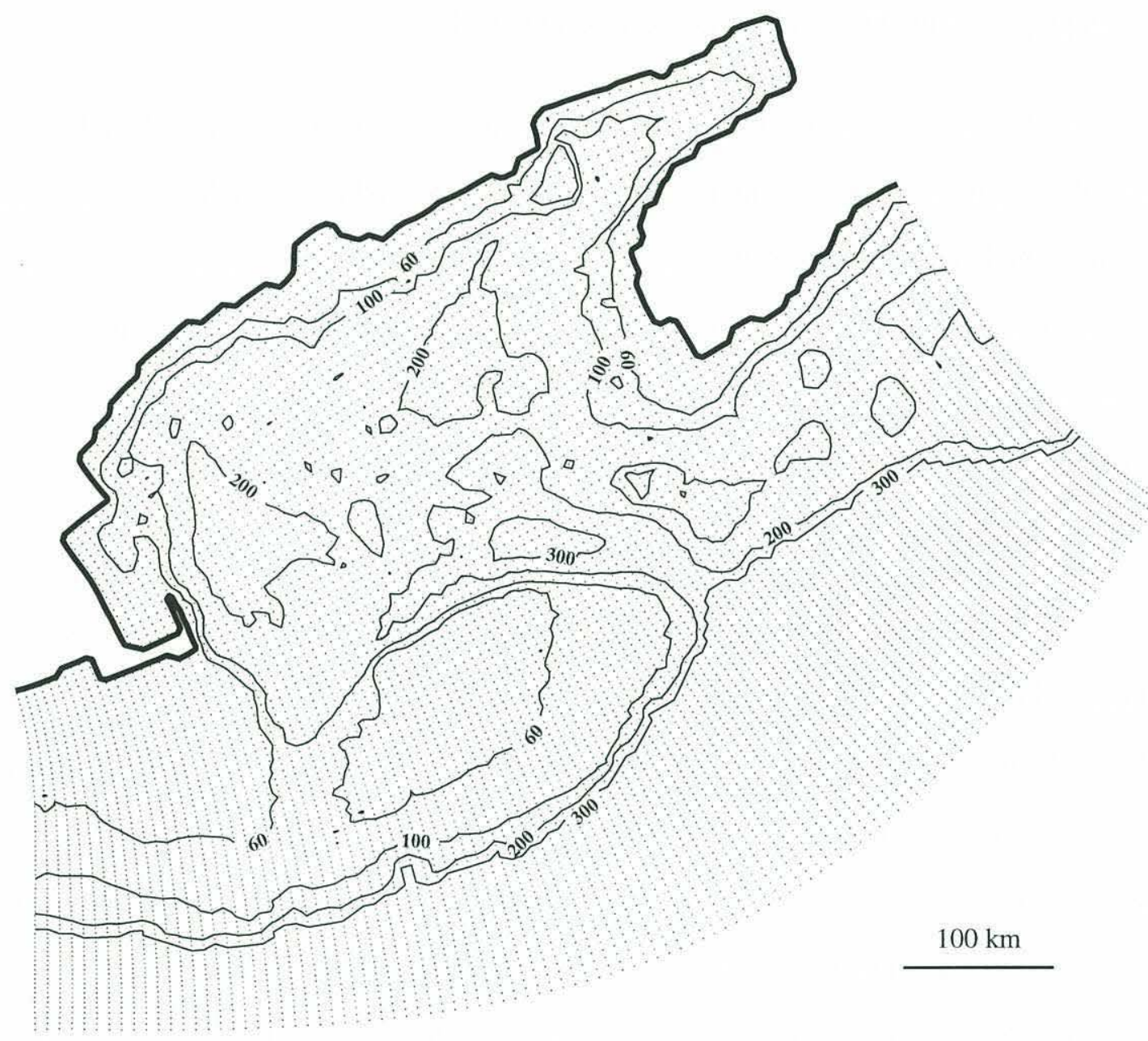

Figure 4.1: Model grid and topography. Location of model grid points are indicated by small dots; coastline is shown in bold.

\section{Numerical Methods}

The numerical solution takes advantage of a number of numerical techniques that have been developed to reduce the computational requirements. It is not feasible to solve the full set of equations on all scales, and the above set incorporates a variety of scale- 
dependent approximations that make such a solution unrealistic in any event. The equations are solved on a finite difference grid in three dimensions, with a horizontal grid scale of approximately $5 \mathrm{~km}$ and 15 sigma levels vertically. The grid domain represents the topography of the Gulf of Maine and Georges Bank.

A staggered Arakawa $\mathrm{C}$ grid is used; velocity components are indexed to the edges of the grid cell and all other components are referenced to the midpoint of the cell. An orthogonal curvilinear grid is used in the horizontal, yielding a model domain with better coverage of the area of interest. The vertical structure is resolved using a sigma coordinate system, with $\sigma=(z-\eta) /(H+\eta)$. The overall domain contains 140 elements in the along-shelf direction, 100 across the shelf, and 16 points in the vertical; the grid includes dry land points at which solutions are not calculated.

The model domain and associated grid on which the above equations are solved includes all of the Gulf of Maine and Georges Bank region, extending over $100 \mathrm{~km}$ south of the $100 \mathrm{~m}$ isobath at all points (Figure 4.1). The coastal boundaries to the north include smoothed realistic bathymetry for the Gulf of Maine region and are closed at coastal points with no-flux boundaries. The eastern and western boundaries (to the south of Nova Scotia and Cape Cod) are open, as is the southern boundary into deep water. A 15 point sponge is used at the western boundary to absorb gravity wave energy propagating toward that boundary, while a 10 point sponge is used at both the southern and eastern boundaries. The grid was extended by 30 points on the western boundary to compensate for numerical difficulties in that region that had limited the solution to $\sim 20$ days. This extension consisted of a 30 point repetition of the topography at that boundary and successfully stabilized the model for the full 60 day runs shown here. Only the behavior of interior points over the neighborhood of Georges Bank is discussed here as 
the selected boundary conditions exclude some important processes (e.g. warm core rings, gulf stream meanders, and riverine buoyancy fluxes).

The semi-implicit feature of the model allowed for longer time step at this resolution than would a fully explicit model. A complete discussion of the mode splitting techniques used is presented elsewhere. Essentially, the model uses an implicit scheme in the vertical direction and a semi-implicit scheme in the horizontal direction for the barotropic mode; the semi-implicit scheme uses the free surface gradient to solve the velocity divergence in the continuity equation implicitly (Casulli, 1990; Blumberg, 1993; Chen and Beardsley, 1995). The solutions discussed below use a time step of 465.75 seconds, which yields exactly 96 time steps per $\mathrm{M}_{2}$ tidal cycle.

The model runs for this work were conducted on a Cray J916 5 at the National Center for Atmospheric Research's Scientific Computing Division. Each 60 day simulation took approximately 100 hours to complete and required about 180 megabytes of memory. Due to limits on storage space, it was not possible to retain all prognostic variables at every time step. A subset of the model results was saved and archived for every run. The depth integrated distribution of biological fields (Fields 1-10 in Figure 4.2) was recorded every two tidal cycles ( $\sim$ day); the full three dimensional distribution of all biological fields at the end of the run also was retained. The vertical profile of the horizontal components of current ( $u$ and $v$ ) was recorded every time step at 10 locations over the bank (stations 1-10 in Figure 4.2). The three dimensional structure of several physical fields $\left(u, v, w, q\right.$, and $\left.K_{m}\right)$, averaged over two tidal cycles, was saved every 10 tidal cycles. For discussion of the results, residual is defined as the time average over one tidal cycle. Depth-averaged current values are averages of the horizontal vector

5 A full description of the system is available at: http://www.scd.ucar.edu/computers/paiute. 
components of current over the entire water column. Detided residual velocities are obtained by subtracting the residual velocity generated by a model run with no wind forcing.

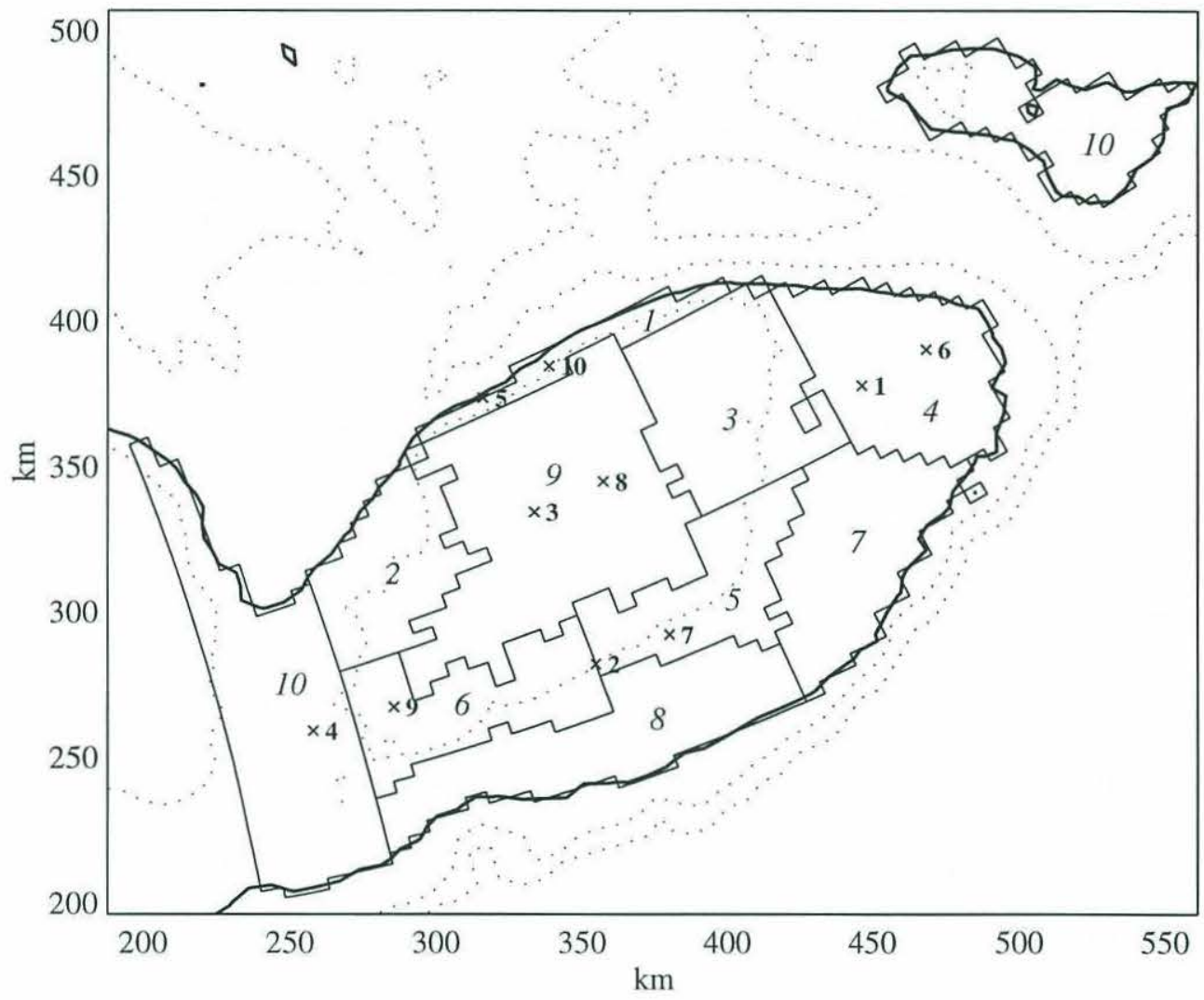

Figure 4.2: Initial tracer distributions are indicated by italicized numbers and delineated by solid lines.

The full time and depth structure of velocity are recorded at locations indicated by an $\mathrm{x}$ and associated station number. The 100 meter isobath is indicated by a bold line; dotted lines indicate 50, 200 and 300 meter isobaths.

\section{Initial Conditions and Forcing}

The physical model was initialized with quiescent, unstratified water with sea surface height uniformly equal to zero throughout the domain. The biological model was initialized, after the physical model had spun up, with a set of tracer fields whose distributions were selected based on two criteria. First, the initial tracer distributions 
completely cover the bank, allowing calculation of total bank losses; second, the distribution isolates major concentrations of Arctica adults (c.f. chapter 2), allowing for prediction of larval transport between those populations. The model forcing included two processes: a tidal signal generated by free-surface forcing at the open boundaries and time varying wind stress imposed over the entire surface of the model.

Initial conditions for the physical parameters were chosen to approximate the winter condition on Georges Bank after stratification has been broken down by mixing and cooling. During this period the circulation is dominated by an underlying tidal signal with variable wind forced flow.
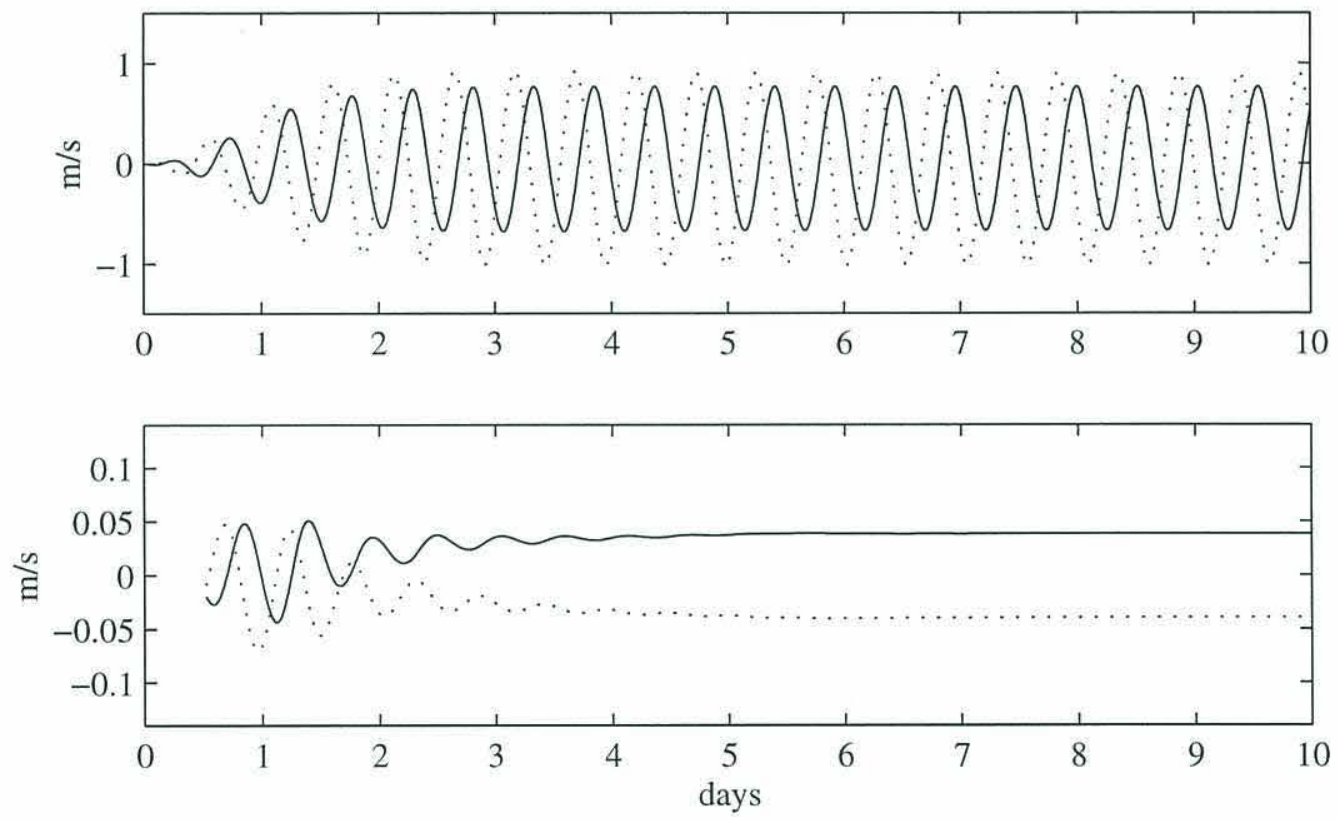

Figure 4.3: Plots of $\mathrm{U}$ (solid) and V (dotted) surface velocity components at station 1 on the Northeast Peak for the first 20 tidal cycles of the 1978 mean run. Also shown are the U and V components of the tidal residual current (current averaged over the preceding 12.42 hour tidal period).

In order to remove transient behaviors from the model, the model was allowed to equilibrate for 10 tidal cycles ( $\sim 5$ days); the tidal signal was linearly increased to full 
strength over the course of one tidal cycle while the wind forcing was linearly increased (to the initial value for the given run) over 10 tidal cycles. The tidal component achieved a stable periodic pattern within 2-3 tidal cycles (Figure 4.3). Linear increasing initial wind forcing (to the value at the beginning of the simulated period) was chosen to provide a wind forced component to the flow field at the start of the run.

Ten fields were used to describe the initial distribution of meroplankton originating at the bottom in nine different areas on the bank and one set off bank (Figure 4.2). These fields were seeded after 10 tidal cycles. All fields were assigned a nominal upward swimming velocity of $5.6 \times 10^{-4} \mathrm{~m} \mathrm{~s}^{-1}$, although a sine function was used to represent the overall velocity distribution with depth (providing swimming velocities of 0 at the surface and bottom). This choice of swimming velocity and behavior was based upon previous research on larval Arctica (Mann and Wolf, 1983). Biological tracers were initialized at the bottom, with the integral of the depth distribution (areal density) at each point equal to $1.0 \mathrm{~m}^{-2}$; i.e. all the tracer was placed in the grid point closest to the bottom, with a density inversely proportional to depth ${ }^{6}$. This is consistent with a scenario in which larvae are produced at an equal rate by benthic organisms, and vertical flux off the bottom was relatively rapid due to both vertical mixing and vertical swimming. The depth distribution of the tracer fields was relatively homogenous after 2 tidal cycles, and did not change much throughout the model run.

6 While there are 16 vertical grid points in the model, only 15 are used to specify the depth distribution, and the tracer was initialized with a value of $1.0 / \Delta \mathrm{Z}$ in point 15 and 0 everywhere else. swimming speed $\left(w_{s}\right)$ was zero at points 1 and 16. 
Table 4.1: Mean magnitude and magnitude and source direction for vector average of wind speed between December 10 of the indicated year and February 13 of the following year. Years used for this work are indicated in bold face. Data from the Fleet Numerical Oceanography Center (Bakun, 1973; Manning and Strout, 1996).

\begin{tabular}{c|c|c|c}
\hline Year & $\begin{array}{c}\text { mean wind speed } \\
(\mathrm{m} / \mathrm{s})\end{array}$ & $\begin{array}{c}\text { vector average } \\
(\mathrm{m} / \mathrm{s})\end{array}$ & $\begin{array}{c}\text { vector average } \\
\text { direction }\left(^{\circ}\right)\end{array}$ \\
\hline 1967 & 8.62 & 3.09 & 328 \\
1968 & 9.20 & 3.73 & 322 \\
1969 & 9.25 & 3.22 & 328 \\
1970 & 8.69 & 3.52 & 322 \\
1971 & 8.12 & 2.87 & 301 \\
1972 & 8.96 & 2.78 & 343 \\
1973 & 7.60 & 1.42 & 313 \\
$\mathbf{1 9 7 4}$ & $\mathbf{7 . 3 3}$ & $\mathbf{2 . 7 5}$ & $\mathbf{3 2 4}$ \\
1975 & 8.59 & 2.57 & 308 \\
1976 & 9.12 & 5.54 & 299 \\
1977 & 8.89 & 1.71 & 312 \\
$\mathbf{1 9 7 8}$ & $\mathbf{1 0 . 0 8}$ & $\mathbf{5 . 5 6}$ & $\mathbf{3 0 3}$ \\
1979 & 9.86 & 5.06 & 340 \\
1980 & 7.88 & 3.50 & 313 \\
1981 & 8.17 & 4.08 & 308 \\
1982 & 8.71 & 2.65 & 355 \\
1983 & 7.16 & 1.70 & 339 \\
1984 & 7.84 & 4.33 & 328 \\
1985 & 7.77 & 2.81 & 301 \\
1986 & 9.03 & 4.01 & 339 \\
1987 & 7.57 & 2.94 & 320 \\
1988 & 8.07 & 2.91 & 317 \\
1989 & 7.84 & 3.03 & 290 \\
1990 & 7.62 & 2.28 & 297 \\
$\mathbf{1 9 9 1}$ & $\mathbf{8 . 4 6}$ & $\mathbf{3 . 5 6}$ & $\mathbf{3 2 6}$ \\
1992 & 9.00 & 2.41 & 12 \\
& & &
\end{tabular}

Five wind forcing regimes were compared, using FNOC wind data for latitude $41^{\circ} \mathrm{N}$ and longitude $68^{\circ} \mathrm{W}$ (Bakun, 1973; Manning and Strout, 1996). Two runs represented the period between December 10, 1974 and February 13, 1975 while two simulated conditions between December 10, 1978 and February 13, 1979 and a fifth modeled the period between December 10, 1991 and February 13, 1992. The first two periods have been previously reported as low- and high-wind winters possibly affecting copepod populations on the bank (Butman, 1987; Davis, 1987; Lewis et al., 1994). 
Table 4.1 shows the mean magnitude and the magnitude and direction of the vectoraveraged winds for the period between December 10 and February 13 of years from 1967 and 1992. The strongest mean winds were observed in 1978. The second weakest mean magnitude occurred in 1974, and 1991 was closest to the average for the 25 years of data presented here. The vector average of the 1974 winds was slightly weaker than the mean (and median) of the vector average, during this period, for all years combined.
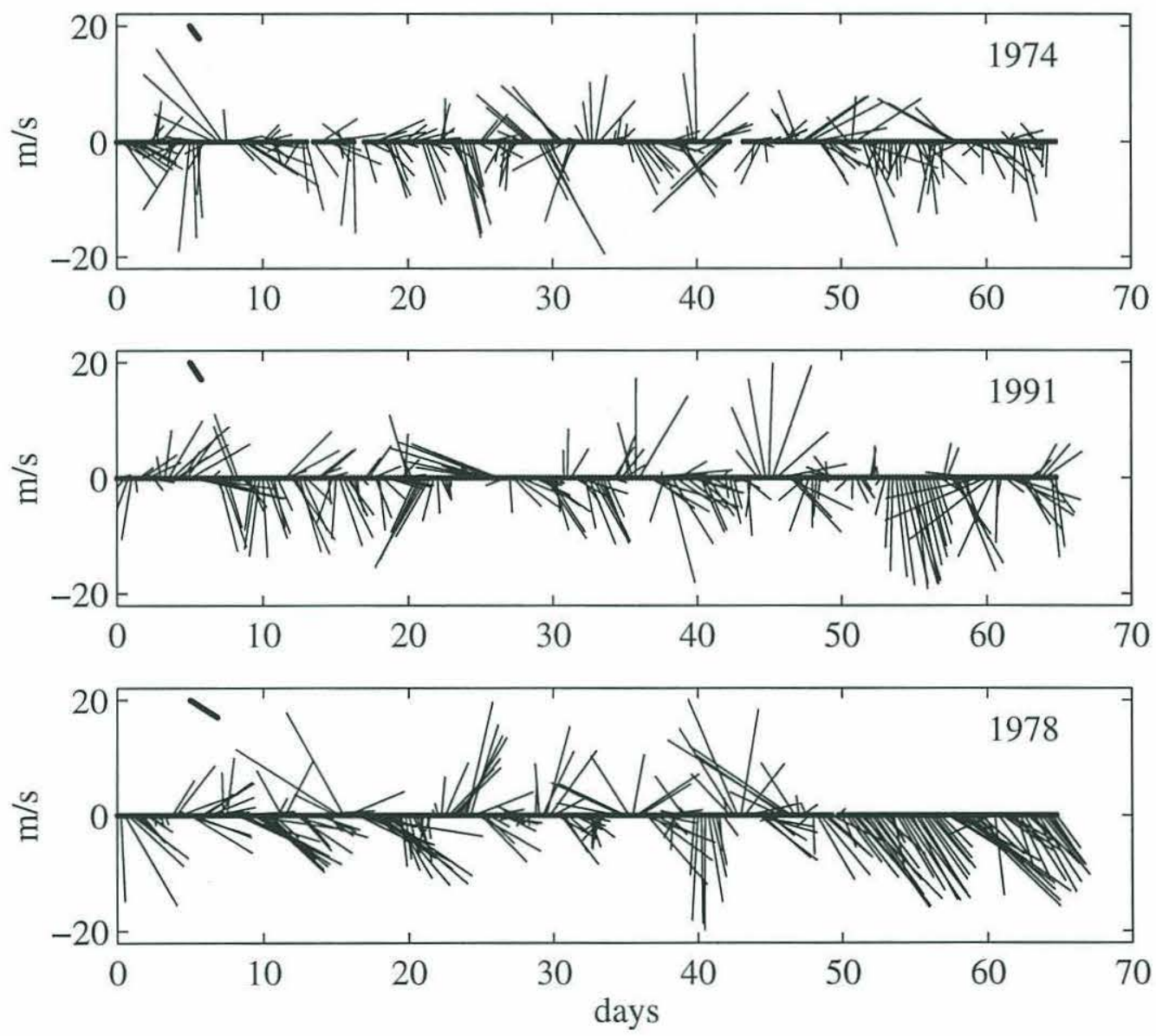

Figure 4.4: Wind forcing for synoptic runs. The top plot is for the period 12/10/74-2/13/75 (lowest wind), the middle is for $12 / 10 / 91-2 / 13 / 92$ (median wind), and the bottom is for $12 / 10 / 78-2 / 13 / 79$ (highest wind). The bar in the upper left corner of each plot represents the vector-averaged mean of the winds for that period.

Five model runs were made to examine wind forcing, hereinafter referred to as 
1978 mean, 1978 synoptic, 1974 mean, 1974 synoptic, and 1991 synoptic. For 1974 and 1978, one run was made using 6 hour averaged winds while a second run was made using the vector average of the same wind data (Figure 4.4); for 1991 only synoptic forcing was used. An additional run, for a period of fifteen days and without wind forcing or tracer fields, was used to estimate tidal circulation.

The model boundaries were forced with a sinusoidal surface gravity wave with an amplitude of 0.50 meters at the lunar semi-diurnal period (12.42 hours) at the southern and western boundaries and an amplitude increasing from 0.50 to 0.76 meters at the eastern boundary. All boundaries were forced in phase. These time dependent surface elevation boundary conditions are very similar to observations over the bank (Brown and Moody, 1987) and those used by Lynch and Naimie (1993) in previous modeling work in this region.

\section{RESULTS AND DISCUSSION}

The selected simulations highlighted several interactions between tidal circulation and wind forcing that have important consequences for the retention and loss of meroplankton from Georges Bank waters. The results indicate that synoptic scale wind events have a marked effect on transport and circulation around Georges Bank that can not be predicted from long term averages of wind speed data.

The effect of simple (constant upward) swimming behavior was tested in earlier work with this model (unpublished results). In the absence of vertical diffusion (i.e. $K_{H}$ $=0$ ), the upward swimming tracers were carried by the surface currents and their final distribution differed greatly from that of passive tracers. However, the presence of diffusion eliminated this distinction and typical vertical swimming speeds of $2 \mathrm{~m} \mathrm{hr}^{-1}$ had 
little effect on the transport of tracer in the presence of diffusion. Vertical distribution of tracers in these model results were largely homogeneous, so discussion of the flow fields will primarily focus on the depth-averaged, tidal residual flow as the most relevant to transport of larvae in this work.
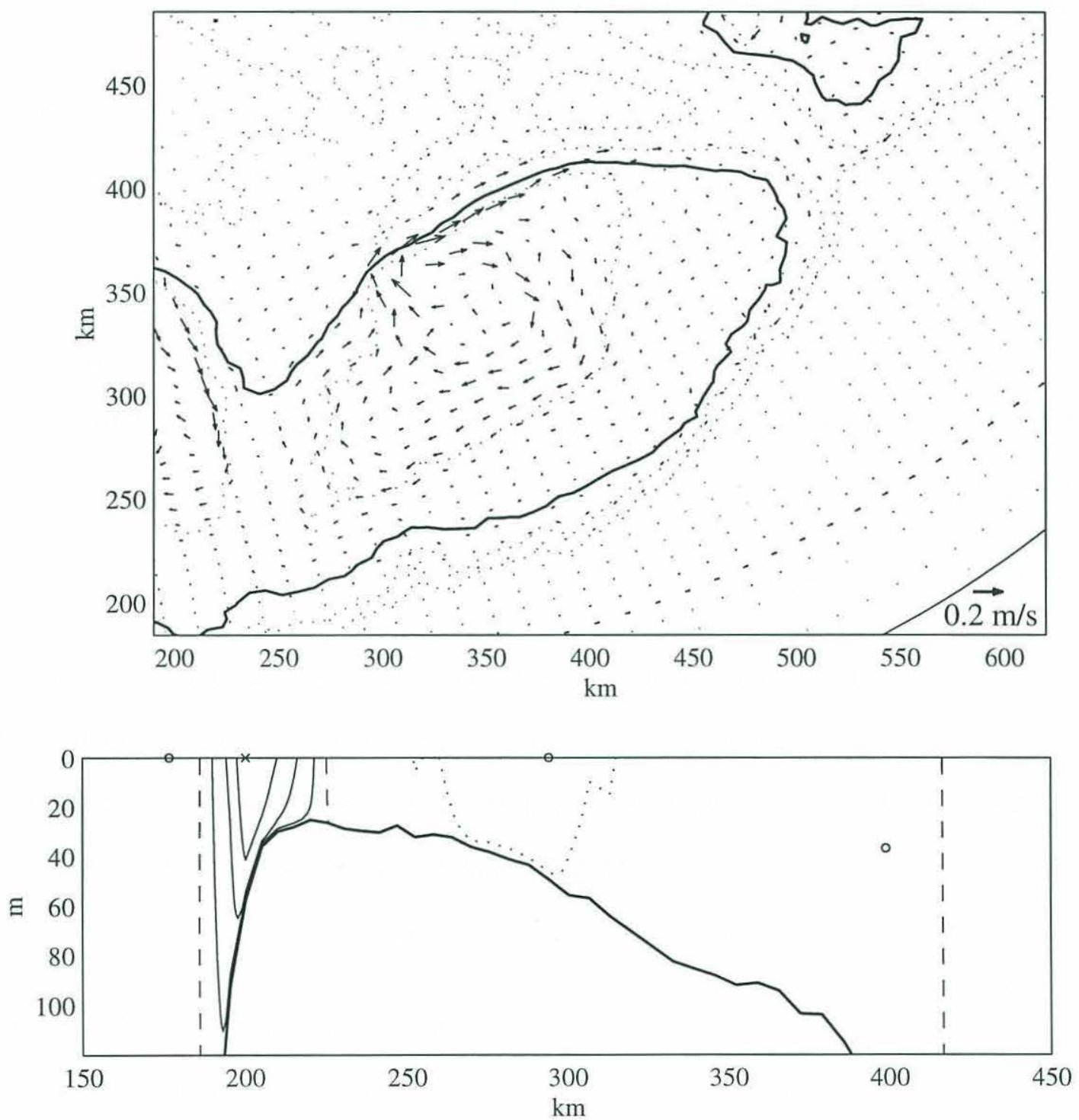

Figure 4.5: (Top) Depth-averaged tidal residual currents for a run with no wind. Bold line indicates 100 meter isobath. (Bottom) Contour plot of $0.05 \mathrm{~ms}^{-1}$ isopleths of velocity (normal to section shown in Figure 4.13). Positive contours (into page) are shown solid, zero contour is dashed, negative contours dotted. Local velocity maxima are denoted by an "x", local minima by an "o". 


\section{Circulation}

When subjected only to tidal forcing without wind $\left(\tau_{\mathrm{w}}=0\right)$, the modeled tidal residual circulation closely resembled previous models and observational data (Greenberg, 1983; Butman, et al., 1987; Flagg, 1987; Lynch and Naimie, 1993; Naimie et al., 1994; Tremblay et al., 1994). The modeled depth-averaged tidal currents in the Georges Bank region show a strong $(\sim 0.25 \mathrm{~m} / \mathrm{s})$ Northern Flank jet with a weak recirculation on the southern flank (Figure 4.5A). The strongest recirculation occurred inside the 60 meter isobath (Figure 4.5B). Currents on the Northeast Peak were diffuse and undirected, as has been observed and predicted previously (Butman et al., 1987; Flagg, 1987), although other modeling work predicts a much stronger jet onto the Northeast Peak (Naimie et al., 1994; Naimie, 1996), likely due to both the inclusion of stratification effects and the large scale climatological mean pressure field imposed on the latter model.

The circulation in the model runs with vector-averaged wind forcing bore a strong qualitative resemblance to the circulation with only tidal forcing. These runs quickly (within 5 days) equilibrated to a periodic flow field in which temporal variation was solely due to the $\mathrm{M}_{2}$ tide. The residual currents for the entire 60 days after initialization showed no noticeable trends in current speed or direction (an example of the rapid equilibration of these flow fields is seen during the first 10 days of the 1978 mean case at station 1 on the Northeast Peak, Figure 4.3). The depth-averaged current field after 62 days of forcing with vector-averaged 1978 winds (Figure 4.6) appears to be nearly the same as that for purely tidal circulation (Figure 4.5B). The detided (wind forced) component of the depth-averaged circulation consists of fairly uniform southwesterly currents over the bank of $\sim 0.01 \mathrm{~m} / \mathrm{s}$. The results for the 1974 mean case are similar, but 
the wind forced component over the bank is even smaller $(\sim 0.003 \mathrm{~m} / \mathrm{s}$ for the depthaveraged flow).
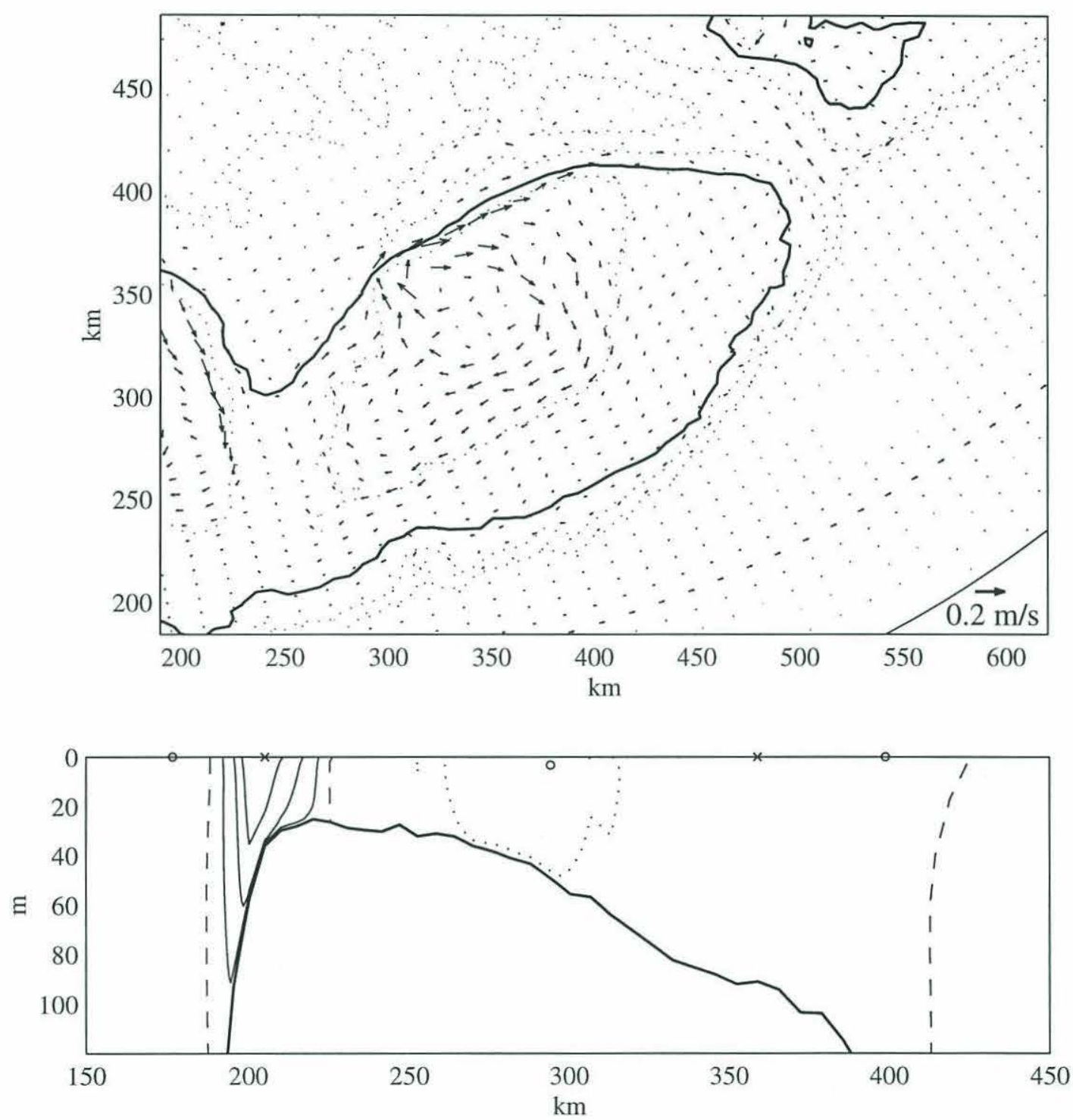

Figure 4.6: 1978 mean wind forcing. (Top) Depth-averaged tidal residual currents. Bold line indicates 100 meter isobath (Bottom) Contour plot of $0.5 \mathrm{~m} \mathrm{~s}^{-1}$ isopleths of velocity (normal to section shown in Figure 4.13). Labeling conventions as Figure 4.5.

The effect of synoptic wind forcing on the distribution of depth-averaged on-bank and around-bank velocity was examined at station 5 on the North Flank (Figure 4.7). 
The tails of the distributions are broader with higher winds, but the mean and median of the distributions in all three years appears similar. At this station flow increased on-bank and decreased around-bank as the magnitude of the northwest wind increased.
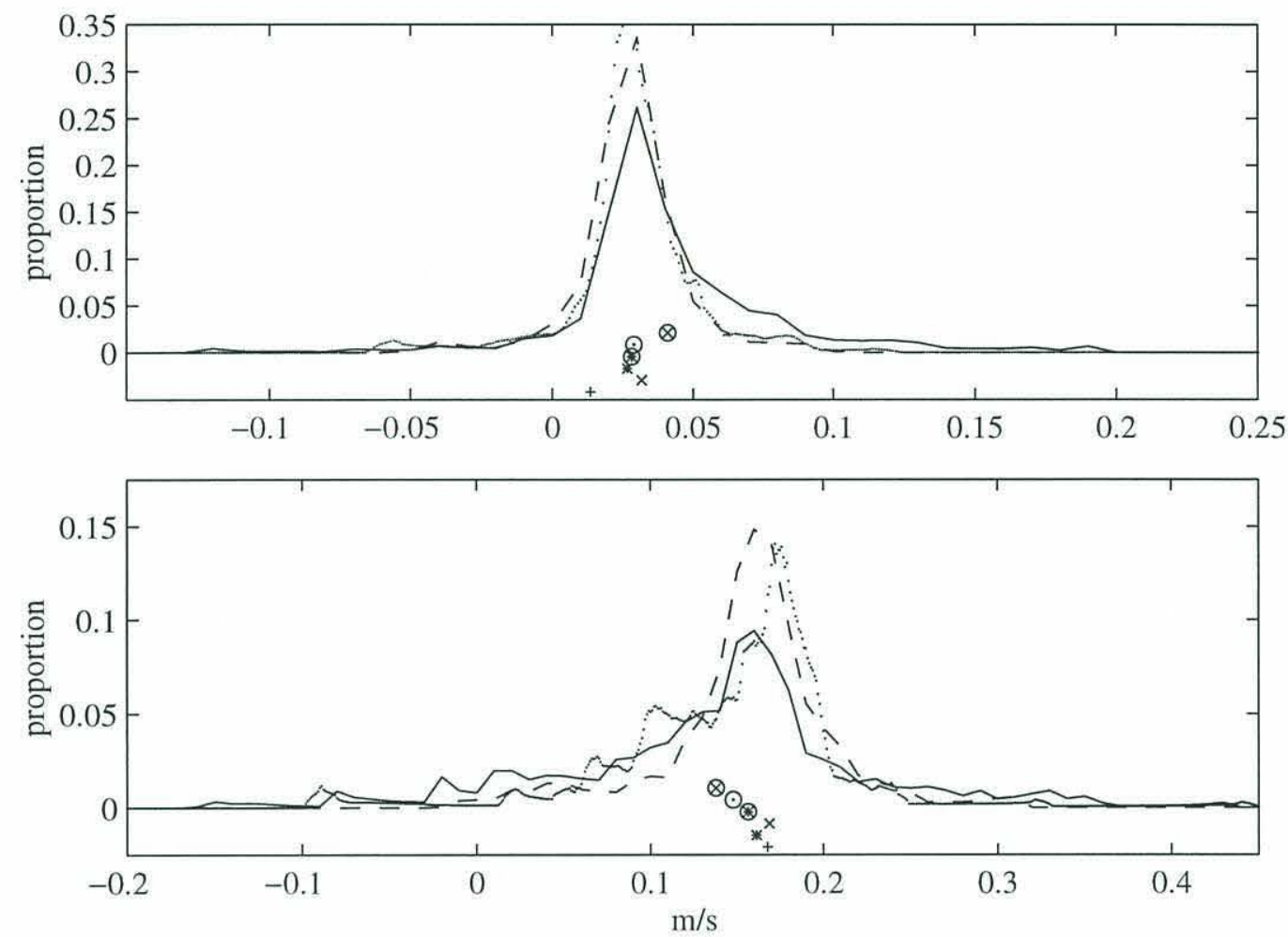

Figure 4.7: Frequency distribution (using $0.01 \mathrm{~m} / \mathrm{s}$ bin size) of residual on-bank (top) and around-bank (bottom) current at station 5 (North Flank) for each synoptic wind run (solid line $=1978$, dotted $=$ 1991 , dash $=1974)$. Symbols below denote the mean of the currents for the tidal $(+)$, vectoraveraged $(*=1974, \mathbf{x}=1978)$, and synoptic $($ circled symbols; $*=1974, \mathbf{x}=1978$, and $\cdot=1991)$ wind runs.

The magnitude and variance of the flow at selected stations around the bank (stations 1-5) for the years 1974, 1978 and 1991 revealed that variance increased with higher mean wind (1974 had the lowest variance at all stations, 1978 the highest, Figure 4.8A-C). The mean of both eastward and northward components of velocity at all stations decreased with increasing wind as would be expected from simple Ekman dynamics, since average winds were from the northwest in all years (Figure 4.4). 


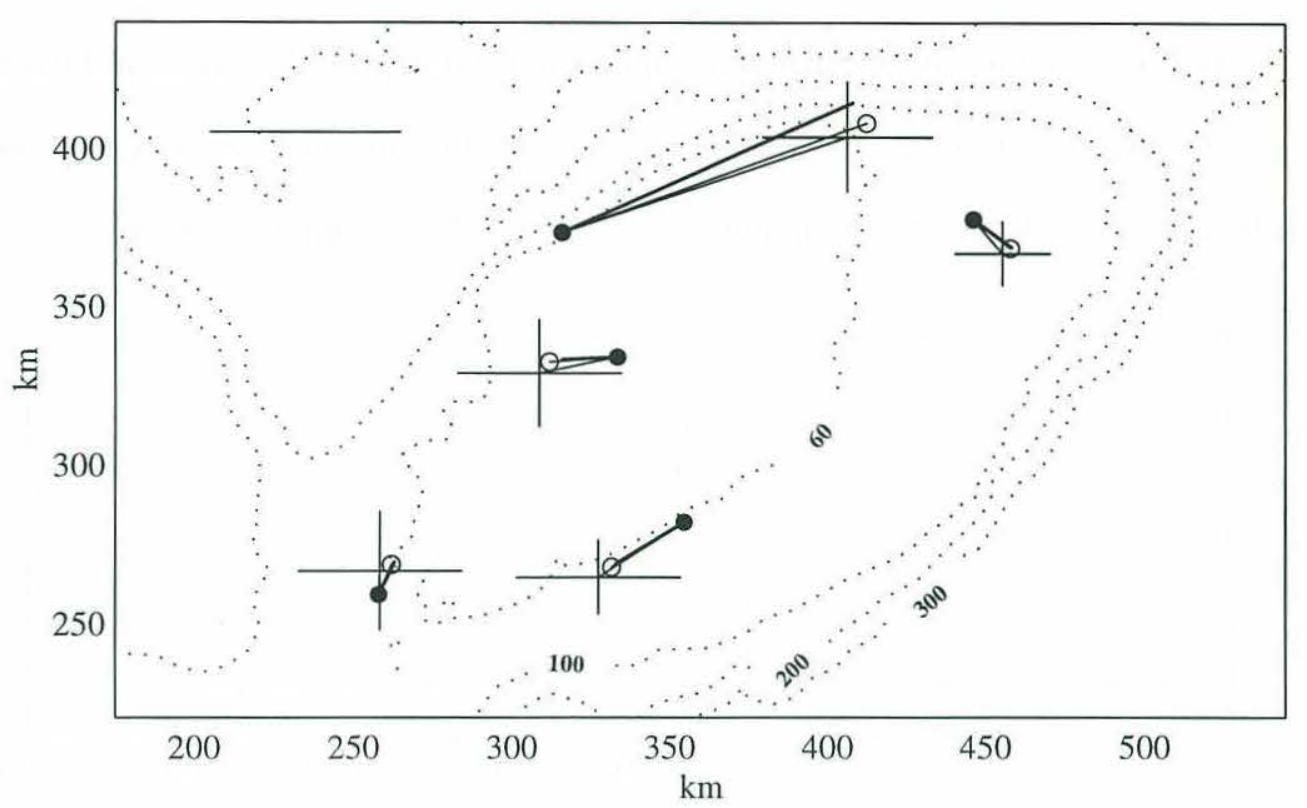

Figure 4.8A: Magnitude, variance, and direction of modeled currents at stations 1-5 for the 1974 model year (contour depths are in meters). The bold line shows the tidal circulation, the line ending in a circle indicates the direction of the currents from the vector-averaged wind case, and the cross shows the mean flow for the synoptic case. The arms of the cross indicate the variance in the velocity component in the respective directions. The scale bar in the upper left corner indicates a current of $0.1 \mathrm{~m} / \mathrm{s}$.

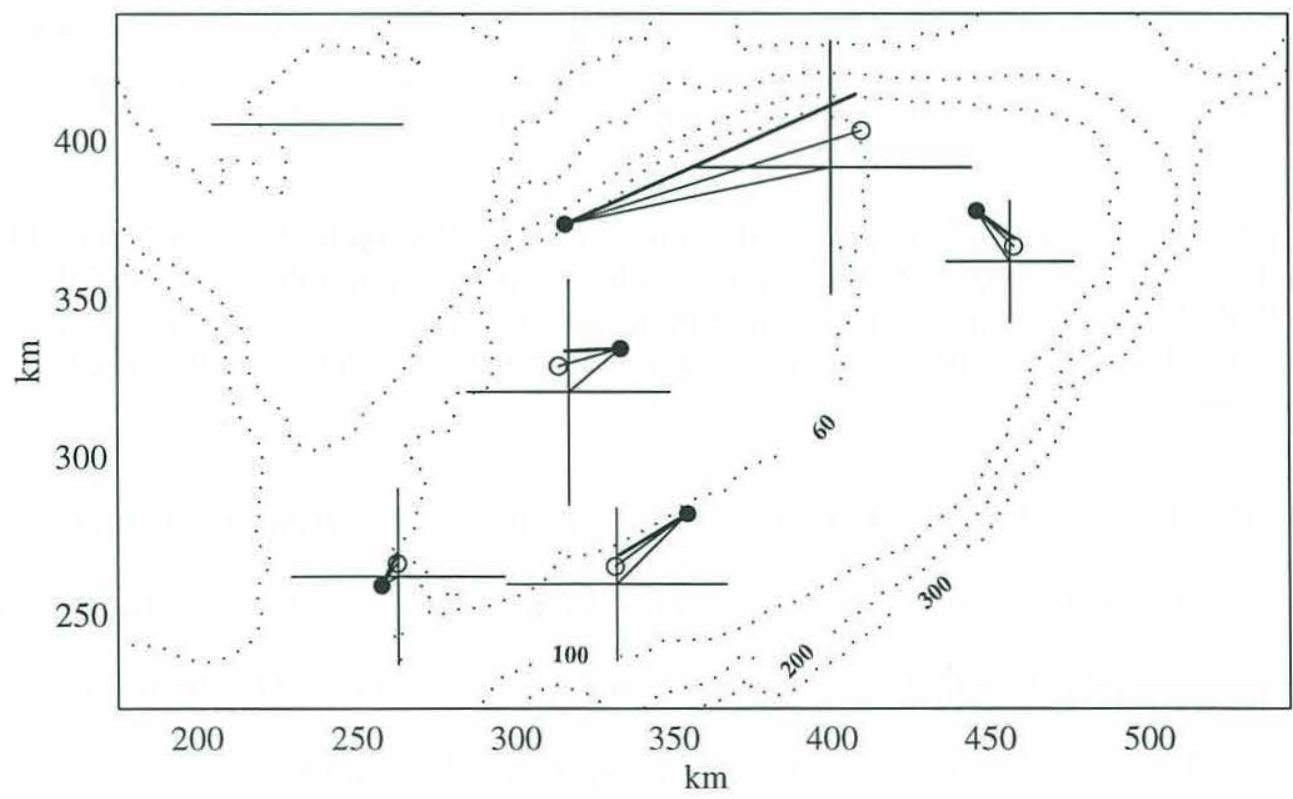

Figure 4.8B: Magnitude, variance, and direction of modeled currents at stations 1-5 for the 1978 model year. Labeling conventions identical to Figure 4.8A. 


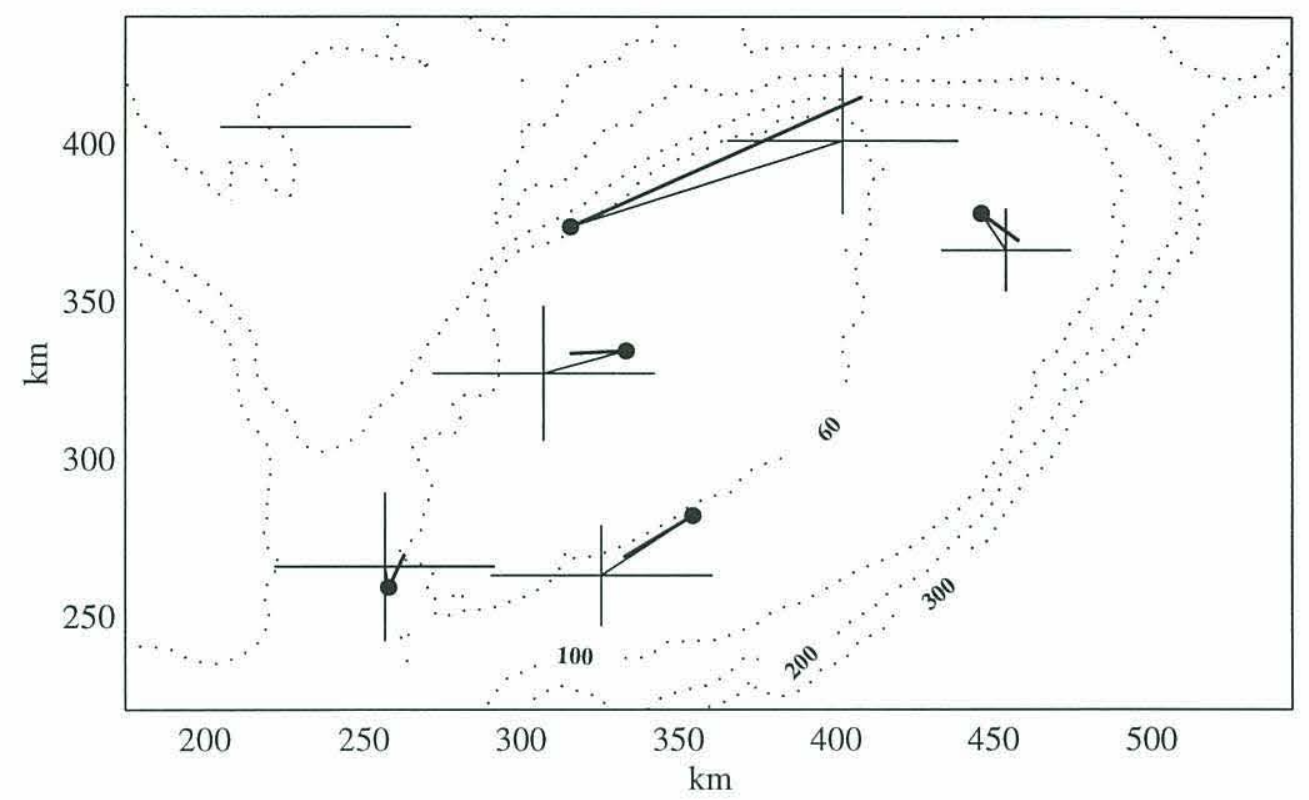

Figure 4.8C: Magnitude, variance, and direction of modeled currents at stations 1-5 for the 1991 model year. Labeling conventions identical to Figure 4.8A; no vector-averaged wind case was simulated for this year.

Modeling wind forced response to 1974 synoptic winds gave results similar to the two vector-averaged runs. In 1974 there were very few major wind events of sufficient strength to strongly affect the North Flank jet at station 5 (this jet is produced by tidal rectification along the steep topography; Loder, 1980). Depth-averaged on-bank (across isobath) flow at station 5 never rose above $0.1 \mathrm{~m} / \mathrm{s}$ (Figure 4.9A), and the around-bank (along isobath) residual flow at this station was reversed only once, reaching $-0.015 \mathrm{~m} / \mathrm{s}$. Wind events occasionally produced noticeable variations in the surface currents, but variation in the direction and magnitude of the depth-averaged, tidal residual flow was less frequent, typically weak and of short duration (Figure 4.9A). Specifically, the depth-averaged residual flow at station 5 consistently shows a strong North Flank jet that was only occasionally altered by episodic wind forcing. Overall, events in the 1974 synoptic wind forcing drove Ekman flows that failed to penetrate deeply into the water column. 

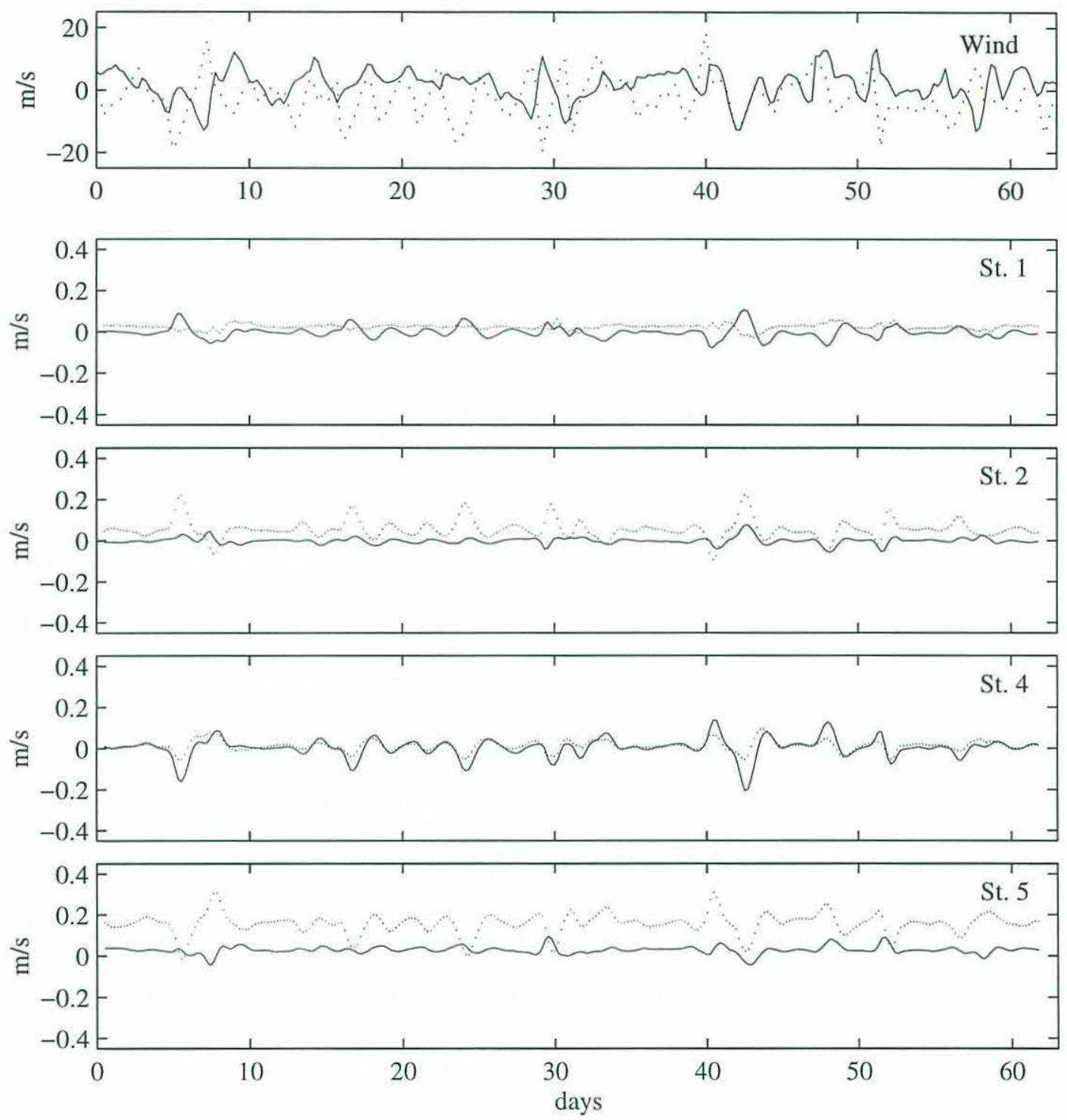

Figure 4.9A: East (solid) and (North) dotted components of wind forcing for 1974 synoptic model run, and the resulting on- (solid) and around- (dotted) bank flow at four stations on the periphery of the bank. As shown in Figure 4.2, St. 1 is on the Northeast peak, St. 2 is on the South Flank, St. 4 is in the Great South Channel, and St. 5 is on the North Flank. Velocity at time $t$ is the mean of the 96 preceding time steps (one tidal cycle). 



Figure 4.9B: East (solid) and (North) dotted components of wind forcing for 1991 synoptic model run, and the resulting on- (solid) and around- (dotted) bank flow at four stations on the periphery of the bank. 

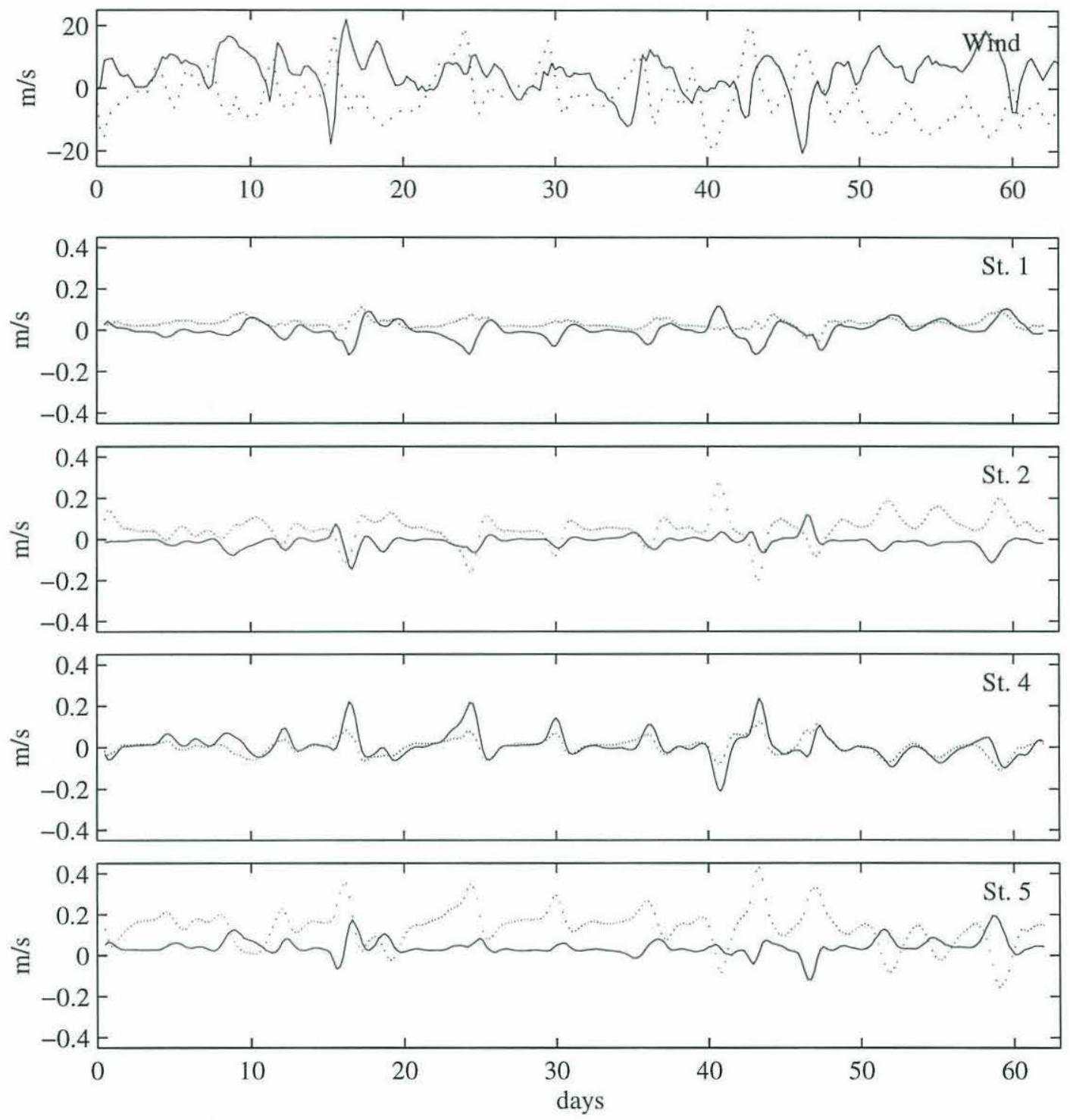

Figure 4.9C: Wind forcing and tidal residual depth-averaged currents at sampling stations for 1978 synoptic forcing run. 
The run using wind forcing from 1991 was intermediate between the other two runs in many ways. Residual, depth-averaged, on-bank flows at station 5 exceeded 0.05 $\mathrm{m} / \mathrm{s}$ several times, and reached $0.12 \mathrm{~m} / \mathrm{s}$ during one storm. The results of the 1991 model run show the effect of several more prominent storm events, most notably in the last twenty days of the run (Figure 4.9B). Specifically, current structure on days 45 and 55 reveal the effects of strong winds from the south and from the north. On day 45 , strong south winds caused a noticeable increase in eastward flow, doubling around-bank flow at station 5 and reversing the around-bank current at station 2 on the South Flank. In contrast, on day 55 a period of strong north winds reversed the North Flank jet and markedly increased flow along the South Flank. Flow at stations 1 and 4 (in the Northeast Peak and Great South Channel) was more sensitive to wind events, with station 4 showing the most sensitivity. The lack of pronounced tidally driven flow in these regions allowed the wind forced response to dominate, with the amplitude of the wind forced response being slightly greater in the Great South Channel.

By contrast, 1978 winds drove on-bank flows at station 5 up to $0.20 \mathrm{~m} / \mathrm{s}$, with many periods where on-bank flow exceeded $0.05 \mathrm{~m} / \mathrm{s}$. In addition, there were five separate wind events in this year during which the depth-averaged flow at this station was reversed, reaching a maximum depth-averaged speed of $0.16 \mathrm{~m} / \mathrm{s}$ in the counterclockwise direction. The 1978 synoptic wind forced model contains the largest number of strong wind events, and also shows much greater variation in on-bank flow on the North and South Flanks. Storm events repeatedly penetrated deep into the water column on the bank, causing residual surface current velocities to reach $0.5 \mathrm{~m} / \mathrm{s}$ over the central and southern flank of Georges Bank where the surface tidal component was typically less than $0.1 \mathrm{~m} / \mathrm{s}$. The flow in the Northern bank jet (station 5) was completely disrupted 
several times (notably around days 10,15-20 and 40-60; Figure 4.9C). A period of north winds on days 39-41 (Figure 4.4) resulted in a broad, relatively uniform southwesterly flow by day 41 that affected the depth-averaged flow field (Figure 4.10); however, by day 46 a period of strong east winds had turned the depth-averaged flow sharply northward (Figure 4.11).
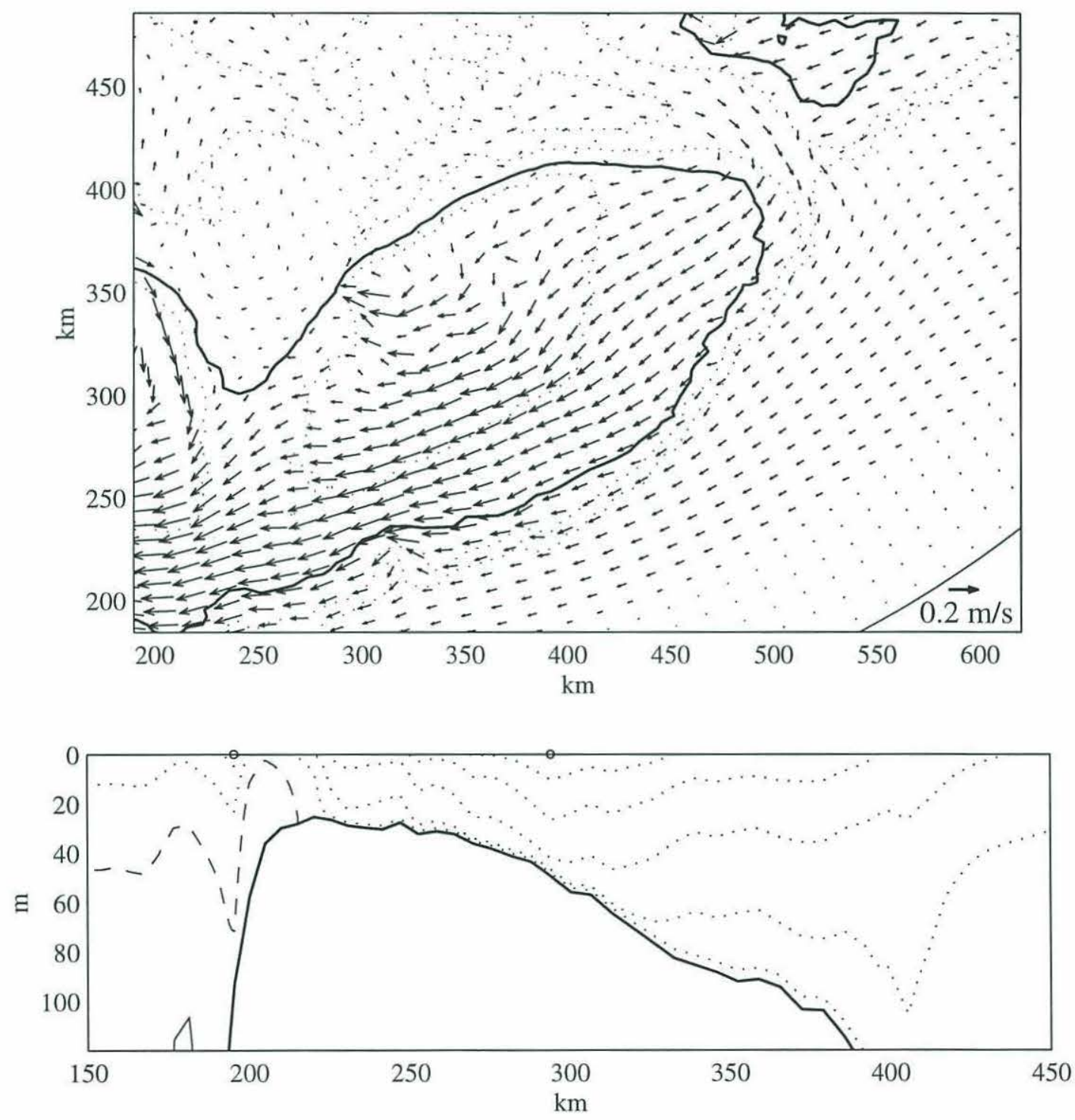

Figure 4.10: Day 41 of the 1978 synoptic run. (Top) Depth-averaged tidal residual currents. Bold line indicates 100 meter isobath (Bottom) Contour plot of velocity (normal to section shown in Figure 4.13). Labeling conventions as Figure 4.5. 

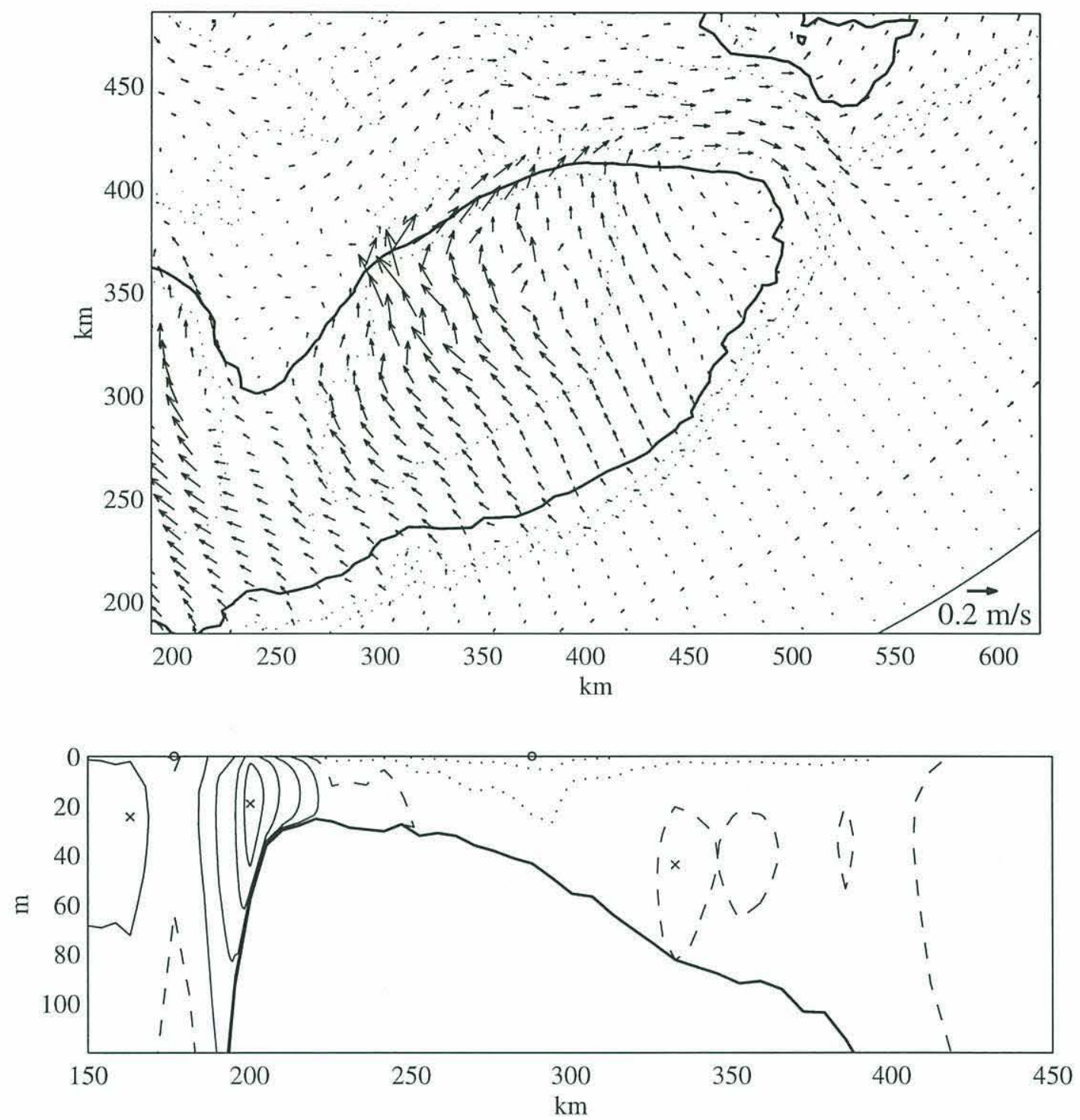

Figure 4.11: Day 46 of the 1978 synoptic run. (Top) Depth-averaged tidal residual currents. Bold line indicates 100 meter isobath (Bottom) Contour plot of velocity (normal to section shown in Figure 4.13). Labeling conventions as Figure 4.5.

In the model runs considered here, one period stands out as the most noticeable event to affect transport and current variability on Georges Bank, namely days 38 to 60 in the 1978 model run (approximately January 17 through February 8, 1979). During this period, consistently strong northeast winds caused tidal residual depth-averaged flow at station 5 to reverse and reach speeds of $0.16 \mathrm{~m} / \mathrm{s}$ in the opposite direction, with 
corresponding on-bank flows of $0.19 \mathrm{~m} / \mathrm{s}$. During this period the on-bank surface component briefly exceeded $0.4 \mathrm{~m} / \mathrm{s}$ and the time course of the on-bank and along-isobath velocity structure on the North and South Flanks of Georges Bank revealed the strong effect of time dependent wind forcing on the flow (Figure 4.12A,B).
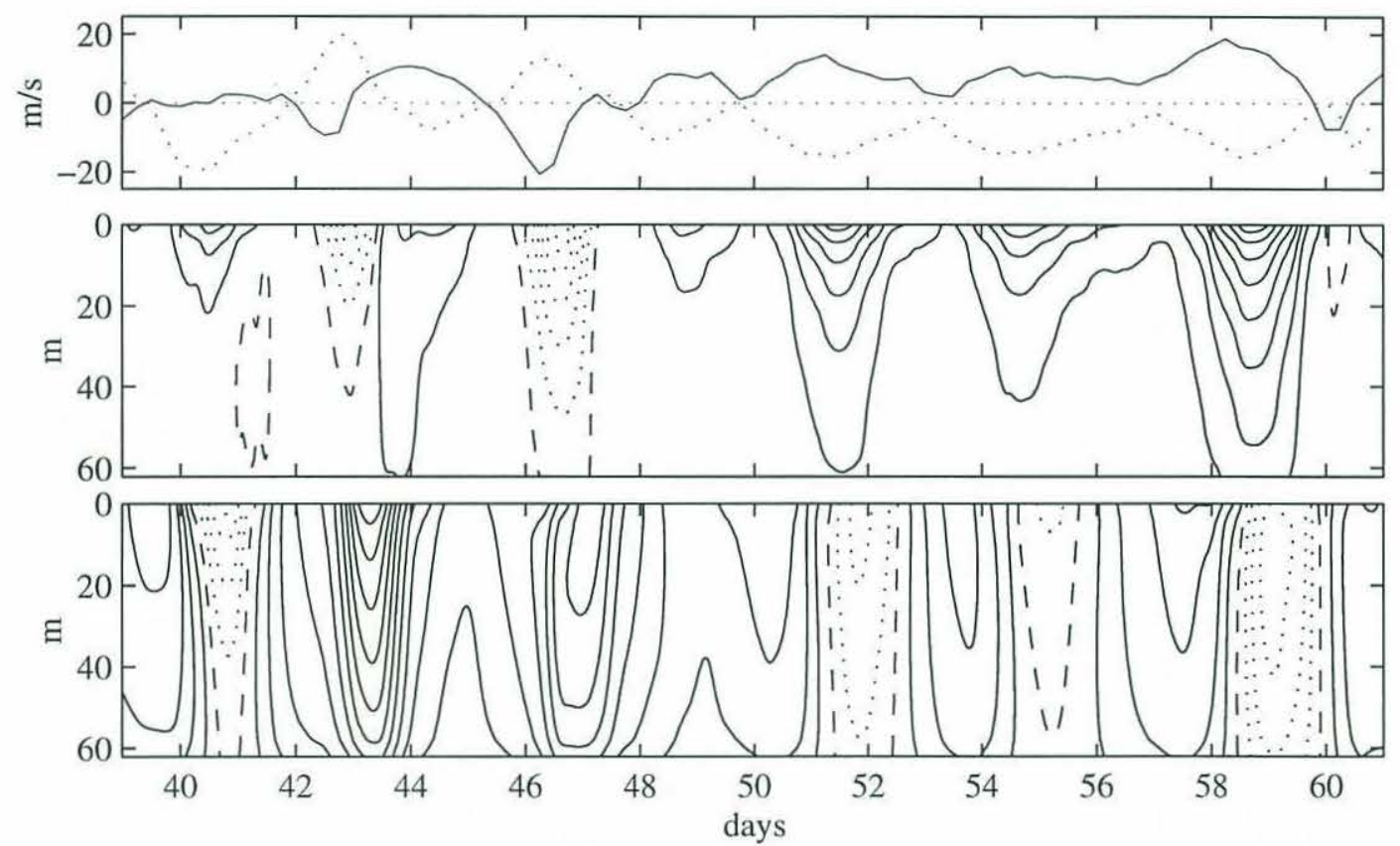

Figure 4.12A: (Top Panel) U (solid) and V (dotted) components of wind and time. Depth distribution of residual (Middle Panel) on-bank and (Bottom Panel) around-bank velocity at station 5 on the North Flank. Contour interval is $0.05 \mathrm{~m} / \mathrm{s}$, with positive isopleths solid, the zero isopleth dashed and negative isopleths dotted.

The comparison of current patterns resulting from the synoptic and vectoraveraged runs highlights the effect of episodic wind events in driving short term variability in currents. The effect of variability on the overall transport of tracer quantities, whether they be physical, chemical, or biological tracers, is a nonlinear product of such short term variability. 

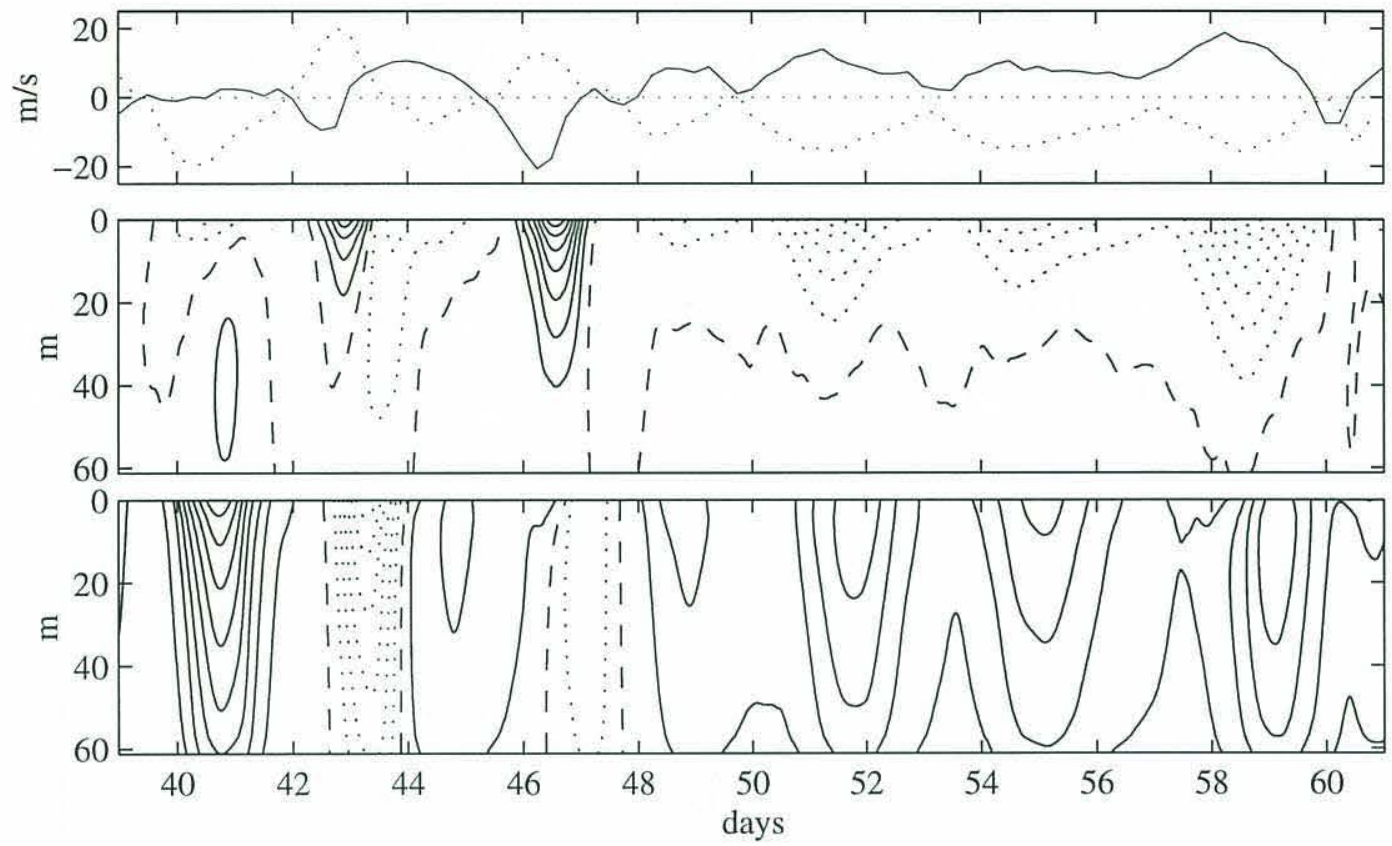

Figure 4.12B: (Top Panel) U (solid) and V (dotted) components of wind and time. Depth distribution of residual (Middle Panel) on-bank and (Bottom Panel) around-bank velocity at station 2 on the South Flank. Contour interval is $0.05 \mathrm{~m} / \mathrm{s}$, with positive isopleths solid, the zero isopleth dashed and negative isopleths dotted.

\section{Transport}

Transport through four sections (shown in Figure 4.13) was calculated and compared to results and data from other work (Naimie et al., 1994; Naimie, 1996). For each run, the time average of velocity over two tidal cycles was integrated over the section area at five day intervals and compared to relevant results from other work are also given (Table 4.2).

For tidal and steady wind forcing, the transport through the four sections reveals strong similarities between these results and those of others modeling the region. The unstratified model used here, with purely tidal forcing, most closely resembled the unstratified, tidally forced models of Naimie, et al. (Naimie (1996) unstratified case and Naimie et al. (1994) unstratified case and January-February case without density 
forcing). Naimie's results show a stronger flow along the Northeast Peak, due perhaps to the imposed large scale pressure field in that model. This is also a region where the bank water begins to adjoin slope waters, and stratification effects drive some of the differences observed between this model and other models. In general the flow fields are very similar, and the transport calculations provide a good summary of the effects of wind forcing in the various regions of the bank.

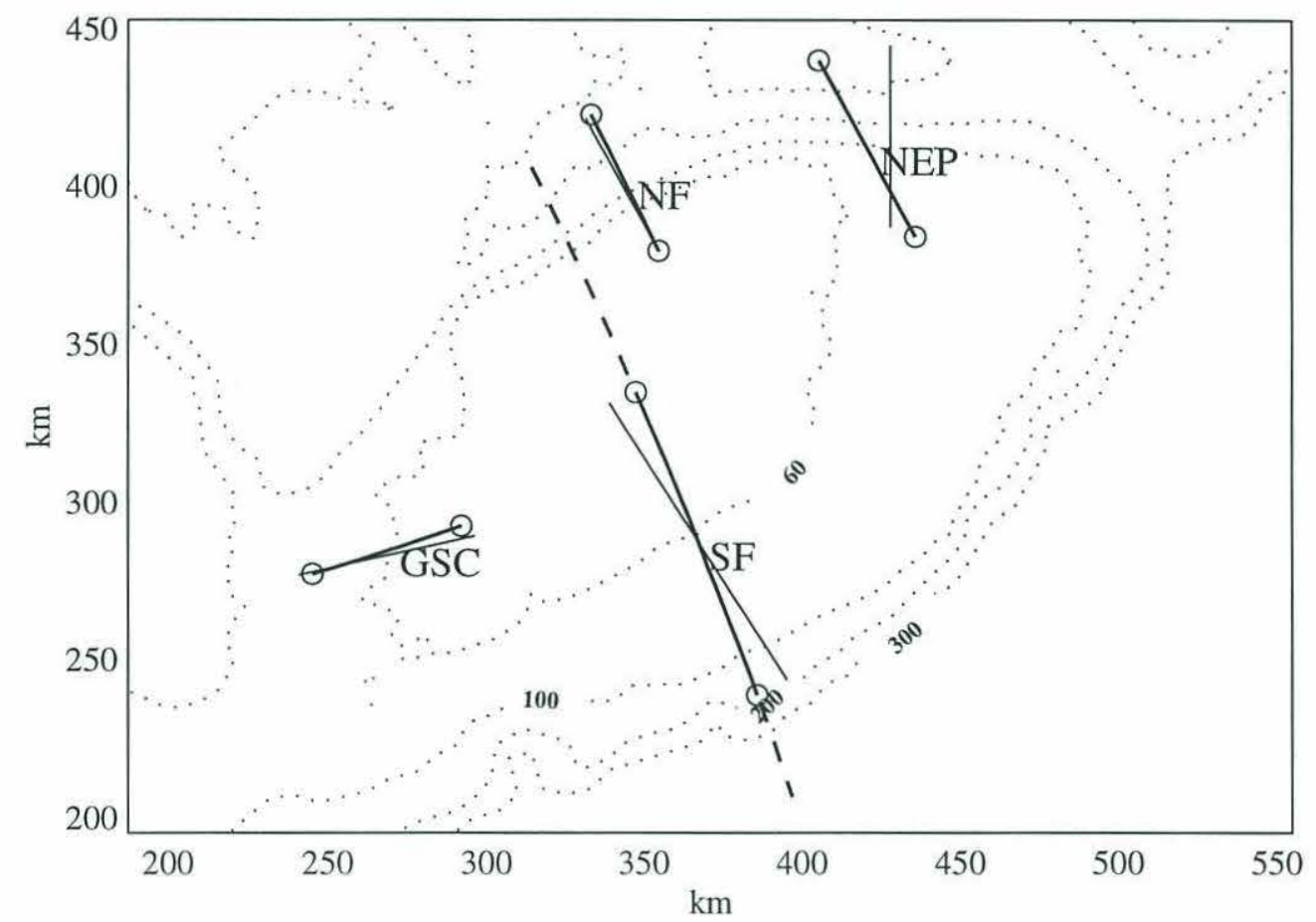

Figure 4.13: Sections through which transport was calculated for this model (solid lines ending in circles), other models (solid lines), and section line for slice plots (dashed line).

On the North Flank, wind-driven Ekman transport opposed the tidal residual, causing a decrease in transport in all cases and the reversal of a transport for the 1978 synoptic run (Table 4.2). The 1991 synoptic run showed only a very slight decrease in transport in this region and, despite the fact that average winds were higher than those in 1974, the North Flank transport was similar in these two years. The difference between 
the vector-averaged and synoptic runs is most notable in this region, i.e. the mean transport in the synoptic run is in the opposite direction and twice the magnitude of the mean from the vector-averaged run. In general, the net transport to the southwest results from flows in the deeper waters of the Gulf of Maine and over the shallowest sections of the bank, while the flow within the jet follows the clockwise circulation around the bank. The variance in the transport increased with mean wind speed.

Table 4.2: The magnitude, variance and range of the transport through the four sections shown in Figure 4.13. Synoptic results are shown as magnitude \pm variance and $\{\min ., \max$.$\} . All values are in \mathrm{Sv}$, with positive values indicating anticyclonic circulation. The four columns represent the transport through the North Flank (NF), South Flank (SF), Great South Channel (GSC), and the Northeast Peak (NEP). Tidal refers to the run using only tidal forcing. $1974 \mathrm{~m}$ and $\mathbf{1 9 7 8 m}$ were runs using vector-averaged mean wind forcing for the respective years, and 1974s, 1978s, and 1991s refer to runs using synoptic wind forcing for those years. NLL94 and N96 are results from Naimie, et al 1994 and Naimie 1996 respectively. U and S are unstratified and stratified cases; N96 MA-O refers to an estimate based on observational data taken from Naimie (1996). JF and MA refer to January-February and March-April simulations.

\begin{tabular}{l|cccc}
\hline & NF & S F & GS C & NEP \\
\hline Tidal & 0.13 & 0.28 & 0.07 & 0.08 \\
\hline $\mathbf{1 9 7 4} \mathbf{m}$ & 0.12 & 0.31 & 0.07 & 0.06 \\
\hline $\mathbf{1 9 7 8} \mathbf{m}$ & 0.06 & 0.33 & 0.06 & -0.01 \\
\hline $\mathbf{1 9 7 4} \mathrm{T978s}$ & $0.05 \pm 0.11$ & $0.35 \pm 0.29$ & $0.06 \pm 0.03$ & $-0.00 \pm 0.15$ \\
& $\{-0.11,0.24\}$ & $\{-0.09,0.96\}$ & $\{0.02,0.13\}$ & $\{-0.20,0.27\}$ \\
\hline $\mathbf{1 9 9 1 s}$ & $-0.10 \pm 0.34$ & $0.53 \pm 0.57$ & $0.04 \pm 0.09$ & $-0.08 \pm 0.44$ \\
& $\{-0.75,0.37\}$ & $\{-0.44,1.74\}$ & $\{-0.12,0.19\}$ & $\{-0.87,0.67\}$ \\
\hline NLL94 U & $0.11 \pm 0.24$ & $0.30 \pm 0.41$ & $0.06 \pm 0.05$ & $0.06 \pm 0.28$ \\
\hline N96 U & $\{-0.40,0.60\}$ & $\{-0.56,1.02\}$ & $\{-0.05,0.15\}$ & $\{-0.61,0.48\}$ \\
\hline NLL94 JF-U & 0.13 & 0.17 & 0.07 & 0.24 \\
\hline NLL94 JF-S & 0.11 & 0.14 & 0.06 & 0.17 \\
\hline NLL94 MA-S & 0.19 & 0.22 & 0.09 & 0.35 \\
\hline N96 MA-S & 0.33 & 0.51 & -0.00 & 0.62 \\
\hline N96 MA-O & 0.25 & 0.42 & 0.01 & 0.58 \\
\hline
\end{tabular}

On the South Flank of the bank, the mean northwest winds serve to reinforce the flow and increase the transport and the synoptic winds augment this process. However, despite the fact that the 1991 vector average is stronger than and roughly parallel to the 1974 average, the 1991 synoptic run showed weaker mean flows over the south flank 
than the 1974 run.

The orientation of the Great South Channel section made it relatively insensitive to variation in wind forcing from the northwest, and transport through this section remained low and relatively similar in all three wind cases. Only in 1978 was the variance in transport greater than the mean transport at this section.

The trends in transport through the Northeast Peak section differ markedly from the other sections; in 1991 the net transport through this section was to the west, while both other years showed a slight eastward transport, consistent with the background tidal circulation.

The calculation of mean transport through the various sections reveals a number of basic trends. First, the use of synoptic scale wind forcing gave markedly different results than did the use of vector-averaged wind forcing. Second, while the mean wind forcing for 1991 had a direction similar to and a magnitude intermediate to those of 1974 and 1978, the resultant modeled mean transport was not intermediate. Rather, the 1991 transports were most similar to both vector-averaged and the purely tidal results. Third, the variation in transport due to variable winds was of similar magnitude to the mean transport, and frequently exceeded it; reversal of the net transport through a section was common in the course of a run with time varying, synoptic wind forcing.

\section{Tracer Transport}

The transport of modeled tracer fields, like the currents, had similar final distributions between the mean wind cases and the 1974 and 1991 synoptic cases, but the transport of tracer in the 1978 synoptic case differed markedly from any of the others. 
The mean wind forcing for 1974 and 1978 (Figure 4.17) and the 1974 (Figure 4.14) and 1991 (Figure 4.16) synoptic wind forcing were generally not strong enough to drive tracers out of the weak Georges Bank recirculation pattern, whereas considerable losses of tracer off the south flank of the bank did occur in the 1978 synoptic case (Figure 4.15). The period of consistent, strong northwest winds at the end of the 1978 case caused a noticeable increase in the off-bank transport and decrease in retention of many of the fields.

The time course of tracer transport can be approximated by tracking the center of mass of each tracer distribution (Figure 4.18). Comparing the 1978 mean wind case (panel D) with the synoptic cases (panels A-C) highlights the lack of high frequency variability in the mean wind forcing. Using vector-averaged winds causes the location of the centroid to proceeds smoothly around the bank, largely directed by tidally driven circulation. In the synoptic cases the motion is much more reflective of transient wind events, with quick jumps and longer periods of little net motion. In some cases the fields split into two distinct patches (notably fields 1 and 2), making the centroid a poor indicator of field position. However, most fields remained cohesive for the entire run.

The centroid tracks provide some indication of the problems involved in using mean wind forcing to model transport; the 1978 synoptic case diverged markedly from the other three simulations, including the 1978 mean. The 1974 mean case underestimated the transport of the tracer on the southern flank of Georges Bank (where wind forced circulation dominated the flow) when compared to the 1974 synoptic case. 

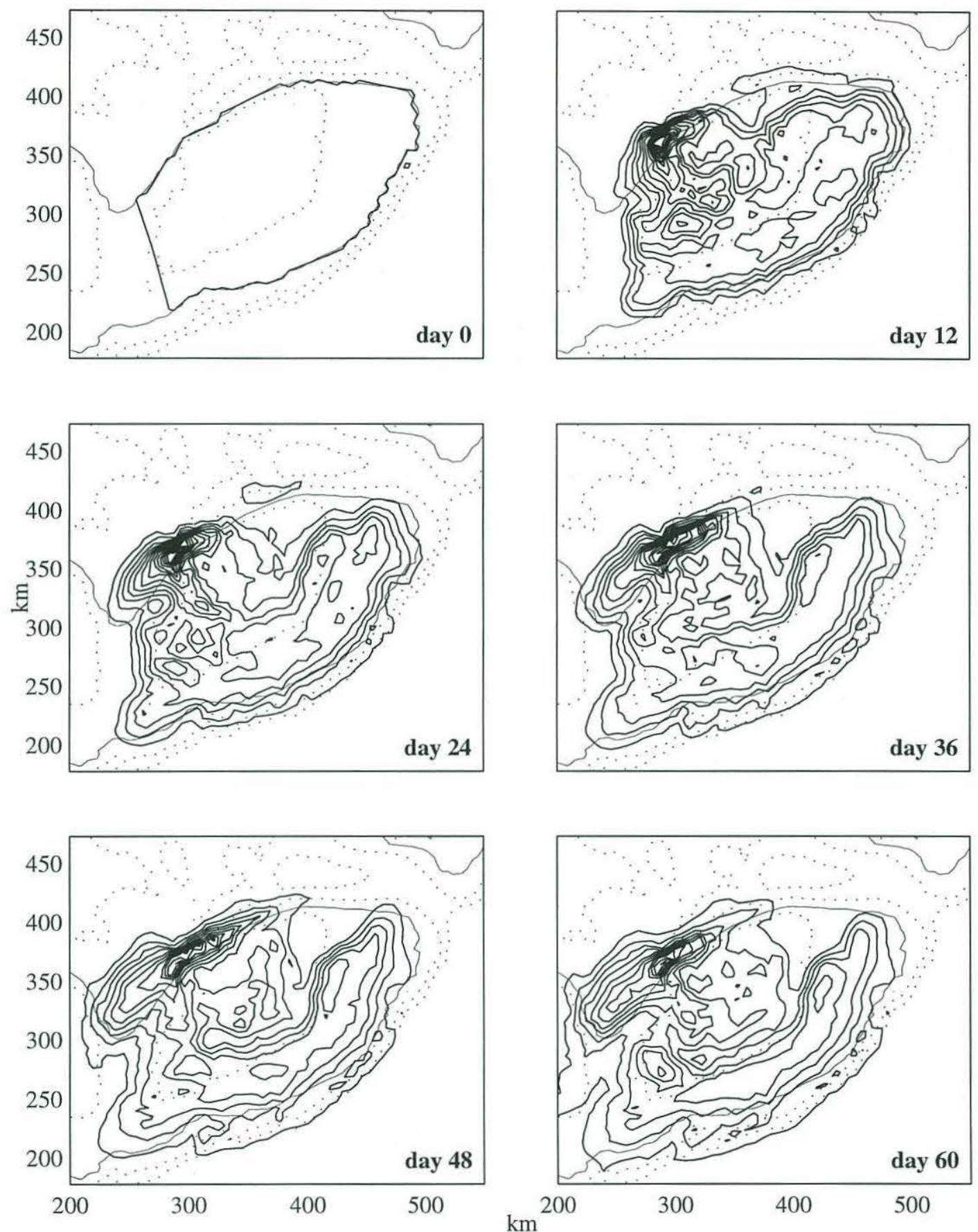

Figure 4.14: Time course of fields 1-9 over the bank during the 1974 synoptic model run. Light line indicates $100 \mathrm{~m}$ isobath; dotted lines indicate 60, 200 and 300 meter isobaths. Contour interval $=$ 0.2 for all plots after day 0 . 

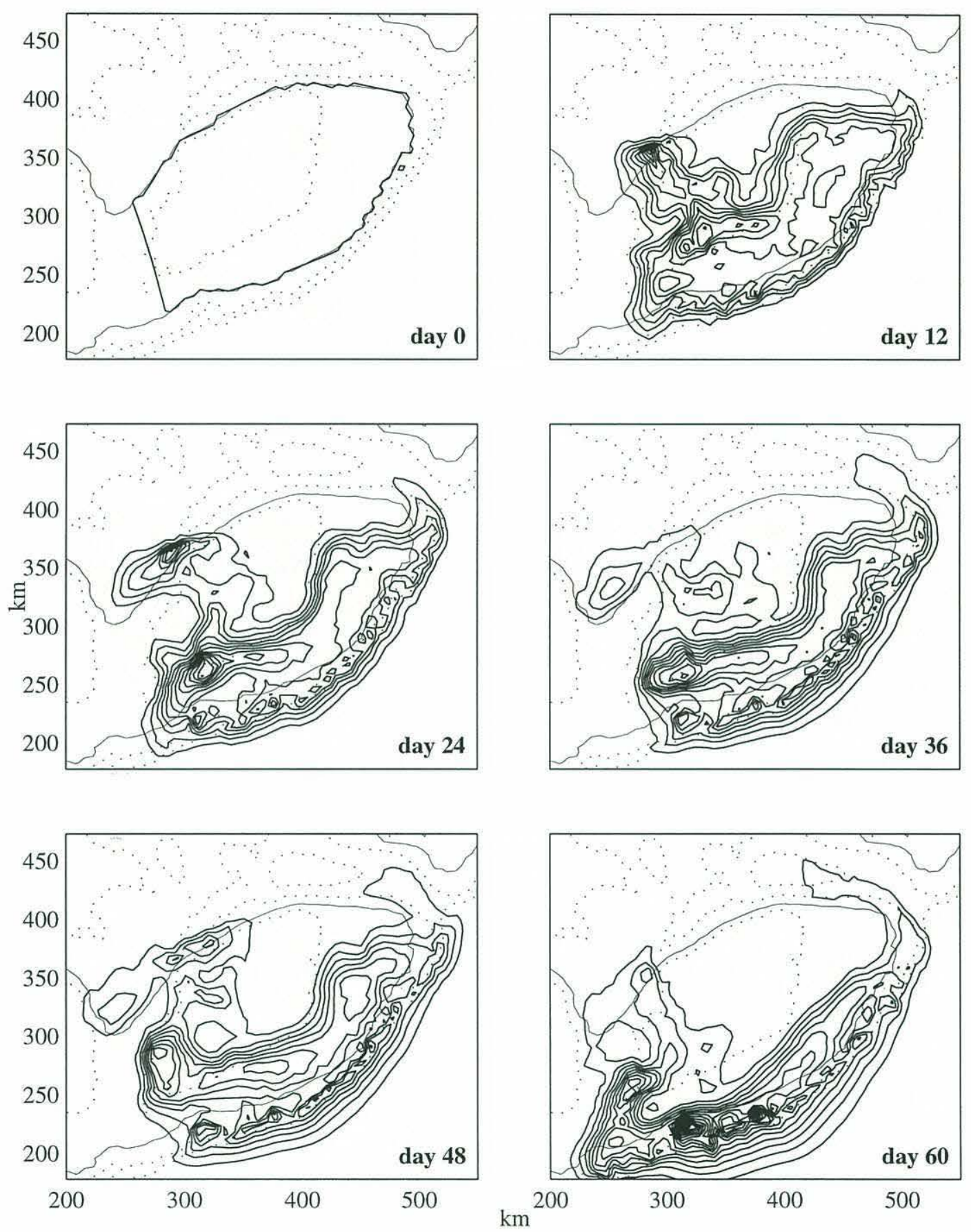

Figure 4.15: Time course of fields 1-9 over the bank during the 1978 synoptic model run. Light line indicates $100 \mathrm{~m}$ isobath; dotted lines indicate 60,200 and 300 meter isobaths. Contour interval $=$ 0.2 for all plots after day 0 . 

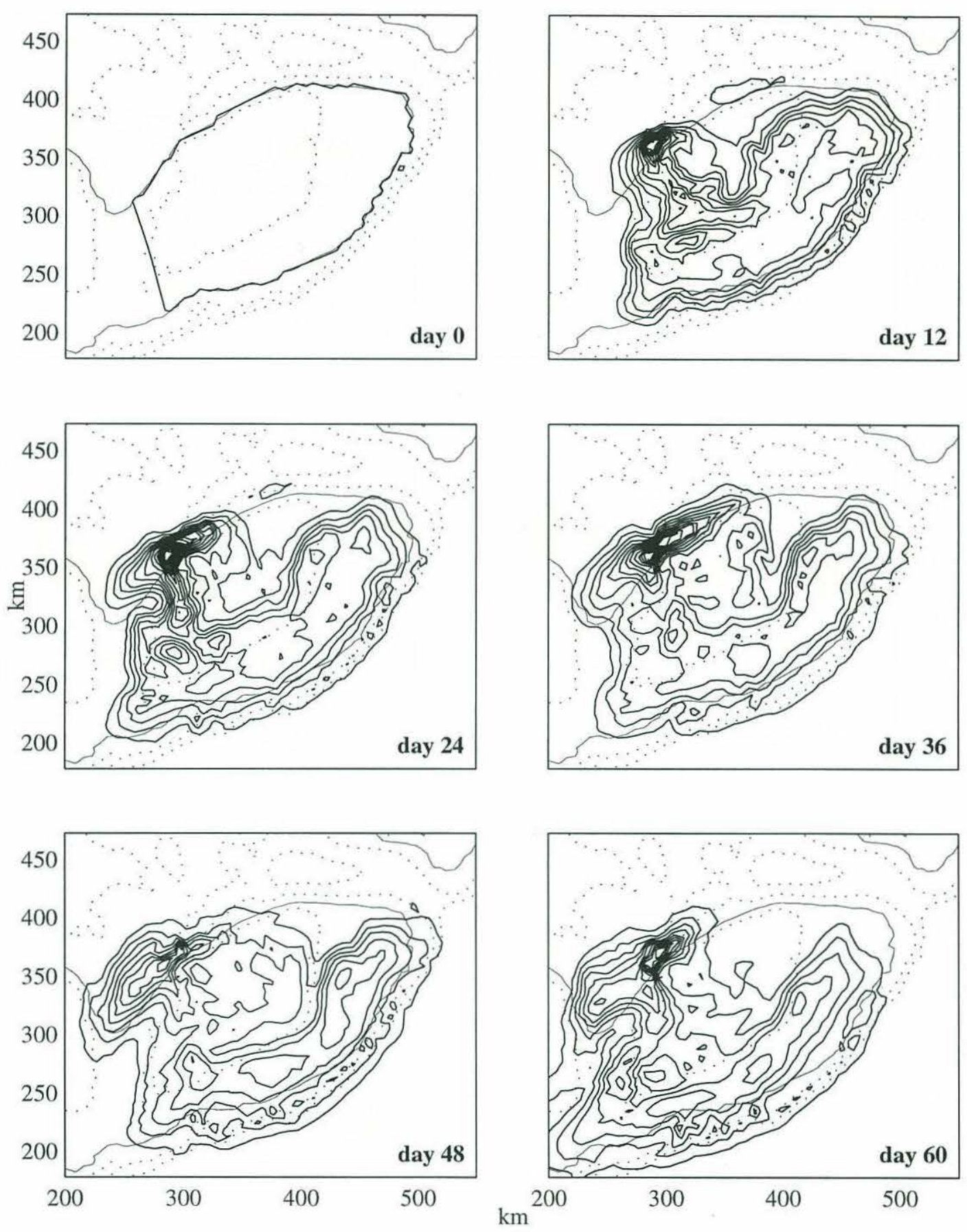

Figure 4.16: Time course of fields 1-9 over the bank during the 1991 synoptic model run. Light line indicates $100 \mathrm{~m}$ isobath; dotted lines indicate 60,200 and 300 meter isobaths. Contour interval $=$ 0.2 for all plots after day 0 . 

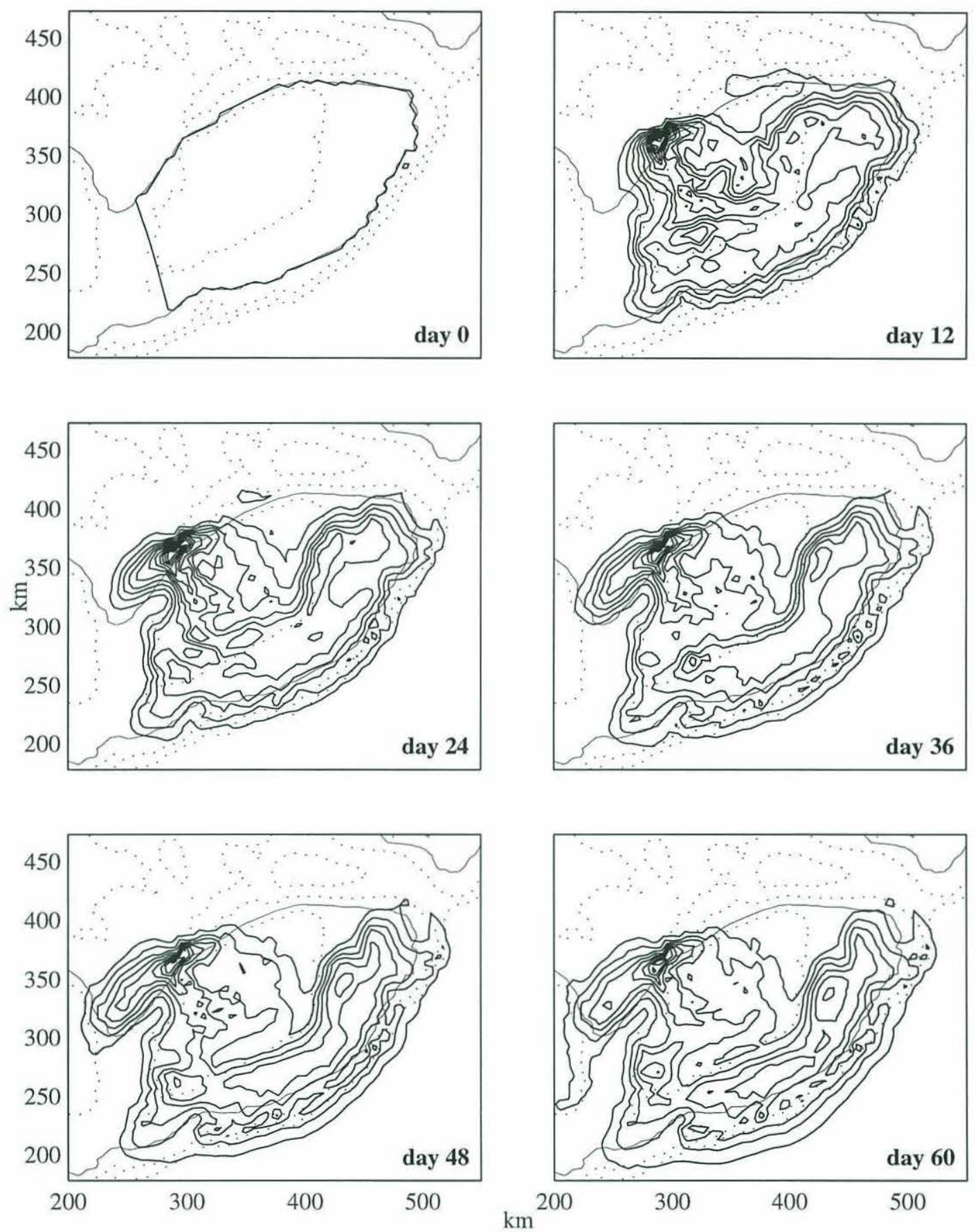

Figure 4.17: Time course of fields 1-9 over the bank during the 1978 mean model run. Light line indicates $100 \mathrm{~m}$ isobath; dotted lines indicate 60,200 and 300 meter isobaths. Contour interval $=$ 0.2 for all plots after day 0 . 

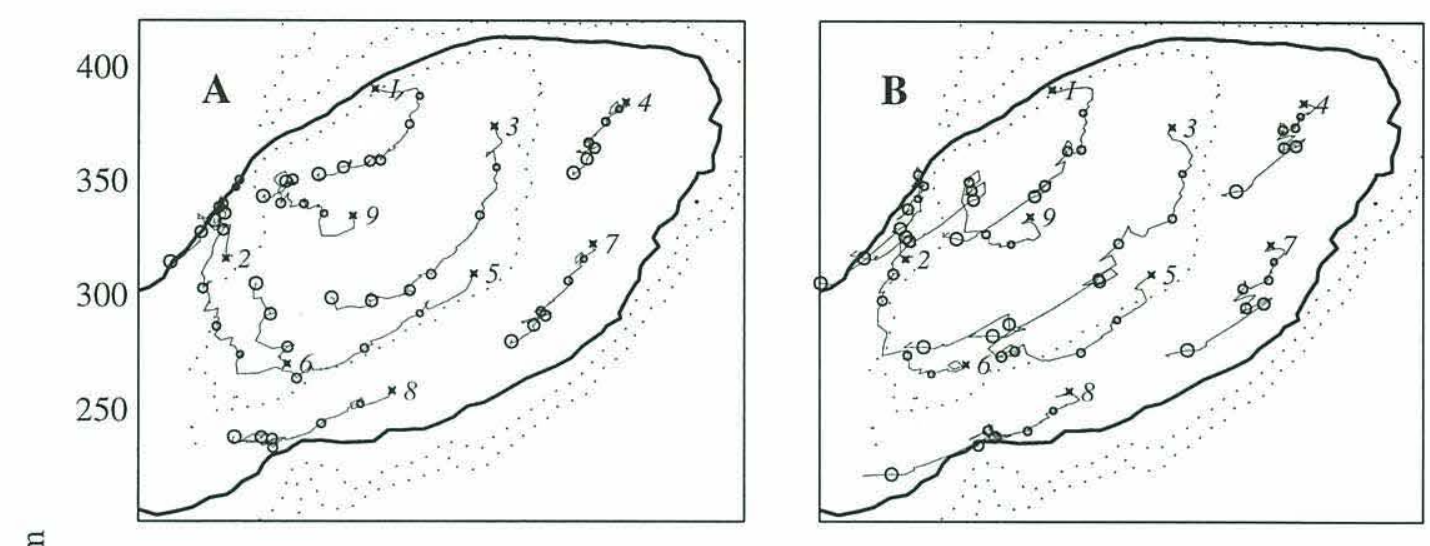

$\underline{\text { E }}$


$\mathrm{km}$

Figure 4.18: Tracks of centroids of fields 1-9 for A) 1974 synoptic, B) 1991 synoptic, C) 1978 synoptic and D) 1978 mean. The tracks originate at numbered points marked with an $\mathbf{x}$, and a circle of increasing size is used to denote 10 day intervals along the track.

One notable distinction in the 1978 centroid tracks is the marked initial jump in the position of the centroid over the course of the first ten days. Despite the relatively low level of wind forcing during the first twenty days, all on-bank fields show a sharp displacement over that period, possibly because of the consistency, in both direction and velocity, of the winds during this period. 


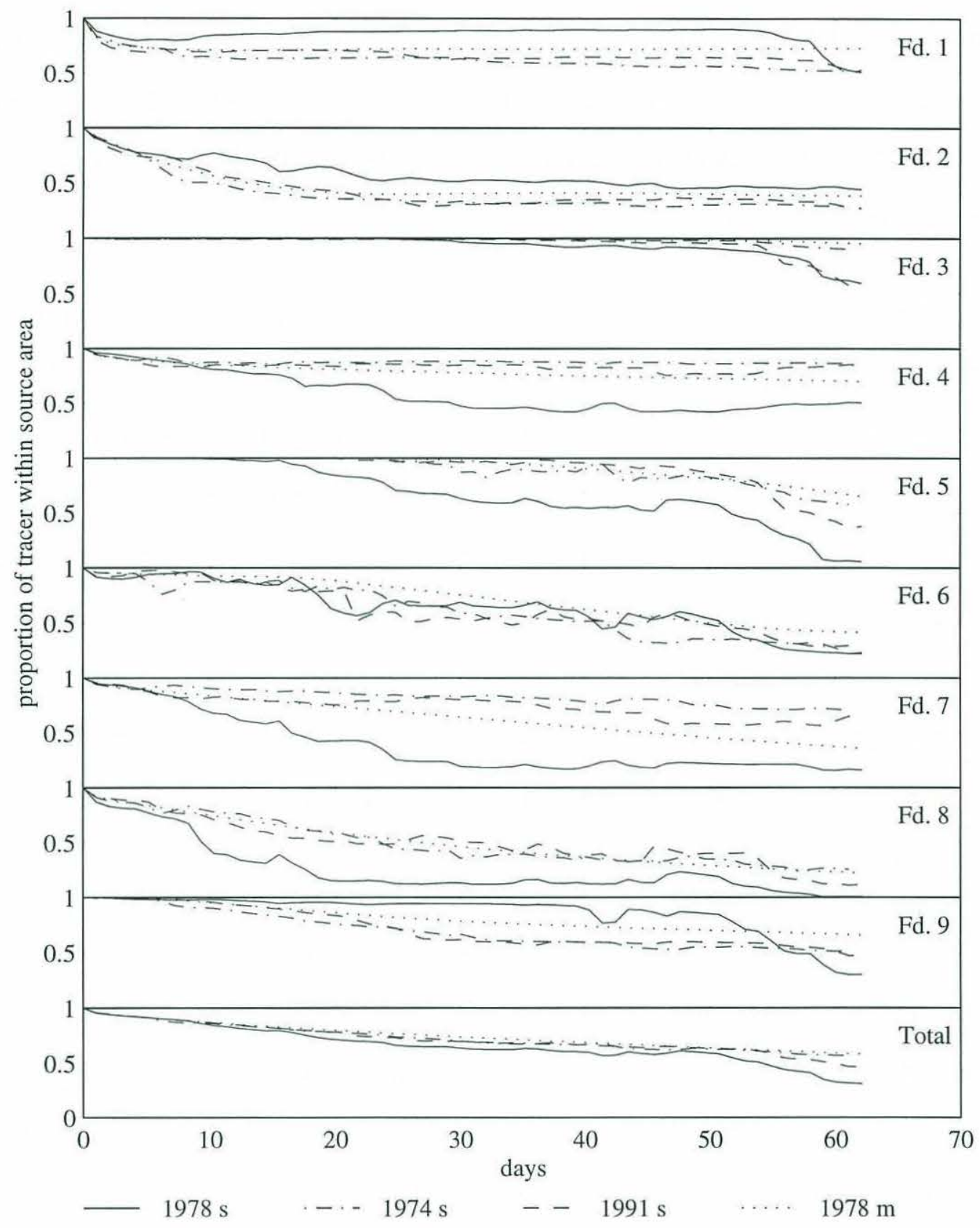

Figure 4.19: Proportion of tracer remaining within the 100 meter isobath for each of the 3 synoptic runs and the 1978 vector-averaged run. Each panel shows the retention for one field; the final panel shows the overall retention for all fields over the bank.

Another indicator of transport is time course of retention of tracers on the bank, i.e. the proportion of the tracer that remained within the $100 \mathrm{~m}$ isobath at any given time 
(Figure 4.19). The initial burst of displacement shown by the centroid tracks for 1978 is not evident within this time series, except for the southernmost fields. The strong winds at the end of the 1978 run are reflected in a sharp increase in the loss rates during the last ten days of the simulation.

Field 1, originating in the northern flank jet, was consistently blown onto the bank, diffusing broadly and generally over a wide region of the bank crest. The behavior of this tracer field was shaped by its long, narrow initial distribution that made it susceptible to rapid diffusion and divergence. In every case the field split, with roughly equal portions going north and south. The northern portion was carried into a slow westward trending flow in the Gulf of Maine, while the southern portion tended to be trapped on the bank crest. In the 1978 synoptic case the tracer was carried well across the bank, ending between the 80 and 100 meter isobath on the south flank after 60 days. In every model run, the retention of this tracer was high due to the consistent Ekman transport onto the bank by prevailing northwest winds.

The westernmost portion of the bank, Field 2, had little sensitivity to wind forcing. In every case the majority of the tracer was carried into the northern end of Great South Channel, with a small plume being swept onto the bank crest. The patch in the Great South Channel spilled slowly onto Nantucket Shoals and was carried southwest. Overall retention of field 2 was low but consistent between runs.

Tracer from the bank crest, Field 9, was captured by the recirculating flow at the western edge of the bank in all but the 1978 synoptic case. In 1978, the winds were strong enough to push this field off the bank crest, through the recirculating gyre and onto Nantucket shoals. 

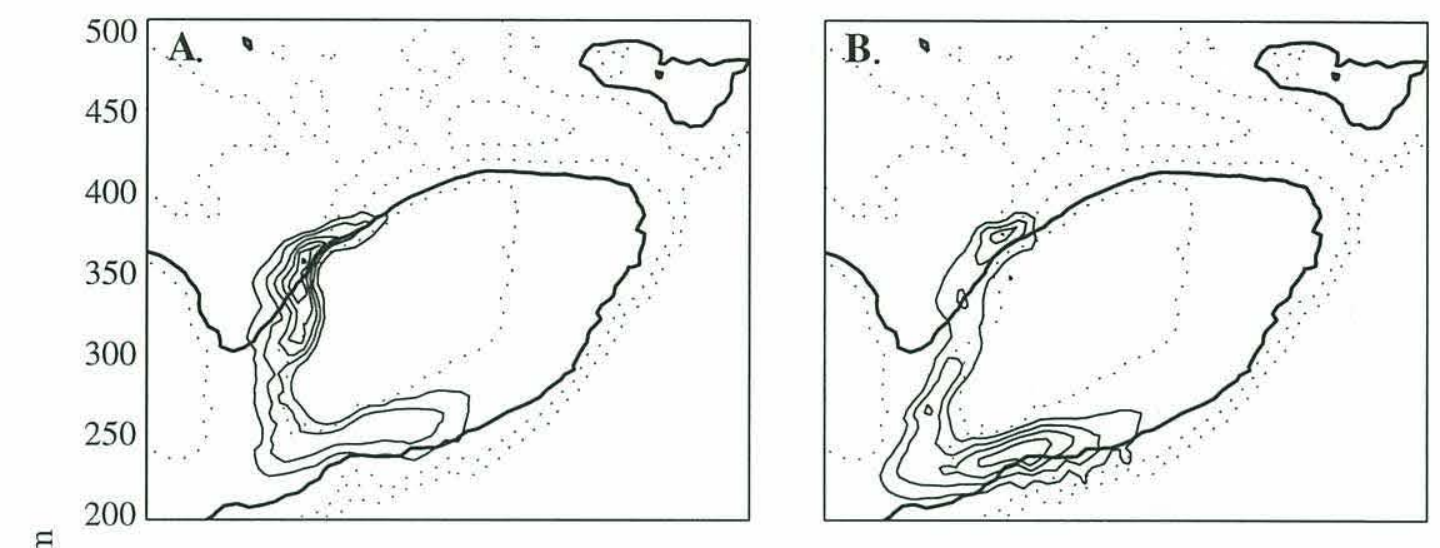

泉
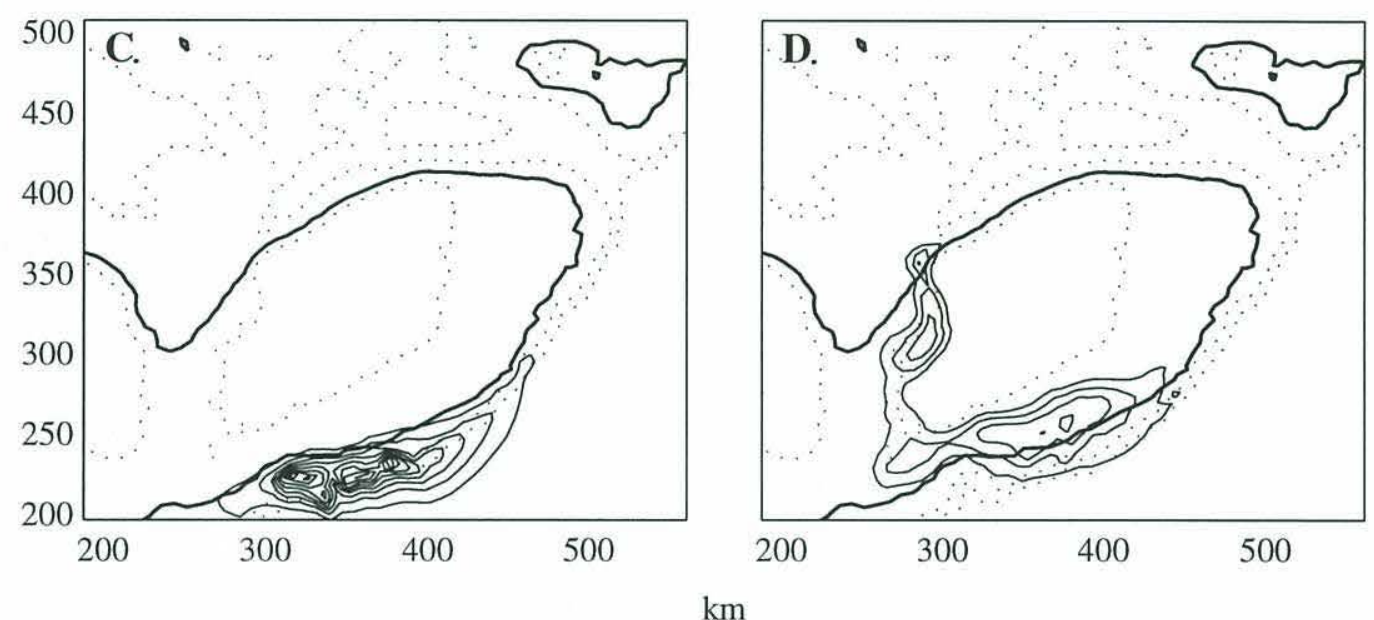

Figure 4.20: Distribution of tracer field 5 after 60 days of wind forcing for each of four runs (1974

synoptic (A), 1991 synoptic (B), 1978 synoptic (C), and 1978 mean (D)). Bold line indicates 100 $\mathrm{m}$ isobath; dotted lines indicate 60, 200 and 300 meter isobaths.

In contrast, tracer from the eastern half of the bank crest and the Northeast Peak, fields 3 and 4, remained on the bank. The bulk of both fields was swept along the southern flank by the tidal and wind driven flow. In the course of 60 days, both tracer fields were largely retained over the bank. Strong south winds drove plumes from field 4 into the deep water of the Northeast channel where it was swept into the Gulf of Maine by prevailing currents. Field 3 showed signs of being swept from the bank in the 1978 synoptic case; this is evidenced in the sharp dip in the retention plot (Figure 4.19). In all but the 1978 synoptic run a portion of field 3 reached the recirculating region on the 
western edge of the bank and was carried north in the Great South Channel.

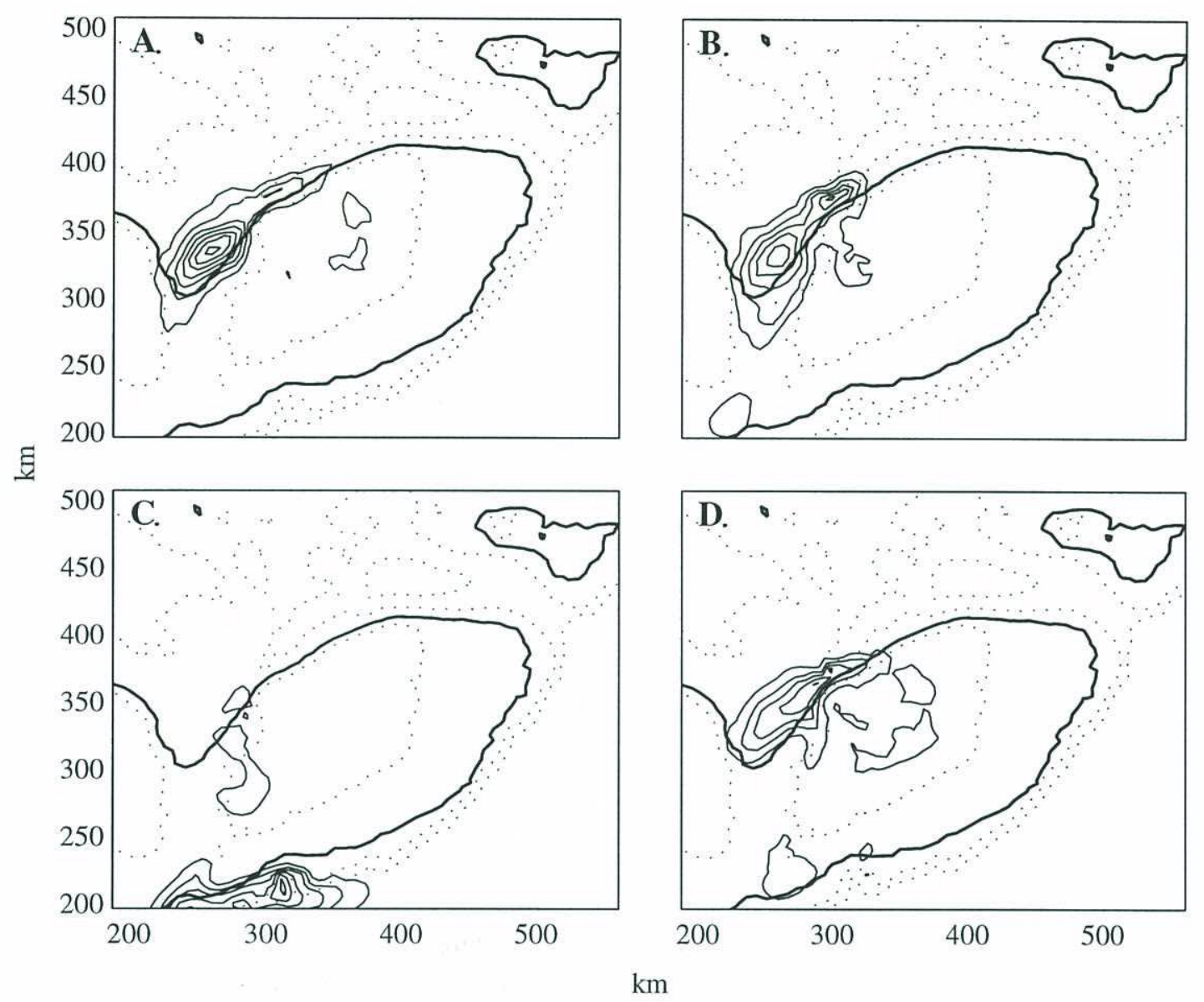

Figure 4.21: Distribution of tracer field 6 after 60 days of wind forcing for each of four runs (1974 synoptic (A), 1991 synoptic (B), 1978 synoptic (C), and 1978 mean (D)).

Fields 5 and 6 showed the greatest sensitivity to strong synoptic variability. In each case, synoptic winds from 1978 forced the bulk of the tracer off the southern flank of the bank and into deep water, while the vector-averaged winds and 1974 and 1991 synoptic winds allowed the tracer to maintain its presence on the bank through recirculation (Figures $4.19,4.20$ and 21 ). In this case, the calculation of retention within the 100 meter isobath fails to account for the distribution of the tracer. Calculated retention of field 6 in every case is dependent on a broad and diffuse patch that covers 
much of the western half of the bank; the bulk of the tracer is located in a high concentration patch, either to the northwest (1991 and 1974 synoptic and 1974 and 1978 mean) or the southwest (1978 synoptic).

Tracer fields on the extreme southern flank of the bank, originating between the 70 and 100 meter isobath, were uniformly lost off that flank. Fields 7 and 8 were carried southward off the bank in all runs, although a small portion of field 8 entered the recirculating western area in both 1974 simulations.

In order to estimate levels of on-bank flow from neighboring shelf regions, tracers originating in shallow water ( $<100$ meters) areas near the bank were simulated. These fields showed relatively little transport across the northeast channel from Brown's bank, even in the presence of consistent favorable and strong winds (1978 synoptic run days 40-60). However, tracers initiated off the southeast tip of Cape Cod were carried into the northern end of Great South Channel, where they fed into the northern flank and bank crest area.

The transport of tracers and the transport differences between synoptic and vectoraveraged forcing highlights the sensitivity of mesoscale transport models to events on a time scale of days and weeks. By modeling the transport of eulerian tracers over the bank, this work identified basic disparity between the two types of forcing that was not obvious merely from the circulation patterns. Use of a long term mean wind did not predict the results of a realistic wind forcing in the 1978 case.

\section{CONCLUSIONS}

Two major features are apparent from the results of this study. First, with respect 
to the technical requirements of modeling circulation over Georges Bank, it is apparent that synoptic wind forcing has a marked effect on the overall circulation and on the calculated transport of eulerian fields. Second, the model identified several general trends in the circulation around Georges Bank that may have significant effects on the retention of planktonic communities on the bank.

In the comparison of synoptic and mean wind forcing, it is readily apparent from analysis of general circulation and tracer transport that models using vector-averaged wind forcing fail to accurately represent wind effects. The vector-averaged wind forcing misrepresented the transport for five of the ten tracer fields modeled. Trends in the vector averages were not born out by synoptic scale forcing, as the transport results for the 1991 winds did not fall in the range between the low winds of 1974 and the high winds of 1978. In some cases (compare Figures 4.15 and 4.17; also 4.20 and 4.21) mean wind forcing sharply underestimated the net displacement of the tracer when compared to models using synoptic forcing. The use of synoptic forcing had a marked effect on the overall retention and transport of Eulerian tracers over the bank, and the need for using synoptic wind forcing in circulation models of Georges Bank is highlighted by these results.

The difference between the purely tidal flow case and the modeling results of Naimie, et al. indicates that density effects are important and should be included in realistic simulations. The similarity of the flow fields between these models implies that the present model is reasonable for comparing variable wind forcing.

The transport of tracers highlighted three features of the bank circulation that may be important for the retention and survival of planktonic organisms. First, they identified 
the northern end of the Great South Channel as a consistent site of retention and recirculation, even in the face of fairly strong winds. The observation of high Arctica adult biomass within this region (Chapter 3) is consistent with these results, recruitment in this area would be least sensitive to interannual variability in wind forcing (a more detailed comparison of observed distributions with model predictions is made in Chapter 5). This modeling also indicates that intercohort variability may be lower in this area. Second, retention of plankton over the southern flank of the bank, between 70 and 100 meters (Fields 7 and 8), is low under all conditions. Even the weakest of winter wind forcing is sufficient to drive plankton from this region off the bank and into deep water. The fact that Arctica adult biomass is low in this region is consistent with this observation. Third, this work identifies those regions where transport and loss rates are sensitive to wind forcing, namely the bank crest and southern flank out to the 70 meter isobath (Fields 9, 3, 5 and 6). Recruitment in these regions is therefore expected to be highly variable. 


\section{Chapter 5: Modeling Population Dynamics of Arctica islandica}

\section{INTRODUCTION}

The hypothesis that larval supply controls population abundance has a long history in benthic ecology (Thorson, 1950; Thorson, 1966; Mileikovsky, 1971; Young, 1990), including a recent renaissance (Gaines and Roughgarden, 1985; Roughgarden et al., 1988; Menge, 1991; Feller, et al., 1992). Significant evidence for recruitmentstructured populations has been found for coral reef fish (Doherty and Fowler, 1994), bivalves (Bachelet, 1986; Nakaoka, 1993), and barnacles (Roughgarden et al., 1988), among others.

The objective of this chapter is to combine estimates of larval transport and Arctica islandica population parameters to estimate the potential effects of interannual meteorological variability on population distributions. Linear multiregional age- and stage-structured matrix models are used to address a series of questions about Arctica distribution and abundance. Are population distributions on Georges Bank consistent with the hypothesis that larval supply determines adult distributions? Does interannual variability in wind-driven circulation significantly affect population growth rates and abundance? What is the sensitivity of the population to changes in demographic parameters?

These questions are addressed by comparing adult distributions predicted by a matrix population model with those measured from field data. The work examines the extent to which the modeled processes can account for the observed distributions. 
The effect of wind-forced variability on circulation and transport was discussed in Chapter 4. Applying the results of that modeling effort to a simple spatial model of population dynamics provides a method of determining whether interannual variation in wind forcing has a significant effect on larval transport, recruitment and population structure.

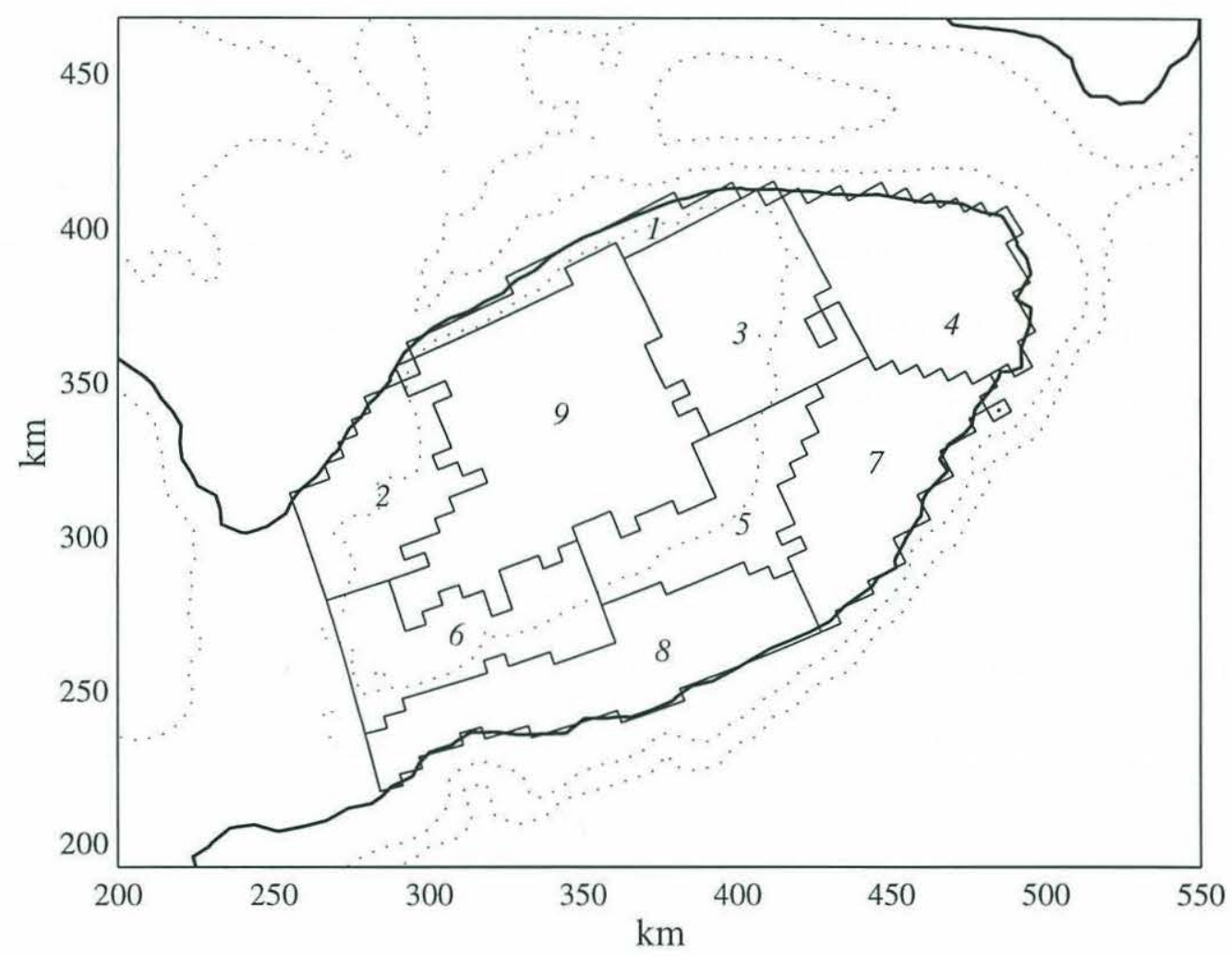

Figure 5.1: Discretization of bank for metapopulation modeling. Each italicized number designates an area defined here as a region, and the population modeling treats clams within each region as a distinct homogenous subpopulation.

Finally, sensitivity analysis is performed on this basic matrix model formulation to determine the relative importance of the various rate parameters on Arctica population growth. Fishing pressure and anthropogenic climate changes both have the potential to adversely or beneficially impact Georges Bank Arctica populations. Modeling the bank 
as a set of interconnected sub-regions makes it possible to identify regions where changes in the vital rates are likely to have the greatest impact on population dynamics.

\section{METHODS}

The work discussed here utilizes a multiregional stage-structured population model (Rogers, 1966; Rogers, 1968; Land and Rogers, 1982; Rogers, 1985; Caswell, 1989). The spatial distribution of the subpopulations is identical to that used for the initial conditions shown in Chapter 4 (Figure 5.1). Each of regions 1-8 is treated as an independent subpopulation with its own population dynamics; each is linked to other subpopulations only by the exchange of larvae.

\section{Model Formulation}

A discrete-time matrix population model (Lewis, 1942; Leslie, 1945, 1948; Caswell, 1978) of the form,

$$
\text { 5.1) } \quad \mathrm{n}_{t+1}=\mathbf{A} \mathbf{n}_{t}
$$

is used, where $\mathbf{n}_{t}$ and $\mathbf{n}_{t+1}$ are vectors containing the density of each age or stage class in each subpopulation at times $t$ and $t+1 .{ }^{7} \mathbf{A}$ is a metapopulation projection matrix whose elements represent exchanges both within and between subpopulations. For purposes of illustration I first discuss a simple case involving only two subpopulations and two stages in each population; a more general solution for $n$ populations will be presented later. The effects of spatial variation in parameters is ignored in this model, as will be discussed in more detail later.

7 Specifying density in each population (rather than total abundance) allows comparison with NMFS survey data (NEFSC, 1986; NEFSC, 1989; NEFSC, 1992; NEFSC, 1994); this choice also eliminates the confounding effect of variable region area on comparisons of regional abundance. 
The two stages represent juveniles (pre-reproductive) and adults (reproductive ):

5.2) $\mathbf{p}=\left[\begin{array}{l}j \\ a\end{array}\right]$.

For 2 subpopulations, this gives the population vector:

5.3) $\quad \mathbf{n}=\left[\begin{array}{l}\mathbf{p}_{1} \\ \mathbf{p}_{2}\end{array}\right]=\left[\begin{array}{l}j_{1} \\ a_{1} \\ j_{2} \\ a_{2}\end{array}\right]$.

The projection matrix, $\mathbf{A}$, is the sum of two projection matrices: a larval production matrix, $\mathbf{R}$, that accounts for processes affecting the newly spawned larvae in their first year of life, and a benthic projection matrix, B, that accounts for the settled juveniles and adults. The projection interval for this model is 1 year, with a census immediately before spawning.

\section{Larval Production matrix}

The projection matrix for the larval stages, $\mathbf{R}$, includes the effects of spawning, larval transport, settlement and mortality during the first year. The larval production of each population, $\mathbf{I}_{p}$, is equal to the product of the stage abundance and the fecundity of each stage:

5.4) $\quad \mathbf{l}_{p}=\left[\begin{array}{l}l_{p, 1} \\ l_{p, 2}\end{array}\right]=\left[\begin{array}{llll}0 & f & 0 & 0 \\ 0 & 0 & 0 & f\end{array}\right] \mathbf{n}=\mathbf{F n}$,

where $\mathbf{F}$ is a fecundity matrix for 2 subpopulations. 
Larvae are transported between subpopulations; $s_{l}$ indicates the fraction of larvae surviving the effects of predation and mortality during transport. This process takes place over only a short period; for this work, all larval transport is assumed to take place in the 60 days following spawning. At the end of this period, the density of settling larvae in each region, $\mathbf{1}_{s}$, is:

$$
\text { 5.5) } \quad \mathbf{I}_{s}=s_{l}\left[\begin{array}{ll}
T_{1 \rightarrow 1} & T_{2 \rightarrow 1} \\
T_{1 \rightarrow 2} & T_{2 \rightarrow 2}
\end{array}\right] \mathbf{l}_{p}=s_{l} \mathbf{T F n} .
$$

where $T_{i \rightarrow j}$ incorporates the transport from population $i$ into population $j$. A $T$ value of 1 indicates that the transported larvae are settling into population $j$ at exactly the same areal density with which they were spawned into the water column over area $i$. If no transport takes place, $\mathbf{T}$ would equal the identity matrix.

Only a proportion of the larvae, $c$, in each region survive settlement and postsettlement mortality to become new juveniles, $\mathbf{j}_{n}$, in the next year $(t+1)$ :

$$
\text { 5.6) } \quad \mathbf{j}_{n}=c \mathbf{l}_{s}=c s s_{l} \mathbf{T F} \mathbf{n}_{t} \text {. }
$$

However, the matrix $\operatorname{cs} l \mathbf{T F}$ only indicates the number of new juveniles in the following year; this matrix must be multiplied by a matrix reflecting the contribution of those juveniles to the full population vector, $\mathbf{n}$. Thus (for a 2 region matrix model) the projection matrix for the new recruiting stages, $\mathbf{R}$, is:

5.7) $\quad \mathbf{R}=\left[\begin{array}{ll}1 & 0 \\ 0 & 0 \\ 0 & 1 \\ 0 & 0\end{array}\right] c s_{l} \mathbf{T F}$. 


\section{Benthic projection matrix}

In the benthic population, a fraction of the adults, $s_{a}$, and of the juveniles, $s_{j}$, survives each year. In the absence of mortality, the probability of transition out of the juvenile stage is $1 / d_{j}$ and the probability of remaining in the juvenile stage is $\left(1-1 / d_{j}\right)$ where $d_{j}$ is the average residence time in the juvenile stage. The benthic portion of a 2 region, 2 stage population after the one year projection interval is thus:

$$
\mathbf{n}_{t+1}=\left[\begin{array}{cc|cc}
s_{j}\left(1-1 / d_{j}\right) & 0 & 0 & 0 \\
s_{j} / d_{j} & s_{a} & 0 & 0 \\
\hline 0 & 0 & s_{j}\left(1-1 / d_{j}\right) & 0 \\
0 & 0 & s_{j} / d_{j} & s_{a}
\end{array}\right]\left[\begin{array}{c}
j_{1} \\
a_{1} \\
j_{2} \\
a_{2}
\end{array}\right]=\mathbf{B n}_{t},
$$

where $\mathbf{B}$ is a benthic projection matrix for 2 regions.

\section{Complete projection matrix}

The population after one year is thus made up of new juveniles (equations 5.6 and 5.7) and the survivors in the benthos (equation 5.8):

$$
\begin{aligned}
\mathbf{n}_{t+1} & =\mathbf{B n}_{t}+\mathbf{R n}_{t} \\
& =\left[\begin{array}{cc|cc}
s_{j}\left(1-1 / d_{j}\right) & s_{l} c f T_{1 \rightarrow 1} & 0 & s_{l} c f T_{2 \rightarrow 1} \\
s_{j} / d_{j} & s_{a} & 0 & 0 \\
\hline 0 & s_{l} c f T_{1 \rightarrow 2} & s_{j}\left(1-1 / d_{j}\right) & s_{l} c f T_{2 \rightarrow 2} \\
0 & 0 & s_{j} / d_{j} & s_{a}
\end{array}\right]\left[\begin{array}{c}
j_{1} \\
a_{1} \\
j_{2} \\
a_{2}
\end{array}\right]_{t}
\end{aligned}
$$

The full projection matrix for a two region population model, $\mathbf{A}$ is:




This formulation of the matrix model accounts all processes occurring within the 1 year projection interval: fecundity, larval mortality, settlement and post-settlement processes and juvenile and adult survival.

\section{Projection matrix analysis}

The projection matrix yields a variety of useful information about the modeled populations. The dominant eigenvalue of the projection matrix, $\lambda$, gives the asymptotic population growth rate. The right eigenvector corresponding to this eigenvalue, w, yields the stable population distribution (whether it be in terms of stage class, age class, metapopulation structure, or some combination of the three). The left eigenvector, $\mathbf{v}$, provides an indication of the relative reproductive value of an individual in each class to future population growth (Caswell, 1989). In the cases described here, the stable structure and reproductive value vectors indicate both stage (juvenile vs. adult) and subpopulation (regions 1-8) structure.

Further analysis of the projection matrix can help discriminate the effects of individual parameters and groups of parameters on the overall population growth rate. The sensitivity of the dominant eigenvalue to changes in an individual parameter, $a_{i j}$, can be calculated from the left and right eigenvectors,

$$
\begin{aligned}
S_{i j} & =\frac{\partial \lambda}{\partial a_{i j}}=\frac{v_{i} w_{j}}{\langle\mathbf{w}, \mathbf{v}\rangle}, \\
\mathbf{S} & =\frac{\mathbf{v} \mathbf{w}^{\prime}}{\mathbf{v}^{\prime} \mathbf{w}}
\end{aligned}
$$

where $v_{i}$ and $w_{j}$ refer to the $i$ th element of the stable age distribution vector $\mathbf{w}$ and the $j$ th element of the reproductive value vector $\mathbf{v}$ (Caswell, 1978). The sensitivity provides an 
indication of the impact changes in an individual demographic parameter will have on the overall population growth rate.

In order to account for the differing magnitudes of the various parameters, it is often more informative to calculate the proportional changes in $\lambda$ with respect to a proportional change in a parameter, a value known as the elasticity, E, calculated by: ${ }^{8}$

$$
\begin{aligned}
E_{i j} & =\frac{a_{i j}}{\lambda} \frac{\partial \lambda}{\partial a_{i j}}=\frac{\partial \ln (\lambda)}{\partial \ln \left(a_{i j}\right)} . \\
\mathbf{E} & =\frac{\mathbf{A}}{\lambda} \circ \mathbf{S}
\end{aligned}
$$

The $E_{i j}$ sum to 1.0 and represent the proportional contribution of each $a_{i j}$ to $\lambda$ (de Kroon, et al., 1986; Caswell, 1989). In the following analysis, elasticities for various groups of parameters will be calculated by summing the elasticities of individual parameters. For example, the overall elasticity of adult mortality will be calculated as the sum of the elasticities of adult mortality for every region. Similarly, elasticity in juvenile survival, intra- and interpopulation larval transport, and maturation is calculated by summing the elasticity component for these parameters. Additionally, elasticity in all parameters relevant to a single population (internal growth and mortality and larval retention and export) will be summed and compared.

\section{Multiregional model}

The two-subpopulation model described by equations 5.1-5.10 is an example of a type of matrix model that examines effects of transport between populations with identical demographics. This assumption, that demographic parameters in all populations are

8 The operation, $\mathbf{E}=\mathbf{A} \circ \mathbf{S}$, indicates a Hadamard product, or element by element multiplication, where $E_{i j}=A_{i j} S_{i j}$. 
identical, can be used to simplify the model analysis and identify the effects of transport on overall demographic trends. The following derivation shows a broader example of how the model structure is developed and what that structure implies for analysis of eigenvalues and eigenvectors of the resulting projection matrix.

The matrix models used here describe the stage structure of a single population by a single vector, $\mathbf{p}$ (equation 5.2). A group of $I$ such subpopulations can then be described by a vector, $\mathbf{n}$, composed of multiple population vectors, $\mathbf{p}_{i}$ :

5.13) $\mathbf{n}=\left[\begin{array}{c}\mathrm{p}_{1} \\ \mathrm{p}_{2} \\ \cdots \\ \mathrm{p}_{I}\end{array}\right]$

The egg production of each stage in a single population, $\mathbf{p}$, can be expressed as the product of a row vector, $\mathbf{f},\left(f_{j}=\right.$ the production of eggs by a member of population stage $j$ ), and the column vector $\mathbf{p}$. Based on the simplifying assumption that all populations have the same demographic parameters, the production of eggs from all populations in $\mathbf{n}$ can be expressed as an overall "fecundity" matrix (a Kronecker product ${ }^{9}$ of an identity matrix of rank $I, \mathbf{I}_{I}$, and the fecundity vector for a sub-population, $\mathbf{f}$ ):

9 In order to simplify the following derivation, a Kronecker matrix product is used (Graham, 1981). The Kronecker product of any two matrices, $\mathbf{M}$ and $\mathbf{N}$, can be expressed as follows (where $\mathbf{M}$ has $i$ rows and $j$ columns):

$\mathbf{M} \otimes \mathbf{N}=\left[\begin{array}{cccc}m_{1,1} \mathbf{N} & m_{1,2} \mathbf{N} & \ldots & m_{1, j} \mathbf{N} \\ m_{2,1} \mathbf{N} & m_{2,2} \mathbf{N} & \ldots & m_{2, j} \mathbf{N} \\ \ldots & \ldots & \ldots & \ldots \\ m_{i, 1} \mathbf{N} & m_{i, 2} \mathbf{N} & \ldots & m_{i, j} \mathbf{N}\end{array}\right]$. 


$$
\begin{aligned}
& \mathbf{I}_{I} \otimes \mathbf{f}=\left[\begin{array}{cccc}
\mathbf{f} & 0 \times \mathbf{f} & \ldots & 0 \times \mathbf{f} \\
0 \times \mathbf{f} & \mathbf{f} & \ldots & 0 \times \mathbf{f} \\
\ldots & \ldots & \ldots & \ldots \\
0 \times \mathbf{f} & 0 \times \mathbf{f} & \ldots & \mathbf{f}
\end{array}\right]
\end{aligned}
$$

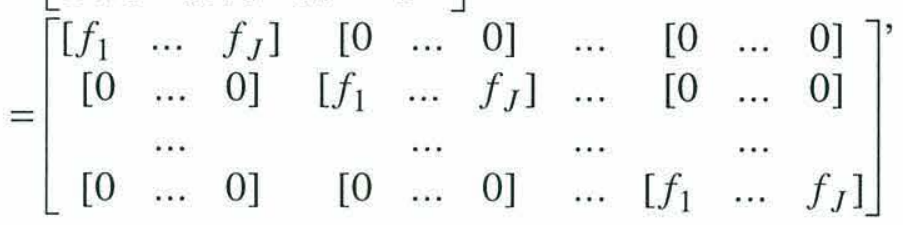

where each row of the resulting matrix expresses the production of eggs by a single population; the presence of zeros in the off diagonal blocks $(0 \times \mathbf{f})$ indicates that eggs produced in one region are only found in that region.

The transport matrixes, $\mathbf{T}$, used in this work are drawn from the results of the physical circulation model described in Chapter 4. The density of larvae settling in region $m$ from region $l$ is given by the average of the larval distribution $\left(D_{l}\right)$ over the area of region $m\left(A_{m}\right)$, at the time of settling $\left(t_{s}\right.$, larvae were transported for 60 days before settlement):

$$
\text { 5.15) } \quad T_{m \rightarrow l}=\frac{\iint D_{l}\left(t_{s}\right) d A_{m}}{\iint d A_{m}} \text {. }
$$

The full matrix of larval settling densities, $\mathbf{T}$, is referred to as the transport matrix. Each element $T_{m \rightarrow l}$ is the density of larvae from area $l$ that would settle over area $m$, assuming an initial areal density of 1.0. In this case, $\mathbf{T}$ accounts only for the effects of transport no planktonic growth or mortality is incorporated, and settlement is assumed to occur simultaneously for all larvae in the water column.

One such matrix can be generated for each day's tracer distribution in the transport modeling results from Chapter 4 . For a simple example, the transport matrix at time $t=0$ 
is the identity matrix. In the absence of transport and demographic processes, the density of larvae settling over their originating area is the same as the spawned density $\left(T_{m \rightarrow l}=1\right.$ for $m=l)$, and no larvae from that region settle elsewhere $\left(T_{m \rightarrow l}=0\right.$ for $\left.m \neq l\right)$. Assuming that larval mortality during the planktonic stage is equal for all populations implies that settling density will be a scalar multiple, $s_{l}$, of the transported larvae. However, it is typically the case that a larval patch from one region will be advected and diffused over several regions, providing settling densities less than 1 in each of several regions (See appendix A for the transport matrices for day 60 used in this work).

From the derivation described above, the settlement density of larvae in each region can be described by the vector $\mathbf{l}_{S}$ :

$$
\text { 5.16) } \quad \mathbf{I}_{s}=s_{l} \mathbf{T}\left(\mathbf{I}_{I} \otimes \mathbf{f}\right) \mathbf{n} \text {. }
$$

Finally, the contribution of the larvae to the population distribution in a given region at the next time step can be calculated by multiplying the number of larvae settling in a region by a matrix, $\mathbf{c}$, that describes the contribution the larvae make to each stage in p. The Kronecker product of the identity matrix and $\mathbf{c}$ describes the transitions from settlement until the end of the projection interval for all populations in $\mathbf{n}$. In this case, the probability of a newly settled larvae surviving until the next year is $c$, and no newly settled larvae become adults within the first year. Thus, the distribution of the dispersing stages at the next time step can be described by:

$$
\begin{aligned}
\mathbf{n}_{t+1} & =\left(\mathbf{I}_{I} \otimes\left[\begin{array}{l}
c \\
0
\end{array}\right]\right) s_{l} \mathbf{T}\left(\mathbf{I}_{I} \otimes \mathbf{f}\right) \mathbf{n}_{t} . \\
& =s_{l}\left(\mathbf{I}_{I} \otimes \mathbf{c}\right) \mathbf{T}\left(\mathbf{I}_{I} \otimes \mathbf{f}\right) \mathbf{n}_{t}
\end{aligned}
$$

Based upon the properties of Kronecker products (Graham, 1981), 5.17 can be reduced 
to:

$$
\begin{aligned}
\mathbf{n}_{t+1} & =s_{l}(\mathbf{T} \otimes \mathbf{c})\left(\mathbf{I}_{I} \otimes \mathbf{f}\right) \mathbf{n}_{t} \\
& =s_{l}\left(\mathbf{T I} \mathbf{I}_{I} \otimes \mathbf{c f}\right) \mathbf{n}_{t} \\
& =(\mathbf{T} \otimes \mathbf{R}) \mathbf{n}_{t} \\
\mathbf{R} & =s_{l} \mathbf{c f}
\end{aligned}
$$

The treatment of non-dispersive stages is simpler. A square projection matrix for these stages, $\mathbf{B}$, describes the annual dynamics, excluding planktonic transport, for all stages in p. B is constructed analogously to equation 5.8:

$$
\text { 5.19) } \quad \mathbf{n}_{t+1}=\left(\mathbf{I}_{I} \otimes \mathbf{B}\right) \mathbf{n}_{t} \text { where, } \mathbf{B}=\left[\begin{array}{cc}
s_{j}\left(1-1 / d_{j}\right) & 0 \\
s_{j} / d_{j} & s_{a}
\end{array}\right]
$$

for the non-dispersive stages of $\mathbf{n}$, again assuming that the vital rates are identical in all areas.

Equations 5.18 and 5.19 can be combined to form:

$$
\mathbf{n}_{t+1}=\left(\mathbf{T} \otimes \mathbf{R}+\mathbf{I}_{I} \otimes \mathbf{B}\right) \mathbf{n}_{t},
$$

The sum of the two Kronecker products is the projection matrix, A. Explicit in the use of the Kronecker product with the identity matrix in equation 5.18, 5.19 and 5.20 is the assumption that population parameters do not vary between populations.

The form of the projection matrix (equation 5.20) allows for the calculation of eigenvalues and eigenvectors of $\mathbf{A}$ in terms of the eigenvalues of $\mathbf{T}$ and a derived matrix, $\mathbf{X}$, where, for the two stage model discussed here: 


$$
\mathbf{X}=\left(\mathbf{R}+\frac{\mathbf{B}}{\lambda_{T}}\right)=\left[\begin{array}{cc}
\frac{s_{j}\left(1-d_{j}\right)}{\lambda_{T}} & s_{l} c f \\
\frac{s_{j} d_{j}}{\lambda_{T}} & \frac{s_{a}}{\lambda_{T}}
\end{array}\right]
$$

The eigenvalues of $\mathbf{A}$ are the product of $\lambda_{\mathrm{T}}$, the eigenvector of $\mathbf{T}$, and $\lambda_{\mathrm{X}}$, the eigenvector of $\mathbf{X}$.

$$
\lambda=\lambda_{T} \lambda_{X}
$$

The right eigenvector of $\mathbf{A}$ is the Kronecker product of $\mathbf{w}_{\mathrm{T}}$, the right eigenvector of the transport matrix, $\mathbf{T}$, and $\mathbf{w}_{\mathbf{X}}$, the right eigenvector of $\mathbf{X}$ :

$$
\mathbf{w}=\mathbf{w}_{T} \otimes \mathbf{w}_{X} .
$$

A similar relationship exists for the left eigenvector, $\mathbf{v}$ :

$$
\mathbf{v}=\mathbf{v}_{T} \otimes \mathbf{v}_{X} .
$$

The relation between the eigenvalues and eigenvectors of $\mathbf{A}$ and those of $\mathbf{T}$ and $\mathbf{X}$ can be seen by the following proof.

$$
\begin{aligned}
\mathbf{A w} & =\lambda \mathbf{w} \\
& =(\mathbf{T} \otimes \mathbf{R}+\mathbf{I} \otimes \mathbf{B})\left(\mathbf{w}_{T} \otimes \mathbf{w}_{X}\right) \\
& =\mathbf{T} \mathbf{w}_{T} \otimes \mathbf{R} \mathbf{w}_{X}+\mathbf{I} \mathbf{w}_{T} \otimes \mathbf{B} \mathbf{w}_{X} \\
& =\lambda_{T} \mathbf{w}_{T} \otimes \mathbf{R} \mathbf{w}_{X}+\mathbf{w}_{T} \otimes \mathbf{B} \mathbf{w}_{X} \\
& =\lambda_{T} \mathbf{w}_{T} \otimes\left(\mathbf{R}+\frac{\mathbf{B}}{\lambda_{T}}\right) \mathbf{w}_{X} \\
\lambda \mathbf{w} & =\lambda_{T} \lambda_{X}\left(\mathbf{w}_{T} \otimes \mathbf{w}_{X}\right)
\end{aligned}
$$

As a result of this relationship, the sensitivity matrix, $\mathbf{S}$, can be described as a 
Kronecker product of the sensitivity matrix for the transport matrix, $\mathbf{T}$, and the matrix $\mathbf{X}$ :

$$
\begin{aligned}
\mathbf{S} & =\frac{\mathbf{v} \mathbf{w}^{\prime}}{\mathbf{v}^{\prime} \mathbf{w}} \\
& =\frac{\left(\mathbf{v}_{T} \otimes \mathbf{v}_{X}\right)\left(\mathbf{w}_{T} \otimes \mathbf{w}_{X}\right)^{\prime}}{\left(\mathbf{v}_{T} \otimes \mathbf{v}_{X}\right)^{\prime}\left(\mathbf{w}_{T} \otimes \mathbf{w}_{X}\right)} \\
& =\frac{\mathbf{v}_{T} \mathbf{w}_{T}{ }^{\prime} \otimes \mathbf{v}_{X} \mathbf{w}_{X}{ }^{\prime}}{\mathbf{v}_{T}{ }^{\prime} \mathbf{w}_{T} \otimes \mathbf{v}_{X}{ }^{\prime} \mathbf{w}_{X}} \\
& =\frac{\mathbf{v}_{T} \mathbf{w}_{T}{ }^{\prime} \otimes \frac{\mathbf{v}_{X} \mathbf{w}_{X}{ }^{\prime}}{\mathbf{v}_{T}{ }^{\prime} \mathbf{w}_{T}}}{\mathbf{v}_{X}{ }^{\prime} \mathbf{w}_{X}} \\
& =\mathbf{S}_{T} \otimes \mathbf{S}_{X}
\end{aligned}
$$

This relationship indicates that the sensitivity to a population parameter scales as the sensitivity of the transport matrix. For example, the ratio of sensitivity to changes in adult mortality in population 1 to the sensitivity of the same parameter in population 2 equals the ratio of elements 1 and 2 on the diagonal of the transport sensitivity matrix, $\mathbf{S}_{T}$.

From this relationship and equation 5.12, the elasticity is:

$$
\text { 5.27) } \quad \mathrm{E}=\frac{\mathrm{A}}{\lambda} \circ\left(\mathrm{S}_{T} \otimes \mathrm{S}_{X}\right) \text {. }
$$

In the numerical analysis it was also noted that the sum of the elasticity components for a population (sum of all rows or columns of $\mathbf{E}$ pertaining to that population) has the same value as the sum of that population's column or row of the elasticity matrix for $\mathbf{T}$. We surmise that this relationship holds for all matrices of the form described by equation 5.20. This observation implies that comparisons of elasticity between populations in a metapopulation matrix model of this form are solely determined by the elasticity of the transport matrix, $\mathbf{E}_{T}$. 
Equations 5.22-5.26 indicate that only the relative rates of exchange are relevant in determining the relative size of populations $\left(\mathbf{w}_{T}\right)$, the comparative reproductive value of a given stage in various populations $\left(\mathbf{v}_{T}\right)$, and the comparative sensitivity of population growth rate to changes in a given population $\left(\mathbf{S}_{T}\right)$ when the spatial variation in demographics is driven only by exchange of propagules between populations. This result also allows the decoupling of multi-stage and multi-population projection matrices into two separate and much more tractable analyses focusing on the effects of demography and transport.

\section{Age structured model}

In addition to the two stage model discussed above, an age structured model with 106 age classes (each consisting of one year class) per region was also used. The formulation of the stage structured model sharply limited the range of possible eigenvalues, as the dominant eigenvalue of a nonnegative matrix must be greater than or equal to the greatest of the diagonal elements, $\lambda \geq \max \left(a_{i i}\right)$ (Horn and Johnson, 1985).

The age structured matrix model uses the same basic population structuring as the stage structured model. However, rather than a two vector elements describing the abundance of juveniles and adults, there are 7 vector elements that reflect the abundance of the juvenile (pre-reproductive) age classes, and 99 adult age classes. The number of juvenile and adult classes was chosen based upon the population parameters described in the following section.

Rather than 2 by 2 matrices describing population dynamics, this formulation uses a 107 by 107 matrix (equation 5.28), with diagonal elements uniformly equal to zero. Survival for each age class is in the first subdiagonal row and reproduction is in the first 
row, and each age class moves completely into the next class at each time step. The reproduction matrix, $\mathbf{R}$, in this case consisted of a matrix in which last 100 elements of the top row all equaled $s_{l} c f$ and all other elements were zero.

$$
\text { 5.28) } \quad \mathbf{B}=\left[\begin{array}{ccccccccccc}
0 & 0 & 0 & 0 & 0 & 0 & 0 & 0 & \ldots & 0 & 0 \\
s_{j} & 0 & 0 & 0 & 0 & 0 & 0 & 0 & \ldots & 0 & 0 \\
0 & s_{j} & 0 & 0 & 0 & 0 & 0 & 0 & \ldots & 0 & 0 \\
0 & 0 & s_{j} & 0 & 0 & 0 & 0 & 0 & \ldots & 0 & 0 \\
0 & 0 & 0 & s_{j} & 0 & 0 & 0 & 0 & \ldots & 0 & 0 \\
0 & 0 & 0 & 0 & s_{j} & 0 & 0 & 0 & \ldots & 0 & 0 \\
0 & 0 & 0 & 0 & 0 & s_{j} & 0 & 0 & \ldots & 0 & 0 \\
0 & 0 & 0 & 0 & 0 & 0 & s_{j} & 0 & \ldots & 0 & 0 \\
0 & 0 & 0 & 0 & 0 & 0 & 0 & s_{a} & \ldots & 0 & 0 \\
\cdots & \ldots & \ldots & \ldots & \ldots & \ldots & \ldots & \ldots & \ldots & \ldots & \ldots \\
0 & 0 & 0 & 0 & 0 & 0 & 0 & 0 & \ldots & s_{a} & 0
\end{array}\right] \text {, }
$$

\section{Parameter selection}

The numbers in $\mathbf{n}$ reflect the average density within a region rather than the total abundance of individuals within the region. The larval production density is proportional to the density of adults in the spawning area. Settlement is proportional to the average areal density of larvae from one region in the water column overlying that region or another.

The choice of parameters (Table 5.1) was based on available data from Arctica and other marine bivalves in similar habitats and climates. The parameters are representative of a population with long-lived adults, low juvenile survival, and low 
recruitment. As noted previously, all parameters were assumed to be the same for all populations.

Table 5.1: Parameter choices for stage and age class modeling.

\begin{tabular}{|c|c|c|c|c|}
\hline Parameter & Dimension & Description & Estimate & Source \\
\hline \multirow[b]{2}{*}{$P_{e}$} & $\begin{array}{l}\text { veligers per } \\
\text { adult }\end{array}$ & fecundity & $4 \times 10^{4}$ & \\
\hline & eggs per adult & $\begin{array}{l}\text { spawning } \\
\text { production }\end{array}$ & $4 \times 10^{5}$ & (von Oertzen, 1972) \\
\hline$P_{f}$ & larvae per egg & $\begin{array}{l}\text { fertilization } \\
\text { success }\end{array}$ & 0.10 & (Landers, 1976) \\
\hline \multirow[t]{3}{*}{$s_{l}$} & & larval survival & $6.77 \times 10^{-5}$ & \\
\hline & days & larval duration & 60 & (Lutz et al., 1982) \\
\hline & day $^{-1}$ & $\begin{array}{c}\text { instantaneous } \\
\text { planktonic } \\
\text { mortality }\end{array}$ & 0.16 & (Rumrill, 1990) \\
\hline$c$ & $\begin{array}{c}\text { year 1 } \\
\text { juveniles per } \\
\text { settled spat }\end{array}$ & $\begin{array}{l}\text { post-settlement } \\
\text { survival }\end{array}$ & 0.29 & $\begin{array}{c}\text { derived from our data and (Brousseau, } \\
\text { et al., 1982) }\end{array}$ \\
\hline$d_{j}$ & year & $\begin{array}{c}\text { juvenile stage } \\
\text { duration }\end{array}$ & 7 & $\begin{array}{c}\text { (Thompson et al., 1980b; Rowell et } \\
\text { al., 1990) }\end{array}$ \\
\hline$s_{j 1}$ & & & $0 . .61$ & derived from our data and \\
\hline$s_{j 2}$ & & survival of & 0.74 & (Brousseau et al., 1982) \\
\hline$s_{j 3}$ & & age classes & 0.94 & \\
\hline$s_{j 4}$ & & $1-7$ & 0.94 & \\
\hline$s_{j 5}$ & & (juveniles) & 0.93 & \\
\hline$s_{j 6}$ & & & 0.95 & \\
\hline$s_{j 7}$ & & & 0.92 & \\
\hline$s_{j}$ & & $\begin{array}{l}\text { juvenile } \\
\text { survival }\end{array}$ & 0.85 & geometric mean of $s_{j i}$ \\
\hline$s_{a}$ & & adult survival & $\begin{array}{c}0.98 \\
(0.90)\end{array}$ & $\begin{array}{l}\text { (Murawski and Serchuk, 1989; } \\
\text { NEFSC, 1995a,b) }\end{array}$ \\
\hline
\end{tabular}

None of these parameter choices are believed to be absolutely correct; they reflect a good estimate based upon available data. There is no canonical set of parameters describing Arctica population dynamics on Georges Bank, as all of the processes described above are believed to exhibit some spatial and temporal variability. This work is intended to identify those parameters in which variation most significantly affects overall population growth and stability, hopefully to focus more effort on better quantifying the important parameters. 


\section{Fecundity}

Estimation of the number of year 1 juveniles produced per adult proved difficult due to the uncertainty in estimating the magnitude of the contributing processes. However, rough estimates exist for Arctica and related species and serve to provide a rough indication of the magnitude of various processes.

The fecundity of Arctica adults has been estimated at 400,000 eggs per individual (von Oertzen, 1972). Although fecundity is probably highly variable and size dependent, this represents the only estimate of this process and is used for this linear model.

Landers (1976), in laboratory studies, showed that between 10 and $27 \%$ of eggs developed to the veliger stage. Since this study was conducted under ideal conditions, and since it is unclear whether this percentage is of unfertilized or fertilized eggs, probability of fertilization was conservatively estimated at 0.10 larvae per egg. These combine to indicate a fecundity $(f)$ of 40,000 larvae per adult.

\section{Planktonic survival}

Available estimates of larval survival vary widely. Instantaneous planktonic mortality estimates for the bivalve Crassostrea gigas differ by a factor of 1.9, from 0.134 days $^{-1}$ to 0.256 days $^{-1}$ (Rumrill, 1990). Integrated over a 60 day planktonic period (Lutz et al., 1982), this variation generates estimates of larval settlement differing by 3 orders of magnitude.

Based upon Rumrill's (1990) summary showing instantaneous mortality values ranging from 0.128 day $^{-1}$ to 0.283 day $^{-1}$, a mortality rate of 0.15 day $^{-1}$ was chosen. A value near the lower limit of previous observations is justified by lower abundances of 
planktonic predators over Georges Bank in winter (Davis, 1987). Applying this rate over the full 60 day larval period yielded a planktonic survival of $6.77 \times 10^{-5}$.

This choice was consistent with published estimates and reflective of the comparatively low predation on Georges Bank in winter. Many of the studies calculated mortality during the development from veliger to settled spat, so this estimate was assumed to include settlement mortality. The lower value was chosen because most studies of planktonic mortality included the effects of advection and diffusion in their estimate while those processes are explicitly resolved in this model (Chapter 4).

\section{Post-settlement and juvenile survival and growth}

The mortality of juveniles and post-settlement larvae was more difficult to estimate as there are no direct estimates of the magnitude of this process for Arctica. However, work on other small bivalve species in subtidal, soft-substrate environments yielded a range of estimates for mortality. Nakaoka estimated annual mortality of Yoldia notabilis to be roughly dependent on shell length (Nakaoka, 1993). Brousseau calculated mortality rates for Mya arenaria in Gloucester, Massachusetts, by $5 \mathrm{~mm}$ size class and used those values to calculate an age based mortality rate (Brousseau, 1978; Brousseau et al., 1982).

In order to estimate annual survival for members of the juvenile stage class, the age of maturity (defined here as first reproduction) was fixed at 8 years (Thompson et al., 1980b; Rowell et al., 1990). Setting duration of the juvenile stage at 7 years (postsettlement) yielded a probability of transition from stage 1 to stage 2 , in the absence of mortality, of $0.143 \mathrm{yr}^{-1}$ (transition probability $\left.=d_{j}^{-1}=1 / 7\right)$.

Juvenile survival, on the other hand, was estimated by assuming that the 
instantaneous mortalities estimated by Brousseau for Mya arenaria were accurate for Arctica of the same size and then using a simple estimate of Arctica growth rates to determine how long juveniles spent in each size class. The von Bertalanffy curve fit to the age data described in Chapter 3 (Figure 3.12; length $=\mathrm{L}_{\infty}\left(1-\mathrm{e}^{-\mathrm{k} \times \mathrm{age}}\right) ; \mathrm{k}=0.131, \mathrm{~L}_{\infty}=$ $91.13 \mathrm{~mm}$ ) was used to estimate growth rate. Mortality for each age class, $s_{j 1}$ through $s_{j 7}$, was calculated by integrating the mortality for the relevant length classes (data from Brousseau, 1982, for Mya arenaria was used to approximate juvenile mortality) over the period of time spent in that length class during that age class. This yielded the specific parameters for each juvenile age class shown in Table 5.1; the geometric mean of the values, $s_{j}=0.85 \mathrm{yr}^{-1}$, was chosen as the annual mortality of the juvenile stage for the stage class model. Survival of newly settled spat until the first census was also estimated from Brousseau's data, yielding an estimate that $29 \%$ of settled larvae survive the first year.

\section{Adult survival}

Annual survival of individuals in the adult stage was calculated from mortality estimates made by the National Marine Fisheries Service (survival $=1$ - mortality). The annual mortality of Arctica has previously been estimated at $0.01-0.03 \mathrm{yr}^{-1}$ (Murawski and Serchuk, 1989). The 19th Northeast Regional Stock Assessment Workshop of the National Marine Fisheries Service (NEFSC, 1995a,b) estimated instantaneous natural mortality to be in the range of $0.01-0.03$, and total mortality (including fishing effects) of 0.064 (Delmarva) to 0.094 (Long Island). Consistent with these estimates, an adult survival of $0.98 \mathrm{yr}^{-1}$ was used for this work. 


\section{Spatial structure}

An 8-population matrix was analyzed for each wind case, using both a stagestructured and an age-structured model. The region over the bank crest was excluded from the calculations (region 9, Figure 5.1) because conditions there are unfavorable to Arctica adults: much of the bank crest is shallower than the typical bathymetric range of Arctica, summer water temperatures in this region are above the normal range for adults, and tidal currents in the area are strong enough to keep sediment constantly in suspension (Twichell et al., 1987). Additionally, this area is inhabited by the Surf Clam, Spisula solidissima, which may be a competitive dominant to Arctica in shallow water. Sources of larvae from off-bank populations were ignored for initial work as it was not possible to parameterize the dynamics of those population directly.

This analysis treats the three different modeled years independently. This approach is equivalent to assuming that the transport conditions for a given year are repeated indefinitely. While this does not represent natural conditions, the results of each of these models indicate the possible range of impacts of transport variations on the population distribution and provide an index of the effect of the transport variations on the population dynamics.

\section{RESULTS}

The results focus on the separate properties of the two matrices, $\mathbf{T}$ and $\mathbf{X}$, that allow determination of the properties of the full projection matrix for Georges Bank, A.

\section{Transport Matrix}

As the eigenvalue of the transport matrix, $\mathbf{T}$, affects the matrix $\mathbf{X}$ for any given 
year (equation 5.25), properties and variation in $\mathbf{T}$ are considered first.

\section{Eigenvalues}

The effect of losses from the bank on overall growth rate varied by model year (1974, 1978, and 1991) and forcing type (vector-averaged vs. synoptic). Every transport matrix had a dominant eigenvalue less than 1 as a result of losses of larvae off-bank (complete retention of larvae within the boundaries of the bank would give $\lambda_{T}=1$, as the transport would return all tracer to the bank to be redistributed in the next time step). The trend in the eigenvalues, lowest for 1978 and highest for 1974, supported the hypothesis that increased wind would reduce population growth rates (Table 5.2). In addition, the eigenvalues were significantly higher for the vector-averaged wind forcing than for synoptic forcing. ${ }^{10}$

Table 5.2:Eigenvalues of Transport matrix, $\mathbf{T}$.

\begin{tabular}{lccccc}
\hline Year & $\mathbf{1 9 7 4}$ & $\mathbf{1 9 7 8}$ & $\mathbf{1 9 9 1}$ & $\begin{array}{c}\mathbf{1 9 7 4} \\
\text { mean }\end{array}$ & $\begin{array}{c}\mathbf{1 9 7 8} \\
\text { mean }\end{array}$ \\
\hline$\lambda_{T}$ & 0.347 & 0.227 & 0.253 & 0.559 & 0.400 \\
\hline
\end{tabular}

The eigenvalues of $\mathbf{T}$ are most useful for addressing relative trends between model years; the transport matrix and its eigenvalue only contribute to a part of the full projection matrix, A (see equations 5.21 through 5.25). With either vector-averaged or synoptic wind forcing, years with stronger winds consistently generated lower eigenvalues than years with weaker winds. The difference between eigenvalues for 1974 and either of the 1978 and 1991 synoptic cases was much greater than the difference between the eigenvalues for 1978 and 1991.

10 Two tailed, two sample t test using Statview II (Abacus Concepts, Inc.; Berkeley, California) for the Macintosh on a Quadra 610. $\mathrm{H}_{0}$ : mean of eigenvalues from synoptic forcing is not less than the mean from the vector averaged forcing, was rejected $(\mathrm{p}=0.0371)$. 


\section{Eigenvectors}

The structure of the eigenvectors of the transport matrix also showed marked sensitivity to wind forcing; in this case 1974 and 1991 had similar eigenvectors, while 1978 differed (Table 5.3). These results highlight the aggregate response of each of the regions to inputs from all of the other regions and the resulting population distribution. The dominant eigenvectors differed markedly between the 1978 and all other years; both the lower and median wind winter, 1974 and 1991, had fairly similar eigenvectors, with highest densities on the southern part of the bank (region 8, Figure 5.1). However, in the high wind winter (1978) the dominant population, in terms of density and reproductive value, was in the northwest corner of the bank (region 2, Figure 5.1), although again the southwest part (regions 6 and 8, Figure 5.1) was comparatively densely settled.

Table 5.3: Right eigenvectors (w, stable population distribution) vectors for the transport matrix, T, from each model year.

\begin{tabular}{ccccccc}
\hline Region & & $\mathbf{1 9 7 4}$ & $\mathbf{1 9 7 8}$ & $\mathbf{1 9 9 1}$ & $\mathbf{1 9 7 4}$ mean 1978 mean \\
\hline $\mathbf{1}$ & North Flank & 0.079 & 0.008 & 0.054 & 0.045 & 0.016 \\
$\mathbf{2}$ & SCOPEX site & 0.180 & 0.437 & 0.225 & 0.086 & 0.040 \\
$\mathbf{3}$ & NE Peak, shallow & 0.030 & 0.003 & 0.013 & 0.035 & 0.013 \\
$\mathbf{4}$ & NE Peak, deep & 0.030 & 0.005 & 0.017 & 0.152 & 0.152 \\
$\mathbf{5}$ & S. Flank, Shallow & 0.080 & 0.047 & 0.079 & 0.078 & 0.037 \\
$\mathbf{6}$ & " & 0.138 & 0.332 & 0.104 & 0.097 & 0.033 \\
$\mathbf{7}$ & S. Flank, Deep & 0.123 & 0.032 & 0.125 & 0.306 & 0.428 \\
$\mathbf{8}$ & " & 0.338 & 0.135 & 0.383 & 0.200 & 0.281 \\
\hline
\end{tabular}

The left eigenvector of $\mathbf{T}$, by equation 5.24 , provides a method of comparing the reproductive value of a given stage or age class between populations; the ratio of reproductive values for adults in any two populations is equal to the ratio of the reproductive values for those populations as indicated by the transport vector, $\mathbf{T}$. With increased wind forcing, highest reproductive value shifted from the Northeast Peak (region 4, Figure 5.1) in the weaker wind cases to the Northwest corner in the high wind 
regime (Table 5.4).

Table 5.4: Left eigenvectors ( $\mathbf{v}$, reproductive value) vectors for the transport matrix, $\mathbf{T}$, from each model

\begin{tabular}{ccccccc}
$\begin{array}{c}\text { year. } \\
\text { Region }\end{array}$ & & $\mathbf{1 9 7 4}$ & $\mathbf{1 9 7 8}$ & $\mathbf{1 9 9 1}$ & $\mathbf{1 9 7 4}$ mean & $\mathbf{1 9 7 8}$ mean \\
\hline $\mathbf{1}$ & North Flank & 0.009 & 0.062 & 0.004 & 0.073 & 0.040 \\
$\mathbf{2}$ & SCOPEX site & 0.011 & 1.000 & 0.005 & 0.064 & 0.025 \\
$\mathbf{3}$ & NE Peak, shallow & 0.128 & 0.011 & 0.054 & 0.679 & 0.309 \\
$\mathbf{4}$ & NE Peak, deep & 1.000 & 0.054 & 1.000 & 1.000 & 1.000 \\
$\mathbf{5}$ & S. Flank, Shallow & 0.014 & 0.000 & 0.004 & 0.128 & 0.025 \\
$\mathbf{6}$ & " & 0.011 & 0.577 & 0.003 & 0.077 & 0.028 \\
$\mathbf{7}$ & S. Flank, Deep & 0.097 & 0.006 & 0.147 & 0.468 & 0.098 \\
$\mathbf{8}$ & " & 0.007 & 0.000 & 0.001 & 0.085 & 0.004 \\
\hline
\end{tabular}

Considered together the left and right eigenvectors highlight important interactions on the bank. Comparison of effects of different years and types of wind forcing on the various subpopulations points out some important features of the overall bank dynamics and exchange between populations. The stable population distribution identifies the most densely settled regions, while the reproductive value vector points out the regions where reproduction has the greatest impact on future population growth.

The North Flank population (region 1, Figure 5.1) is consistently sparsely settled in all model years; its location coincides with the northern flank jet, and its position puts it at the upstream side of the bank for the Ekman flows. Winds from the northwest (the most common winter wind direction) drive Gulf of Maine waters onto the North Flank, preventing transport of Georges Bank populations onto the North Flank. Maine coast populations are probably too far away to provide a consistent source of larvae for Georges Bank, although that hypothesis is not addressed by this work.

The population on the northwest corner of the bank, near the site of the South Channel Ocean Productivity Experiment (region 2, referred to here as the SCOPEX region, Kenney and Wishner, 1995), plays a key role in the dynamics of the overall 
population in every case. In the lower wind years the population densities in this region are the second highest on the bank, at about $50 \%$ of maximum population densities.

The Northeast Peak showed consistently low population densities, even in the lowest wind case. Regions 3 and 4 had relatively low population densities across the three cases, ranging from $1 \%$ to $9 \%$ of the maximum density. Density varied consistently with wind forcing, and lowest relative density in this region was seen in the 1978 wind case.

A noticeable contrast exists between region 2 and 4; in the high wind case, region 2 has both the highest density and highest reproductive success, its larvae feed back to itself and to areas on the southwest corner of the bank. In the low wind cases, the recirculation of the bank made reproductive value fairly high for individuals in region 4 , but low population densities made the region a relatively insignificant contributor to other populations.

On the southern flank of the Bank, populations were consistently high in both of the lower wind cases. The trend was to highest density in the deeper water and toward the southwest, both consistent with the dominant direction of tidal residual and wind forced transport. The shallow water populations (regions 5 and 6), ranging from 40 to 70 meters, showed some of the most consistent behavior among bank populations. The southwestern group (region 6) had high densities in all three cases. The northeastern area (region 5), was more sensitive to wind forcing with the density there being reduced by $50 \%$ in the 1978 simulation.

The deeper water (70 to 100 meters) populations on the South Flank showed a very similar trend. The downstream population (region 8) had consistently high 
densities, while density in the upstream region was generally high, but was strongly impacted by high wind forcing. Reproductive value for these populations was typically low, with one exception; the shallow water population on the southwest corner of the bank (region 6) supplied larvae to itself and to the SCOPEX region (region 2).

A comparison of the eigenvectors from the synoptic and the vector averaged cases (Table 5.3-4, see also Figure 5.3, below), again highlights the marked differences in model results based on the type of wind forcing used and consequent differences in predicted transport. The asymptotic population growth rate in either of the vectoraveraged model runs is higher than any of the predicted values from the synoptic runs; the stable population distributions also differ sharply between the synoptic models and the vector-averaged model runs from the corresponding year.

Table 5.5: Diagonal of sensitivity matrix for each year's transport matrix, $\mathbf{S}_{T}$, assuming 8 populations and a 60 day larval transport time. This also represents the "contribution" of population $i$ to $\lambda$ for the designated years.

\begin{tabular}{ccccccc}
\hline Region & & $\mathbf{1 9 7 4}$ & $\mathbf{1 9 7 8}$ & $\mathbf{1 9 9 1}$ & $\mathbf{1 9 7 4}$ mean 1978 mean \\
\hline $\mathbf{1}$ & North Flank & 0.014 & 0.001 & 0.005 & 0.009 & 0.003 \\
$\mathbf{2}$ & SCOPEX site & 0.036 & 0.694 & 0.027 & 0.015 & 0.005 \\
$\mathbf{3}$ & NE Peak, shallow & 0.072 & 0.000 & 0.018 & 0.065 & 0.020 \\
$\mathbf{4}$ & NE Peak, deep & 0.567 & 0.000 & 0.445 & 0.419 & 0.750 \\
$\mathbf{5}$ & S. Flank, Shallow & 0.020 & 0.000 & 0.009 & 0.028 & 0.005 \\
$\mathbf{6}$ & " & 0.029 & 0.305 & 0.008 & 0.021 & 0.004 \\
$\mathbf{7}$ & S. Flank, Deep & 0.221 & 0.000 & 0.479 & 0.396 & 0.208 \\
$\mathbf{8}$ & \multicolumn{1}{c}{} & 0.041 & 0.000 & 0.009 & 0.047 & 0.005 \\
\hline
\end{tabular}

\section{Sensitivity and Elasticity}

As discussed previously (equation 5.26), sensitivities for a given demographic parameter, between populations, scale as $\mathbf{S}_{T}$. In this model the demographic parameters for the benthic stages appear in the diagonal blocks of $\mathbf{A}$ (Equation 5.10) and their sensitivities in the diagonal blocks of $\mathbf{S}$. Only the diagonal terms of $\mathbf{S}_{T}$ affect these sensitivities (Equation 5.26, Table 5.5). The sensitivity of larval transport terms is a 
function of the off-diagonal elements of $\mathbf{S}_{T}$ (Figure 5.2), as shown in equation 5.26.

The diagonal elements of the sensitivity matrix, $S_{i, i}$ also represent the sum of the columns of the elasticity matrix corresponding to region $i$. This sum indicates the "contribution" of population $i$ to $\lambda$ (Caswell, 1989).

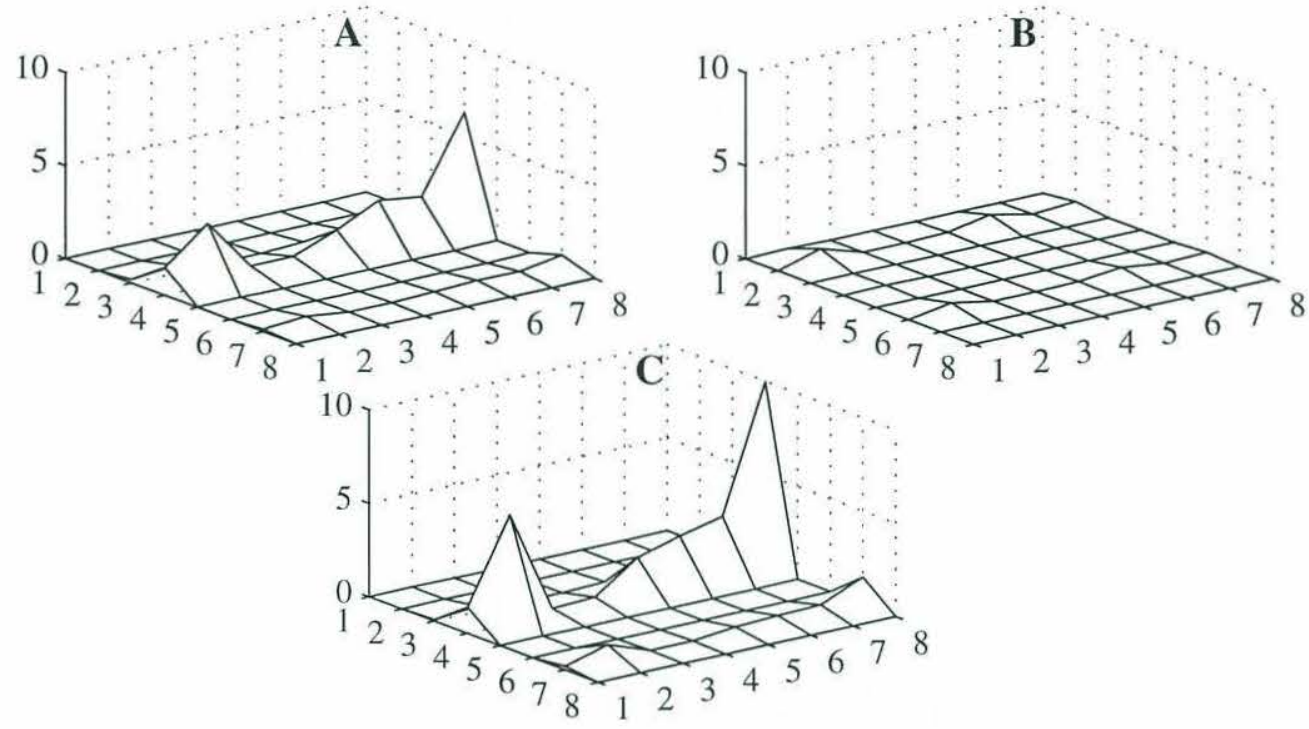

Figure 5.2: Sensitivity matrices of the transport matrix, $\mathbf{S}_{T}$ (equation 5.26). Panels $\mathbf{A}-\mathbf{C}$ are for years 1974, 1978 and 1991 respectively. Numbers on the right hand axis indicate which population individuals come from, and the left hand axis indicates where they settle.

In the lower wind synoptic cases (1974 and 1991) and in both vector averaged cases, the largest sensitivity in the transport matrix was to changes in the terms governing transport into regions 4 and 7 (Figure 5.2; Table 5.5). Additionally, over 75\% of the elasticity was in these two regions in all runs other than the 1978 synoptic run. The full structure of the sensitivity matrix shows that highest sensitivity was to changes in transport from each of the other populations into the Northeast Peak population (region 4). The consistent emphasis on the Northeast Peak populations likely rests on their position as the upstream source in the prevailing anticyclonic gyre. Of the other regions, 
only region 3 has an elasticity value greater than $5 \%$.

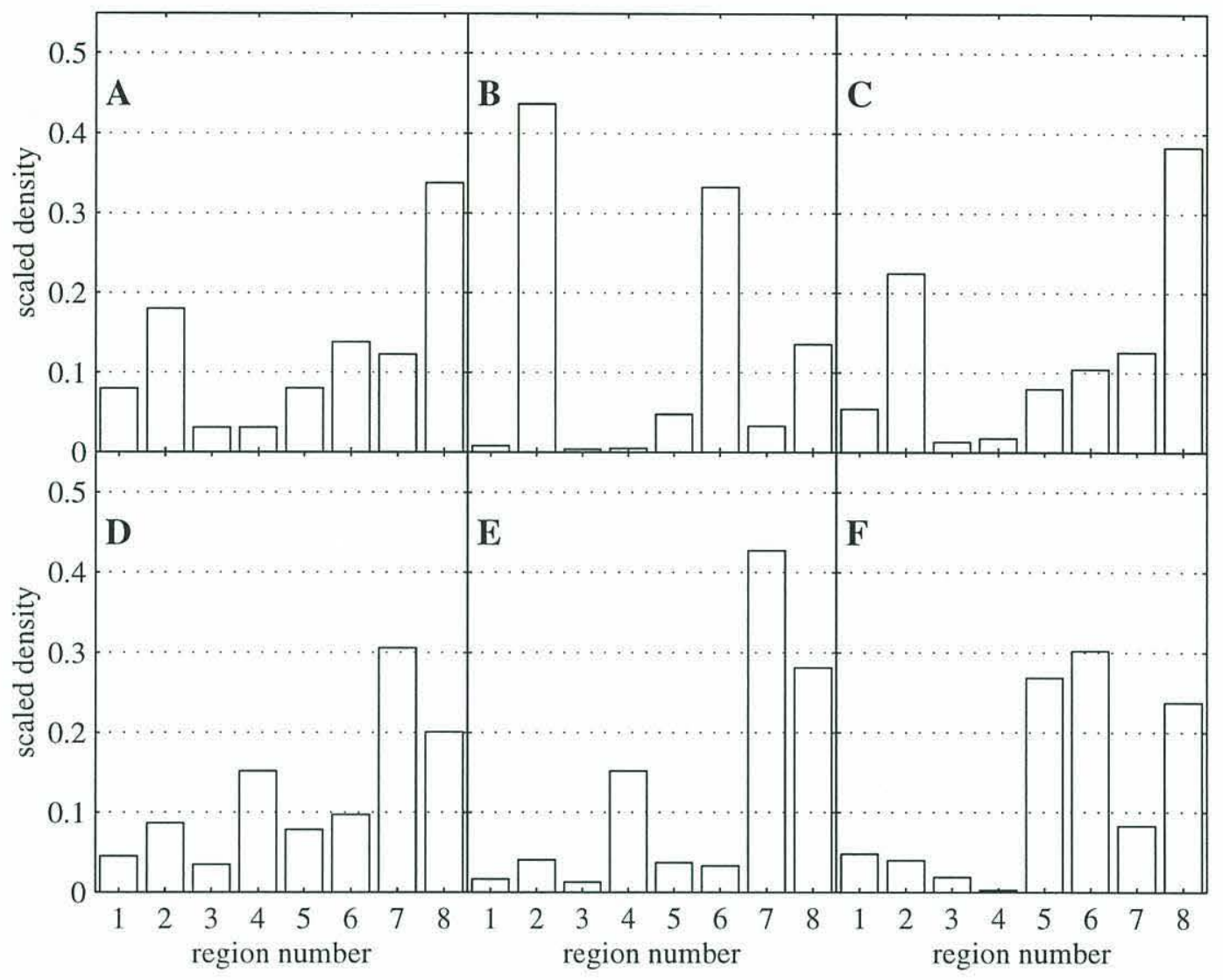

Figure 5.3: Graph of right eigenvector of the transport matrix, T. Panels A-C are for synoptic modeling for years 1974, 78 and 91 respectively. Panels $\mathbf{D}$ and $\mathbf{E}$ use transport from the 1974 and 78 vector averaged wind cases, and panel $\mathbf{F}$ is normalized data taken from 1982-94 National Marine Fisheries Service shellfish assessment cruises.

In contrast, highest sensitivities in the high-wind case (1978 synoptic) were for the two dominant populations (regions 2 and 6 on the western edge of the bank), and exchange between these two populations. The dominant winds prevented significant transport into this area from most of the eastern portion of the bank, leaving only the recirculation in the north end of the Great South Channel as a source of larvae. In this case only regions 2 and 6 have elasticities greater than 5\%; the summed elasticity for all other regions was $0.1 \%$. The full sensitivity matrix for the high wind case also differs 
markedly from all other synoptic runs (Figure 5.2). Sensitivities in this case were much lower, and focused only on the exchange between the two active populations (2 and 6), whereas sensitivity in the other cases focused on the inputs to the Northeast Peak population that was upstream of the large habitat area on the South Flank (region 4).

\section{Comparison with field results}

The comparison of these model results with observed Arctica distributions (Chapter 3 and Figure 5.3F) provides some support for our hypothesis that population levels are sensitive to larval supply. Comparison of the modeling results for the low wind winter (Figure 5.3A) with observations taken from NMFS tows (Figure 5.3F) shows some similarities in spatial trends in population density. This comparison is based on the assumption that a strictly linear model with no time variation in winds can provide some indication of the effects of transport, whereas observed distribution are the result of many years of time variation of winds and a variety of other parameters. This comparison asks the question: are field distributions consistent with modeled transport?

Actual Arctica density on Georges Bank (Figure 5.3F and 5.4) was low over the Northeast Peak (regions 3 and 4) and high across the South Flank (regions 5-8). Highest densities occurred in a long swath along the 70 meter isobath over the South Flank and in a small area within region 2 (Figure 5.4). 


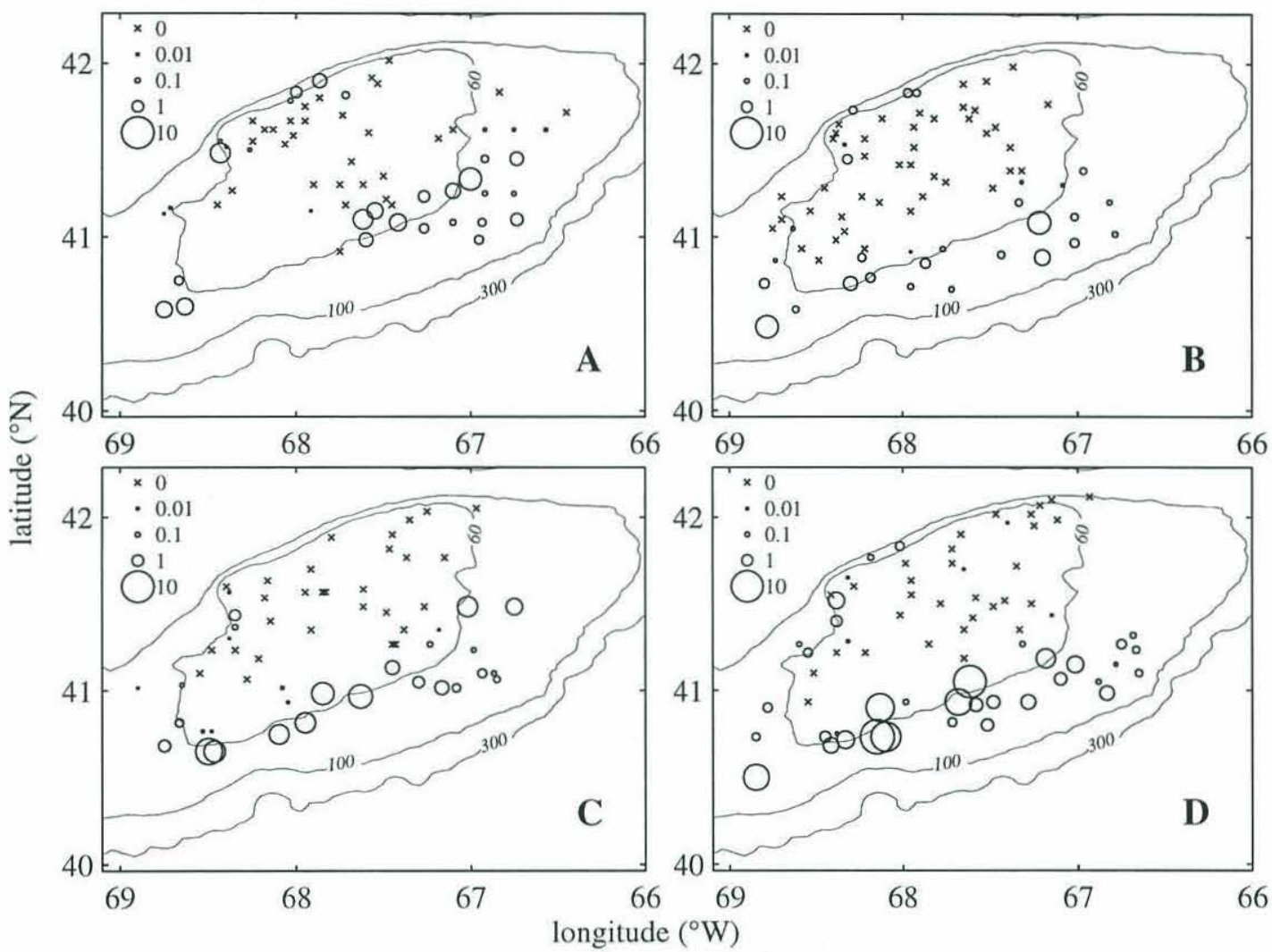

Figure 5.4: Arctica islandica density (\# $\mathrm{m}^{-2}$ ) from the A) 1982, 1983 and 1984, B) 1986 and 1989, C) 1992, and D) 1994 survey cruises. Area of circle is proportional to density. Isobaths are in meters. (taken from chapter 3)

Some aspects of the modeled distribution compared favorably with the data for the low and high low wind synoptic cases, although distinct differences were found for some regions. For all synoptic cases, model results agree with the observation of low densities over the Northeast Peak (regions 3 and 4). The lower wind model runs (1974 and 1991) gave higher densities in the SCOPEX region and the North Flank (regions 1 and 2) than on the Northeast Peak (regions 3 and 4), agreeing with the data (Figures 5.3 and 5.4). The model results, however, show higher density in the SCOPEX region (region 2) than is evident in the data. A noticeable failure in the model is in the prediction of abundances in the shallow waters of the South Flank (regions 5 and 6). The observed densities in these two regions were the highest of any region on the bank. The model, while 
accurately reflecting the increasing trend from northeast to southwest, represents these populations as being of lower density than regions 2 and 8 .

In comparing the model results to the NMFS field observations, none of the model runs had statistically significant rank correlations with data ${ }^{11}$. The 1974 and 1978 synoptic runs had the best fit to the data, with both years giving rank correlations of 0.429 with the data (probability of this correlation arising by chance was 0.089 ). The rank correlations for the 1991 model year and the two vector-averaged models were not significant, although the 1991 results were closer than the vector-averaged results. A trend of increasing abundance moving from northeast to southwest along the flank of the bank is seen in both the data and the models in comparisons of region 5 with region 6 and region 7 with region 8 . The model, however, consistently predicts higher abundance in deeper water than in shallow water, a result not supported by the data.

In general, while the matrix model is not significantly consistent with the overall bankwide distribution, it does generate an abundance peak in the SCOPEX site (region 2) and reproduces the increase in density from the northeast to the southwest along the South Flank. Model results tend to predict higher abundances in the deep regions than in neighboring shallow regions, contrary to the field data (e.g. compare regions 5 to 7 and 6 to 8). The presence of spatial variation in demography and stratification-dependent physics would make such comparisons more meaningful.

11 Kendall's rank correlation coefficient, $\tau$, and the probability, $\mathrm{p}(\tau)$, of generating, by random selection of ranks, a $\tau^{\prime}$ such that $\tau^{\prime} \geq \tau$, for each of the model runs:

\begin{tabular}{cccccc}
\hline Year & $\mathbf{1 9 7 4}$ & $\mathbf{1 9 7 8}$ & $\mathbf{1 9 9 1}$ & $\mathbf{1 9 7 4}$ mean & $\mathbf{1 9 7 8}$ mean \\
\hline$\tau$ & 0.429 & 0.429 & 0.286 & 0.071 & 0.071 \\
$\mathbf{p}(\tau)$ & 0.089 & 0.089 & 0.199 & 0.452 & 0.452 \\
\hline
\end{tabular}


Given the basic consistency, analysis of the model for parameter sensitivity and elasticity may be expected to provide useful information about the population behavior as a whole. The simple linear model allows quantification and comparison of the importance of several demographic and oceanographic processes.

\section{Demographic Structure}

Addition of demographic structure did allow analysis of the overall effect of including larval transport into an otherwise homogeneous set of populations. The effect of various transport terms on the overall sensitivity of the population growth rate to changes in demographic parameters was also examined.

Table 5.6: Eigenvalues and age structure (proportion of adults) for multiregional stage and age structured matrix models. $\mathbf{B}+\mathbf{R}$ denotes the results for a projection matrix with no transport losses.

\begin{tabular}{llllccc}
\hline Stage Str. & $\mathbf{B}+\mathbf{R}$ & $\mathbf{1 9 7 4}$ & $\mathbf{1 9 7 8}$ & $\mathbf{1 9 9 1}$ & $\mathbf{1 9 7 4}$ mean 1978 mean \\
\hline$\lambda$ & 1.188 & 1.076 & 1.048 & 1.055 & 1.118 & 1.087 \\
$\%$ adults & 0.369 & 0.559 & 0.641 & 0.620 & 0.469 & 0.532 \\
\hline Age Str. & $\mathbf{B}+\mathbf{R}$ & $\mathbf{1 9 7 4}$ & $\mathbf{1 9 7 8}$ & $\mathbf{1 9 9 1}$ & $\mathbf{1 9 7 4}$ mean 1978 mean \\
\hline$\lambda$ & 1.106 & 1.045 & 1.027 & 1.032 & 1.069 & 1.052 \\
$\%$ adults & 0.325 & 0.539 & 0.630 & 0.606 & 0.438 & 0.509 \\
\hline
\end{tabular}

\section{Eigenvalues}

The eigenvalues of the full multi-regional, age- and stage-structured matrix population models (Table 5.6) show similar trends to the eigenvalues for the transport matrix (as might be expected from equation 5.22). However, the large (up to 50\%) relative difference between the eigenvalues shown in Table 5.2 is greatly reduced by the introduction of population structure to the models. The proportion of adults increased with decreasing growth rates as increases in transport losses gave stage and age structures biased towards adults. 
The differences between the eigenvalues and proportion of adults predicted by the two structures is slight. Both show the same overall trends in population structure with magnitude and type of wind forcing. The age-structured model had lower growth rates than did the stage-structured model; however, the proportion of adults in the population in either model was almost identical for a given year. Overall, this result indicated that the addition of full age-structure to the model had little impact on the overall growth rate or structure of the population.

The 107 by 107 age structured population model gave similar results to the stage class model in which juvenile and adults stages were aggregated. A significant decline in cohort size through the juvenile stages, where mortality was $10-20 \%$ per year, was followed by a much slower decline in cohort size through adulthood, where losses were only $2 \%$ per year. The stable age distribution of a population with no transport losses (represented by the sum of $\mathbf{B}$, benthic survival and growth terms, and $\mathbf{R}$, larval settlement, with no transport losses [ $\mathbf{T}=1]$ ) had $33 \%$ adults.

The relatively high proportion of adults in the predicted stage structures is a result of the fact that these structures assume that the census takes place an entire year after spawning. In contrast, a census taken immediately after settlement would show very high numbers of newly settled spat, and the proportion of adults could be expected to cycle as the high mortality of newly settled spat causes their numbers to fall dramatically between spawning seasons. In the sampling survey work done by the National Marine Fisheries Service (see Chapter 3 for a discussion), many of the early juvenile stages are too small to be reliably captured by standard sampling equipment (Chapter 3), so comparison of these results with field observations is not possible. The model results, however, imply that the generally observed low juvenile numbers may be reflective of a 
low replacement rate in this long-lived population, rather than just an artifact of the sampling equipment.

Table 5.7: The sensitivity of $\lambda_{\mathrm{A}}$ for each matrix element and contributing parameter in $\mathbf{X}$ (Caswell, 1989); results for the stage structured model. The column labeled $\mathbf{B}+\mathbf{R}$ indicates the sensitivity of the parameter in a single population model without export or import of larvae $(\mathbf{T}=1)$.

\begin{tabular}{|c|c|c|c|c|c|c|}
\hline Parameter & $B+R$ & 1974 & 1978 & 1991 & $1974 \mathrm{VA}$ & $1978 \mathrm{VA}$ \\
\hline$x_{1,2}$ & 0.182 & 0.096 & 0.071 & 0.077 & 0.129 & 0.105 \\
\hline$f$ & 0.000 & 0.000 & 0.000 & 0.000 & 0.000 & 0.000 \\
\hline$P_{e}$ & 0.000 & 0.000 & 0.000 & 0.000 & 0.000 & 0.000 \\
\hline$P_{f}$ & 1.433 & 0.751 & 0.561 & 0.606 & 1.016 & 0.824 \\
\hline$s_{l}$ & 2115.297 & 1108.787 & 827.575 & 895.071 & 1499.862 & 1216.115 \\
\hline$d_{l}$ & -0.023 & -0.012 & -0.009 & -0.010 & -0.016 & -0.013 \\
\hline$P_{m}$ & -8.596 & -4.506 & -3.363 & -3.637 & -6.095 & -4.942 \\
\hline$c$ & 0.494 & 0.259 & 0.193 & 0.209 & 0.350 & 0.284 \\
\hline$x_{1,1}$ & 0.312 & 0.075 & 0.040 & 0.047 & 0.146 & 0.092 \\
\hline$x_{2,1}$ & 1.178 & 0.215 & 0.104 & 0.126 & 0.467 & 0.271 \\
\hline$d_{j}$ & -0.015 & -0.007 & -0.005 & -0.005 & -0.010 & -0.008 \\
\hline$s_{j}$ & 0.436 & 0.274 & 0.217 & 0.231 & 0.344 & 0.294 \\
\hline$x_{2,2}$ & 0.688 & 0.272 & 0.187 & 0.206 & 0.412 & 0.308 \\
\hline$s_{a}$ & 0.688 & 0.783 & 0.824 & 0.813 & 0.738 & 0.769 \\
\hline$\lambda_{T}$ & 0.143 & 0.216 & 0.247 & 0.239 & 0.182 & 0.206 \\
\hline
\end{tabular}

\section{Sensitivity and elasticity}

The sensitivity of population growth to changes in demographic parameters (and the relative importance of those parameters to that rate; Caswell, 1989) can be assessed with simple sensitivity and elasticity calculations (Table 5.7 and 5.8). These calculations highlight those demographic parameters in which variation has the greatest effect on overall population growth rates, the first stressing absolute sensitivity, the second focusing on sensitivity proportional to the value of the parameter.

The evaluation of the sensitivity and the elasticity ignores the age structured model for two reasons: 1) the results were very similar to the results of the stage structured 
model, contributing no new insights, and 2) the analysis of the 107 by 107 element matrix does not highlight specific processes as clearly as the stage structured model does. This section focuses primarily on the effect of demographic processes ( $\mathbf{B}$ and $\mathbf{R}$ ), and their interaction with transport ( $\mathbf{A}$ and $\mathbf{X}$ ), where the preceding sensitivity analysis focused on the transport matrix, T. Unless otherwise stated, all the sensitivities and elasticities discussed are for the full 8-population matrix model, although much of the analysis relies on the decomposition of that model described in equations 5.12-18.

The highest sensitivity was to changes in the overall larval survival term, $\mathbf{s}_{l}$, a result of the extremely small magnitude $\left(6.77 \times 10^{-5}\right)$ of that value. Also notable, however, is the sensitivity to instantaneous planktonic mortality $\left(P_{m}\right)$, one of the factors contributing to the larval survival term. The sensitivity of overall growth rate to changes in the eigenvalue of the transport matrix is also instructive. This value reveals that, in this model, large variations in transport contribute little to the overall growth rate of the population; this is consistent with the previous observation that, although wind forcing caused about a 35\% decrease in the eigenvalue between the 1974 and 1978 model runs, the resultant difference in population growth rates on the bank was much smaller.

The wide variation in magnitude of the demographic parameters, however, makes consideration of their elasticity (proportional sensitivity) much more revealing (Table 5.8). The elasticity of a parameter is the same as elasticity of any parameters of which it is a product. In some cases, most notably the planktonic survival, $\boldsymbol{s}_{l}$, the parameter has a more complicated functional relationship $\left(s_{l}=\mathrm{e}^{-} d_{l} P_{m}\right)$, which gives the contributing parameters a much stronger proportional sensitivity.

This analysis showed that adult mortality was, in general, the dominant 
component of elasticity matrices (Table 5.8), although the factors affecting the larval survival $\left(d_{l}\right.$, and $\left.P_{m}\right)$ ranked a close second in all transport models and actually had the highest elasticity in the single population model. If only the four elements of the projection matrix are considered, the elasticity is mostly in the adult survival term, more so in the transport models than the single population matrix.

Table 5.8: The elasticity of $\lambda_{\mathrm{A}}$ for each matrix element and contributing parameter in $\mathbf{X}$ (Caswell, 1989); results for the stage structured model (Caswell, 1989). The column labeled $\mathbf{B}+\mathbf{R}$ indicates the elasticity of the parameter in a single population model without export or import of larvae $(\mathbf{T}=1)$.

\begin{tabular}{ccccccc}
\hline Parameter & $\mathbf{B}+\mathbf{R}$ & $\mathbf{1 9 7 4}$ & $\mathbf{1 9 7 8}$ & $\mathbf{1 9 9 1}$ & $\begin{array}{c}\mathbf{1 9 7 4} \\
\text { mean }\end{array}$ & $\begin{array}{c}\mathbf{1 9 7 8} \\
\text { mean }\end{array}$ \\
\hline $\begin{array}{c}\lambda_{T}, \boldsymbol{x}_{1,2}, \boldsymbol{x}_{2,1}, f, \\
\boldsymbol{s}_{l}, \boldsymbol{c}, P_{e}, P_{f}\end{array}$ & 0.121 & 0.070 & 0.053 & 0.057 & 0.091 & 0.076 \\
\hline$d_{l}, P_{m}$ & -1.157 & -0.670 & -0.513 & -0.552 & -0.873 & -0.727 \\
\hline $\boldsymbol{x}_{1,1}$ & 0.192 & 0.147 & 0.123 & 0.129 & 0.171 & 0.155 \\
\hline $\boldsymbol{d}_{j}$ & -0.089 & -0.045 & -0.033 & -0.036 & -0.062 & -0.050 \\
\hline $\boldsymbol{s}_{j}$ & 0.312 & 0.217 & 0.176 & 0.187 & 0.262 & 0.231 \\
\hline $\boldsymbol{x}_{2,2}, \boldsymbol{s}_{a}$ & 0.567 & 0.713 & 0.770 & 0.756 & 0.647 & 0.694 \\
\hline
\end{tabular}

Two factors emerge from this analysis as being critical determinants of Arctica growth rate. The obvious factor for this long-lived species was adult survival. The model showed the population growth to be very sensitive to variations in the death rate of adults. Also of primary importance were the factors determining larval mortality; larval duration and planktonic mortality had proportional sensitivities very nearly as high as that of adult mortality.

\section{DISCUSSION}

This work identified mathematical features of multiregional matrix models that can be applied to a variety of systems where spatial variation in demographic parameters is neglected. In addition, these models provide a number of interesting indications about the health, interdependence and stability of Arctica populations on Georges Bank. 
The assumption that there is no spatial variation in demographic parameters, other than the transport exchange and losses of larvae, may neglect some known biological dynamics, but can be supported on several grounds; first, the present study is directed at identifying the effects of transport on spatial variability in recruitment and population dynamics, and introduction of spatial variability in population processes would confound the analysis. This work isolates the effects of transport and identifies the population interactions based solely on those transport effects. Second, very little data exist to determine what might drive mesoscale spatial variability in Arctica population parameters. While depth and temperature limits are known for this species (Nicol, 1951; Landers, 1976), any attempt to assign a functional response to either of these parameters would be purely speculative.

\section{Demography}

The dominant eigenvalue of a nonnegative matrix must be greater than or equal to the greatest of the diagonal elements, $\lambda \geq \max a_{i i}$ (Horn and Johnson, 1985). This implies that the asymptotic population growth rate has a lower bound, i.e. any discussion of the model eigenvalues and vectors must take into account the fact that the population's growth rate has a lower constraint. In general, matrix population models only have diagonal elements if they are size or stage structured, rather than age structured.

These constraints also have ramifications for the elasticity and sensitivity. A population in which there is no successful reproduction would have an eigenvalue equal to the maximum diagonal element. In stage structured models whose eigenvalues are near the maximal $a_{i i}$, sensitivity and elasticity begin to focus on changes in the maximal $a_{i i}$, while the sensitivity and elasticity of all other elements drop to zero as $\lambda$ nears max $a_{i i}$. 
For example, consider a population whose dynamics are described by the projection matrix B (no successful reproduction) in equation 5.8; for the parameters presented here, the sensitivity and elasticity of this matrix are:

$$
\begin{gathered}
\mathbf{S}=\left[\begin{array}{lc}
0 & 0.49 \\
0 & 1
\end{array}\right] . \\
\mathbf{E}=\left[\begin{array}{ll}
0 & 0 \\
0 & 1
\end{array}\right]
\end{gathered}
$$

The sensitivity is highest and elasticity is focused entirely for the adult survival term in the lower right, whereas the complete lack of reproduction comes through only in the lack of sensitivity to changes in juvenile survival and growth parameters. For biological analysis of matrix models, this result can point to counterintuitive conclusions; the relative importance (elasticity) of changes in reproduction decreases to 0 precisely when the loss of reproduction would be causing the population to exponentially decay to extinction.

\section{Biological-physical interactions}

The matrix models highlighted the disparity between transport models using synoptic scale and average wind forcing. The two different types of wind forcing were shown previously to cause significant differences in the levels of transport between regions and the overall distribution of transported tracers.

The multiregional models discussed here highlighted those differences. The dependence of the modeled population structure solely on the transport matrix implies that changes in the transport matrix result in corresponding changes in the population distributions. Furthermore, levels of larval retention in the transport models using vector averaged winds were much higher, resulting in population growth rates lower than those 
predicted by the synoptic wind cases. The difference between the eigenvalues of the 1974 synoptic and 1974 mean case was greater than the difference between any two synoptic cases.

These results carried through to the interpopulation comparisons of the eigenvectors. The vector averaged case predicted distributions unlike any of the synoptic wind forcing cases, and the predicted population distributions for the vector averaged cases had a much lower correlation with the observed data.

The comparison of the model results to field data highlighted the need for refinement of the model. One of the most noticeable deviations between the model results and field data was the model's failure to predict the greater abundance in shallow water (regions 5 and 6) than deep water (regions 7 and 8) populations on the South Flank. However, one of the more important features of Georges Bank circulation during the late fall and early winter spawning period of Arctica is the tidal mixing front, centered around the 60 meter isobath (Butman et al., 1987). This is a convergent front that is likely to accumulate upward swimming larvae (Franks, 1992) and concentrate them in the area where highest adult densities are observed (Figure 5.4). This feature is not represented by our unstratified model.

The present work identified the magnitude of processes affecting larval transport of Arctica, and highlighted several requirements for more accurate modeling. These results, combined with those of chapter 2 , indicate the magnitude of transport effects on Georges Bank plankton populations. These findings also provide support for use of realistic time-dependent wind forcing in circulation models, and indicate that stratification may play an important role. A significant disparity between the results of synoptic and 
vector averaged wind forcing was found. Realistic transport computation is essential for accurate biological-physical modeling.

\section{Arctica on Georges Bank}

The linear stage structured model analysis of Arctica islandica populations on Georges Bank identified three important features and regions of significance to management of the population: 1) the observed population densities do not show a statistically significant rank correlation with model results, although some common features can be identified, 2) relative sensitivity of population growth to changes in various parameters and populations was identified, and 3) variations in larval transport were shown to have a noticeable effect on bankwide distributions of adults. This comparison of the field data to model eigenvalues tests the assumption that the natural temporal variation in demography and circulation explained by linear, time-invariant transport patterns. The transport matrix eigenvectors (and consequent abundance patterns) shown here would be observed in any model with no spatial variation in vital rates and linear population dynamics.

The lack of a statistically significant correlation indicates that the model fails to account for some processes; however the existence of trends common to both the model results and the field data (NEFSC, 1986, 1989, 1992, 1994) imply that larval supply may play a role in determining recruitment into and distribution of the adult population. The increase in abundance along the South Flank, and the identification of region 2 as an area where recirculation in the SCOPEX region maintains high larval concentrations are two features of the model that are consistent with field data.

As discussed previously, the lack of stratification in the physical model may 
account for some of the differences; stratification is known to play a key role in convergence zones near the $60 \mathrm{~m}$ isobath, and such zones have been identified as regions where upward-swimming larvae can accumulate. Greater knowledge about spatial and temporal variation in demographic parameters is also critical to isolating the mechanisms driving Arctica stock levels. The effects of interannual variations in post-settlement and juvenile mortality could also be driving temporal variation in recruitment into the adult population. The models presented here focused on identifying the relative importance of various processes, and on quantifying the magnitude of a process that has previously proven difficult to study: the effect of circulation and physical variability on larval transport. While the lack of statistical correlation is troubling, it is hoped that these results can guide further research into the processes and demographics important to Arctica population dynamics and Georges Bank dynamics.

An important result of these models is that adult mortality is a critical determinant of population growth. The elasticity was highest for the adult mortality term. The age structured models also indicated that sensitivity was highest to adult mortality. The sensitivity to adult mortality is broadly consistent with other stage structured analyses of long-lived species in identifying adult mortality as one of the key processes controlling population growth (Crouse, et al., 1987; Crowder, et al., 1994; Doak, et al., 1994), although other authors use more stages to resolve their population dynamics, allowing for multiple reproductive stages.

The increased elasticity and sensitivity of the maximal diagonal element as $\lambda$ decreases can be seen in other stage-structured models of long-lived species. For example, in a 5 stage model of Loggerhead Sea Turtle demography, elasticity is highest for the matrix element determining survival of those remaining in stage $5\left(a_{5,5}\right.$ was the 
maximal diagonal element), but the authors later show that greatest changes in the intrinsic rate of increase can be effected by changes in the survival of stage 3 (Crowder $e t$ al., 1994). A 7 stage model analysis of desert tortoise population dynamics had a maximum elasticity to changes in $a_{6,6}$ whereas $a_{7,7}$ was the maximum diagonal element (Doak et al., 1994). These authors, however, put some emphasis on identifying conditions which yield population equilibrium or growth $(\lambda \geq 1)$, while failing to note that some of their alternative scenarios result in $\max \left(a_{i, i}\right)=1$, a case which for which $\lambda \geq$ 1 is guaranteed (Horn and Johnson, 1985).

After adult mortality, the next highest elasticity lay in factors determining larval survival, namely the duration of the larval stage and the mortality experienced while in the plankton. These two factors both had a negative elasticity, i.e. decreases in either duration in the plankton or mortality yielded an increase in the population growth rate. A third factor in planktonic survival is the transport loss, which would also decrease with decreased planktonic period. While the present work considered only one specific planktonic duration (60 days), it is likely (and evident from the results shown in Chapter 4) that reducing transport time will reduce transport losses.

This modeling work implies that the outlook for a sustained fishery of this species is poor. These strictly linear models fail to account for the extreme variation in stockrecruitment ratios observed in nature, but the underlying features still provide insight into the behavior of the population under increased fishing pressure. The potential existence of variations in interannual larval supply and recruitment into the adult population only underscores the need for caution in fishing this species. As the interval between successful recruitment grows, the effects of increased fishing mortality also make themselves felt. A $1 \%$ increase in annual mortality over the course of 10 years results in 
approximately a $10 \%$ reduction in standing stock.

However, in the face of the continuing pressure for open fisheries, the results of this work do suggest management strategies that offer more promise for maintaining stocks. Comparison of sensitivity and reproductive value between populations provides a good index of where fishing is likely to have the greatest long term impact on population dynamics. Both of the lower wind models point to the greatest sensitivity to changes in demographic parameters on the Northeast Peak (regions 4 and 7). This finding follows from the observation that the recirculating gyre on Georges Bank makes the northeastern and eastern side of Georges Bank the source populations for the entire South Flank. Larvae originating in this region feed into the entire southern flank habitat, a broad, flat area known to contain high densities of Arctica adults. The reproductive value of individuals from the southwestern areas of the bank (regions 5, 6, and 8) was, in both lower wind cases, less than $1 \%$ of comparable stage individuals on the Northeast Peak (region 4). In general, this would suggest that most management efforts should focus on the regions upstream of the Southern Flank, the eastern tip and Northeast Peak. Previous management efforts by the United States National Marine Fisheries Service have largely ignored this region, although some data from Canadian survey work is available (Thouzeau et al., 1991b).

This discussion, however, requires two caveats. First, the time of peak spawning for these clams, August through October, corresponds to the period when stratification still plays a strong role in bank circulation. It is possible that the weak recirculation observed in these unstratified results could, in the presence of stratification, be intense enough to carry larvae across the North Flank and into the Northeast Peak. Such a flow would provide a source of larvae for the critical Northeast Peak populations (regions 4 
and 7), and sustain greater fishing pressure in those regions.

In addition, these models consider the Georges Bank population as an isolated group, whereas this area is likely to serve as a significant source of larvae for regions to the southwest. Taken together, these two processes present an interesting mechanism; Georges Bank could be serving as a "bank account" for Arctica all along the Middle Atlantic Bight. With recirculation allowing the Bank population to maintain the adults ("principal") on Georges Bank and the shelf flow carrying some recruits ("interest") south, Georges Bank could be a source population for much of the U.S. East Coast.

In summary, the matrix population models provided a simple method of incorporating transport and demography into a single format and comparing their effects on population dynamics. The model was somewhat consistent in predicting the relative sizes of populations. These models identified the Northeast Peak as a critical management region, and exhibited highest sensitivity to changes in adult mortality. They indicate that fishing pressure, where it is allowed, should be carefully monitored to maintain spawning stocks sufficient to support future recruitment, and that population assessment should pay particular attention to the northeastern and eastern edge of Georges Bank, an area previously little addressed. 


\section{Chapter 6: Conclusion}

\section{SYNOPSIS}

Together, the analyses conducted in this work addressed one of the basic oceanographic questions; what causes recruitment variation? Key processes operating on a benthic and a planktonic species on Georges Bank were identified using field data and numerical models.

The approximate scale and timing of a recent recruitment event in Arctica islandica was identified using size and age structure, and the general utility of age banding for determining recruitment in Arctica was considered in Chapter 3. The numerical models presented represent two methods of coupling biological and physical oceanographic processes into a single system. Such coupled models provide the ability to compare the importance and magnitude of various processes and help identify the underlying forces driving ecosystem dynamics. These models, despite their many limitations, provide the ability to experiment on processes and scales that are otherwise impossible to manipulate. The models address the roles of wind forcing, stratification, and tidal rectification in controlling Georges Bank circulation and the resulting dynamics of planktonic and benthic ecosystems. In Chapter 2 , the effects of a 20 day period of high winds on the dynamics of a holoplanktonic population over an isolated offshore bank are considered. Chapters 4 and 5 develop a coupled biological-physical model representing the dynamics of Arctica islandica in an idealized system including a variety of physical and biological processes. 
Chapter 2 used an idealized model of Georges Bank to address the hypothesis that winter and early spring storms have the potential to sweep developing plankton populations off the bank, preventing establishment and development of high on-bank plankton concentrations in the early spring. The results of this model supported this "washout" hypothesis. Using a simple four-stage model of copepod (Pseudocalanus sp.) dynamics, the stronger winds yielded copepod concentrations that were $33 \%$ lower over the entire bank and $70 \%$ lower over the Ekman gain flank of the bank. A simple model of a three element food chain (nutrients, phytoplankton, and an herbivore) predicted zooplankton concentrations that were $14 \%$ lower over the entire bank and $22 \%$ lower over the bank crest.

In chapter 3, size structures collected on seven NMFS Arctica islandica Stock Assessment Surveys (from 1982-94) were analyzed for evidence of recruitment pulses, and the timing of a recruitment event on the South Flank was estimated from age structure of clams taken during the 1994 survey. This work indicated that detectable recruitment pulses in Arctica on Georges Bank have occurred and identified a single event, probably in 1986, on the southeast flank of Georges Bank. However, the accuracy of the method, even for young clams, did not allow the identification of the precise date of such events.

Chapters 4 and 5 describe the application of a coupled biological-physical model to Arctica larval transport and population dynamics on Georges Bank. In chapter 4, a three dimensional model of unstratified, tidal and wind forced flow over Georges Bank is used to describe the exchange and loss of larvae from 9 benthic sub-populations on the bank, under wind conditions derived from observations during a low (1974-5), medium (1991-2), and high (1978-9) wind winter on Georges Bank. The utility of vectoraveraged versus synoptic winds in three dimensional modeling was addressed in two 
cases (1974 and 1978; these two years were also considered in Chapter 2 using shorter period, steady winds). Differences in predicted larval transport were found between the two lower (1974 and 1991) and the high (1978) wind winter, and between the vectoraveraged and realistic simulations using the 1978 winds.

The results of the work in Chapter 4 were used in Chapter 5 in a linear, multiregional matrix model of Arctica population dynamics to address several questions: 1) Are Arctica distributions on Georges Bank consistent with settling patterns of larvae determined by a model of unstratified, tidal- and wind-forced flow over Georges Bank? 2) Do different year's wind forcing predict different overall abundance patterns? 3) Do models using vector-averaged winds predict similar abundance patterns to models using realistic wind forcing? 4) Given the transport patterns and losses predicted by the circulation models, which demographic parameters are most "important" in determining long-term growth rates?

Comparisons of model results and observational data on Arctica densities over Georges Bank were not statistically significant (at a 95\% confidence level), although the models using realistic low (1974) and high (1978) winds gave the best fit (probability of rank correlation arising by chance, $\mathrm{p}=0.09$ ), while models using vector-averaged winds gave the worst fit $(\mathrm{p}=0.45)$. The lack of a statistically significant fit to the field data indicates that the model, as it stands, fails to incorporate one or more processes regulating Arctica distribution and abundance (although abundance data are scarce in some regions considered by this work). Processes known to be neglected by this work include those for which information on parameters is not available (e.g. spatial and temporal variation in the ecological parameters determining mortality and growth) or which are difficult or impossible to incorporate into the numerical model (e.g. stratification and heat flux, 
greater spatial resolution of physics and population boundaries and multiple spawning events). Although the model does not incorporate all possible processes, it does provide a method of studying the comparative effects of wind forcing and some basic demographic parameters on a population of benthic bivalves on Georges Bank. Analysis of the model results may help to guide further study on the use and relevance of wind forced models on Georges Bank in general and on measurement of Arctica life history parameters.

Analysis of the model response to different years and types (vector-averaged versus realistic) of wind forcing agrees with the results of Chapter 4; models using the vector average of wind speed and models using realistic wind forcing do not generate the same results. The lack of a statistically significant fit to the data precludes a conclusion as to which most accurately models processes affecting Arctica dynamics, but the models using vector-averages had lowest rank correlations. Despite the differences in windforced transport, the sensitivity of the dominant eigenvalue to changes in the contributing demographic parameters showed the same overall pattern for all types and years of wind forcing used in this work. Larval survival and planktonic mortality had the highest sensitivity, while adult survival, planktonic mortality, and larval duration had the highest elasticity (proportional sensitivity).

The results of Chapter 5 indicate that further field and modeling work is necessary to accurately determine the fundamental processes driving Arctica dynamics. The models, used to predict an equilibrium population structure, indicate that vector-averaged wind forcing does not accurately reflect the wind dynamics taking place in a given year, and that wind records for different years predict very different population distributions. Despite the relatively high variation in predicted population patterns, all models identified 
planktonic mortality and duration and adult survival as the most "important" parameters determining population growth rates. The models using realistic winds from 1974 and 1991 (the two lower wind years, using realistic winds) identified the Northeast Peak as a key spawning area, while models using 1978 realistic wind indicated that the north end of Great South Channel may also be important.

In addition to providing new insights into the nature and effects of processes operating on Georges Bank ecosystems, these results also suggest a number of directions for further research. In the course of this study, a number of limitations in the model resolution were encountered that, if solved, would greatly facilitate further research into the problems discussed here and related issues.

\section{FUTURE WORK}

A significant need exists for a single physical model allowing the inclusion and comparison of all processes discussed here. The different models used in this work incorporated effects of stratification, steady and time varying winds, tidal rectification, turbulence-closure based mixing, and realistic topography, but did not allow the comparison of all effects in a single model. The omission of some processes in each the two models prevents a complete study of the interactions and effects that are known make Georges Bank such a oceanographically complex place to study. While inclusion of every one of the myriad processes operating on the bank is nearly impossible, inclusion of the major mesoscale processes discussed here would, I believe, greatly facilitate further work in this region.

Greater resolution and understanding of the biological processes involved would also be of great help. The biological models presented here represent are relatively 
simple, with the number of "dimensions" (trophic levels, species and/or population stages) being limited by the speed and memory of the computers used, and the interactions being limited to fairly simple nonlinear terms. Further work is needed to identify the optimal methods for simplifying complex ecosystems and including them into these physical models in a realistic and computationally tractable fashion.

Finally, the modeling and data analysis directed at resolving Arctica islandica dynamics identified several possibilities for further research on that species. Collection of more information concerning the distribution and abundance of early juveniles, greater use of banding data, and greater spatial coverage during the survey would improve understanding of the population dynamics of this species. While the model used here did not distinguish between natural and fishing mortality, it did indicate that, of all the demographic parameters included in the model, adult survival made the greatest direct contribution to population growth rates. The equilibrium growth rate determined by the matrix model was most sensitive to changes in planktonic mortality and larval duration in the plankton, but had the highest proportional sensitivity to adult mortality. These results suggest that a fishery for the adults (decreasing adult survival) should be managed with great caution. Also, the greatest sensitivity is to changes in planktonic processes about which little is known.

\section{SUMMARY}

In summary, several basic conclusions can be drawn concerning the impact of winds on Georges Bank ecosystems. The results imply that strong Northwest winds have the capability to markedly increase losses of plankton off the South Flank of the bank in the face of tidal (Chapter 4) and stratification (Chapter 2) driven flows around the 
bank. Models using realistic wind forcing give results different from models using vector averages of the same winds. The field data and models addressing Arctica islandica dynamics identified several important aspects of the dynamics of that species on Georges Bank. From the structure of the demographic models, adult survival seems to be the most important parameter controlling Arctica growth rate, with larval mortality and planktonic duration also playing an important role in determining overall population growth rates. Populations on the Northeast Peak were identified as a source region for much of the South Flank.

This work indicates that wind-forced circulation may play a significant role in planktonic and benthic recruitment on Georges Bank and that interannual differences in these winds can yield very different abundance patterns over the bank. Additionally, this work also provides a guide for future research in this area, identifying processes and combinations of processes that may be of import. 


\section{Appendix A: Transport MATrices}

Table A1-A5: Transport matrices used for the matrix modeling work in Chapter 5. Values are the density of settling larvae transported from the region designated by column, to the region designated by row.

SYNOPTIC FORCING

\begin{tabular}{|c|c|c|c|c|c|c|c|c|}
\hline $\mathbf{1 9 7 4}$ & \multicolumn{7}{|c|}{ From: } \\
\hline To: & $\mathbf{1}$ & $\mathbf{2}$ & $\mathbf{3}$ & $\mathbf{4}$ & $\mathbf{5}$ & $\mathbf{6}$ & $\mathbf{7}$ & $\mathbf{8}$ \\
\hline $\mathbf{1}$ & 0.033 & 0.052 & 0.039 & 0.003 & 0.055 & 0.068 & 0.000 & 0.002 \\
\hline $\mathbf{2}$ & 0.028 & 0.041 & 0.218 & 0.000 & 0.203 & 0.058 & 0.002 & 0.065 \\
\hline $\mathbf{3}$ & 0.011 & 0.018 & 0.043 & 0.077 & 0.000 & 0.020 & 0.000 & 0.000 \\
\hline $\mathbf{4}$ & 0.000 & 0.000 & 0.022 & 0.298 & 0.000 & 0.000 & 0.007 & 0.000 \\
\hline $\mathbf{5}$ & 0.033 & 0.026 & 0.220 & 0.245 & 0.003 & 0.004 & 0.044 & 0.000 \\
\hline $\mathbf{6}$ & 0.040 & 0.009 & 0.495 & 0.028 & 0.083 & 0.001 & 0.063 & 0.038 \\
\hline $\mathbf{7}$ & 0.001 & 0.000 & 0.049 & 0.365 & 0.002 & 0.000 & 0.243 & 0.000 \\
\hline $\mathbf{8}$ & 0.003 & 0.000 & 0.106 & 0.018 & 0.135 & 0.001 & 0.353 & 0.175 \\
\hline
\end{tabular}

\begin{tabular}{|c|c|c|c|c|c|c|c|c|}
\hline $\mathbf{1 9 7 8}$ & \multicolumn{10}{|c|}{ From: } \\
\hline To: & $\mathbf{1}$ & $\mathbf{2}$ & $\mathbf{3}$ & $\mathbf{4}$ & $\mathbf{5}$ & $\mathbf{6}$ & $\mathbf{7}$ & $\mathbf{8}$ \\
\hline $\mathbf{1}$ & 0.000 & 0.003 & 0.000 & 0.025 & 0.000 & 0.001 & 0.000 & 0.000 \\
\hline $\mathbf{2}$ & 0.004 & 0.148 & 0.000 & 0.000 & 0.000 & 0.103 & 0.000 & 0.000 \\
\hline $\mathbf{3}$ & 0.000 & 0.001 & 0.000 & 0.030 & 0.000 & 0.000 & 0.001 & 0.000 \\
\hline $\mathbf{4}$ & 0.000 & 0.000 & 0.006 & 0.138 & 0.000 & 0.000 & 0.012 & 0.000 \\
\hline $\mathbf{5}$ & 0.027 & 0.021 & 0.071 & 0.034 & 0.000 & 0.003 & 0.000 & 0.000 \\
\hline $\mathbf{6}$ & 0.017 & 0.136 & 0.000 & 0.001 & 0.000 & 0.048 & 0.000 & 0.000 \\
\hline $\mathbf{7}$ & 0.023 & 0.000 & 0.315 & 0.321 & 0.013 & 0.000 & 0.122 & 0.000 \\
\hline $\mathbf{8}$ & 0.120 & 0.057 & 0.386 & 0.044 & 0.033 & 0.003 & 0.017 & 0.003 \\
\hline
\end{tabular}

\begin{tabular}{|c|c|c|c|c|c|c|c|c|}
\hline 1991 & \multicolumn{10}{|c|}{ From: } \\
\hline To: & $\mathbf{1}$ & $\mathbf{2}$ & $\mathbf{3}$ & $\mathbf{4}$ & $\mathbf{5}$ & $\mathbf{6}$ & $\mathbf{7}$ & $\mathbf{8}$ \\
\hline $\mathbf{1}$ & 0.015 & 0.027 & 0.017 & 0.007 & 0.028 & 0.040 & 0.000 & 0.000 \\
\hline $\mathbf{2}$ & 0.030 & 0.110 & 0.041 & 0.000 & 0.093 & 0.114 & 0.000 & 0.028 \\
\hline $\mathbf{3}$ & 0.006 & 0.006 & 0.033 & 0.063 & 0.000 & 0.001 & 0.000 & 0.000 \\
\hline $\mathbf{4}$ & 0.000 & 0.000 & 0.007 & 0.199 & 0.000 & 0.000 & 0.007 & 0.000 \\
\hline $\mathbf{5}$ & 0.022 & 0.013 & 0.275 & 0.381 & 0.001 & 0.001 & 0.045 & 0.000 \\
\hline $\mathbf{6}$ & 0.088 & 0.059 & 0.189 & 0.019 & 0.021 & 0.012 & 0.013 & 0.002 \\
\hline $\mathbf{7}$ & 0.000 & 0.000 & 0.021 & 0.333 & 0.002 & 0.000 & 0.204 & 0.000 \\
\hline $\mathbf{8}$ & 0.024 & 0.001 & 0.262 & 0.051 & 0.174 & 0.001 & 0.328 & 0.095 \\
\hline
\end{tabular}


VECTOR-A VERAGED FORCING

\begin{tabular}{|c|c|c|c|c|c|c|c|c|}
\hline $\mathbf{1 9 7 4}$ & \multicolumn{7}{|c|}{ From: } \\
\hline To: & $\mathbf{1}$ & $\mathbf{2}$ & $\mathbf{3}$ & $\mathbf{4}$ & $\mathbf{5}$ & $\mathbf{6}$ & $\mathbf{7}$ & $\mathbf{8}$ \\
\hline $\mathbf{1}$ & 0.023 & 0.052 & 0.028 & 0.005 & 0.066 & 0.101 & 0.000 & 0.015 \\
\hline $\mathbf{2}$ & 0.019 & 0.027 & 0.044 & 0.000 & 0.186 & 0.050 & 0.000 & 0.120 \\
\hline $\mathbf{3}$ & 0.023 & 0.030 & 0.110 & 0.049 & 0.004 & 0.041 & 0.000 & 0.000 \\
\hline $\mathbf{4}$ & 0.008 & 0.000 & 0.156 & 0.436 & 0.000 & 0.000 & 0.042 & 0.000 \\
\hline $\mathbf{5}$ & 0.060 & 0.067 & 0.294 & 0.062 & 0.028 & 0.020 & 0.033 & 0.006 \\
\hline $\mathbf{6}$ & 0.038 & 0.017 & 0.295 & 0.000 & 0.143 & 0.011 & 0.009 & 0.129 \\
\hline $\mathbf{7}$ & 0.007 & 0.001 & 0.166 & 0.172 & 0.056 & 0.000 & 0.439 & 0.000 \\
\hline $\mathbf{8}$ & 0.003 & 0.000 & 0.068 & 0.000 & 0.131 & 0.011 & 0.109 & 0.323 \\
\hline
\end{tabular}

\begin{tabular}{|c|c|c|c|c|c|c|c|c|}
\hline $\mathbf{1 9 7 8}$ & \multicolumn{10}{|c|}{ From: } \\
\hline To: & $\mathbf{1}$ & $\mathbf{2}$ & $\mathbf{3}$ & $\mathbf{4}$ & $\mathbf{5}$ & $\mathbf{6}$ & $\mathbf{7}$ & $\mathbf{8}$ \\
\hline $\mathbf{1}$ & 0.016 & 0.043 & 0.000 & 0.010 & 0.014 & 0.076 & 0.000 & 0.000 \\
\hline $\mathbf{2}$ & 0.004 & 0.052 & 0.027 & 0.000 & 0.179 & 0.086 & 0.000 & 0.015 \\
\hline $\mathbf{3}$ & 0.016 & 0.013 & 0.045 & 0.021 & 0.000 & 0.016 & 0.000 & 0.000 \\
\hline $\mathbf{4}$ & 0.004 & 0.000 & 0.063 & 0.357 & 0.000 & 0.000 & 0.013 & 0.000 \\
\hline $\mathbf{5}$ & 0.058 & 0.056 & 0.194 & 0.051 & 0.002 & 0.018 & 0.002 & 0.000 \\
\hline $\mathbf{6}$ & 0.095 & 0.054 & 0.246 & 0.000 & 0.058 & 0.010 & 0.000 & 0.013 \\
\hline $\mathbf{7}$ & 0.019 & 0.001 & 0.336 & 0.358 & 0.025 & 0.000 & 0.260 & 0.000 \\
\hline $\mathbf{8}$ & 0.035 & 0.005 & 0.325 & 0.002 & 0.271 & 0.025 & 0.089 & 0.207 \\
\hline
\end{tabular}




\section{APPENDiX B: Biographical SKetCh}

I was born in Seattle, Washington on September 27, 1967, the third child of George and Verna Lewis. By the tender young age of three I began my unguided forays into swimming pools, mud puddles and all accessible bodies of water, presaging my long-standing fascination with that medium. My attraction to water has typically preceded my understanding of it, a failing that has caused my parents no end of concern.

My youth was taken up in being dragged off to mountains and oceans on weekends and summers, and dragging myself off to Tahoma School District schools on weekdays. I survived that education, for better or for worse, and actually managed to finish on time, a feat that I have not managed to repeat at any other institution.

I moved on to Stanford University, dedicating myself for almost three years to the pursuit of a financially rewarding engineering career...but it was not to be. After a friend returned from a summer internship, waxing rhapsodic about the joys of designing engine mounts at Ford, I decided to renew my acquaintance with marine life. I forgot to graduate at the end of my senior year, and spent an extra year accumulating the minimal requirements for a degree in biology.

During this time I was strongly urged to march straight off to Graduate School, and followed the instructions like a fine little lemming, little realizing what I had set myself up for. After considering schools in California, Oregon and Hawaii, I chose one in Massachusetts. Six and a half years later, I can say I've survived and enjoyed the experience, and might even recommend it to some.

\section{CURRiculum Vitae}

\section{Education}

Ph.D. Woods Hole Oceanographic Institution, Biological Oceanography Joint Program with the Massachusetts Institute of Technology

B.S. Stanford University

Mechanical Engineering and Biology

1997

1990

\section{Research Interests}

- Modeling interactions of oceanographic processes and population dynamics.

- Effects of population dynamics on trophic level interactions in marine communities.

\section{Research Experience}

Biology Department, Woods Hole Oceanographic Institution: 1990-Present

- Studied population dynamics of the ocean quahog (Arctica islandica) using NMFS data, shell-sectioning, and matrix population models.

- Coupled population and trophic models to prognostic, three dimensional, primitive equation models (SPEM 3.0 and ECOM-si) of mesoscale circulation on Georges Bank. 
- Analyzed meteorological and oceanographic data from satellite, ground, and shipboard instrumentation.

- Four months of sea time conducting hydrographic, benthic and planktonic sampling.

- Extensive experience with MATLAB and FORTRAN in UNIX environments. Limited experience in PASCAL, BASIC, and HTML.

- Certified Scientific Diver (WHOI), 140 dives in neritic and pelagic environments.

Hopkins Marine Station, Stanford University: Summer 1990

- Used SCUBA and ROV Ventana for vertical zonation survey in Carmel Canyon and Point Lobos.

\section{Employment}

Schlumberger Wireline Services, Shekou, China: July 1989

- Engineering intern: assisted engineers in well logging in the South China Sea. Washington State Dept. of Natural Resources, Enumclaw, WA: Summers 1986-88

- Firefighter (86-87) and Helitac supervisor (88).

\section{Miscellaneous}

Awards

National Merit Scholar; Tau Beta Pi; ONR Graduate Fellowship. Affiliations Activities

American Geophysical Union.

- Competitive: Rowing, bicycling, swimming, running and underwater hockey.

- Recreational: Backpacking, sea kayaking, skiing, scuba diving, and biking. 


\section{BIBLIOGRAPHY}

Alexander, S. E. and J. Roughgarden (1996). "Larval transport and population dynamics of intertidal barnacles: A coupled benthic/oceanic model." Ecological Monographs 66:3, pp. 259-275.

Bachelet, G. (1986). "Recruitment and year to year variability in a population of Macoma balthica (L.)." Hydrobiologia 142, pp. 233-248.

Backus, R. H. and D. W. Bourne, Eds. (1987). Georges Bank. Cambridge, Massachusetts, MIT Press.

Bailey, K. M. (1981). "Larval transport and recruitment of Pacific hake Merluccius productus." Marine Ecology Progress Series 6, pp. 1-9.

Bailey, K. M. and E. D. Houde (1989). "Predation on eggs and larvae of marine fishes and the recruitment problem." Advances in Marine Biology 25, pp. 1-83.

Bakun, A. (1973). Coastal upwelling indices, west coast of North America, 1946-71. National Oceanic and Atmospheric Administration NOAA-TR-NMFS-SSRF 671.

Bennett, J. T., K. K. Turekian, W. J. Shaul and J. W. Ropes (1982). "Using natural radionuclides to measure shell growth rates and ages of the bivalves Arctica islandica (Linne) and Panope generosa (Gould)." Journal of Shellfish Research 2:1, pp. 88-89.

Blumberg, A. F. (1993). A primer for ECOM-si. Hydroqual, Inc. Mahwah, New Jersey

Blumberg, A. F. and G. L. Mellor (1983). "Diagnostic and prognostic numerical circulation studies of the South Atlantic Bight." Journal of Geophysical Research 88:C8, pp. 4579-4592.

Blumberg, A. F. and G. L. Mellor (1987). "A description of a three-dimensional coastal ocean circulation model." Three-dimensional Coastal Ocean Models. Ed. N. S. Heaps. Washington, DC., American Geophysical Union. pp. 1-16.

Botsford, L. W., C. L. Moloney, A. Hastings, J. L. Largier, T. M. Powell, K. Higgins and J. F. Quinn (1994). "The influence of spatially and temporally varying oceanographic conditions on meroplanktonic metapopulations." Deep Sea Research II 41:1, pp. 107-145.

Brey, T., W. E. Arntz, D. Pauly and H. Rumohr (1990). "Arctica (Cyprina) islandica in Kiel Bay (Western Baltic): Growth, production and ecological significance." Journal of Experimental Marine Biology and Ecology 136:3, pp. 217-235.

Brousseau, D. J. (1978). "Population dynamics of the soft-shell clam Mya arenaria." 
Marine Biology 50, pp. 63-71.

Brousseau, D. J., J. A. Baglivo and J. George R. Lang (1982). "Estimation of equilibrium settlement rates for benthic marine invertebrates: its application to Mya arenaria (Mollusca: Pelecypoda)." Fishery Bulletin 80:3, pp. 642-644.

Brown, B. (1987). "The fisheries resources." Georges Bank. Eds. R. H. Backus and D. W. Bourne. Cambridge, Massachusetts, MIT Press. pp. 480-493.

Brown, W. S. and J. A. Moody (1987). "Tides." Georges Bank. Eds. R. H. Backus and D. W. Bourne. Cambridge, Massachusetts, MIT Press. pp. 100-107.

Butman, B. (1987). "The effect of winter storms on the bottom." Georges Bank. Eds. R. H. Backus and D. W. Bourne. Cambridge, Massachusetts, MIT Press. pp. 7477.

Butman, B. and R. C. Beardsley (1987). "Physical Oceanography." Georges Bank. Eds. R. H. Backus and D. W. Bourne. Cambridge, Massachusetts, MIT Press. pp. 88-98.

Butman, B., R. C. Beardsley, B. Magnell, D. Frye, J. A. Vermersh, R. Schlitz, R. Limeburner, W. R. Wright and M. A. Noble (1982). "Recent observations of the mean circulation on Georges Bank." Journal of Physical Oceanography 12, pp. 559-591.

Butman, B., J. W. Loder and R. C. Beardsley (1987). "The seasonal mean circulation: observation and theory." Georges Bank. Eds. R. H. Backus and D. W. Bourne. Cambridge, Massachusetts, MIT Press. pp. 125-138.

Casulli, V. (1990). "Semi-implicit finite difference methods for the two-dimensional shallow water equations." Journal of Computational Physics 86, pp. 56-74.

Caswell, H. (1978). "A general formula for the sensitivity of population growth rate to changes in life history parameters." Theoretical Population Biology 14, pp. 215230.

Caswell, H. (1989). Matrix Population Models. Sunderland, Mass., Sinauer Associates.

Chase, J. (1955). "Winds and temperatures in relation to brood strength of Georges Bank haddock." Journal du Conseil International pour l'Exploration de la Mar 21, pp. 17-24.

Chen, C. (1992). Variability of currents in Great South Channel and over Georges Bank: observation and modeling. Ph.D. Thesis. Woods Hole Oceanographic Institution and Massachusetts Institute of Technology.

Chen, C. and R. C. Beardsley (1995). "A numerical study of stratified tidal rectification over finite-amplitude banks. Part I: Symmetric banks." Journal of Physical Oceanography 25, pp. 2090-2110. 
Chen, C., R. C. Beardsley and R. Limeburner (1995). "A numerical study of stratified tidal rectification over finite-amplitude banks. Part II: Georges Bank.” Journal of Physical Oceanography 25, pp. 2111-2128.

Corkett, C. J. and I. A. McLaren (1978). "The biology of Pseudocalanus." Advances in Marine Biology 15, pp. 1-231.

Crouse, D. T., L. B. Crowder and H. Caswell (1987). "A stage-based population model for loggerhead sea turtles and implications for conservation." Ecology 68:5, pp. 1412-1423.

Crowder, L. B., D. T. Crouse, S. S. Heppell and T. H. Martin (1994). "Predicting the impact of turtle excluder devices on Loggerhead Sea Turtle populations." Ecological Applications 4:3, pp. 437-445.

Cura, J. J. (1987). "Phytoplankton." Georges Bank. Eds. R. H. Backus and D. W. Bourne. Cambridge, Massachusetts, MIT Press. pp. 213-218.

Cushing, D. H. (1975). Marine Ecology and Fisheries. Cambridge, Cambridge University Press.

Davis, C. S. (1983). "Laboratory rearing of marine calanoid copepods." Journal of Experimental Marine Biology and Ecology 71, pp. 119-133.

Davis, C. S. (1984a). "Food concentrations on Georges Bank: non-limiting effect on development and survival of laboratory reared Pseudocalanus sp. and Paracalanus parvus (Copepoda: Calanoida)." Marine Biology 82, pp. 41-46.

Davis, C. S. (1984b). "Interaction of a copepod population with the mean circulation on Georges Bank." Journal of Marine Research 42, pp. 31-40.

Davis, C. S. (1984c). "Predatory control of copepod seasonal cycles on Georges Bank." Marine Biology 82, pp. 31-40.

Davis, C. S. (1987). "Zooplankton life cycles." Georges Bank. Eds. R. H. Backus and D. W. Bourne. Cambridge, Massachusetts, MIT Press. pp. 256-267.

Davis, C. S., G. R. Flierl, P. J. S. Franks and P. H. Wiebe (1991). "Micropatchiness, turbulence, and recruitment in plankton." Journal of Marine Research 49:1, pp. 109-151.

Davis, C. S., M. D. Grosslein, P. H. Wiebe, G. D. Grice and S. Murawski (1985). WHOI-NEFC fisheries ecology seminar series, a summary. Woods Hole Oceanographic Institution WHOI Technical Report 85-25.

de Kroon, H., A. Plaiser, J. van Groenendael and H. Caswell (1986). "Elasticity: the relative contribution of demographic parameters to population growth rate." Ecology 67, pp. 1427-1431.

De Wilde, P. A. W. J., E. M. Berghuis and A. Kok (1984). "Structure and energy 
demand of the benthic community of the Oyster Ground, Central North Sea." Netherlands Journal of Sea Research 18:1-2, pp. 143-159.

De Wilde, P. A. W. J., E. M. Berghuis and A. Kok (1986). "Biomass and activity of benthic fauna on the Fladen Group (northern North Sea)." Netherlands Journal of Sea Research 20:2-3, pp. 313-323.

Doak, D., P. Kareiva and B. Klepetka (1994). "Modeling population viability for the desert tortoise in the Western Mojave desert." Ecological Applications 4:3, pp. 446-460.

Doherty, P. and T. Fowler (1994). "An empirical test of recruitment limitation in a coral reef fish.” Science 263:18 February, pp. 935-939.

Efron, B. and R. J. Tibshirani (1993). An introduction to the bootstrap. New York, NY, Chapman Hall.

Feller, R. J., S. E. Stancyk, B. C. Coull and D. G. Edwards (1992). "Recruitment of polychaetes and bivalves: long term assessment of predictability in a soft bottom habitat." Marine Ecology Progress Series 87, pp. 227-238.

Flagg, C. (1987). "Hydrographic structure and variability." Georges Bank. Eds. R. H. Backus and D. W. Bourne. Cambridge, Massachusetts, MIT Press. pp. 108-124.

Flierl, G. R. and C. S. Davis (1995). "Reduction of complexity in biological/physical models.", pp.

Fogarty, M. J. (1981). "Distribution and relative abundance of the ocean quahog Arctica islandica in Rhode Island Sound and off Martha's Vineyard, Massachusetts." Journal of Shellfish Research 1:1, pp. 33-39.

Forster, G. R. (1981). "A note on the growth of Arctica islandica." Journal of the Marine Biological Association of the United Kingdom 61:3, pp. 817.

Franks, P. J., J. S. Wroblewski and G. R. Flierl (1986). "Behavior of a simple plankton model with food-level acclimation by herbivores." Marine Biology 91, pp. 121129.

Franks, P. J. S. (1992). "Sink or Swim: accumulation of biomass at fronts." Marine Ecology Progress Series 82, pp. 1-12.

Frost, B. W. (1989). "A taxonomy of the marine calanoid copepod genus Pseudocalanus." Canadian Journal of Zoology 67, pp. 525-551.

Funder, S. and A. Weidick (1991). "Holocene boreal molluscs in Greenland palaeoceanographic implications." Palaeogeography, Palaeoclimatology, Palaeoecology. 85:1-2, pp. 123-135.

Gaines, S., S. Brown and J. Roughgarden (1985). "Spatial variation in larval concentrations as a cause of spatial variation in settlement for the barnacle, 
Balanus glandulus." Oecologia 67, pp. 267-272.

Gaines, S. and J. Roughgarden (1985). "Larval settlement rate: a leading determinant of structure in an ecological community of the marine intertidal zone." Proceedings of the National Academy of Sciences, USA. 82, pp. 3707-3711.

Garlo, E. V. E. (1982). "Increase in a surf clam population after hypoxic water conditions off little egg inlet, New Jersey." Journal of Shellfish Research 2:1, pp. 59-64.

Gawarkiewicz, G. (1993). "Steady wind forcing of a density front over a circular bank." Journal of Marine Research 51, pp. 109-134.

GLOBEC (1989). Report of a workshop on global ocean ecosystem dynamics. Global Ocean Ecosystem Dynamics., Wintergreen, Va., Joint Oceanogr. Inst. Inc., Washington, DC.

Goldman, J. (1977). "Biomass production in mass cultures of marine phytoplankton at various temperatures." Journal of Experimental Marine Biology and Ecology 27, pp. 161-169.

Graham, A. (1981). Kronecker products and matrix calculus: with applications. Chichester, England, Ellis Horwood Limited.

Greenberg, D. A. (1983). "Modeling the mean barotropic circulation in the Bay of Fundy and the Gulf of Maine." Journal of Physical Oceanography 13, pp. 886-904.

Halpern, D. (1974). "Observations of the deepening of the wind-mixed layer in the northeast Pacific Ocean." Journal of Physical Oceanography 4, pp. 454-466.

Harris, G. B. and B. B. Piccinin (1977). "Photosynthesis by natural populations." Archiv für Hydrobiologie 80, pp. 405-457.

Harrison, W. G. and T. Platt (1986). "Photosynthesis-irradiance relationships in polar and temperate phytoplankton populations." Polar Biology 5, pp. 153-164.

Hastings, A. and K. Higgins (1994). "Persistence of transients in spatially structured ecological models." Science 263, pp. 1133-1136.

Hjort, J. (1914). "Fluctuations in the great fisheries of northern Europe viewed in the light of biological research." Rapport Process-Verbaux Réunions Conseil Perm. Intern. Exploration Mer 20, pp. 1-228.

Horn, R. A. and C. R. Johnson (1985). Matrix Analysis. Cambridge, England, Cambridge University Press.

Houde, E. D. (1987). "Fish early life dynamics and recruitment variability." American Fisheries Society Symposium 2, pp. 17-29.

Iles, T. D. and M. Sinclair (1982). "Atlantic Herring: stock discreteness and abundance." 
Science 215, pp. 627-633.

Ivlev, V. S. (1955). Experimental ecology of the feeding of fishes. New Haven, Yale University Press.

Jones, D. S. (1980). "Annual cycle of shell growth increment formation in two continental shelf bivalves and its paleoecologic significance." Paleobiology 6, pp. 331-340.

Jones, D. S. (1981a). "Reproductive cycles of the Atlantic surf clam Spisula solidissima, and the ocean quahog Arctica islandica off New Jersey." Journal of Shellfish Research 1:1, pp. 23-32.

Jones, D. S. (1981b). "Reproductive cycles of the ocean quahog Arctica islandica and the Atlantic surf-clam Spisula solidissima off New Jersey." Journal of Shellfish Research 1:1, pp. 117.

Kraus, M. G., B. F. Beal and S. R. Chapman (1989). "Growth rate of Arctica islandica Linne: A comparison of wild and laboratory-reared individuals." Journal of Shellfish Research 8:2, pp. 463.

Kraus, M. G., B. F. Beal, S. R. Chapman and L. McMartin (1992). "A comparison of growth rates in Arctica islandica (Linnaeus, 1767) between field and laboratory populations." Journal of Shellfish Research 11:2, pp. 289-294.

Land, K. C. and A. Rogers, Eds. (1982). Multidimensional mathematical demography. Studies in population. New York, NY, Academic Press.

Landers, W. S. (1976). "Reproduction and early development of the Ocean Quahog, Arctica islandica, in the laboratory." The Nautilus 90:2, pp. 88-92.

Large, W. G. and S. Pond (1981). "Open ocean momentum flux measurements in moderate to strong winds." Journal of Physical Oceanography 11, pp. 324-336.

Lasker, R. (1975). "Field criteria for survival of anchovy larvae: the relationship between inshore chlorophyll maximum layers and successful first feeding." Fisheries Bulletin 73, pp. 453-462.

Leslie, P. H. (1945). "On the use of matrices in certain population mathematics." Biometrika 33, pp. 183-212.

Leslie, P. H. (1948). "Some further notes on the use of matrices in certain population mathematics." Biometrika 35, pp. 213-245.

Lewis, C. V. W., C. S. Davis and G. Gawarkiewicz (1994). "Wind forced biologicalphysical interactions on an isolated offshore bank." Deep Sea Research II 41:1, pp. 51-73.

Lewis, E. G. (1942). "On the generation and growth of a population." Sankhya: The Indian Journal of Statistics 6, pp. 93-96. 
Loder, J. W. (1980). "Topographic rectification of tidal currents on the sides of Georges Bank." Journal of Physical Oceanography 10, pp. 1399-1416.

Loosanoff, V. L. (1953). "Reproductive Cycle in Cyprina islandica." Biological Bulletin of the Marine Biological Laboratory, Woods Hole 104, pp. 146-155.

Lough, R. G., W. G. Smith, F. E. Werner, J. W. Loder, F. H. Page, C. G. Hannah, C. E. Naimie, R. I. Perry, M. Sinclair and D. R. Lynch (1994). "Influence of winddrive advection on interannual variability in cod egg and larval distributions on Georges Bank: 1982 vs. 1985.” ICES Marine Science Symposium 198, pp. 356378.

Lough, R. G., P. C. Valentine, D. C. Potter, P. J. Auditore, G. R. Bolz, J. D. Neilson and R. I. Perry (1989). "Ecology and distribution of juvenile cod and haddock in relation to sediment type and bottom currents on eastern Georges Bank." Marine Ecology Progress Series 56, pp. 1-12.

Lutz, R. A., R. Mann, J. G. Goodsell and M. Castagna (1982). "Larval and early postlarval development of Arctica islandica." Journal of the Marine Biological Association of the United Kingdom 62:4, pp. 745-769.

Lynch, D. R., J. C. Ip, C. E. Naimie and F. E. Werner (1995). "Convergence studies of tidally-rectified circulation on Georges Bank." Quantitative Skill Assessment for Coastal Ocean Models. Eds. D. R. Lynch and A. M. Davies. American Geophysical Union. pp.

Lynch, D. R., J. T. C. Ip, C. E. Naimie and F. E. Werner (1996). "Comprehensive coastal circulation model with application to the Gulf of Maine." Continental Shelf Research 16:7, pp. 875-906.

Lynch, D. R. and C. E. Naimie (1993). "The M2 tide and its residual on the outer banks of the Gulf of Maine." Journal of Physical Oceanography 23, pp. 2222-2253.

Maciolek, N. J. and J. F. Grassle (1987). "Variability of the benthic fauna, II: the seasonal variation, 1981-1982." Georges Bank. Eds. R. H. Backus and D. W. Bourne. Cambridge, Massachusetts, MIT Press. pp. 303-314.

Mann, R. (1981). "Reproduction in Arctica islandica and its relationship to the oceanography of the Middle Atlantic Bight." Journal of Shellfish Research 1:1, pp. 119.

Mann, R. (1982). "The seasonal cycle of gonadal development in Arctica islandica from the Southern New England Shelf." Fishery Bulletin 80:2, pp. 315-325.

Mann, R. (1985). "Seasonal changes in the depth-distribution of bivalve larvae on the southern New England shelf." Journal of Shellfish Research 5:2, pp. 57-64.

Mann, R. (1989). "Larval ecology of Arctica islandica on the inner continental shelf of the eastern United States." Journal of Shellfish Research 8:2, pp. 464. 
Mann, R., R. A. Lutz and M. Castagna (1981). The reproductive biology of Arctica islandica. ICES Meeting, Woods Hole, Massachusetts. 12 p.

Mann, R. and C. C. Wolf (1983). "Swimming behavior of larvae of the ocean quahog Arctica islandica in response to pressure and temperature." Marine Ecology Progress Series 13, pp. 2-3.

Manning, J. and G. Strout (1996). "Georges Bank Winds: 1975-1995.” AtmosphereOceans (Submitted), pp.

McLaren, I. A., J. M. Sevigny and C. J. Corkett. (1989). "Temperature dependent development in Pseudocalanus species." Canadian Journal of Zoology 67, pp. 559-564.

Mellor, G. L. and T. Yamada (1982). "Development of a turbulence closure model for geophysical fluid problems." Reviews of Geophysics and Space Physics 20:4, pp. 851-875.

Menge, B. A. (1991). "Relative importance of recruitment and other causes of variation in rocky intertidal community structure." Journal of Experimental Marine Biology and Ecology 146, pp. 69-100.

Merrill, A. S. and J. W. Ropes (1969). "The general distribution of the surf clam and ocean quahog." Proceedings of the National Shellfisheries Association 59, pp. 40-45.

Mileikovsky, S. A. (1971). "Types of larval development in marine bottom invertebrates, their distribution and ecological significance: a re-evaluation." Marine Biology 10, pp. 193-213.

Murawski, S. A., J. W. Ropes and F. M. Serchuk (1982). "Growth of the ocean quahog, Arctica islandica, in the Middle Atlantic Bight." Fisheries Bulletin, U.S. 80:1, pp. 21-34.

Murawski, S. A. and F. M. Serchuk (1989). "Mechanized shellfish harvesting and its management: The offshore clam fishery of the eastern United States." Marine Invertebrate Fisheries: Their Assessment and Management. Ed. J. F. Caddy. pp. 479-506.

Muus, K. (1973). "Settling, growth and mortality of young bivalves in the Øresund." Ophelia 12, pp. 79-116.

Myers, R. A. and K. F. Drinkwater (1988). "Offshelf Ekman transport and larval fish survival in the Northwest Atlantic." Biological Oceanography 6, pp. 45-64.

Naimie, C. E. (1996). "Georges Bank residual circulation during weak and strong stratification periods: prognostic numerical model results." Journal of Geophysical Research 101:C3, pp. 6469-6486.

Naimie, C. E., J. W. Loder and D. R. Lynch (1994). "Seasonal variation of the three- 
dimensional residual circulation on Georges Bank." Journal of Geophysical Research 99:C8, pp. 15967-15989.

Nakaoka, M. (1993). "Yearly variation in recruitment and its effect on population dynamics in Yoldia notabilis (Mollusca: Bivalvia), analyzed using projection matrix model." Researches in Population Ecology 35, pp. 199-213.

NEFSC, N. F. S. C. (1986). Fishermen's Report: Surf Clam and Ocean Quahog survey. Cape Hatteras - Georges Bank, June 17 - July 18, 1986. NOAA/National Marine Fisheries Service.

NEFSC, N. F. S. C. (1989). Fishermen's Report: Surf Clam and Ocean Quahog survey. Cape Hatteras - Georges Bank, June 26 - July 21, 1989. NOAA/National Marine Fisheries Service.

NEFSC, N. F. S. C. (1990). Report of the Spring 1990 NEFC Stock Assessment Workshop. NOAA/National Marine Fisheries Service. Northeast Fisheries Science Center Reference Document 90-07.

NEFSC, N. F. S. C. (1992). Fishermen's Report: Surf Clam and Ocean Quahog survey. Cape Hatteras - Gulf of Maine, June 8 - July 13, 1992. NOAA/National Marine Fisheries Service.

NEFSC, N. F. S. C. (1994). Fishermen's Report: Surf Clam and Ocean Quahog survey. Cape Hatteras - Gulf of Maine, July 18 - August 24, 1994. NOAA/National Marine Fisheries Service.

NEFSC, N. F. S. C. (1995a). Report of the 19th Northeast Regional Stock Assessment Workshop: Stock Assessment Review Committee (SARC) consensus summary of assessments. NOAA/National Marine Fisheries Service Northeast Fisheries Science Center Reference Document 95-08.

NEFSC, N. F. S. C. (1995b). Report of the 19th Northeast Regional Stock Assessment Workshop: the plenary. NOAA/National Marine Fisheries Service Northeast Fisheries Science Center Reference Document 95-09.

NEFSC, N. F. S. C. (1996). Report of the 22nd Northeast Regional Stock Assessment Workshop: Stock Assessment Review Committee (SARC) consensus summary of assessments. NOAA/National Marine Fisheries Service Northeast Fisheries Science Center Reference Document 96-16.

Nelson, W. M., M. Ingham and W. Schaaf (1977). "Larval transport and year class strength of Atlantic menhadden, Brevoortia tyrannus." Fisheries Bulletin 75, pp. 23-41.

Nichols, F. H. and J. K. Thompson (1982). "Seasonal growth in the bivalve Macoma balthica near the southern limit of its range." Estuaries 5:2, pp. 110-120.

Nicol, D. (1951). "Recent species of the Veneroid pelecypod Arctica." Journal of the Washington Academy of Sciences 41:3, pp. 102-106. 
O'Reilly, J. E., C. Evans-Zetlin and D. A. Busch (1987). "Primary production." Georges Bank. Eds. R. H. Backus and D. W. Bourne. Cambridge, Massachusetts, MIT Press. pp. 220-233.

Ohman, M. D. (1986). "Predator-limited population growth of the copepod Pseudocalanus sp." Journal of Plankton Research 8:4, pp. 673-713.

Rogers, A. (1966). "The multiregional matrix growth operator and the stable interregional age structure.” Demography 3, pp. 537-544.

Rogers, A. (1968). Matrix Analysis of International Population Growth and Distribution. Berkeley, University of California Press.

Rogers, A. (1985). Regional population projection models. Revelry Hills, Ca., SAGE Publications, Inc.

Ropes, J. W. (1984a). "Methods for aging oceanic bivalves." Underwater Naturalist 15:1, pp. 12-15.

Ropes, J. W. (1984b). "Procedures for preparing acetate peels and evidence validating the annual periodicity of growth lines formed in the shells of Ocean Quahogs, Arctica islandica." Marine Fisheries Review 46:2, pp. 27-35.

Ropes, J. W. (1985). "Modern methods used to age oceanic bivalves.” Nautilus 99, pp. 53-57.

Ropes, J. W. (1987). Preparation of acetate peels of valves from the Ocean Quahog, Arctica islandica, for age determinations. NOAA, National Marine Fisheries Service NOAA Technical Report NMFS 50.

Ropes, J. W. and A. J. Jearld (1987). "Age determination of ocean bivalves." Age and Growth in Fish. Eds. R. C. Summerfelt and G. E. Hall. pp. 517-526.

Ropes, J. W., D. S. Jones, S. A. Murawski, F. M. Serchuk and D. A. Jearld, Jr. (1983). "Documentation of annual growth lines in the ocean quahog Arctica islandica Linne." Journal of Shellfish Research 3:1, pp. 100.

Ropes, J. W., D. S. Jones, S. A. Murawski, F. M. Serchuk and D. A. Jearld, Jr. (1984). "Documentation of annual growth lines in the ocean quahog Arctica islandica Linne." Fishery Bulletin 82:1, pp. 1-19.

Ropes, J. W. and D. Pyoas (1982). Preliminary age and growth observations of ocean quahogs, Arctica islandica Linne, from Georges Bank. ICES Meeting, Copenhagen, Denmark. 6 p.

Roughgarden, J., S. Gaines and H. Possingham (1988). "Recruitment dynamics in complex life cycles.” Science 241, pp. 1460-1466.

Roughgarden, J., Y. Iwasa and C. Baxter (1985). "Demographic theory for an open marine population with space-limited recruitment." Ecology 66, pp. 54-67. 
Roughgarden, J., J. T. Pennington, D. Stoner, S. Alexander and K. Miller (1991). "Collisions of upwelling fronts with the intertidal zone: The cause of recruitment pulses in barnacle populations of central California." Acta Oecologica 12:1, pp. 35-51.

Rowell, T. W., D. R. Chaisson and J. T. McLane (1990). "Size and age of sexual maturity and annual gametogenic cycle in the ocean quahog, Arctica islandica (Linnaeus, 1767), from coastal waters in Nova Scotia, Canada." Journal of Shellfish Research 9:1, pp. 195-203.

Rumrill, S. S. (1990). "Natural mortality of marine invertebrate larvae." Ophelia 32, pp. 163-198.

Sager, G. and R. Sammler (1983). "Mathematical investigations into the longevity of the ocean quahog Arctica islandica (Mollusca: Bivalvia)." INT. Revue Gesamt. Hydrobiol. 68:1, pp. 113-120.

Santiago-Mandujano, F. and E. Firing (1990). "Mixed layer shear generated by wind stress in the central equatorial Pacific." Journal of Physical Oceanography 20, pp. $1576-1582$.

Scheltema, R. S. (1974). "Biological interactions determining larval settlement of marine invertebrates.” Thalassia Jugoslavica 10:1/2, pp. 263-296.

Scheltema, R. S. (1985). On dispersal and planktonic larvae of benthic invertebrates: An eclectic overview and summary of problems. Proceedings of the invertebrate larval biology workshop, Friday Harbor Marine Laboratories, University of Washington.

Scheltema, R. S. and I. P. Williams (1983). "Long-distance dispersal of planktonic larvae and the biogeography and evolution of some Polynesian and western Pacific mollusks." Bulletin of Marine Science 33:3, pp. 545-565.

Silverman, B. W. (1981). "Using kernel density estimates to investigate multimodality." Journal of the Royal Statistical Society B 43, pp. 97-99.

Silverman, B. W. (1983). "Some properties of a test for multimodality based on kernel density estimates." Probability, Statistics, and Analysis. Eds. J. F. C. Kingman and G. E. H. Reuter. Cambridge, UK, Cambridge Univ. Press. pp. 248-260.

Sinclair, M. (1988). Marine populations: an essay on population regulation and speciation. Seattle, Washington Sea Grant.

Smagorinsky, J. (1963). "General circulation experiments with the primitive equations, I. the basic experiment." Monthly Weather Review 91, pp. 99-164.

Smolowitz, R. J. and V. E. Nulk (1982). "The design of an electrohydraulic dredge for clam surveys." Marine Fishery Review 44:4, pp. 1-18.

Thompson, I., D. S. Jones and D. Dreibelbis (1980a). "Annual internal growth banding 
and life history of the ocean quahog Arctica islandica (Mollusca: Bivalvia)." Marine Biology 57:1, pp. 25-34.

Thompson, I., D. S. Jones and J. W. Ropes (1980b). "Advanced age for sexual maturity in the ocean quahog Arctica islandica (Mollusca: Bivalvia)." Marine Biology 57:1, pp. 35-39.

Thorson, G. (1950). "Reproductive and larval ecology of marine bottom invertebrates." Biological Review (Cambridge) 25, pp. 1-45.

Thorson, G. (1966). "Some factors influencing the recruitment and establishment of marine benthic communities." Netherlands Journal of Sea Research 3:2, pp. 267293.

Thouzeau, G., G. Robert and S. J. Smith (1991a). "Spatial variability in distribution and growth of juvenile and adult sea scallops Placopecten magellanicus (Gmelin) on eastern Georges Bank (Northwest Atlantic)." Marine Ecology Progress Series 74:2-3, pp. 205-218.

Thouzeau, G., G. Robert and R. Ugarte (1991b). "Faunal assemblages of benthic megainvertebrates inhabiting sea scallop grounds from eastern Georges Bank, in relation to environmental factors." Marine Ecology Progress Series 74:1, pp. 6182 .

Tremblay, M. J., J. W. Loder, F. E. Werner, C. E. Naimie, F. H. Page and M. M. Sinclair (1994). "Drift of sea scallop larvae Placopecten magellanicus on Georges Bank: a model study of the roles of mean advection, larval behavior and larval origin." Deep Sea Research II 41:1, pp. 7-49.

Tremblay, M. J. and M. Sinclair (1990). "Sea Scallop larvae Placopecten magellanicus on Georges Bank: vertical distribution in relation to water column stratification and food." Marine Ecology Progress Series 61, pp. 1-15.

Tremblay, M. J. and M. Sinclair (1992). "Planktonic Sea Scallop larvae (Placopecten magellanicus) in the Georges Bank region: broadscale distribution in relation to physical oceanography." Canadian Journal of Fisheries and Aquatic Sciences 49, pp. $1597-1615$.

Turekian, K. K., J. K. Cochran and Y. Nozaki (1982). "Determination of shell deposition rates of Arctica islandica from the New York Bight using natural ${ }^{228} \mathrm{Ra}$ and ${ }^{228} \mathrm{Th}$ and bomb-produced ${ }^{14} \mathrm{C}$." Limnology and Oceanography 27:4, pp. 737-741.

Turner, H. J. (1949). The Mahogany Quahog resource of Massachusetts: Report on investigation of methods of improving the shellfish resources of Massachusetts. Mass. Dept. of Conservation, Div. of Mar. Fish. 12-16.

Twichell, D. C., B. Butman and R. S. Lewis (1987). "Shallow structure, surficial geology, and the processes currently shaping the bank." Georges Bank. Eds. R. H. Backus and D. W. Bourne. Cambridge, MIT Press. pp. 31-37. 
Uchupi, E. and J. A. Austin Jr. (1987). "Morphology." Georges Bank. Eds. R. H. Backus and D. W. Bourne. Cambridge, Massachusetts, MIT Press. pp. 25-30.

von Oertzen, J.-A. (1972). "Cycles and rates of reproduction of six Baltic Sea bivalves of different zoogeographical origin." Marine Biology 14, pp. 143-149.

Weidman, C. R. and G. Jones (1993a). A new high-temporal resolution paleoceanographic tool for the northern North Atlantic: The mollusc Arctica islandica. ICES Meeting, Dublin, Eire. 11 p.

Weidman, C. R. and G. A. Jones (1993b). "A shell derived time history of bomb ${ }^{14} \mathrm{C}$ on Georges Bank and its Labrador Sea implications." Journal of Geophysical Research 98:C8, pp. 14,577-14,588.

Weinberg, J. R. (1993). Ocean Quahog populations from the Middle Atlantic Bight to the Gulf of Maine in 1992. NOAA/National Marine Fisheries Laboratory Reference Document 93-02.

Werner, F. E., F. H. Page, D. R. Lynch, J. W. Loder, R. G. Lough, R. I. Perry, D. A. Greenberg and M. M. Sinclair (1993). "Influences of mean advection and simple behavior on the distribution of cod and haddock early life stages on Georges Bank." Fisheries Oceanography 2:2, pp. 43-64.

Werner, F. E., R. I. Perry, R. G. Lough and C. E. Naimie (1996). "Trophodynamic and advective influences on Georges Bank larval cod and haddock." Deep Sea Research II, pp.

Winter, J. E. (1969). "On the influence of food concentration and other factors on filtration rate and food utilization in the bivalves Arctica islandica and Modiolus modiolus." Marine Biology 4, pp. 87-135.

Young, C. M. (1990). "Larval ecology of marine invertebrates: a sesquicentennial history." Ophelia 32:1-2, pp. 1-48. 